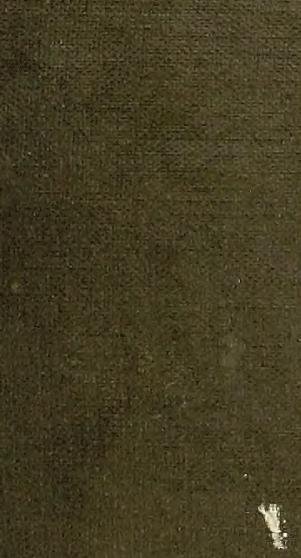

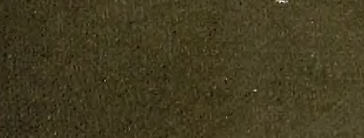

(10)

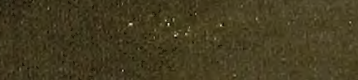

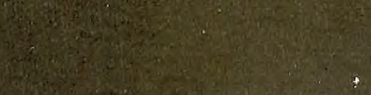

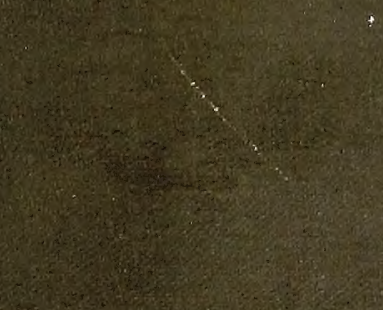




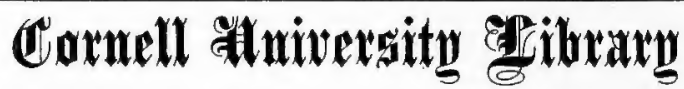

BOUGHT WITH THE INCOME FROM THE

SAGE ENDOWMENT FUND THE GIF'T OF

Henrg W. Sage I89x

4245372 $23 / 6 / 100$ 


\section{Cornell University Library}

QL 739.D26 1910

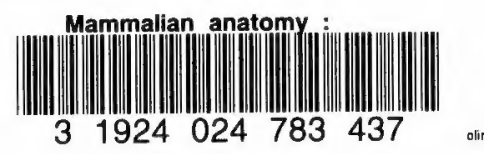




\section{Cornell University Library}

The original of this book is in the Cornell University Library.

There are no known copyright restrictions in the United States on the use of the text. 


ELEMENTS OF

MAMMALIAN ANATOMY

\author{
DAVISON
}





\title{
Mammalian Anatomy
}

\author{
WITH SPECIAL REFERENCE TO
}

\section{THE CAT}

BY

ALVIN DAVISON, Ph.D.

EX-EELLOW OF PRINCETON UNIVERSITY; PROFESSOR OF BJOLOGY IN LAFAYETTE COLLEGE

SECOND EDITION, REVISED

WITH II 4 ILLUSTRATIONS, MOST OF WHICH WERE MADE BY W. H. REESE, A.M., FROM THE AUTHOR'S DISSECTIONS

"Study nature, not books."

- Agrassiz.

PHILADELPHIA

P. BLAKISTON'S SON \& CO.

ioI 2 Walnut Street 
Copyright, igio, by P. Blakiston's Son \& Co. 


\section{PREFACE TO THE SECOND EDITION.}

When the first edition of this book was published less than a half dozen medical schools in the United States required the entering student to have any knowledge of the structure of the lower animals. To-day a knowledge of mammalian anatomy or zoology is considered one of the first requisites for entering upon an intelligent study of medicine. The signs of the times indicate that in the near future no medical school will receive students without some practical knowledge of the structure of a mammal.

That the students of modern psychology, the teachers of physiology in all high schools and the directors of all gymnasiums need a definite knowledge of the essentials of the anatomy of a mammal, is becoming more and more evident. These facts and the steady demand for the first edition of this book have been the principal factors in determining the preparation of a second edition.

Owing to the gradual acceptance, in part at least, of the B. N. A. nomenclature, numerous changes have been made in the body of the text. The names used in this edition are such as have found favor with the majority of American anatomists. The author's easy and quick method of preparing the skeleton for stucly is for the first time presented in print. In several instances the language has been made more clear, and several new figures and a glossary have been aclded which will be of special help to the beginning student of anatomy.

Alvin Davison. 



\section{PREFACE TO THE FIRST EDITION.}

Huxley after years of pedagogical experience reached the conclusion that it is unwise to introduce the beginner at once to new and strange forms of microscopic life when it is possible to use a subject of which the student is bound to know something,- - the elementary anatomy of a vertebrate animal. The late $T$. Jeffrey Parker and numerous other eminent zoologists likewise advocate beginning zoological work by studying one of the higher animals. Since the majority of college students have time for only one year of zoological work, they cannot acquire a fruitful knowledge of both vertebrates and invertebrates. A study of the former enables one not only to become familiar with the anatomy and physiology of his own body, -a matter of vital importance, - - but throws a clear light on the significant problem of organic evolution such as is not to be derived from a study of invertebrate forms. Inasmuch as the genealogical histories are best worked ont among the Mammalia, and since a careful study of the anatomy of the cat familiarizes one with the anatomy of the human body, as is evidenced by the fact that our best medical schools now adyise their prospective students to dissect either a dog, a cat, or a rabbit as a preparation for their later work, it is apparent that a knowledge of the mammals is of the greatest worth.

This brief work is intended to acquaint the student with the general structure of the cat, and at the same time introduce him to some of the most important morphologic features of the Mammalia. The following works are useful for reference: "Anatomical Technology," Wilder and Gage; "Anatomy of the Cat," Reighard and Jennings; 
"Mammals Living and Extinct," Flower and Leydekker; "Primary Factors of Organic Evolution," E. D. Cope; "Vertebrate Zoology," J. S. Kingsley; "Anatomie des Hundes," Ellenberger and Baum; "Human Physiology," Schenck and Gürber; "Osteology of the Mammalia," Flower; "Human Histology," Piersol.

In the preparation of this book I have consulted a large number of works on human and comparative anatomy and 1)hysiology. Those giving most assistance are the works mentioned above, in addition to "Mammalian Anatomy" by Jayne, "Anatomie Descriptive et Comparative" by Strauss-Durckheim, "Nervöse Centralorgane" by Edinger, and "Vertebrate Palæontology" by Woodward. I am especially indebted to my artist, Mr. W. H. Reese, of the Phillipsburg High School, for the care and patience exercised in making the drawings from my own dissections. Mr. D. S. Hartline, of the Bloomsburgh State Normal School, has read the entire manuscript and made valuable criticisms. Above all, I have to thank Prof. J. S. Kingsley for numerous valuable suggestions and important corrections in the manuscript.

Alvin Davison. 


\section{CONTENTS.}

PAGE.

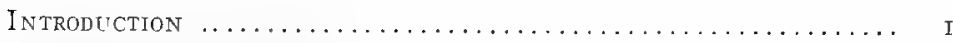

The Biological Sciences....................... I

Classification of the Animal Kingdom................ 2

Preparation and Preservation of Material.............. 4

General Structure of a Vertebrate.................. i 3

External Features......................... 18

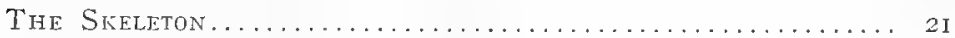

General Terms Used in Description of Bones.............. 2 I

Tabulation of Bones....................... 22

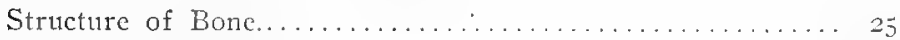

Bones of the Stull......................... 26

Vertebral Column....................... 4 I

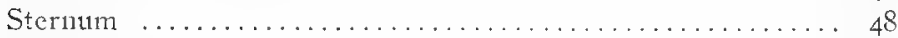

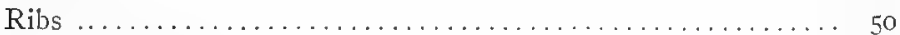

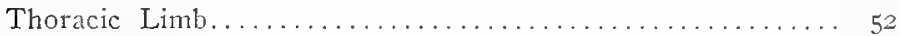

Pelvic Limb............................... 64

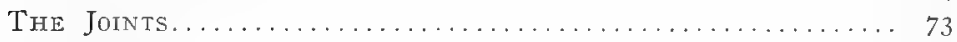

ThE Muscles............................. 7

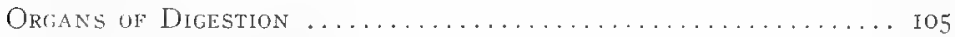

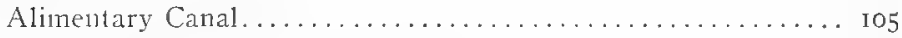

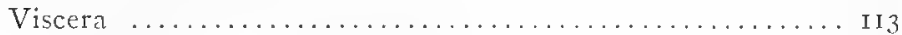

Accessory Glands of Digestion................. I 2 I

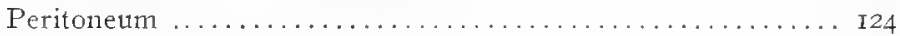

The Vascular Sytem......................... I29

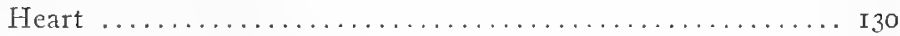

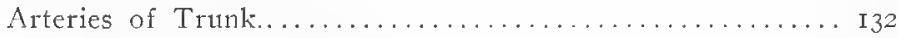

Arteries of Neck and Head.................. I35

Arteries of Thoracic Limb...................... I37

Arteries of Pelvic Limb....................... I40

Venous System ........................ I4 42

Lymplatic System ......................... I49

Ductless Glands .......................... I54

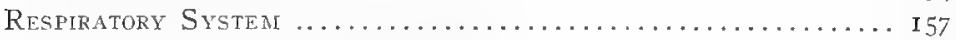

Excretory and Reproductive Systems................... I64

Glands of the Skin...................... I64

Urinary Organs ......................... I65

Female Organs of Reproduction................... I67

Male Organs of Reproduction.................... I70 


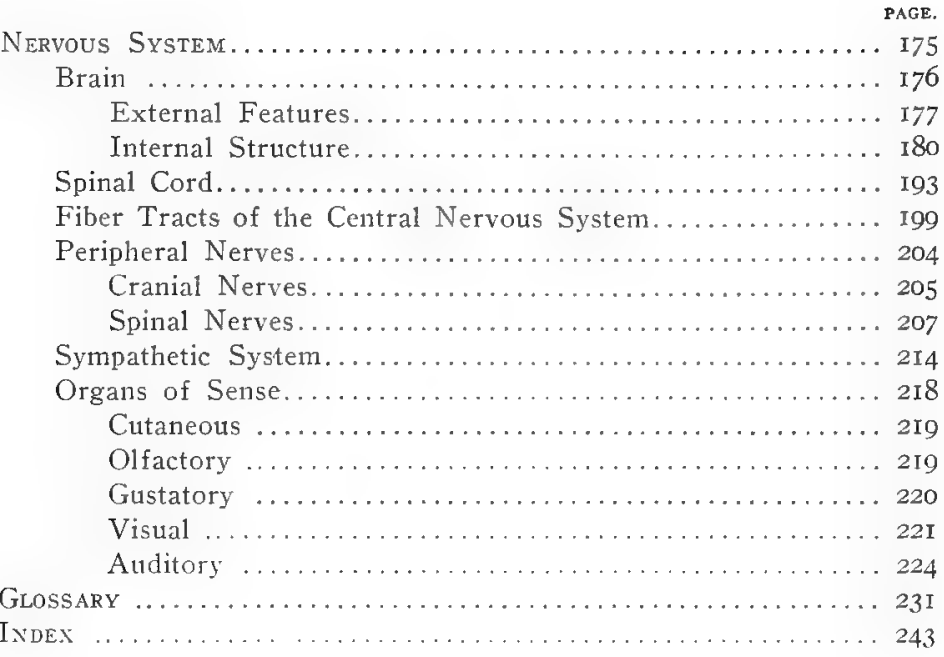




\section{LIST OF ILLUSTRATIONS.}

FIG.

FAGE.

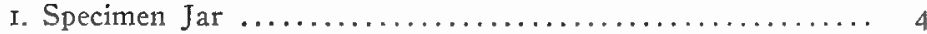

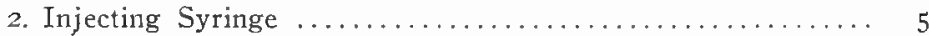

3. Diagrammatic View of Operation for Injection........... 6

4. Method of Making Incision in the Carotid Artery for Injection 6

5. Method of Inserting the Cannula into a Vessel........... 7

6. Palmar Aspect of Cat's Paw with Cannula Inserted........ 8

7. Flat Epithelium Cells from the Mouth............... I3

8. Involuntary Muscle ......................... I3

9. Cells of Cartilage ............................. I4

I0. Fibers of Voluntary Muscle..................... I5

. II. Fibers of Connective Tissue..................... I6

I2. Longitudinal Section of the Humerus of a Kitten.......... 23

13. Longitudinal Section of the Femur.................. 24

r4. Cross-section of Cat's Femur.................... 25

I5. Diagram of the Bones of the Mammalian Skull Viewed

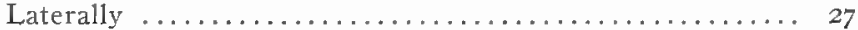

I6. Dorsal Aspect of the Cat's Skull .................. 28

I7. Ventral Aspect of the Skull with the Left Auditory Bulla Removed ................................ 32

18. Cut Surface of a Sagittally Bisected Skull.............. 35

I9. Medial or Inner Aspect of the Mandible................ 38

20. Ventral Aspect of Larynx, Hyoid Bones, and Tongue....... 39

21. Lateral Aspect of the Skeleton...................... 42

22. Plan of a Vertebra.............................. 44

23. Dorsocaudal Aspect of Atlas........................ 44

24. Lateral Aspect of the Axis.......................... 45

25. Latero-caudal Aspect of a Thoracic Vertebra............. 45

26. Caudal Aspect of Fourth Lumbar Vertebra............... 47

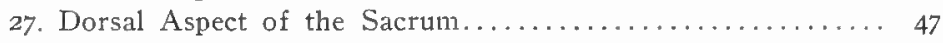

28. Ventral Aspect of the Bones of the Thorax.............. 49

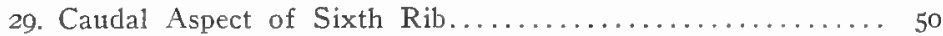

30. Lateral Aspect of the Scapula........................ 53

3I. Caudal Aspect of the Clavicle........................ 53

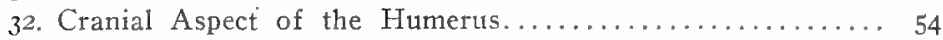

33. Lateral Aspect of the Ulna....................... 55

34. Medial Aspect of the Radius...................... 56

35. Genealogy of the Horse......................... 57

36. Dorsal Aspect of Cat's Manus...................... 59 
FIG.

368. Generalized Type of Carpus...................... 59

37. Lateral Aspect of Forelimb of Equus................... 60

38. Latcral Aspect of Innominate Bone................... 64

39. Ventral Aspect of Innominate Bones.................. 64

40. Caudal Aspect of Femur....................... 66

41. Cranial Aspect of Tibia........................ 66

42. Medial Aspect of Fibula....................... 68

43. Dorsal Aspect of Hind-foot...................... 7o

44. Diagram of a Diarthrodial Joint................... 73

45. Lateral Aspect of Dissected Knee-joint............... 74

46. Caudal Aspect of Knee-joint.................... 75

47. Ventral Aspect of Trunk and Neck Muscles............. 8I

48. Lateral Aspect of the Muscles of the Cat................ 88

49. Lateral Aspect of the Muscles of the Thoracic Limb......... 90

50. Medial Aspect of the Muscles of Thoracic Limb.......... 98

5I. Ventral Aspect of the Muscles of Trunk and Thigh.......... IOI

52. Lateral Aspect of the Muscles of the Leg................. IOI

53. Caudal Aspect of the Muscles of Crus and Foot............ IO2

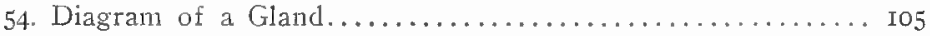

55. Diagram of the Chief Organs of the Cat............... I06

56. Dorsal Aspect of the Tongue and Larynx.................. Io8

57. Longitudinal Section of the Canine Tooth................ Iog

58. Lateral Aspect of the Permanent Dentition.............. I Io

59. Viscera of the Human Body................... II 3

6o. Ventral Aspect of the Alimentary Canal................ I 6

6I. Transverse Section of the Cat..................... II7

62. Cross-section of the Cardiac End of the Stomach.......... II7

63. Gastric Glands ........................... I 8

64. Cross-section of the Small Intestine. . . . . . . . . . . . . . . II9

65 . Villi and Glands of Intestine..................... I I9

65B. Lacteals and Portal System of Dog................... I20

66. Salivary Glands ........................... I22

67. Diagram of the Stomach of a Ruminant............... I26

68. Photograph of the Human Heart.................... I30

69. Heart Viewed Ventrally.......................... Izo

7o. Heart Viewed Ventrally with Caudal Third Cut off.......... I II

$7 \mathrm{r}$. Heart Viewed Dorsally ..................... I3I

72. Chief Arteries of the Trunk.................. I33

73. Ventral Aspect of the Arteries of the Head and Neck....... I36

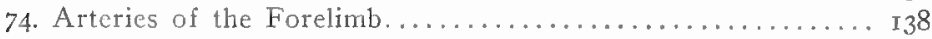

75. Arteries of the Leg........................... I40

76. Cross-section of Artery and Vein................. I42

77. Vein with Valves........................... I43 
FIG.

PAGE.

78. Veins of Cat................................ 45

79A. Arterial System of a Rabbit..................... I47

798. Arterial System of a Man....................... I47

80. Ventral Aspect of Chief Lymphatic Vessels of the Cat...... I 52

8I. Photograph of the Lymphatic Capillaries and Vessels of Cat's

Eat ............................. 153

82. Diagrammatic Transverse Section of the Chest........... I 58

83. Photograph of a Lung Corrosion of a Puma.............. I59

84. Termination of a Bronchiole.................... I6I

85. Photograph of Human Heart and Lungs................. I62

86. Ventral Aspect of Female Urogenital System............ I65

87. Median Longitudinal Section of a Kidney................ I66

88. Diagram of Structure of Kidney.................. 166

89. Section of Ovary........................... I69

90. Ventral Aspect of Male Reproductive Organs.............. I7 I

9r. Spermatozoa ............................ I72

92. Dorsal Aspect of the Brain..................... I77

93. Ventral Aspect of the Brain...................... I79

94. Diagram of the Ventricles.................... I8I

95. Sagittal Section of the Brain................... I 83

96. Dorsal Aspect of the Brain with the Cerebellum and Portion of Cerebrum Removed .................... I 85

97. Cross-section of the Brain Caudad of the Optic Chiasm...... I87

98. Cross-section of the Brain through Anterior Commissure..... I89

99. Photomicrograph of Cross-section of Human Spinal Cord.... I93

roo. Diagrammatic Section of Spinal Cord.................. I95

Ior. Nerve-cell .................................. I96

102. Diagram of the Relation of Cells and Fibers in the Spinal Cord I97

I03. Diagram of Some Fiber-tracts.................... 200

I04. Diagram of Chief Fiber-tracts of the Mammalian Brain...... 202

105. Ventral Aspect of the Branchial Plexus................. 208

I06. Ventral Aspect of the Nerves of the Pelvic Limb.......... 212

I07. Cranial Half of Sympathetic System................ 2I5

I08. Caudal Half of Sympathetic System................. 217

I09. Pacinian Corpuscle ....................... 2 I9

I Io. Longitudinal Section of the Eye................... 222

III. Diagram of the Mammalian Ear.................. 225

II2. Section of the Cochlea of the Calf................ 226

II3. Photograph of Human Brain.................... 227

II4. Brain of the Rabbit. . . . . . . . . . . . . . . . 229 



\section{ELEMENTS}

\section{OF \\ MAMMAIIAN ANATOMY.}

\section{ERRATA}

Page 33, 9th line from bottom, for "Fig. 90" read "Fig. 93."

Page 54, $3 \mathrm{~d}$ line from bottom, for "Figs. 72 and 89 " read "Figs. 74 and 105."

Page 77, Ioth line from top, for "Fig. 9I " read "Figs. 107 and $108 . "$

Page 78, 16 th line from top, for "abductor muscles" read "aiductor muscles."

Page 78, I7th line from top, for "abductor" read "adductor."

Page 78, 18th line from top, for "abductors" read " adductors."

Page 7', 2d line from bottom, for "Fig. 47 " read "Fig. 48."

Page 175 , I2th line from top, for "Figs. 94 and 95 " read "Figs. Io 7 and ro8."

I he same species or anmais are not round in all parts of the world. The lion and tiger are found wild only in 



\section{ELEMENTS}

\section{OF \\ MAMMALIAN ANATOMY.}

\section{INTRODUCTION.}

Since this book is designed for the use not only of students who have pursued the study of biology for some time, but also for those making their first actual acquaintance with the subject, it may be well to call attention to the fact that any animal or plant may be considered from several different standpoints. A general study of structure and of the relations of the various systems and organs is known as Anatomy. Histology concerns itself with the cell and cell aggregates or tissues composing the organs. These two sciences are included in Morphology, a term which by many is made to include also Embryology or Ontogeny, treating of the development of an organism from the egg, or its vegetable homologue, to the period of assuming adult characteristics. Since ontogeny deals not only with the growth of structure but also the process of growth, it may likewise be included under Physiology, a science which has for its province the investigation of the functions of the organs and systems. A special field of physiology having for its consideration the operations, especially the conscious operations of the nervous system, constitutes the science of Psychology.

The same species of animals are not found in all parts of the world. The lion and tiger are found wild only in 
the old world, while the opossum is confined to the new world. Again, many species of animals whose fossil remains indicate their existence on earth several millions of years ago, have at present no living representatives. A consideration of this geographical and stratigraphical location of organisms forms the science of Distribution. The science of Phylogeny seeks to discover the geological ancestral history of an organism.

A casual giance shows at once striking similarities and differences between the common cat, the lion, and the tiger. Ail have retractile claws, the same number and kind of teeth, and the same number of toes. On the other hand, the resemblances between these cat-like animals and the dogs are less marked, while the differences are more striking. The cats and dogs resemble each other more closely than either does a horse. Horses, dogs, and cats have numerous characters in common which are not present in birds. The recognition of such resemblances and differences furnishes a basis of classification, the treatment of which forms the science of Taxonomy.

The following is a brief classification of the animal kingdom:

Invertebrata: Animals with no skeletal axis and without a central nervous system entirely dorsal of the alimentary canal.

Protochordata: Small marine forms having, during part of their life at least, a rudimentary skeletal axis and other features marking them as a connecting-link between the invertebrates and vertebrates. Tunicates or sea squirts, Amphioxus.

Vertebrata: Forms with a skeletal axis and dorsal nerve-cord whose anterior end is dilated into a brain.

Pisces (fish).

Ampibia (frogs, toads, and salamanders).

Reptitia (snakes and lizards).

Aves (birds). 
Mammalia (vertebrates suckling their young).

Prototheria: Oviparous mammals. Ornithorhynchus. or duck-bill and Echidna or spiny ant-eater.

Eutheria: Viviparous mammals with anus and urogenital opening distinct.

Marsupialia (opossums and kangaroos). Insectivora (moles, shrews, and hedgehogs).

Edentata (sloths and ant-eaters).

Chiroptera (bats and flying foxes).

Rodentia (rabbits, squirrels, mice, and rats).

Cetacea (whales, porpoises, and dolphins).

Sirenia (sea cow).

Ungulata (the hoofed mammals).

Carnivora (dogs, cats, wolves, and foxes).

Primates (monkeys and man).

A glance at the above outline shows that the class Mammalia is divided into two subclasses, the latter of which includes ten orders. Each of these orders consists of several families which in turn are composed of genera made up of species. The order Carnivora includes eleven families, of which Canidæ (the dogs), Felide (the cats), and Ursidæ (the bears) are the most frequently seen in America. The family Felidæ is represented by only two living genera, Cyncelurus and Felis. The genus Felis inclides several species, of which Felis leo (the lion), Felis tigris (the tiger), and Felis domestica (the cat) are the most familiar. Of the last species, there are several varieties, such as Maltese, Angora, and Manx cats.

Linnæus, born in Sweden, I702, invented the system of binomial nomenclature in accordance with which the scientific name of every plant and animal is composed of two parts, the generic and specific. Thus the house cat is designated Felis domestica; the lion, Felis leo; the dog, 
Canis familiaris; the wolf, Canis lupus; the pig, Sus scrofa; the red deer, Corvas elephas; the elephant, Elephas Africants; the ourang-outang, Simia satyrus; and man, Homo sapiens.

\section{METHODS OF PRESERVING MATERIAL.}

Alcohol has been widely used as a preservative, but owing to the fact that it is expensive and quickly evaporates from the specimen exposed to the air, thereby rendering the parts

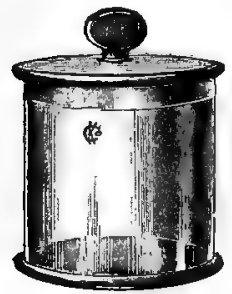

Fig. I. Specimen JAR. dry and brittle, its use has been largely supplanted by formalin. Formalin, $\mathrm{CH}_{2} \mathrm{O}$, is often sold under the names of formose, formol, formine, formalosa, and formaldehyd. It can be purchased for about thirty cents a pound. For preserving any animal or plant, the concentrated $40 \%$ formaldehyd is diluted with water in the proportion of ninety-five parts of the latter to five parts of the former. It is evident, therefore, that one pound of formaldehyd will make about ten liters of preserving fluid.

The specimens may be kept a year or two without changing the formalin in ordinary stone jars with covers, but for permanent preservation the glass jar with the groundglass cover should be used (Fig. I).

Preparation of V Vascular System.-To render the vessels plainly visible and distinguish the arteries from the veins, it is advisable to inject the former with a red mass and the latter with a blue mass. These fluid masses should be of such a character as to harden in a short time after injection, so that they will not run out when the vessels are cut during dissection.

A syringe of hard rubber, having a capacity of about two 
ounces, serves very well for injection. A cannula of correct size may be had by asking the druggist for the filling cannula of the Parke Davis serum syringe. The end to be inserted into the blood-vessel should be ground off obliquely and smoothly on a whetstone. The connection between the cannula and nozzle is formed by stiff rubber tubing which should be securely tied to the cannula (Fig. 2).

The injecting mass is prepared by thoroughly mixing Ioo c.c. of water, 20 c.c. of glycerin, 20 c.c. of concentrated formalin, and $85 \mathrm{gm}$. of common laundry starch. One-half should be colored red by adding to it one or two grams of powdered carmin made into a paste with a few drops of ammonia, and the other colored blue by dissolving in it a gram or two of soluble Berlin blue. These liquid masses, after being passed through a fine wire strainer or a coarse piece of cheese-cloth stretched across a funnel, may be preserved for any length of time in covered jars.

The animal may be anesthetized by placing it in a tight box with a cloth or absorbent cotton wet with 30 c.c. of ether or chloroform. If only the arteries are to be injected, the cat may remain in the box until dead; but if the

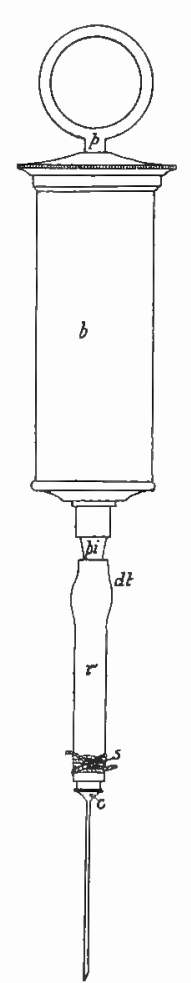

FIG. 2, InJECTING SYRINGE. $\times \frac{1}{6}$.

$p$, Plunger handle; $b$, barrel; pi, nozzle; $c$, cannula; $r$, rubber tube; $d t$, point of detachment; $s$, string. veins are also to be injected, it is preferable to use ether for the anesthetic and then remove the animal to the tray as soon as it is unconscious, and reflect a portion of skin, ex- 
posing the external jugular veins (Fig. 3). With the curved forceps thrust beneath the vein a cord may be pulled

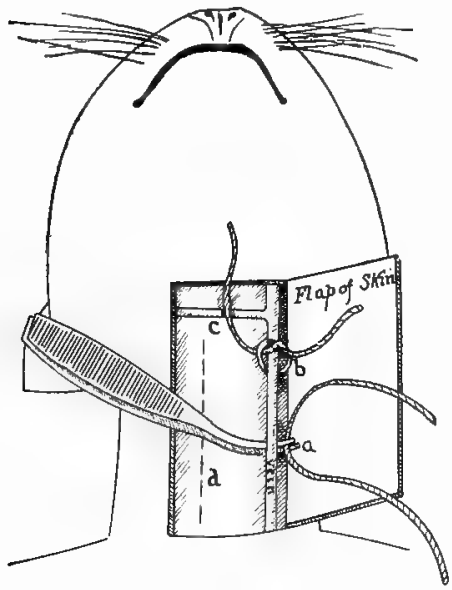

Fig. 3. Diagrammatic View of Operation FOR INJECTION.

$d$, Broken line showing course of the carotid artery beneath; $b$, string loosely tied; $c$, transverse vein uniting external jugulars; $a$, points of curved forceps containing string. through and tied in a loose knot. One-half inch from the latter a second cord should be tied around the vein loosely. An oblique cut (Fig. 4) with the point of the scissors directed caudad is then made in the veins between the cords. The incision should extend about half-way through the vessel. Absorbing the blood with absorbent cotton as it runs from the vessel will prevent clogging. If too much ether has not been used, the blood will continue running fifteen minutes. When it has nearly ceased flowing, the carotid artery. must be found by making a slit in the muscle alongside of the trachea just mediad of the jugular, as indicated by the line $d$ (Fig. 3 ). Having cut through the muscle, two white cords are seen along either side of the trachea. The medial one may be red, as it is the carotid artery. The lateral one, lying in the same sheath with the preceding, is the vagus or tenth cranial nerve. Separate the artery

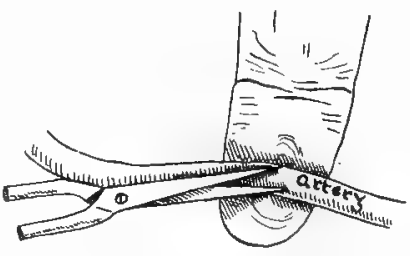

Fig, 4. Method of Making INCTSTON IN THE CAROTID ARTERY FOR INJECTION. from the nerve and tie two cords loosely around the ves- 
sel as in the case of the jugular. Lift up the artery with the index finger (Fig. 4), and make an oblique incision with the scissors. The cannula with the connecting tube attached should then be inserted caudad in the oblique cut of the artery (Fig. 5), and the string $s$ drawn tight so as to hold the cannula in place. The string st should then be tightened to prevent the injection mass from running out where the cannula is inserted. After stirring the red mass, filling the syringe, and slipping the nozzle into the connecting tube the operator should press slowly but continuously on the plunger until that portion of the carotid craniad of the string $s t$ is well distended. In a large cat this will not occur until the syringe is nearly or quite empty. When the vessels are full, the cannula is withdrawn while the string $s$ is

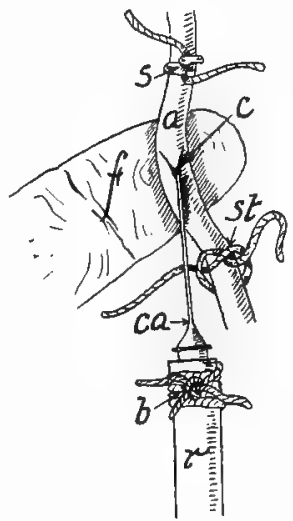

Fig. 5. Method OF In Serting the CANNULA into a VesSEL.

tightened. The syringe is washed out, after which the blue mass is well stirred and injected caudad into the external jugular in the same manner as described for the arteries.

By making a slit about three inches long in the abdominal wall, a fold of the intestine may be pulled out so that its lumen can be filled with about 200 c.c. of $15 \%$ formalin. The same amount should be injected into the lungs by inserting the cannula caudad into the ventral wall of the trachea. If the cat is not to be used at once, it may be preserved indefinitely in a jar of five per cent. formaline.

The portal system is not injected through the jugular vein. The portal trunk just caudad of where it enters the liver may be found by cutting a piece from the abdominal wall on the right ventral aspect just caudad of the last rib. 
After two loose knots are tied around this trunk as rirected for the jugular, the cut is made and the cannula inserted caudad. About I5 c.c. of the blue mass may be injected into the portal system of a large specimen. This should not be injected until the other systems have been filled.

The lymphatic system must likewise be injected for demonstration. While the cat is being anesthetized, $5 \mathrm{gm}$. of soluble Berlin blue are dissolved in $100 \mathrm{gm}$. of water,

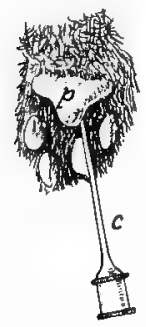

Fig. 6. PALMAR ASPECT OF CAT'S PAW WITH CANNULA INSERTED. and the solution warmed to about the temperature of the body. As soon as the cat is unconscious the syringe should be warmed by filling it with hot water, and the point of the cannula pushed obliquely proximad under the thick skin on the palm (Fig. 6) of the paw. The syringe after being half filled with Berlin blue solution is attached to the cannula and the plunger pushed in very slowly so that one-fourth of the amount in the syringe is forced out in ten minutes. While the injection is being made the limb should be gently massaged by pinching and rubbing from the foot toward the body. This facilitates the flow of the liquid in the lymph-vessels. In this manner the lymphatics of each limb are filled. The author has been able to fill the left thoracic duct by continuing the injection for about twenty minutes in the palm of the left paw. The lymphatics of the head and neck may be injected in a similar manner by inserting the cannula beneath the skin on the tip of the ear, the tip of the tongue, the tip of the nose, and the lips.

In order to inject the lacteals the abdominal cavity must be opened, and the cannula inserted very obliquely into the wall of the small intestine so that its point is between the mucous and muscular coats. The half-filled syringe being 
attached, very gentle pressure should then be exerted on the plunger, until the blue solution appears in the lacteals. To inject all the lacteals it is necessary to insert the cannula into the wall of the intestine at a dozen different places. To fill the thoracic duct, injection may be made into the large lymphatic gland lying at the point where the converging blood-vessels of the mesentery meet. The best solution for injecting the thoracic duct is made by dissolving $7 \mathrm{gm}$. of gelatin in a warm Berlin blue solution (4 gm. of Berlin blue to Ioo c.c. water). This should be filtered through a single layer of absorbent cotton and then injected while still quite warm. In all cases injections to fill the lymphatics must be warm and must be pushed in very slowly. These lymphatic injections are best preserved by injecting the trachea and intestine with $95 \%$ alcohol and immersing the cat in a jar of $70 \%$ alcohol.

\section{Preparation of a Mammal for Dissection of the} Muscles, Peripheral Nerves and Viscera.-The simplest method is to anesthetize the animal as before described and then remove the skin, taking great care to avoid cutting away the superficial muscles. The cannula should be pushed through into the trachea and Ioo c.c. of $15 \%$ formaline injected to fill the lungs. An equal amount of formaline should be injected into the stomach through a glass tube pushed down the esophagus. The same quantity of formalin should be injected at two or three different places into the intestines by making a median incision into the abdominal wall and pulling out a loop of the intestine into which the cannula may be thrust. The specimen is then to be immersed in a jar of $5 \%$ formalin. A better method is to inject into the carotid artery 200 c.c. of glycerinated formalin (water I40 c.c., glycerin 30 c.c., formalin zo c.c.), and half that amount into the intestine and trachea. The specimen may then be preserved in $5 \%$ formalin. 


\section{Preparation of the Central Nervous System.-The} animal may be killed either with chloroform or ether. About 200 c.c. of formal-bichromate (r 70 c.c. of $5 \%$ potassium bichromate and 30 c.c. of formalin) are then injected slowly craniad into the carotid artery (Figs. 3, 4, and 5). After skinning, the eyes should be cut out and the flesh removed from the head and dorsal side of the vertebral column. On a line connecting the caudal borders of the orbits, cut through the skull to the brain with the bone cutters and remove piece by piece the roof of the skull. Next cut away the lateral walls down to the base of the brain. Care must be exercised in laying bare the cerebellum, and cutting loose the tertorium cercbelli, the plate of bone separating the cerebrum from the cerebellum. The spinal cord is next laid bare dorsally, beginning with the atlas, by cutting through the pedicles of the neural arches on either side. With a sharp knife or a pair of scissors the spinal nerves may then be cut and the cord lifted from behind forward out of its bed, until the brain is reached. The latter must be carefully raised while the nerves at its base are cut, and the dura mater loosened.

The brain is firm enough to dissect as soon as removed, but it is better to further harden it and differentiate the white and gray matter by placing it in weak formal-bichromate $(5 \%$ formalin, 500 c.c. $+5 \%$ potassium bichromate, 500 c.c.) one week in the dark. Light causes a precipitate. At the end of one week the specimen should be placed in IOOO c.c. of $5 \%$ formalin for another week, after which it is ready for dissection. In case brains of calves or sheep are used a hammer and hone chisel are necessary for opening the skull. The head should first be nailed to the tray. As soon as the brain is removed it should be placed in a large pan of water and the dura mater carefully cut away, the clotted bloorl washed off and a syringeful of strong 
formal-bichromate injected into the third ventricle by pushing the cannula about half an inch through the infundibulum (Fig. 90). The brain of a sheep or calf will be very soft when removed, as it cannot be hardened previously by injecting the hardening fluid into the arteries. Therefore it is necessary to lay the specimen on absorbent cotton in the jar of formal-bichromate, which must be exchanged for fresh fluid on the second and third days. At least two weeks are required for hardening the brain of a sheep or calf, after which it is placed in $5 \%$ formalin for a week or more to wash out the bichromate before dissection. Brains are best preserved permanently in $85 \%$ alcohol.

Preparation of the Osseous System.-A mounted skeleton of the cat may be purchased for about eight dollars. It is far more satisfactory, however, to use the disarticulated bones for study. These are easily prepared in the following manner: As soon as the animal is dead, the skin and the greater part of the flesh should be cut away and the internal organs removed. The bones with much flesh remaining on them are then put into 7000 c.c. of water containing 150 grams of gold dust. This may then be boiled from two to four hours but better results are given by using the low flame and keeping the solution at a temperature between 75 and 90 degrees centigrade from 3 to 6 hours. As soon as the flesh falls freely off the bones they should be brushed clean in a pan of water and the brain broken to pieces with a bent wire thrust into the foramen magnum. The contents of the skull may then be washed out under the tap. This treatment renders the bones perfectly clean, white and free from grease.

By heating the bones from one to two hours only and not allowing the temperature to rise above 85 degrees, the flesh may be brushed from the limbs without removing the 
ligaments holding the bones together. When dry, the bones are held firmly in their natural relations. In treating the skeletons of kittens or those of smaller animals such as mice, birds and frogs, only one half the amount of gold dust should be used and a temperature between 70 and 80 degrees maintained. 


\section{GENERAL STRUCTURE.}

The study of any vertebrate reveals the presence of numerous organs, each of which is for the performance of a particular function. Thus the heart is the organ for the propulsion of the bloód, the kidney for the elimination of the nitrogenous waste. Several organs combined for a common purpose constitute a system. The heart, with the various vessels for conveying the blood, forms the circulatory system. The following eight systems are found in all

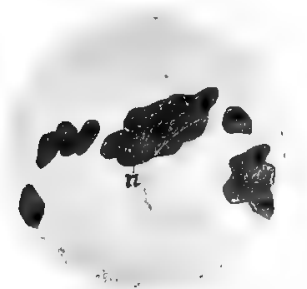

Fig. 7. Flat Epithelium Cells From the Mouth. $X$ I50.

$n$, Nucleus of the cell.

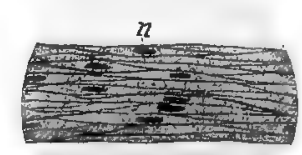

F1G. 8. Involuntary MuscleCELLS. $\times 250$.

$n$, Nucleus of a cell.

Mammalia: Osseous or bony, muscular, digestive, respiratory, vascular, excretory, reproductive, and nervous.

The relative locations of the various systems are represented diagrammatically in Fig. 54. The organs have the same arrangement throughout all the orders of nammals. Moreover, the minute structure of the same organ is so similar in the different species that in many cases even the microscope will not enable one to tell from which of several kinds of mammals the organ has been taken. The organs are composed of four classes of tissues: Epithelial, which covers all free surfaces; connective, forming the bones, binding together the muscular fibers and elements of the 
nervous system and making up cartilage and ligaments (Fig. I I) ; muscular, composing the greater part of the

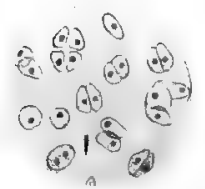

FIG. 9. CELLS oF Cartilage. $\times$ I 50 . muscular system; and nervous, constituting the nervous system (Fig. 97).

The naked eye is unable to distinguish the elements of the tissues, but the microscope reveals the fact that each kind of tissue is formed of either cells or fibers or, as is most frequently the case, a combination of both.

The different relative arrangements of these anatomic elements, together with their morphology, permit one to know from what organ any particular section of tissue under consideration has been taken.

These ultimate units of structure are still further resolved into parts by the chemist, who has shown that they are composed largely of carbon, hydrogen, oxygen, and nitrogen. Since there can be no energy developed in the body without the disintegration and consequent death of some of the particles composing the millions of tiny cells, it is plain that they must have their losses replaced in order to continue their existence. Therefore a method of preparing the food for the use of the cells, and a way of transporting it to each of them are necessary.

The former is accomplished by the digestive system, which, through the agency of the salivary, gastric, pancreatic, and other glands, transforms the food into a special liquid state capable of being absorbed by the millions of minute finger-like villi of the small intestine (Fig. 63). Thence it is transferred by the lacteal vessels and veins to the heart, whence it is conveyed by the arteries to their capillary distribution in the neighborhood of every cell in the body.

The dead matter or waste material resulting from the 
cell activity is of two kinds, gaseous and liquid. Both diffuse through the capillary walls into the blood. The

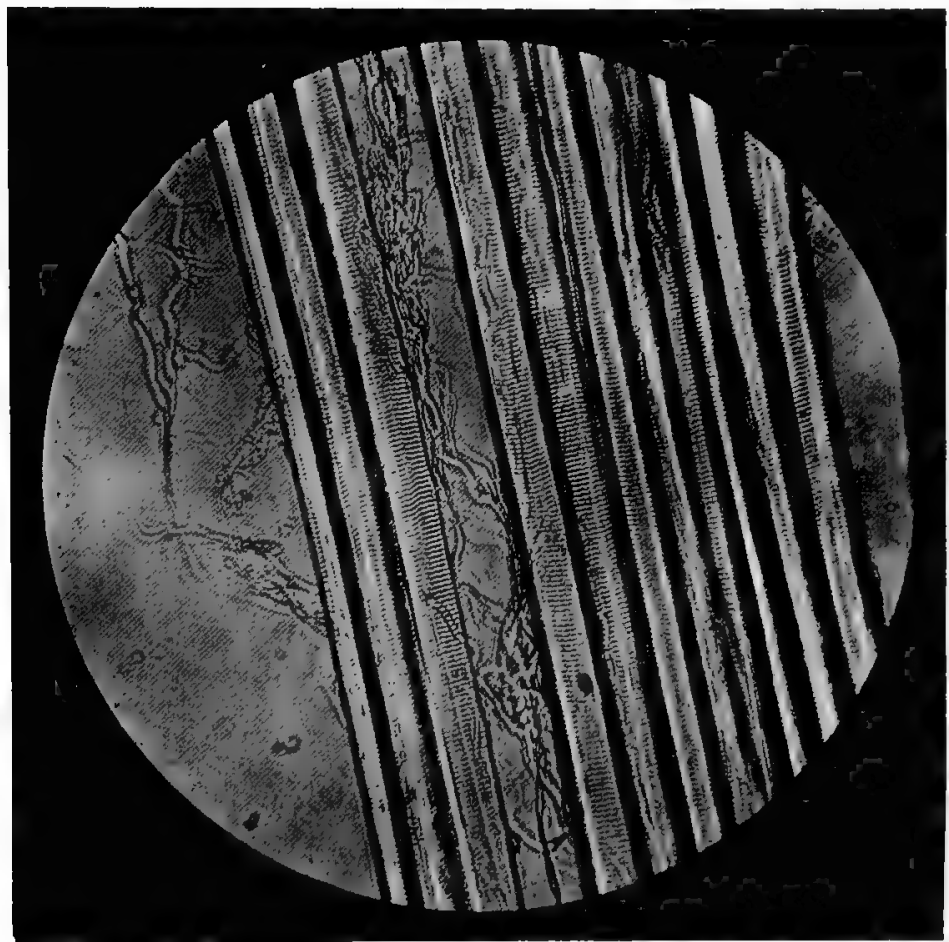

Fig. io. Photomicrograph of Fibers of Voluntary Muscle. $X$ ioo. Note the finer threads of connective tissue.

former, which is carbon dioxid, is carried to the heart and thence by the pulmonary arteries to the lungs, where it passes into the terminal branches of the trachea, and finally by expiration reaches the exterior. The liquid excretion is transported by means of the veins and arteries to the kidneys, where it diffuses through the walls of the capillaries into the minute tubules opening into the ureters leading to the bladder. It must be remembered that the 
material known as feces passed out of the alimentary canal through the anus is not an excretion of the cells of the body, but largely that portion of the food not transformed into a condition permitting it to be absorbed by the villi.

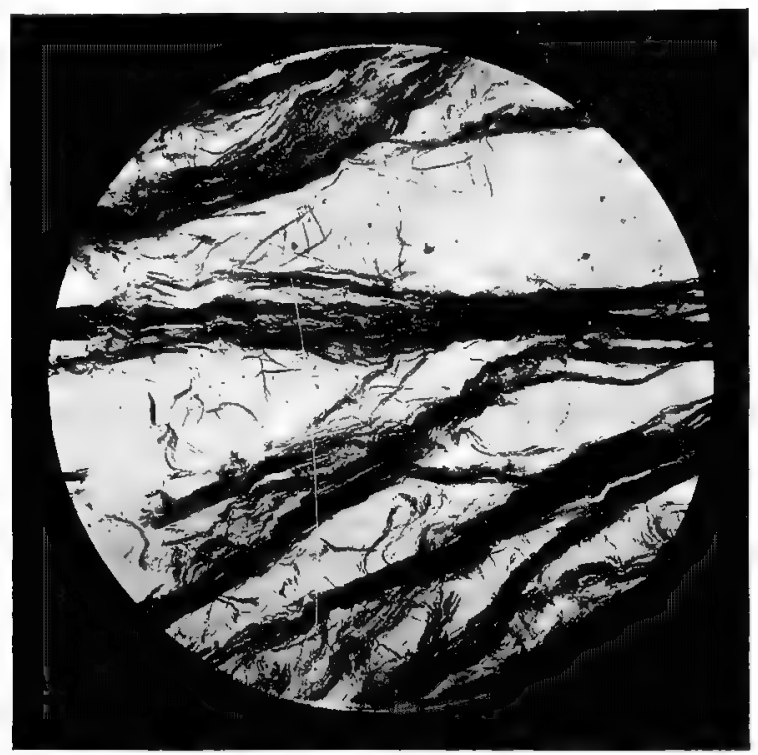

Fig. it. Fibers of Connective Tissue. $\times 300$.

In addition to these systems necessary for the maintenance of life, the cat requires a means for supporting the body and moving about, furnished by the osseous and muscular systems. The osseous system serves not only for support and locomotion, but also for the protection of the delicate vital organs. The skull and spinal column contain the brain and spinal cord, while the heart and lungs are well shielded by the dorsal vertebra, the ribs, and sternum. Likewise the muscles ward off serious injuries from the blood-vessels, as they cover to a considerable depth nearly 
all large arteries, and also aid by their contraction in moving the lymph through the numerous lymphatic vessels extending from the extremities to the jugular veins.

These systems previously described are capable of performing their functions only when supplied with nerves through which impulses can be transmitted from the brain and spinal cord. Stimuli sent by the brain or cord through the nerves cause the gastric juice to flow into the stomach, the bile and pancreatic secretions to be formed and poured forth into the intestines, the kidneys to eliminate the waste from the blood, the heart to beat, and the muscles to contract and relax.

The only system which is not absolutely necessary to the life of the cat is the reproductive; but this is required for the continuance of the species. It is not, however, functional during the entire life, but as a rule only from the end of the first to the tenth year.

\section{PRACTICAL QUESTIONS. AND SUGGESTIONS.}

r. What advantages are derived from the study of mammalian anatomy?

2. Define morphology and state a fact from that science.

3. What two sciences does biology include?

4. What five sciences are included in zoology?

5. Make a physiologic statement concerning the heart.

6. State five facts belonging to the science of distribution.

7. What is taxonomy?

8. Name five classes of vertebrates.

9. By examining specimens discover what external feature distinguishes a reptile from an amphibian.

Io. Do all mammals have hair?

II. What habit is common to no other vertebrates except mammals?

12. Give two points of difference between the two subclasses of Mammalia.

13. Name the ten orders of Eutheria and give an example of each.

I4. Which orders derive their names from the habits of the animals?

15. Which orders derive their names from anatomic features?

16. Which orders are aquatic? 
I7. What is the ultimate syllable of all family names?

18. Explain what is meant by binomial nomenclature.

I9. Name three families of Carnivora.

20. Examine specimens and determine wherein the teeth of Canidr differ from those of Felidx.

21. What two rank names constitute the scientific name of an animal?

22. Give the scientific name of five Carnivora, two Ungulata, and two Primates.

23. Define organ, system, tissue, and cell.

24. Nane two organs belonging to each system.

25. How do the elements of the four kinds of tissue differ?

\section{EXTERNAL FEATURES.}

The cat, like all other mammals, possesses two welldefined skeletons, the endoskeleton, consisting of the true bones, and the exoskeleton, composed of the skin and its appendages. The skin invests the body completely and is continuous with the lining of the digestive and urogenital canals. It varies in thickness in different regions, being very thin on the lips, ears, and eyelids, and exceedingly thick on the pads of the feet and on the ventral neck region, where, in contest with an enemy, it is most likely to be seized. A fibrous connective tissue binds the skin to the subjacent structures. In some places the union is very firm, as on the distal parts of the limbs and the head, while in other regions it is loose, as on the lateral aspect of the trunk.

The skin consists of an external layer, the cpidcrmis, and beneath this, the dcrmis or true skin, designated the corium. The epidermis is composed of numerous strata of epithelial cells. Those on or near the surface are much flattened while the deeper ones are more or less cubical. As the superficial layer clesquamates in minute fragments, forming what is commonly called dandruff, it is replaced by cells developed from the deeper layers.

At the orifices of the internal passages, such as the diges- 
tive and genital tracts, the epithelium changes to a soft delicate nature, and is then known throughout these passages as mucous membrane.

The corium or dermis is a form of fibrous connective tissue whose deepest portion forms the white fluffy areolar substance cut in removing the skin. In many regions just below the true skin is a layer of adipose tissue, which when examined under the microscope is seen to be composed of numerous giobular fat-cells supported by fibrous areolar tissue. The seven pads on the forepaw and the five on the hind one consist of greatly thickened epidermis, the corium. and masses of fibrous connective tissue enveloping many fat-cells.

The sebaceous or oil glands lie in the corium, and by means of a duct open into the hair follicle near the surface. The sudoriparous or swcat glands, composed of coiled tubes, are present in the subcutaneous tissue, from whence a duct extends to the surface. Although there are no blood-vessels in the epidermis, numerous nerve terminations are present in the deeper portions. The true skin is richly supplied with both nerves and blood-vessels.

The claws produced by a special modification of the epidermis are among the most important appendages of the skin. Five of these are present on each forefoot, while only four occur on the hind one. At the root of each claw, the dermis forms a crescentic fold over it, and beneath is a number of papille richly supplied with blood-vessels. This entire structure forms the matrix of the claw, which is set around the terminal part of the distal phalanx of each digit. Claws, or some similar structures, such as nails or hoofs, are present in all mammals except the Cetacea.

Another important appendage of the skin is the hair, which covers the entire body except the tip of the nose and the pads of the feet. Its length and color vary with the 
variety of the cat. The Mombus cat of Africa has short stiff hair, while the Angora or Persian cat is remarkable for the length and delicacy of its soft fur. The hair, like the nails, is an extreme modification of the epidermis. Each hair grows from a papilla at the bottom of a small sac, the follicle, which is a depression in the corium. The central part of the hair is the pith, and the external portion, formed of thin overlapping scales, the cuticle. The coloring-matter lies in the superficial scales, and may be disposed in such an irregular manner that one-half of a hair is white, and the other half yellow.

The large hairs on either side of the nose are known as ribrissa. Their roots are provided with delicate nerveendings of touch, so that the animal may find its way with ease through dark narrow passages. There are a few long hairs above the eyes, forming the eyebrows, but no eyelashes are present.

Most of the hairs are inserted obliquely into the skin, but when angered the cat can erect them by the contraction of a small muscle passing from the skin to the hair-bulb.

On some mammals the hairy covering is partial and limited to particular regions; in others, as the hippopotamus and the Sirenia, it is very scanty, but scattered over the whole surface; while in the Cetacea it is reduced to a few: small bristles about the mouth.

Some kinds of hair, as those of the mane and tail of the horse, are shed and renewed annually. Most mammals have a long hairy coat in winter which gives place in spring to a short coat. The Arctic fox, hare, ermine, and numerous other animals of the colder regions undergo a complete change of color in the two seasons, being white in winter and brown or gray in summer. By this protective coloration they escape many of their enemies. 


\section{THE SKELETON.}

The number of bones in the skeleton of the cat varies with its age, since two or more bones separate in the young may form one mass in the old animal. The three portions of the innominate bone which are distinct (Fig. 38) in the young, become fused in the adult. In very old age many sutures of the skull become partially or wholly obliterated. In the young adult cat the number of bones, exclusive of the teeth, ear bones, chevron bones, and sesamoid bones, is about 233. The sacrum is reckoned as one bone, though composed of three coalesced vertebræ. The structure and embryology of the teeth show that they belong to a different category from the bones. The ossicula auditus, or ear bones, are the malleus, incus, and stapes of the middle ear. The chevron bones are eight in number, attached to the ventral side of the vertebre of the tail. The sesamoid bones number about forty, of which the patella, or knee-cap, is the largest. They are formed in the tendons where there is much pressure or friction, as upon the volar surface of the metacarpus. The outline on page 22 gives the classification, names, and number of the different bones of the skeleton.

\section{GENERAL TERMS USED IN DESCRIPTION OF BONES.}

In reference to shape the bones are spoken of as long, short, flat, and irregular. Long bones are those having a shaft or diaphysis in which is a cavity filled with marrow, and two enlarged extremities or epiphyses (Fig. I3): femur, fibula, metacarpals, and phalanges. Short bones 


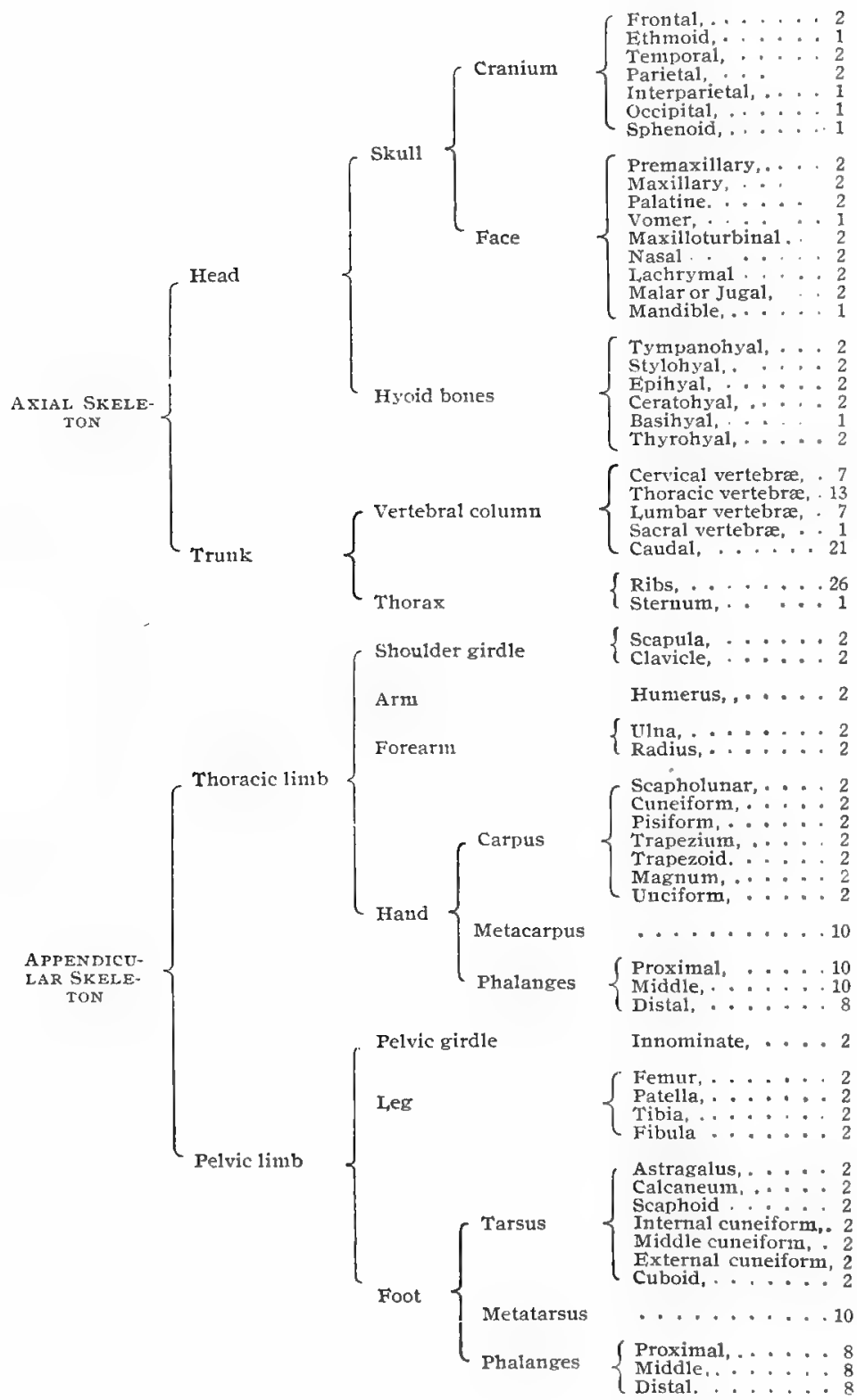


are those not elongated and with no medullary cavity: tarsus and carpus. Flat bones are plate-like, with a layer of cancellous tissue between two layers of compact tissue: parietal, scapula, and innominate. Irregular bones are those which have an exceedingly itregular shape: ethmoid and vertebra. The aspect of a bone is the portion seen when viewed from a given direction. The border of a bone is the margin, edge, or ridge at the juncture of two surfaces. Proximal is used to designate the portion of a structure nearer the axis or spinal column, in distinction to distal, which signifies the part farther removed from the axis. Cranial indicates the part of an organ nearer to the plane passing just beyond the head and perpendicular to the spinal axis, while caudal is applied to the other part of the organ nearer to the perpendicular plane at the end of the extended tail.

Sagittal refers to the plane bisecting the animal in a vertical and longitudinal direction. Mcdial and lateral are adjectives, the former meaning nearer to the sagittal plane and the latter more remote on either side of that plane. Proximad, distad, craniad, caudad,

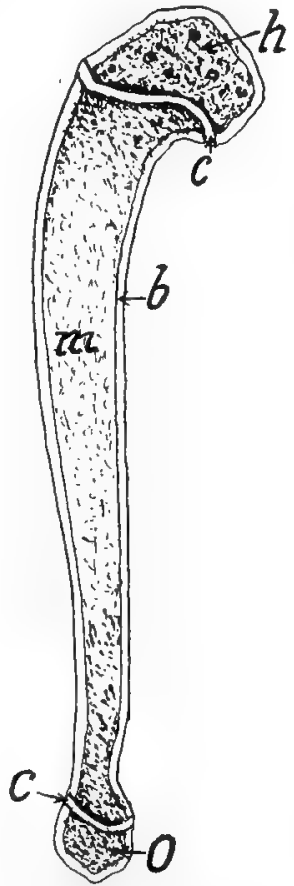

FIG. I2, Longitudinal Section of THE HUMERUS OF A KrTTEN.

$h$, Epiphysis for head; $c$, cartilage $; b$, bone ; $m$, medullary substance; 0 , epiphysis for olecranon process. mediad and laterad are adverbs indicating direction in accordance with the adjectives to which they are related.

A process is projection or elevation.

A tuberosity is a rough obtuse process. 


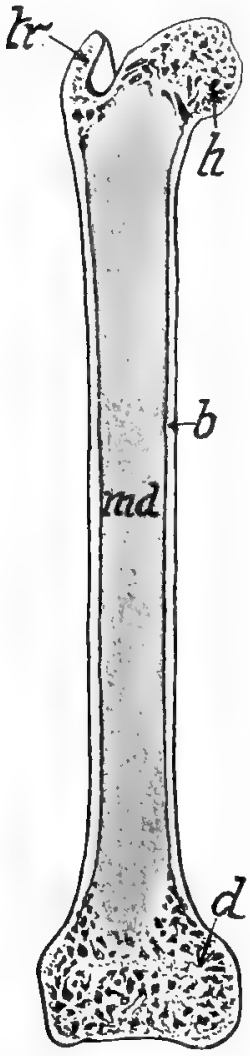

FIG. I3. LONGItudinal Section oF THE FeMUr.

ind, Medullary cavty ; $d$ and $h$, cancellous $t$ is sue; $t r$, cancellous tissue of trochanter process; $b$, compact bony tissue.

A tubercle is a small and usually more or less pointed process.

A condyle is a rounded and somewhat elongated smooth articular process. The distal end of the femur presents a pair of condyles (Fig. 40).

A fossa is an irregular depressed area (Fig. 30).

A foramen is an aperture for the passage of vessels or nerves.

The shaft is the body or middle portion of an elongated bone.

The head is a spheroidal prominence at one end of an elongated bone (Fig. 40).

The epiphysis is a small process of bone ossified from a separate center. In the young animal it is attached to the main bone by cartilage, but in the adult becomes a part of the main bone (Fig. I2). The femur has four epiphyses, one for the head, one for the distal extremity, and one for each trochanter process (Fig. 40). With the exception of the phalanges, metacarpals, and metatarsals, all of the long bones have an epiphysis at each extremity. In the human, these epiphyses do not unite with the shaft before the sixteenth year. Diplöe is the spongy layer of bone between the compact surface layers of the flat bones (Fig. I8).

The articulation of a bone has reference to its contact with other bones by means of joints. 


\section{STRUCTURE OF BONE.}

Every bone is completely covered except on its articulating surfaces with a tough membrane, the periosteum, which serves for the attachment of muscles, and the renewal of bony tissue in case of injury. The long bones contain a cavity, the medullary cavity, filled with marrow (Fig. 12).

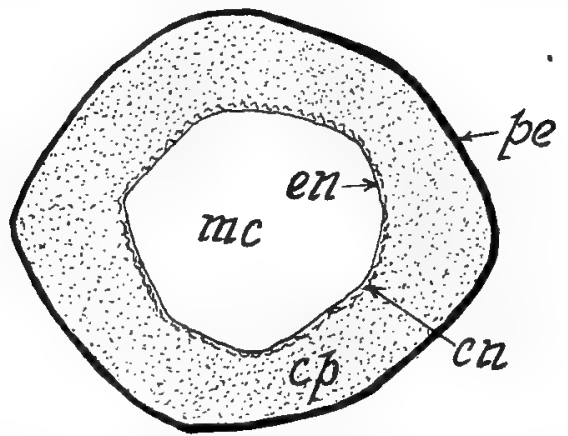

Fig. I4. Cross-section of Cat's Femur. $\times 5$.

$c p$, Compact tissue ; $c n$, cancellous tissue ; $c n$, endosteum; $m c$, medullary canal; pe, periosteum.

This cavity is lined with endosteum, a membrane similar to the periosteum.

The shaft of the long bone is composed mainly of compact bony tissue through which extend longitudinally intercommunicating microscopic channels, Haversian canals, for the conveyance of blood-vessels, nerves, and lymphatics.

The lacunce, or spaces for the bone cells during life, are arranged concentrically about the Haversian canals. The canaliculi, or processes of the lacunæ, communicate with one another. At the extremities of the bones the place of the medullary canal is taken up by cancellous tissue (Fig. I3, d), the compact tissue being very thin. The flat bones have no medullary canal, but the diploë or cancellous tissue lying between the outer compact tissue has its spaces filled with a 
red marrow of the same nature as that in the cancellous tissue of the long bones, wherein the red blood-corpuscles are formed. The large medullary cavity or canal is filled with yellow' or fatty marrow.

\section{BONES OF THE SKULL.}

The skull is usually considered in two parts, the cranium and face. The former is composed of nine bones, which will be described in order.

The frontal bones (Figs. I 5 and I6) are two in number, lying between the orbits, and articulating with one another in the median line. They form the roof of the cranial part of the brain cavity and the caudal portion of the roof of the nasal chamber. A lateral projection (po, Fig. I6) is known as the postorbital process. Within the frontal bone is a cavity, the frontal sinus (Fig. I8), which contains air and is lined with mucous membrane. It communicates with the nasal cavity. The lateral descending portion of the bone, articulating with the palatine and orbitosphenoid, is the orbital plate of the frontal.

In the majority of the Mammalia the frontal is a paired bone, but in man the two portions become anchylosed during the fifth or sixth year. The horns of ruminants are outgrowths of these bones. Among the Cervidæ (deer) horns are usually developed only on the male, and are shed every year. In the Bovidæ (cattle) the horns are permanent when present.

The ethmoid (Fig. I8) is a single bone lying ventral to the frontals and nasals. It separates the cranial cavity from the nasal cavity and projects into the latter in the form of two thin scroll-like plates of bone and a median vertical plate. In order to see the relations of this bone, three skulls must be used, one of which should be bisected sagittally, a second should have the roof of the cranial and 
nasal cavities removed, and the third should be cut transversely on a line joining the middle of the orbits. The ethmoid is usually visible externally as a small rhomboid plate on the medial wall of the orbit between the frontal,

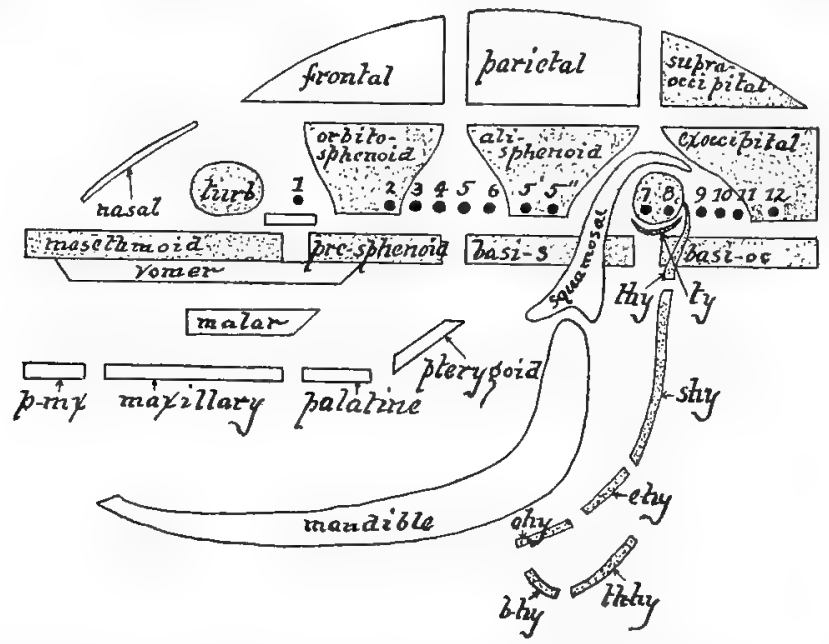

Fig. I5. Diagram of the Bones of the Mammalian Skull Viewed LATERALLY.

I, 2, 3, etc., indicate the places of exit of the twelve cranial nerves. pmx Premaxillary; ty, tympanic, 7 and 8 are on periotic; thy, tympanohyal; shy, stylohyal; ehy, epihyal; chy, ceratohyal; bhy, basihyal; thhy, thyrohyal. The cartilage bones are shaded.-(From Flower, after Huxley.)

lachrymal, and palatine bones. It consists of four parts: the paired ethmoturbinals or lateral ethmoids (Fig. I8), the mesethmoid, and the cribriform plate. The ethmoturbinals are in the form of scroll-like laminæ which project forward from the transverse cribriform plate into the nasal cavities. The portion which appears externally in the medial wall of the orbit is the os planum. In the recent state, the surfaces of these bones within the nasal cavity are covered with a mucous membrane over which the first pair of cranial nerves (olfactory) are distributed. The delicacy 
of the sense of smell is proportional to the development of the ethmoturbinals. In most orders of animals five scrolls are present, but in Echidna there are six and in some Ungulates there are eight, while in adult Primates there are only from one to three, more, however, being present in the embryo.

The mesethmoid is the perpendicular plate of bone which, prolonged craniad by cartilage, separates the nasal cavity into two portions. Caudad it is united to the cribriform

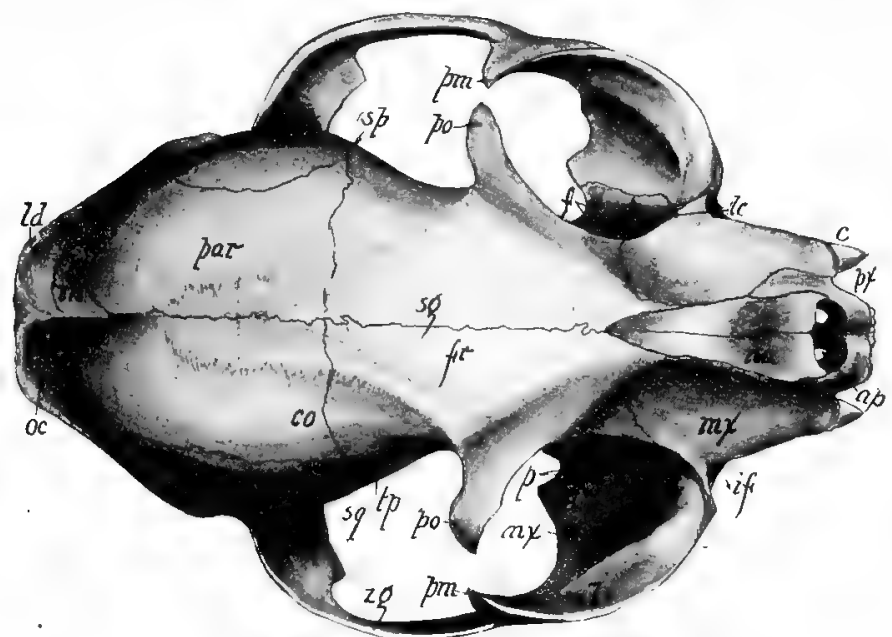

Fig. 16. Dorsal Aspect of the Cat's Skull.

$a p$, Anterior palatine foramen; $c$, canine tooth; co, coronal suture; $f$, foramina in palatine bone, the lateral one is the posterior palatine and the medial one is the sphenopalatine; $f r$, frontal; if, infraorbital foramen; in, interparietal; $l c$, lachrymal canal at the medial border of the lachrymal bone; $l d$, lambdoidal crest; $m l$, malar; $m x$, maxillary; $n a$, nasal; $o c$, occipital; $p$, vertical plate of the palatine; $p o$, postorbital process of the frontal; pm, postorbital process of the malar; par, parietal; $p x$, premaxillary; $s q$, squamosal part of the temporal; $s g$, sagittal suture; $s p$, alisphenoid part of the sphenoid; $t p$, temporal fossa; $z g$, zygomatic process of the squamosal.

plate, dorsally it articulates with the median descending plates of the frontals and the nasals, and ventrally it articu- 
lates with the vomer and presphenoid. The cribriform plate is the caudal portion of the ethmoid (Fig. I8), which, extending transversely between the frontals, separates the cranial cavity from the nasal cavity. It is pierced by many pinhole foramina for the exit of the olfactory rierve. In Ornithorhynchus (duck-bill of Australia) there is a single large foramen in the cribriform plate, as is also the case in birds.

The temporal is a paired bone lying at the base and side of the skull. It contains the organs of hearing. It consists of four parts: the squamous or expanded portion (Fig. I6), to which the zygomatic process is attached; the mastoid (Fig. I7), which is the part caudad of the squamosal and dorsal to the bulla; the tympanic, which forms the auditory bulla; and the petrous (Figs. I7 and I8), which contains the internal ear. The squamous portion overlaps the parietal dorsally in a scale-like manner and is limited ventrally by a clearly defined projecting ridge extending above the external auditory meatus as the dorsal border of the zygoma.

The zygomatic process extends craniad to join the zygomatic process of the malar, the two together forming the zygomatic arch, or zygoma, to which the masseter muscle is attached. Ventral of the root of the zygomatic process is the glenoid cavity for the articulation of the condyle of the mandible. Immediately caudad of this cavity is the postglenoid proccss. The mastoid portion of the bone is somewhat triangular in shape, about two centimeters long, and lies caudad of the external meatus.

The tympanic portion appears on the base of the skull as the auditory bulla. Its cavity is divided into two unequal chambers by a bony septum rising from the floor and reaching almost to the roof. The cranial or true tympanic chamber, sometimes called the middle ear, is the smaller, 
and has on its lateral wall a horseshoe-shaped prominence known as the tympanic ring, to which the tympanic membrane of the drum of the ear is attached. There are four apertures in the walls of the cranial tympanic chamber: The meatus anditorius extcrnus, or the external auditory canal; the Eustachian tube, leading from the cranial dorsal angle of the chamber to the pharynx; the fenestra ovalis and the fenestra rotundum, opening into the internal ear. The caudal or medial chamber of the bulla is larger than the cranial, but has no special features worthy of consideration.

The petrous portion of the temporal bones is not visible on the external surface of the skull, but may be seen by looking into the external auditory meatus. It forms the medial wall of the tympanic cavity. The foramen seen in its dorsal part is the fenestra ovalis. In a sagittally bisected skull the petrous (Fig. I7) may be recognized by the internal auditory meatus entering it. By removing the bulla, a large portion of the petrous bone may be seen from its ventral aspect. A central prominence, the promontory. contains the fenestra rotundum opening into the base of the cochlea. The apex of the promontory, mediad of the fenestra rotundum, forms the wall of the first whorl of the cochlea. Dorsal to the fenestra rotundum is the fenestra ovalis, opening into the vestibule of the internal ear. In the recent state this opening is closed by a membrane in which is imbedded the foot of the stapes. The cochlea in the interior of the bone may be displayed by cutting away the bony rim of the fenestra rotundum and then chipping off a crust of bone in a line from this foramen to the juncture of the basioccipital and basisphenoid bones.

The petrous bone, viewed dorsally in a bisected skull, appears in the floor of the brain cavity ventrad of the tentorium, the plate of bone partly separating the cerebrum from the cerebellum. Its surface is pierced by the internal 
auditory meatus, which gives passage to the auditory nerve. Close examination reveals a division of the canal into two parts, a ventral for the eighth nerve and a dorsal, the aqueductus Fallopii, for the facial nerve. This aqueduct twists through the petrous laterad, and thence between the petrous, squamosal, and mastoid to the stylomastoid foramen (Fig. I7).

The parietal bone is paired and joins its fellow in the median line, forming the caudal half of the sagittal suture. Its point of greatest convexity is the parietal eminence. Its cerebral or internal surface presents slight arborescent grooves which in the recent state sheltered the meningeal artery of the brain. The plate of bone projecting obliquely craniad from the caudal border of the parietal is the tentorium, an ossification of the dura mater separating the cerebrum from the cerebellum.

The interparietal is a triangular bone situated at the junction of the two parietals and occipital bones. Its sutures are usually obliterated quite early.

The occipital (Figs. I6, I7, and I8) is a single bone surrounding the foramen magnum and articulating with the interparietal, parietals, temporals, and sphenoid. In the young kitten it is composed of four parts: the supraoccipital, lying dorsal to the foramen magnum, the two exoccipitals, lying laterad of it, and a basioccipital, bounding it ventrally. The crescentic elevation on the supraoccipital near its parietal margin is the lambdoidal ridge, to which several muscles are attached.

The cxoccipitals bound the cerebellum laterally and support the occipital condyles, which articulate with the atlas or first vertebra. Immediately caudad of the bulla is the paroccipital process. There are two foramina, one of which, the anterior condyloid, opens ventrally with the jugular foramen adjacent to the bulla, while the other, the 


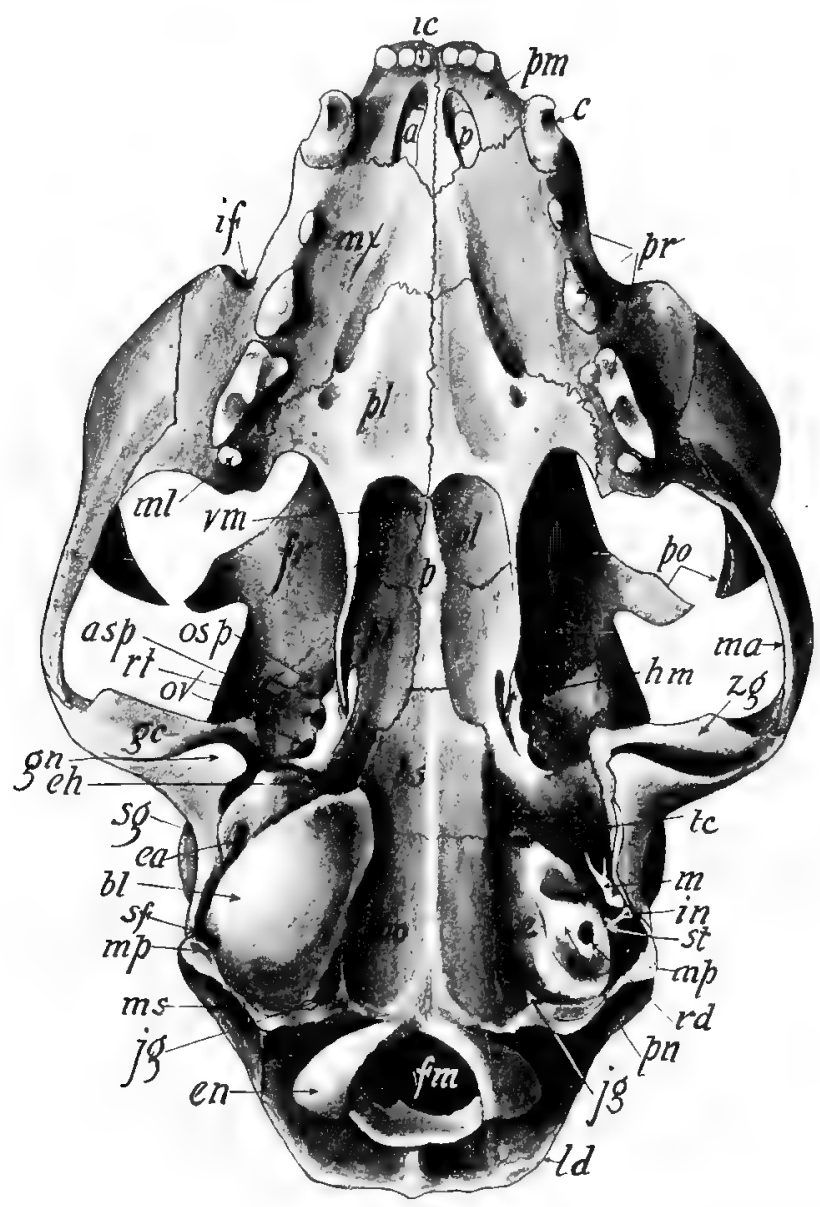

Fig. I7. Ventral Aspect of the Skull with the Left Auditory Bulla Removed.

$a s p$, Alisphenoid; $a p$, anterior palatine foramina; $b s$, basisphenoid; $b l$, auditory bulla; $b o$, basioccipital; $c$, canine tooth ; $e$, petrous portion of the temporal; en, occipital condyle; $e a$. external auditory meatus; $c h$, opening of the Eustachian tube; $f r$, frontal ; $f m$, foramen magnum; $g c$, glenoid cavity; $g n$, postglenoid process; $h m$, hamular process of the pterygoid; $i c$, incisor tooth; if, infraorbital foramen; in, incus; $j g$, jugular foramen; $l d$, lambdoidal ridge; $m x$, maxilla; $m l$, molar tooth; $m p$, mastoid process; $m s$, mastoid portion of the tem-

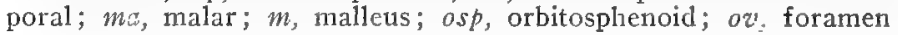


posterior condyloid, opens more dorsally at the side of the condyle. The former transmits the twelfth (hypoglossal) cranial nerve, supplying the larynx, hyoid bone, and tongue. The jugular foramen, or foramen lacerum posterius, is at the juncture of the bulla, exoccipital, and basioccipital. The internal jugular vein and the ninth, tenth, and eleventh nerves pass through it. The basioccipital portion of this bone lies entirely on the ventral aspect of the skull. It articulates craniad with the basisphenoid by a suture which is generally obliterated in cats three or four years old.

The sphenoid bone lies in the center of the base of the skull. It is composed of eight parts, corresponding to eight distinct bones in the lower vertebrates: the basisphenoid, articulating caudad with the basioccipital; two alisphenoids, extending dorsad from the basisphenoid and articulating caudad with the temporals (Figs. I7 and I8) two pterygoids, projecting ventrally from the basisphenoid and terminating in sharp processes; a presphenoid in the midventral line craniad of the basisphenoid; two orbitosphenoids, extending dorso-laterally from the presphenoid and articulating craniad with the frontals. In an old cat, the sutures between these eight parts become more or less obliterated. The basisphenoid together with the alisphenoids is sometimes called the posterior sphenoid in distinction to the anterior sphenoid, composed of the presphenoid and orbitosphenoids.

The basisphenoid presents on its dorsal or cerebral surface the sella turcica, or pituitary fossa, which lodges the pituitary body of the brain (Fig. 90). The posterior boundary of this fossa is the clinoid plate, and its lateral

ovale; $p$, presphenoid; $p l$, palatine; $p t$, pterygoid; $p n$, promontory of the petrous; $p o$, postorbital process; $p r$, premolar teeth; $p m$, premaxillary; $r d$, fenestra rotundum; $r t$, foramen rotundum; st, stapes; sg, squamosal; sf, stylomastoid foramen; $t c$, carotid foramen, or foramen lacerum medius; $v m$, vomer, forming the septum between the posterior nares; $z g$, zygomatic process of squamosal. 
projections are the posterior clinoid processes. On each side of the basisphenoid there extends dorsally in a narrow strip to the parietal the alisphenoid, at the base of which, craniad of the auditory bulla, are three foramina in a line. The most cranial and largest one is the sphenoidal fissure, or anterior lacerated foramen, which transmits the third, fourth, and sixth cranial nerves supplying the eyeball muscles, and the first branch of the fifth nerve. This foramen is between the alisphenoid and the orbitosphenoid. The other two foramina, rotundum and ovale, transmit the second and third divisions of the fifth nerve.

TABLE OF THE FORAMINA OF THE SKULL.

Foramina.
Infraorbital.
Anterior palatine.
Sphenopalatine.
Posterior palatine.
Olfactory fora-
mina.
Optic.

Lacerum anterius, - or sphenoidal fissure.

Rotundum.

Ovale.

Lacerum medium.

Internal auditory meatus.

Aqueduct of Fallopius.

Stylomastoid.

Jugular or posterior lacerated.

Anterior condyloid
Bones Surrounuing
THE Foramina.

Superior maxillary

Maxillary and premaxillary.

Palatine.

Palatine.

Ethmoid.

Orbitosphenoid.

Alisphenoid and orbitosphenoid.

Alisphenoid.

Alisphenoid.

Petrous and basisphenoid.

Petrous.

Petrous, mastoid, and tympanic.

Tympanic and mastoid.

Occipital and temporal.

Exoccipital.
STRUCTURES TRAVERSING THE FORAMINA

Infraorbital nerve of the superior maxillary division of the fifth.

Nasopalatine branch of the fifth cranial nerve and nasal artery.

Sphenopalatine nerve and sphenopalatine artery.

Palatine nerve and artery.

Olfactory nerve.

Optic nerve and meningeal artery.

Third, fourth, and sixth cranial nerves and first division of fifth cranial nerve.

Second division of fifth cranial nerve,

Third division of fifth cranial nerve.

Internal carotid artery.

Eighth cranial nerve.

Seventh cranial nerve,

Seventh cranial nerve.

Ninth, tenth, and eleventh cranial nerves and jugular vein.

Twelfth cranial nerve. 
The pterygoid portion of the sphenoid is a paired bone (Figs. I7 and I8) lying on either side of the cranial half of the basisphenoid and the caudal half of the presphenoid.

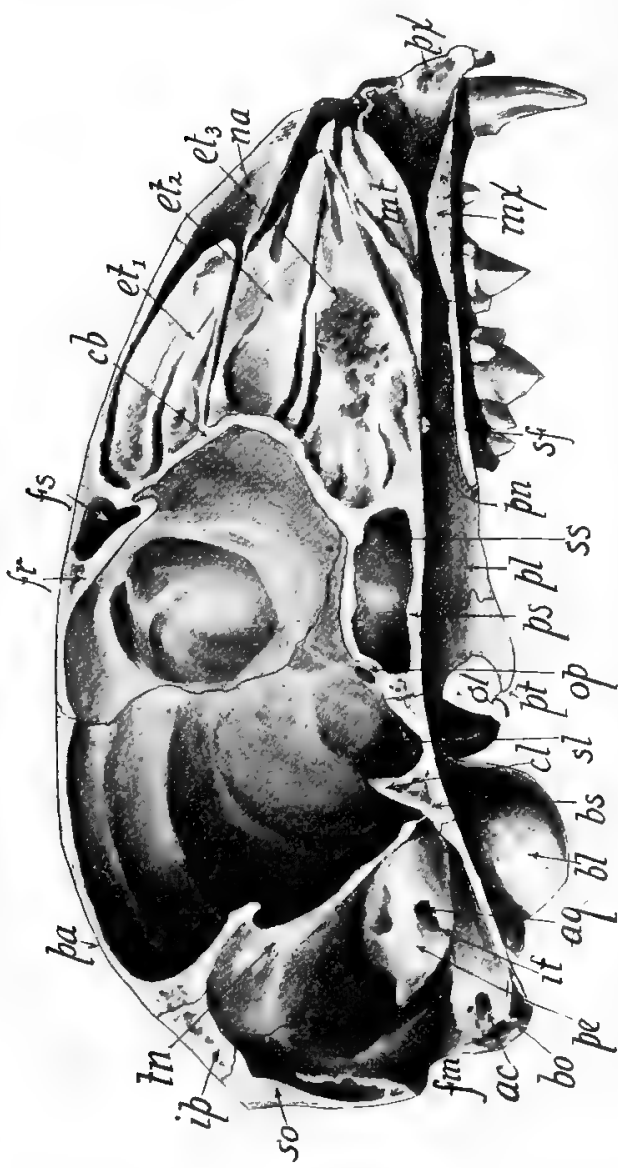

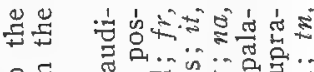

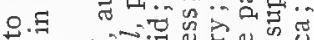

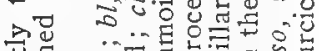

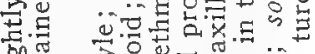

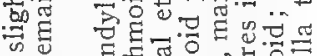

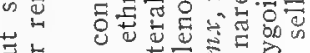

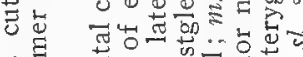

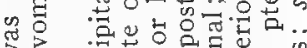

者

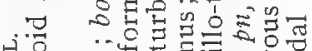

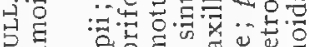

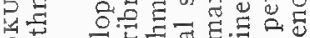

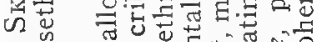

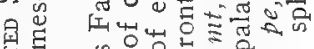

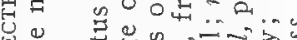

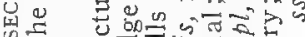

击

थ + पुण

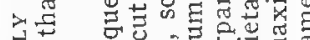

1

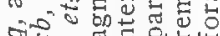
要

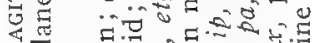

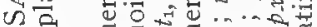
४

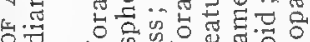
명

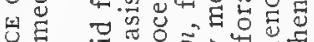

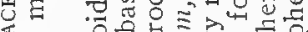
舟 宩

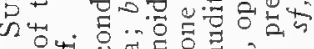
워

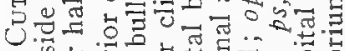

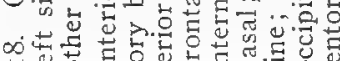

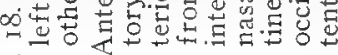
岁

In the adult cat the sutures are sometimes obliterated so that this bone appears as a caudal continuation of the palatine. The two pterygoid bones or plates form the descending walls, and, together with the median portion of the 
sphenoid, the roof of the median pterygoid fossa, whose cranial continuation is the posterior nares. From the ventral posterior angle of each projects the hamular process, dorsal of which is seen the small external pterygoid process. Between the bases of the hamular and the external pterygoid processes is the small external pterygoid fossa.

The presphenoid bone is the narrow median bone extending from the basisphenoid to the vomer. It contains within it two large sinuses into which project the ventral scrolls of the ethmoturbinal bones. The orbitosphenoids enter into the formation of the medial walls of the orbits and are perforated at their bases by the optic foramina, through which pass the optic nerves.

\section{BONES OF THE FACE.}

There are seven paired bones in the face and two single ones, making in all sixteen (Figs. I6 and I7).

The premaxillary, with its fellow, extends ventrad and laterad of the anterior nares. These bones bear the six incisor teeth. The anterior palatine or incisor foramina connect the oral cavity with that of the anterior nares. In life, these foramina transmit the naso-palatine nerves. In the Primates, the premaxillary is anchylosed to the maxillary although it arises from a separate center of ossification.

The maxillary is a paired bone which meets its fellow in the median line in the roof of the mouth. All its articulations are visible externally except those with the maxilloturbinal, ethmoid, and vomer. Five teeth, a canine, three premolars, and a molar, are present in this bone of the adult cat. The molar is wanting to the young. The several portions of the bone are as follows: the palatine plate, appearing in the roof of the mouth; the nasal process, extending dorso-caudad to the frontal; the malar process, extending ventrad to the orbit to articulate with the malar 
bone; and the orbital plate, which is the roof of the malar process, forming a partial floor to the orbital cavity. The large foramen leading from the orbital cavity through the orbital plate is the infraorbital foramen for the passage of the infraorbital branch of the superior maxillary branch of the fifth nerve.

The palatine bone with its fellow helps to form the roof of the oral cavity and the floor of the nasal cavity. It is composed of two plates: one, vertical, forming the lateral walls of the posterior nares and the cranial part of the walls of the median pterygoid fossa, and a portion of the nasal wall of the orbital cavity; the other, horizontal, forming part of the roof of the mouth. The vertical plate is pierced by two foramina, the posterior palatine and the sphenopalatine, each of which transmits a palatine nerve and artery (Fig. I6).

The vomer is a single narrow bone which in the nasal cavity articulates dorsally with the mesethmoid and ventrally with the palatines and the palatine plates of the maxillary, in the median line. This bone, with the mesethmoid and its cartilage, forms the nasal septum, dividing the nasal cavity into two chambers. It is best demonstrated by removing the palatines, when it may be seen extending craniad from its bifurcated articulation with the presphenoid to its articulation with the premaxillaries. The caudal portion of the bone is expanded horizontally and articulates with the ventral ethmoturbinals. Its dorsal margin is bifurcated for articulation with the mesethmoid.

The maxilloturbinal is a paired bone occupying the anterior portion of the nasal cavity (Fig. I8). It is composed of a few scrolls which, when the nasal bone is removed, may be seen attached to the maxillary. It consists of a horizontal longitudinal plate, whose lateral border is fixed to the maxillary while the medial border bifurcates into a 
dorsal curved plate and a ventral scroll. The space between the maxilloturbinal and cranial portion of the lateral ethmoid is the middle nasal meatus. The maxilloturbinal bone in man receives the name of the inferior turbinated, in distinction to the middle and superior turbinated bones, constituting the lateral ethmoid.

The nasal bone, joining with its fellow in the median line, forms a large part of the roof of the nasal chamber. It articulates with the premaxillary, maxillary, and frontal on the surface, and the ethmoid within the nasal chamber.

The lachrymal bones are two in number and lie in the cranial part of the nasal walls of the orbits. Each articulates with the maxillary, frontal, os planum of the ethmoid, and the malar. The bone has about half of the area of the finger-nail. The lachrymal canal is bounded by the lachry-

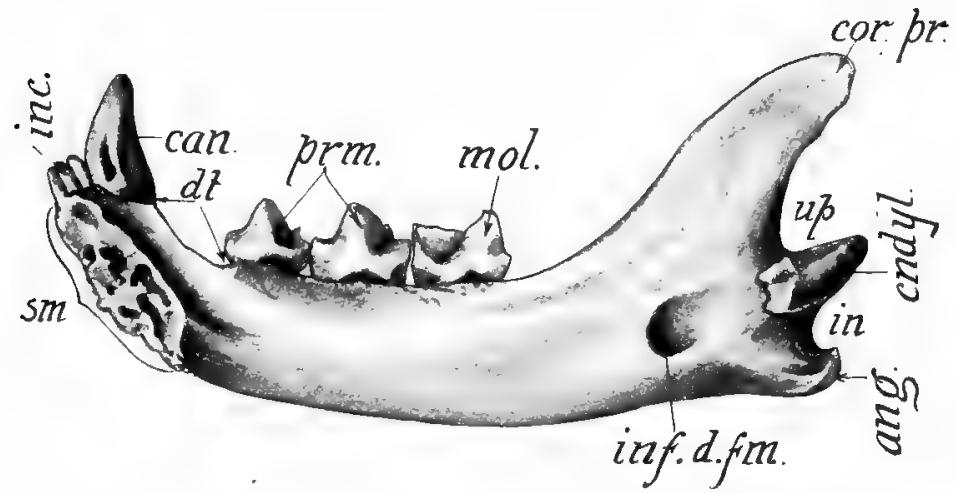

Fig. I9. Medial or Inner Aspect of the Mandible.

ang, Angle; cudyl, condyle; cor. pr, coronoid process; can, canine tooth; inc, incisor teeth; inf. $d$. fm, inferior dental foramen; in, inferior notch; mol, molar tooth; prm, premolar teeth; $d t$, diastema; sm, surface of symphysis; $u p$, stperior notch.

mal and the maxilla. This canal, beginning in a vertical groove, the lachrymal groove, carries the duct permitting the tears to pass from the eye into the nasal chamber (Fig. I6). 
The malar bone is paired. It forms the cheek as well as the lateral and cranial border of the orbit. The arch largely formed by this bone is the zygoma. The process projecting dorsad toward the postorbital process of the frontal bone is the postorbital process of the malar. The masseter muscle originates on the border of the malar.

The mandible or inferior maxillary is the single bone forming the lower jaw (Figs. I9 and 2I). It is made up of two halves which are united by an immovable articulation or symphysis at the chin. Each half consists of a horizontal and an ascending ramus. On its alveolar border the horizontal ramus bears three incisor teeth, a canine, two premolars and a molar tooth. In the caudal part of the medial surface of this ramus is the inferior dental foramen, which transmits the inferior dental nerve and artery traversing the dental canal extending within the bone to the mental foramen on the lateral surface near the base of the canine tooth. The space on the dorsal border between the canine and the first premolar tooth is called the diastema.

The ascending ramus or portion of the bone caudad of the

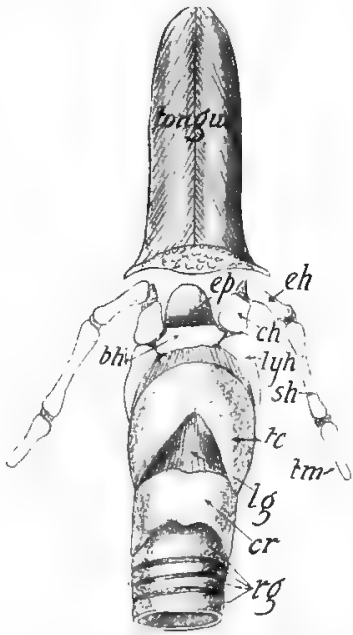

Fig, 20. Ventral Aspect OF LARYNX, Hyoid Bones, And Tongue. The tongue has been cut transversely near its middle and its muscles fixing it to the hyoid have been removed. bh, Basihyal ; ch, ceratohyal; cr, cricoid cartilage of the larynx; $e h$, epihyal; $e p$, epiglottis; $l g$, cricothyroid ligament; lyh, thyrohyal ; $r g$, rings of cartilage in the trachea; $t c$, thyroid cartilage of the larynx; $t m$, tympanohyal; sh, stylohyal. inferior tooth is marked by six features: (I) the fossa on the outer or lateral surface which gives insertion to the 
masseter muscle; (2) the angle which is the caudoventral termination of the bone; (3) the inferior notch immediately dorsal of the angle; (4) the condyle for the articulation with the glenoid cavity of the temporal; (5) the superior notch dorsal of the condyle; (6) the coronoid process, which is the dorsal termination of the ascending ramus and gives insertion to the temporal muscle.

\section{THE HYOID BONES OR HYOID APPARATUS.}

The hyoid bones consist of two jointed rods, one on either side (Figs. 20 and 2I), hanging from the temporal bone, and supporting the larynx. Each rod is composed of six parts: the epihyal; the ceratohyal; the tympanohyal; the - basihyal; and the thyrohyal. The dorsal end of the thyrohyal is prolonged by a piece of cartilage, the chondrohyal.

The hyoid apparatus varies greatly among mammals. In man it consists of a single bone composed of the body or basihyal, two small cornua representing the ceratohyals, and two large cornuta representing the thyrohyals. The bone is suspended from the skull by ligaments corresponding to the bony chain in the cat.

\section{PRACTICAL QUESTIONS AND SUGGESTIONS.}

I. How many more bones are present in the cat than in man?

2. In what two parts of the skeleton does the number of bones in the cat exceed those in man?

3. What is a sesamoid bone?

4. Find on a specimen a sesamoid bone and describe it.

5. Draw a lateral aspect of the skull and label all parts.

6. What are the paired bones of the cranium?

7. Name the single bones of the face.

8. Draw the caudal aspect of the skull and label all parts.

9. Which bones of the skull derive their names from their location?

10. Which bones of the skull are pierced by more than two foramina?

I1. Write a description of the orbital cavity.

I2. Which foramina of the skull derive their names from their shape or size? 
I3. Which foramina derive their names from their location?

14. Which foramina transmit important blood-vessels?

15. Draw figures representing relative shapes and sizes of all foramina of the skull.

16. What bones enter into the formation of the brain cavity?

17. Write about 200 words describing the nasal cavity.

18. Draw a ventro-lateral aspect of the anditory bulla and label all features.

I9. Write a description of the auditory bulla and name some mammals in which it is absent.

20. Which bones of the skull are composed of more parts in the young than in the adult?

2I. Name the principal sutures of the skull.

22. Name the parts of the sphenoid bone in the order of size.

23. Name the bones of the skull visible from the dorsal aspect.

24. Name the bones of the skull visible from the cranial aspect.

25. What bone of the cranium paired in the cat is single in man?

26. What bone present in face of the cat is wanting as a separate element in man?

27. Draw lateral aspect of mandible and label all features.

28. Name the bones bearing the teeth.

29. Name the elements of hyoid apparatus in order.

30. Draw a section of the frontal bone showing diploe.

3I. Describe the difference between the relative locations of the cranial and facial portions of the skull in cat and man.

32. Name five membrane bones and five cartilage bones.

\section{VERTEBRÆ.}

The vertebral column is composed of the following five groups of vertebræ: seven cervical, thirteen thoracic, seven lumbar, three sacral, and caudal varying from four to twenty-six. The following six features are common to all of the vertebre in the first four groups except the atlas: (I) the body of the vertebra (Fig. 22), which forms the floor of the neural canal and articulates with the adjacent vertebræ by means of interposed discs of cartilage; (2) the transverse processes, which project laterad from the body or from the walls of the neural canal; (3) a spinous process, which projects dorsad from the roof of the neural canal; 
(4) the neural arch, composed of a pedicle on either side, forming the ventrolateral walls of the neural canal, and the

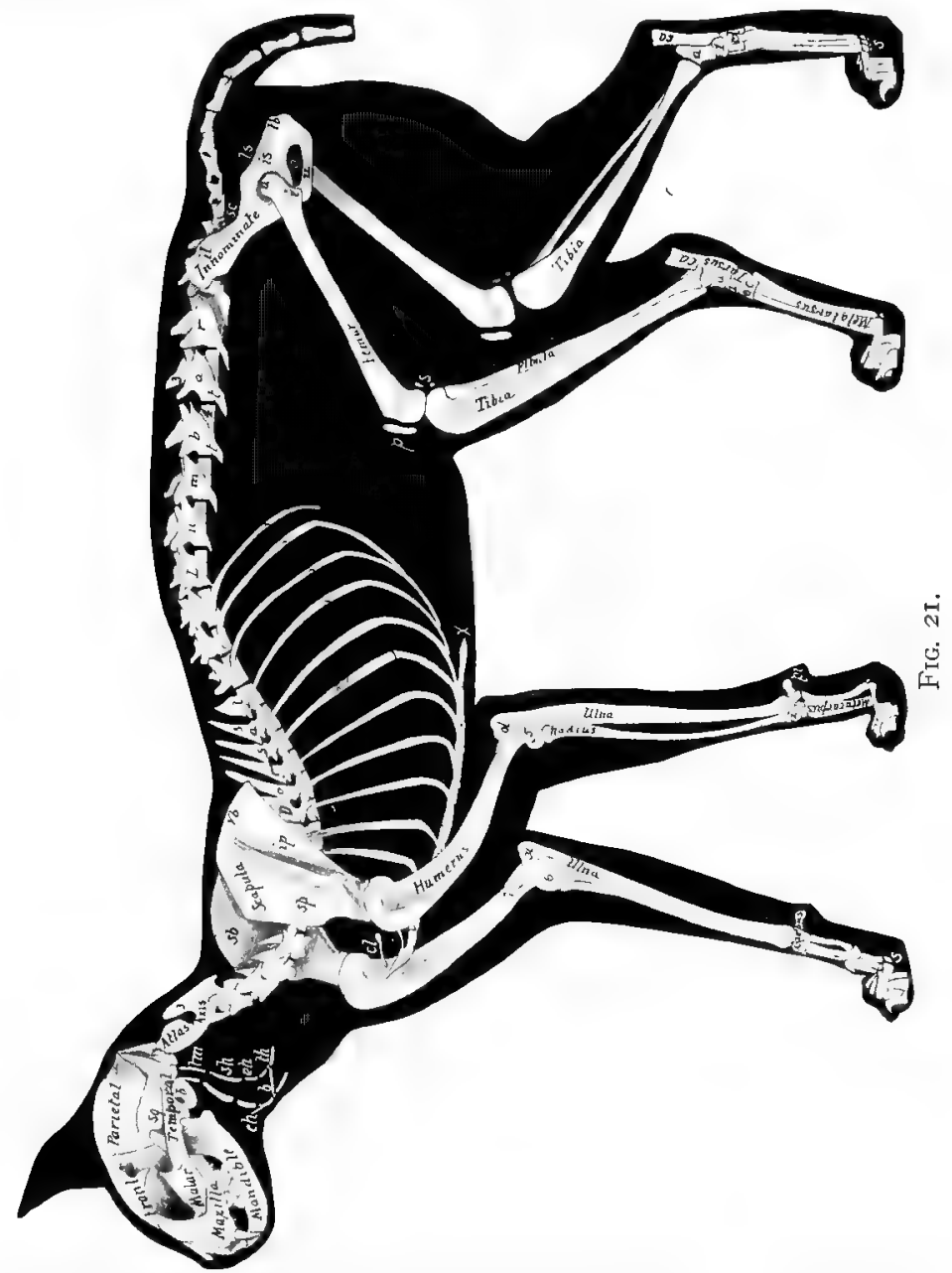

lamince, extending dorsad from the pedicles to complete the dorsal wall of the neural canal; (5) the intervertebral notch, which, with the notch of the succeeding vertebra, forms the 


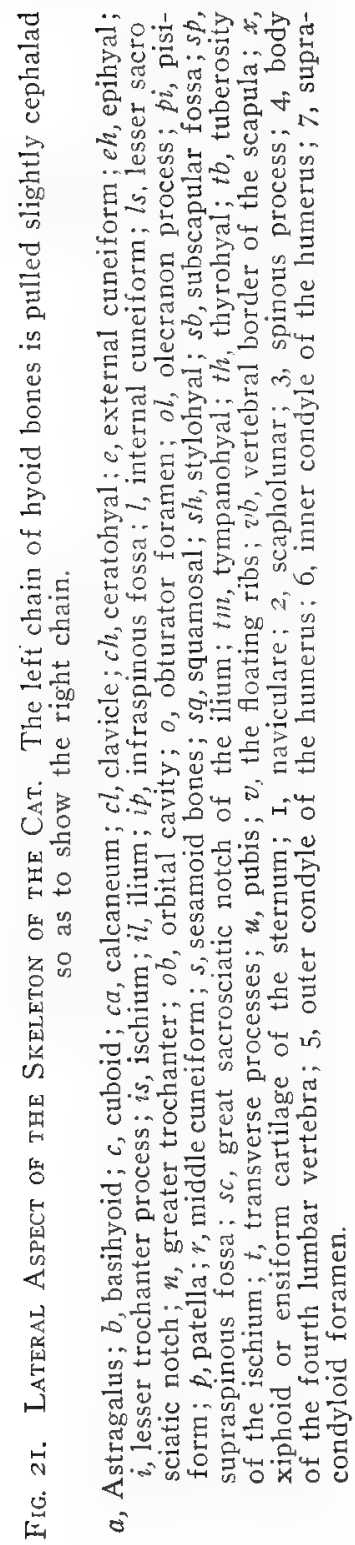


intericrtebral foramcu for the exit of a spinal nerve; (6) the articular processes, two of which project craniad and

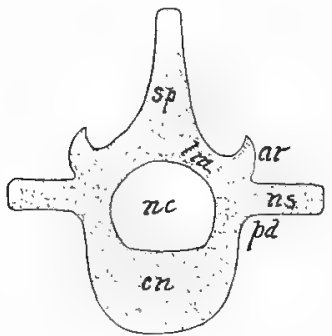

Fig. 22. Plan of a VerTEBRA.

$s p$, Spinous process; ar, articular process; $n s$, transverse process; $n c$. neural canal; $p d$, pedicle: lm, lamina; $c n$, centrum or body. two cauclad from each vertebra. The former are called the anterior articular processes and the latter posterior articular processes.

The first cervical vertebra, or atlas, is characterized by its large horizontally expanded transverse processes, the absence of a spinous process, and its rudimentary body. Its true body in the embryo becomes united to the axis as the odontoid process. The cranial margin of the neural arch is prolonged at each side into a process or articulation with the occipital condyles (Fig. I7) of the skull. The root of this articular process is pierced by a foramen giving passage to the first spinal nerve and the vertebral artery and vein (Fig. 23, $f r$ ). From the lateral opening of this foramen $(f r)$ a groove is continued ventrad to the middle of the transverse process, where it leads into the transzerse foramen common to the first six cervical vertebre. The vertebral artery and vein course through this canal (Fig. 23).

The axis, or second vertebra, is characterized by its odontoid process, which projects within the

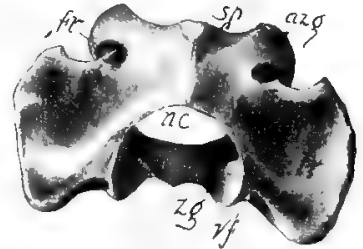

Fig. 23. Dorsocaudal AsPECT OF Atlas.

tr. Transverse process; $n c$, neural canal; $s p$, spinous process; $f r$, aperture of the transverse foramen which enters the atlas at $v f$; $a z g$, anterior articular process; $z g$, posterior articular process.

atlas, and also by its elongated spinous process, which projects both craniad and caudad. The transverse process pro- 
jects caudad from the body, which is flattened dorsoventrally.

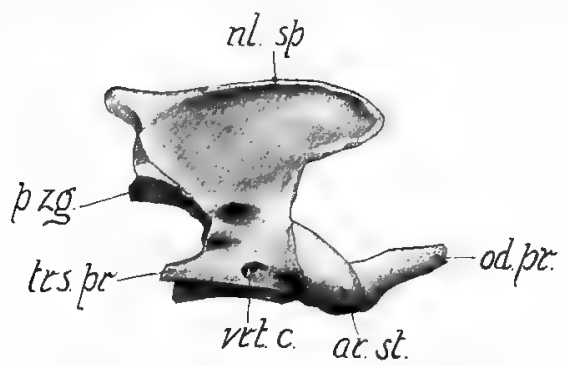

Fig. 24. Lateral Aspect of the Axis.

ar. st, Anterior articular process; od. pr, odontoid process; $n l . s p$, netral spine or spinous process; $p$. $z g$, posterior articular process; trs. $p r$, transverse process; vrt. $c$, transverse foramen.

This process is pierced at its base by the transverse foramen.

The remaining five cervicals are very similar to one another. The seventh has no transverse foramen. The spinous processes grow successively longer from the third to the seventh (Fig. 2 I). The transverse processes of the fourth and fifth are bifurcated, the dorsal branch being called the transuerse element and the ventral one the costal element, since it is really the rudiment of a rib. The transverse process of the fifth ends in three branches. The following features are common to all thirteen thoracic vertebræ: a spinous process, projecting from the dorsum of the

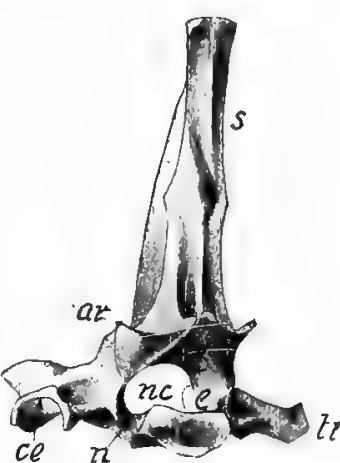

Fig. 25. Laterocaudal AsPECT OF THE SECOND THORACIC VERTEBRA.

tr, Transverse process; $n c$, neural canal; $c e$, facet for tubercle of rib; ar, posterior articular process; $s$, spinous process; $c$, centrum ; $n$, intervertebral notch; $e$, pedicle; $l$, lamina. neural arch; two cranial articular processes, facing dorsad or dorsolaterad; two caudal articular processes, facing ven- 
trad or ventromediad; a body whose transverse diameter is greater than the vertical diameter; and transverse processes. There are two half facets on each side of the body of every thoracic vertebra except the first, eleventh, twelfth, and thirteenth. The head of a rib thus articulates with two vertebra (Fig. 28). The body of the first vertebra bears on each side a whole facet and a half facet. The eleventh. twelfth, and thirteenth bear a whole facet on each side of the body.

The transverse processes of the first eleven bear facets for the articulation with the tubercles (Fig. 25) of the ribs. The last three thoracic vertebra are characterized by mammillary processes springing from the dorsolateral portion of the roots of the anterior processes.

The following features are common to all of the lumbar zcrtebrc: a spinous process projecting dorsocraniad (Fig. 26) ; a transwerse process projecting ventrocraniad on either side from the body; antcrior articular processes and posterior articular processcs. A mammillary process is present on the root of the anterior articular process of the first five bones, and an accessory process occurs on the caudal margin of the wall of the neural arch of all except the last vertebra. The transverse processes increase in length and curvature caudally. The spinous processes increase in length in the same order, and the neural canal likewise enlarges caudally.

The sacrum is a single bone (Fig. 27) formed by the union of three sacral vertebra. The limit of each element is marked by the dorsal and ventral intervertebral foramina which furnish passage for the dorsal and ventral branches of the spinal nerves. The two tubercles on either side of each of the three median spinous processes are the result of the fusion of the articular processes. The cranial portion of the bone presents on its lateral aspect the auricular 
surfaces for articulation with the ilium. This expansion appears to be a modified transverse process. Prominent transverse processes also project from the caudal angles.

The caudal vertebræ vary greatly in number. According to Mivart, there are only four in the Manx cat; and according to Jayne, there may be as many as twenty-six in some varieties of the common cat. The transverse processes

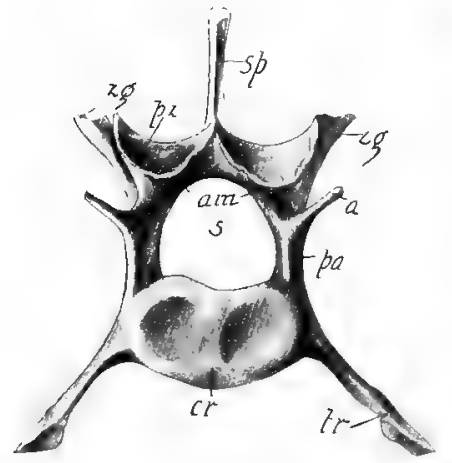

Fig. 26. Caudal Aspect of Fourth Lumbar Vertebra.

$a$, Accessory process; $c r$, centrum or body; pa, pedicle; tr, transverse process; $s$, neural canal; $s p$, spinous process; $z g$, the mammillary process of the anterior articular process; am, lamina; $p z$, articular process.

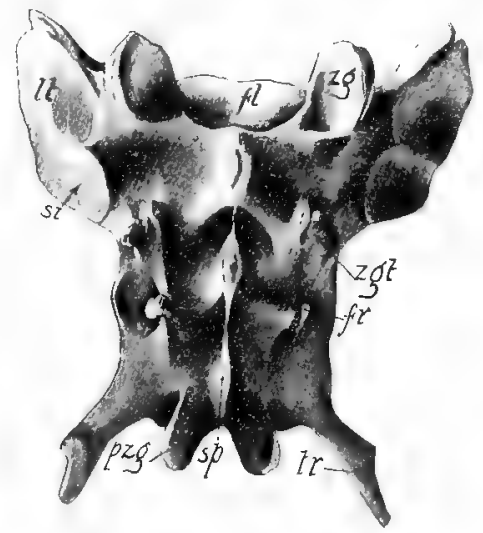

Fig. 27. Dorsal Aspect of the Sacrum.

$f$, Floor of the neural canal; $f r$, dorsal aperture of the intervertebral foramen: $l t$, lateral mass; $p z g$, posterior articular process; $s p$, spinous process; $s i$, auricular surface for articulation with the ilium; $t r$, transverse process; $z g t$, tubercle formed by fusion of the articular processes; $z g$, anterior articular processes.

and articular processes become less prominent from the third vertebra to the eighth or ninth, where they are present only as slight ridges. The spinous process is present in the first three, but dwindles to a ridge in the fourth. The first six or seven elements possess a neural arch which more distally loses its roof, making the neural canal a mere 
groove. The groove becomes fainter distally and finally risappears entirely. The chorron bones are the paired ossicles projecting ventrad from the cranial ends of the bodies of the vertebra, from the second or third to the thirteenth vertebra. In the sixth, seventh, and eighth vertebre the chevron bones unite ventrally in the middle line. forming an arch. The last ten caudal vertebra are scarcely more than cylinders of bone representing the bodies of the vertebra.

The number of vertebra in the different species of mammals varies widely. As a rule, there are seven elements in the cervical region. The sea cow (Manatus) has only six cervical vertebra, while the three-toed sloth has nine. The number of thoracico-lumbar varies from sixteen in the orang to thirty-six in the cetacean Delphinus. The elements composing the sacrum likervise vary from one in the ape, Cercopithecus, to nine in some of the Edentata. The human sacrum is composed of from four to six vertebræ. The same is true of the gorilla, chimpanzee, and orang. The catclal vertebre vary greatly in number in the different forms. In the adult human there are present only four or five vertebre, which form a single bone, the coccyx, while in the embryo eight segments make up the caudal region. Ossification takes place, however, in only five or six segments.

\section{THE STERNUM.}

The sternum of the cat is composed of eight pieces, called stcucbra, which lie in the median line on the ventral sicle of the chest (Fig. 2I). The sternum serves for the attachment of the cartilaginous portions of nine pairs of ribs. The first sternebra (Fig. 28), which ends craniad in a laterally compressed pointed process, is the manubrium. The six succeeding sternebræ form the body or 
gladiolus; the caudal piece is called the ensiform or xiphoid process. It is terminated by a flat piece of cartilage. The cartilaginous portion of the first rib articulates with the manubrium near its middle. The ribs from the second

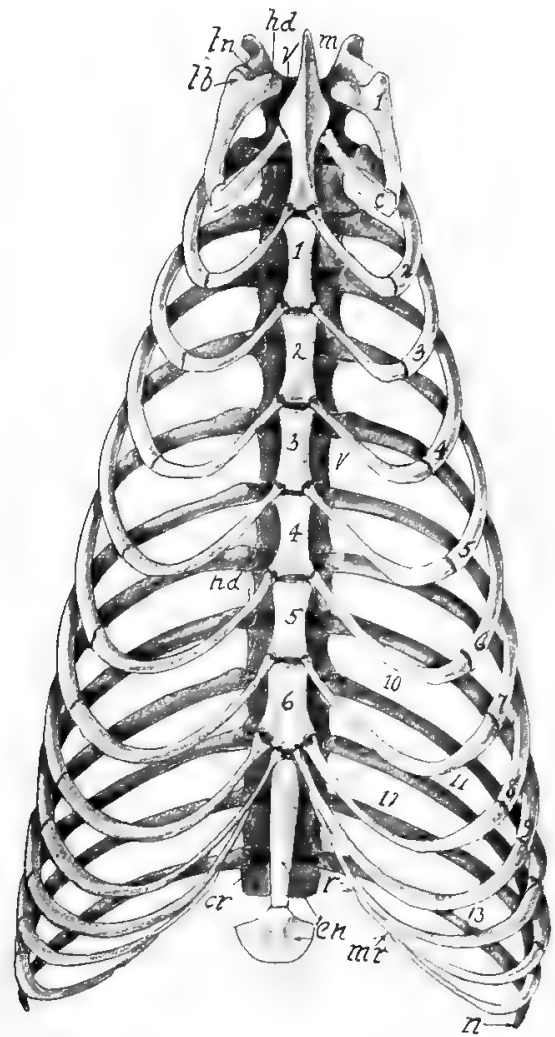

Fig. 28. Ventral Aspect of the Bones of the Thorax. The numbers on the vertebral or bony portions of the ribs indicate the names of the ribs. The numbers of the last four ribs are placed just craniad of them.

$c$, Cartilaginous part of the first rib; $c r$, cartilaginous disc between the bodies of the vertebra; $c n$, ensiform process; $h d$, heads or capitula of ribs; $m$, manubrium, $m r$, attachment of twelf th to the eleventh rib; $n$, free termination of thirteenth rib; $r$, attachment of the eleventh to the tenth $r i b ; t b$, tubercle of first rib; $t n$, transverse process of first thoracic vertebra; $v$, body of vertebra. 
to the seventh inclusive are attached at the junctions of the sternebra. The eighth and ninth ribs are attached near together on the caudal end of the seventh sternebra.

\section{RIBS.}

There are thirteen pairs of ribs in the cat. The nine cranial are called true ribs because they articulate dorsally with the spinal column and ventrally with the sternum.

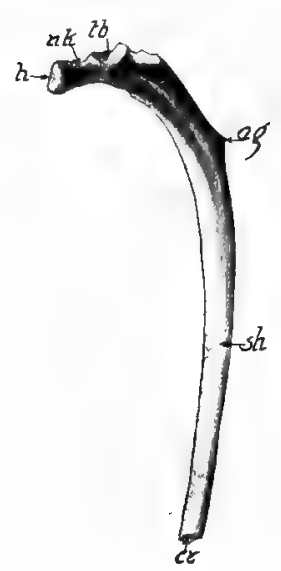

Fig. 29. Caudal As.pect of Sixth Rib.

ag, Angle; $c r$, pit for articulation with cartilaginous portion; $h$, capitulum; $n k$, neck; sh, shaft; $t b$, tubercle with facet for articulation with transverse process. The other four (Fig. 28) are false ribs, three of which articulate ventrally with other ribs, while the fourth has no ventral articulation, and is therefore called a floating rib. Each rib is composed of two parts, the vertebral or bony portion and the sternal or cartilaginous portion.

The following description of the sixth will serve to give a correct idea in general of the anatomy of a rib. Its vertebral portion (Fig. 29) presents four features: a head or capitulum, which articulates with the bodies of the fifth and sixth thoracic vertebræ; a tubercle, which articulates with the transverse process of the sixth thoracic vertebra; a neck, which is the constricted portion between the capitulum and tubercle; and the shaft, including the portion of the rib between the tubercle and its articulation with the sternal or cartilaginous portion. The bend in the shaft beyond the tubercle is the angle. The sternal portion of the rib, consisting of cartilage, is sometimes called the costal rib. In the sixth rib the costal portion is about half as long as the vertebral portion. 
Certain ribs present marked features varying from the sixth. The first rib is stout and flat and has no distinct angle. The articular surface of its head is not divided into two facets, as is the case in all the others except the three caudal ones. The lengths of the ribs increase from the first to the ninth. The last three ribs have no necks and no tubercles for articulation with the transverse processes of the vertebræ.

The number of ribs varies from nine pairs in the cetacean Hyperoödon to twenty-four in the two-toed sloth (Cholœpus). In most fishes and snakes, ribs are present throughout both the trunk and tail regions, but with the assumption of life on land, and the development of limbs, the vertebrates have suffered a degeneration of the ribs in all parts except the middle portion of the trunk. In the embryo, however, anlage (beginning) of ribs occurs in all regions of the trunk, but they early coalesce with the vertebra except in the thorax.

\section{PRACTICAL QUESTIONS AND SUGGESTIONS.}

I. Draw caudal aspect of third thoracic vertebra and label all features.

2. Describe the differences between the first and last thoracic vertebra.

3. What feature common to all thoracic vertebra not present on any of the other vertebræ?

4. Draw the caudal aspect of the fourth cervical vertebra.

5. What feature common to all cervical vertebra except seventh but not present in any other vertebræ?

6. Draw cranial aspect of atlas and label all features.

7. Compare the third and seventh cervical vertebræ.

8. What two features serve to distinguish the lumbar from all other vertebræ?

9. Draw the cranial aspect of the second lumbar vertebra and label all features.

Io. Wherein does the seventh lumbar vertebra differ from the first?

II. How do you distinguish the caudal from the cranial aspect of any vertebra? 
I2. Draw ventral aspect of sacrum and label all features.

I3. Give the two features distinguishing the caudal vertebra from all others.

I4. Note the size and direction of the spinous process throughout the column.

I5. Describe the variation in number of the different groups of vertebræ in other mammals.

I6. Draw lateral aspect of sternum and label all features.

I7. Describe the attachment of ribs to sternum.

I8. What features common to all the ribs?

19. Name ribs having a tubercle.

20. Draw first rib and label all features.

21. Draw cranial aspect of ninth rib and label all features.

22. How do you distinguish a false rib from a true rib?

23. What features mark the caudal aspect of a rib?

24. Make a drawing showing the articulation of a rib with the spinal column and label all parts.

25. How do ribs vary as to number in mammals?

\section{THE THORACIC LIMB.}

The thoracic or fore-limb of the cat is composed of a scapula, clavicle, humerus, ulna, radius, seven carpals, five metacarpals, and fourteen phalanges (Fig. 2I). The scapula and clavicle form the shoulder girdle.

The scapula, commonly called the shoulder-blade (Fig. 30 ), is not articulated with the bones of the trunk, but is held in position by the serratus magnus, levator anguli scapula, and other less important muscles. It articulates with the head of the humerus by the glenoid cavity. It presents three well-marked borders: the cranial or anterior, the vertebral, and the axillary adjacent to the vertebra on the side near the axilla or armpit. The outer surface of this bone is divided by a strong spine into two nearly equal foss $x$, the cranial of which is the supraspinous, and the caudal one the infraspinous, fossa. From the lower part of the spine project the acromion and mctacromion processes. The subscapular fossa occupies the entire inner or medial surface. 
A slight constriction between the base of the spine and the margin of the glenoid cavity is termed the neck. From

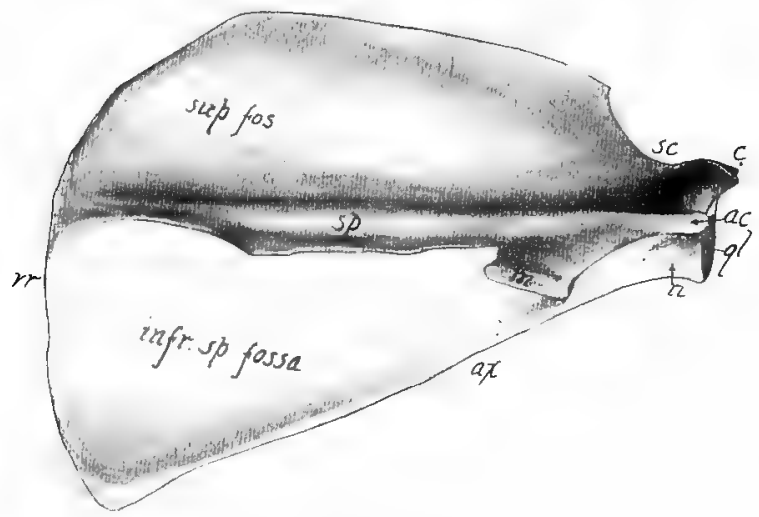

Fig. 30. Lateral or Outer Aspect of the Scapula.

$a c$, Acromion process; ax, axillary border; $c$, coracoid process; gi, glenoid cavity; m, metacromion process; sc, suprascapular notch; $s p$, spine; sup. fos, supraspinous fossa; $v r$, vertebral border; $n$, neck.

the cranial side of the latter the coracoid process curves mediad.

The clavicle is a slender curved bone, about one inch long, imbedded in the muscle between the manubrium and the coracoid process (Fig. 2I). It does not ar-

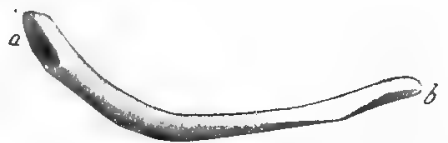

Fig. 3i.-Caudal Aspect of Left Clavicle.

$b$, Medial end; $a$, lateral end. ticulate with any bone, but is held in place by the cephalohumeral and cleidomastoid muscles (Fig. 48).

The shoulder girdle varies somewhat among the Mammalia. The clavicle is never fully developed in any of the Carnivora. Primates, Chiroptera, Edentata, and Monotremata are the only orders in which all the species possess clavicles. A third element of the shoulder girdle, known as the coracoid, is a fully developed bone only in the Monotre- 
mata, where it articulates at one end with the scapula, forming part of the glenoid cavity, and at the other end

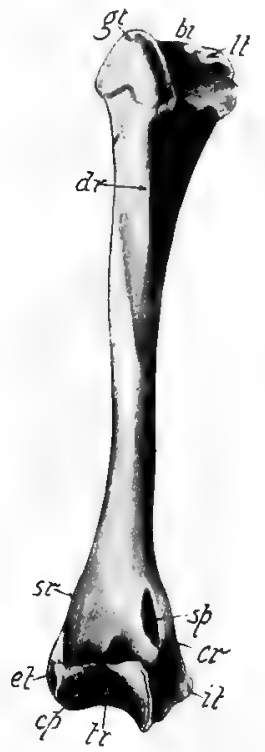

Fig. 32. Cranial AsPECT OF RIGHT HUMERUS.

$b l$, Bicipital groove; cr, supracondyloid ridge; $c p$, capitellum for articulation with the radius; $d r$, deltoid ridge; et, external condyle; gt, greater tuberosity; it, internal condyle; $l t$, lesser tuberosity; sp, supracondyloid foramen or entepicondylar foramen; sr, supinator ridge; $t r$, trochlea for articulation with ulna. with the presternum. In the other mammals the coracoid is represented by the coracoid process of the scapula, which ossifies from a separate center. In many of the lower vertebrates a distinct coracoid is present.

The humerus is the bone of the arm or brachium. It articulates proximally with the glenoid cavity of the scapula (Fig. 2I) and distally with the ulna and radius. It consists of three parts: the proximal extremity bearing the head, the middle portion or shaft, and the distal extremity (Fig. 32). The greater and lesser tubcrosities separated by the bicipital groove lodging the tendon of the biceps muscle, are the two processes on the proximal extremity. The former is the larger and more craniad and serves for the insertion of the supraspinatus muscle (Fig. 49). The distal extremity is marked by two important projections, the external and internal condyles. Extending proximad from the external condyle is the supinator ridge. Proximad of the internal condyle is the supracondyloid foramen transmitting the median nerve and brachial artery (Figs. 72 and 89). The olecranon fossa is the deep cavity on the caudal aspect of the bone, opposite the coronoid fossa. The articu- 
lar surface of the distal extremity consists of the capitellum, for articulation with the head of the radius, and the trochlea for articulation with the sigmoid cavity of the ulna. On the cranial side of the proximal third of the bone is the rough deltoid ridge for the insertion of the deltoid muscle which arises from the shoulder girdle.

The ulna is the longest bone of the forearm or antebrachium, and is caudad of the radius. It articulates in the greater sigmoid cavity with the trochlea of the humerus and in the lesser sigmoid cavity with the head of the radius. The distal articulation is with the radius, cuneiform and pisiform (Fig. 2I). The olecranon process forms the proximal termination of the bone and serves for the insertion of the triceps muscle. Distad of the sigmoid cavity is a projection known as the coronoid process. The styloid process forms a small projection on the distal extremity of the bone.

The radius is the preaxial or cranial bone of the antebrachium. It articulates proximally with the capitellum of the humerus and the lesser sigmoid cavity of the ulna, and distally with the scapholunar and ulna. It bears but two processes, the tubercle and the styloid process. The tubercle (Fig. 34) is a slight knot near the proximal end on the ulnar side.

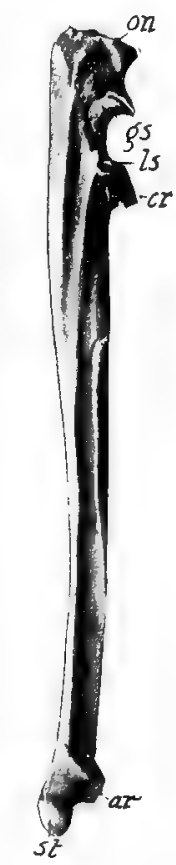

FIG. 33. LATERAL OR OUter AsPECT OF THE Right ULNA.

ar, Articular facet for radius; $c r$, coronoid process; gs, greater sigmoid cavity; Is, lesser sigmoid cavity; on, olecranon process; st, styloid process.

Proximal from the tubercle is the neck which supports the head bearing a concave crown for articulation with the 
capitellum of the humerus. The styloid process projects from the distal end parallel with the process of the same name on the ulna.

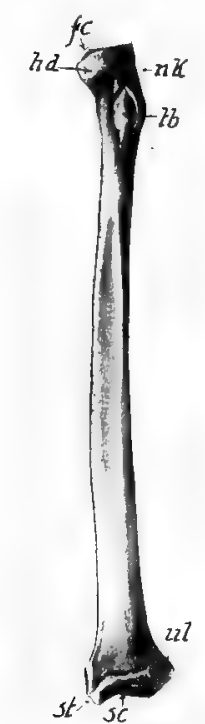

Fig. 34. Medial or InNer AsPECT OF RIGHT RADIUS.

fc, Articulatory surface for capitellum of hitmerus; $h d$, head -the point of the arrow is on the articulating surface for the lesser sigmoid cavity; $n k$, neck; sc, articulatory surface for scapholunar; $s t_{\text {, }}$ styloid process; $t b$, tubercle; $u$, facet for ulna. Equus scarcely more than the proximal third remains (Fig. 37). many mammals are more or less coalesced. In the Chiroptera and many of the Ungulates the radius is enlarged at the expense of the ulna, whose proximal third only remains. The primitive Ungulates of the lower tertiary period possessed a complete ulna as well as radius. The phylogeny of the horse's limb illustrates the gradual development of the antebrachium of the Equidæ (Fig. 35). Fossil remains reveal the fact that mammals existed as early as the triassic period, when the sedimentary rock forming the triassic strata was laid down. This probably occurred I0,000,000 years ago.

According to palæontological investigations, the Ungulata arose from the Condylarthra, a group of small five-toed mammals of the lower Eocene, best represented by the typical genus Phenacodus. In this genus and its successor, Hyracotherium, the ulna and radius are well developed and distinct. Orohippus, the descendant of Hyracotherium, also shows a distinct radiuts and ulna, but in the later forms of the horse line the ulna gradually diminishes in size and becomes more and more coalesced with the radius, until in

The bones of the antebrachium in 
Carpus.-The carpus consists of seven bones arranged in two rows (Fig. 36). Beginning on the pollex side, the scapholunar, cuneiform, and pisiform compose the proxi-
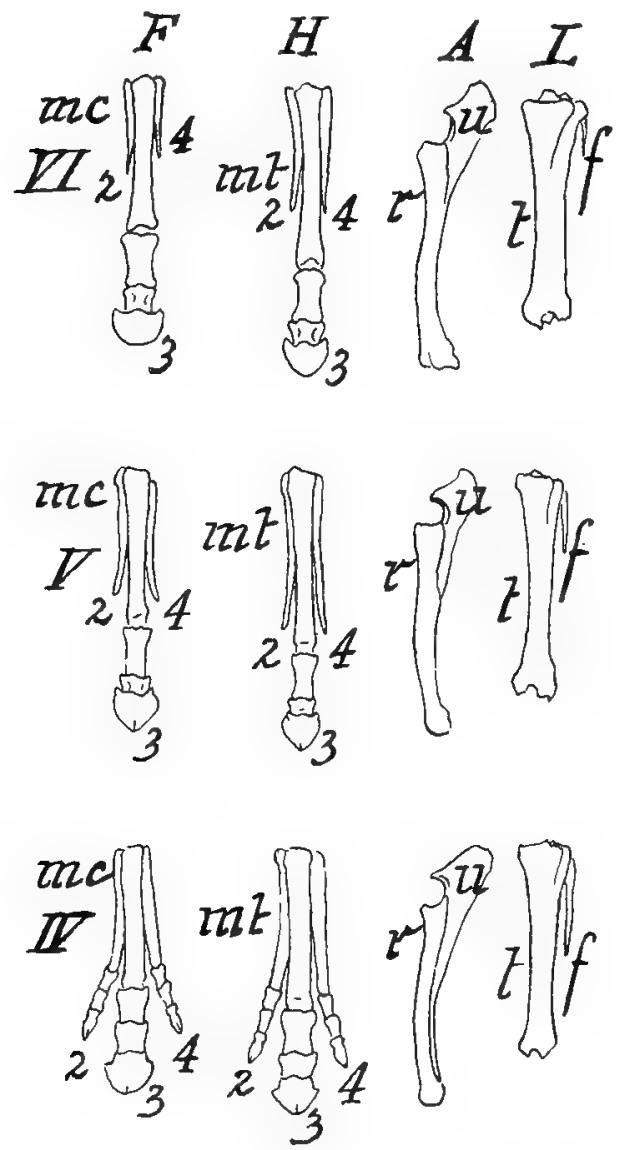

FIG. 35. (See next page for explanation.)

mal row, and the trapezium, trapezoid, magnum, and unciform form the distal row. The scapholunar, easily distinguished because of its large size, articulates with the 
radius, cuneiform, unciform, magnum, trapezoid, and trapezium. The cuneiform articulates with the ulna, unciform, pisiform, and scapholunar. The pisiform is next to the scapholunar in size. It projects prominently laterad
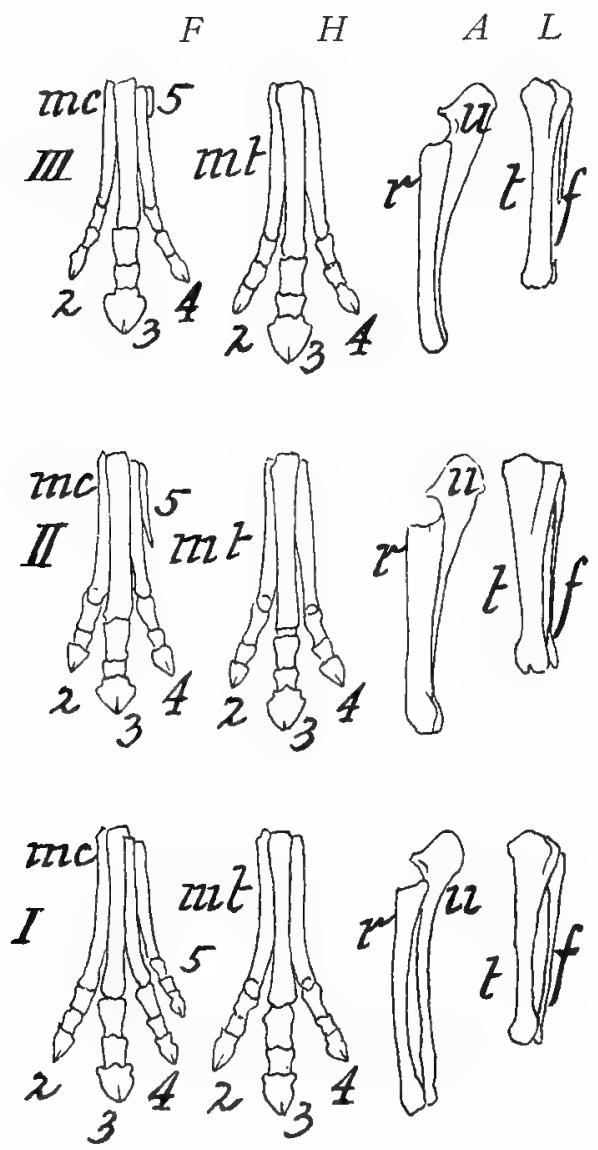

Fig. 35. Genealogy of the Horse.

$F$, Forefoot; $H$, hindfoot; $A$, forearm; $L$, leg; $I$, Orohippus; II, Mesohippus; $I I I$, Miohippus; $I V$, Protohippus; $V$, Pliohippus; $V i$, Equus; 2, 3, 4, and 5 are the second, third, fourth, and fifth digits respectively; $m c$, metacarpus; $m t$, metatarsus; $p$, phalanges; $u$, ulna; $r$, radins; $t$, tibia; $f$, fibula.-(After Marsh.) 
from the cuneiform and articulates with the ulna and cuneiform. The trapezinm is the smallest bone of the

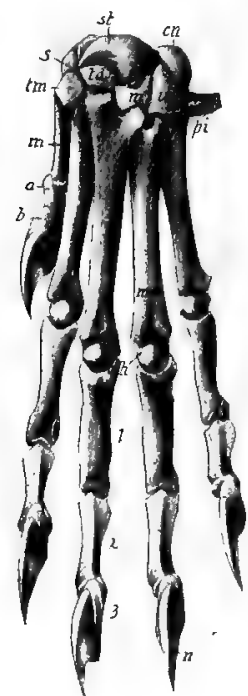

A. carpus. It is crescentic in shape and articulates with the scapholunar, trapezoid, and first and second metacarpals. The trapezoid is almost as small as the trapezium. It is distinguished by its flatness. It articulates with the scapholunar, mag-

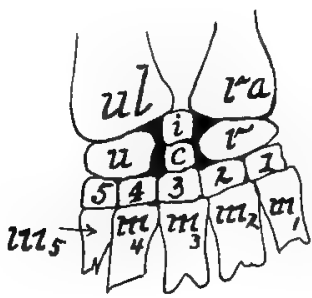

Fig. 36.

B.

A, Dorsal aspect of left manus of cat: $a$, First phalanx of the pollex; $b$, second or terminal phalanx; $c n$, cuneiform; $h$, head of fourth metacarpal; $m$, magnum; $m$ t, metacarpal 4 ; $n$, claw; $p i$, pisiform; $s$, sesamoid bone; st, scapholunar; $t d$, trapezoid; $t m$, trapezium; $u$, unciform; I, 2, and 3, first, second, and third phalanges of the middle digit.

$\mathrm{B}$, Generalized type of carpus as found in lower vertebrates : $c$, Centrale ; $i$, intermedium or lunare; $r$, radiale or scaphoid; $r a$, radius; $m$, metacarpals; $u$, ulnare or cuneiform; $u l$, ulna; $r$, carpalia $I$, or trapezium; 2 , carpalia 2, or trapezoid; 3 , carpalia 3, or magnum; 4 and 5 , carpalia 4 and 5 , or unciform.

num, second metacarpal, and trapezium. This bone is not visible on the palmar surface of the wrist. The magnum articulates with the scapholunar, trapezoid, unciform, and second, third, and fourth metacarpals. The unciform can se recognized by its wedge shape. It articulates with the scapholunar, cuneiform, magnum, and fourth and fifth metaarpals. Each carpal bone develops from a single center axcept the scapholunar, which develops from two centers. 
The typical arrangement of the vertebrate carpus is shown in figure $36, \mathrm{~B}$. The pisiform does not belong to the

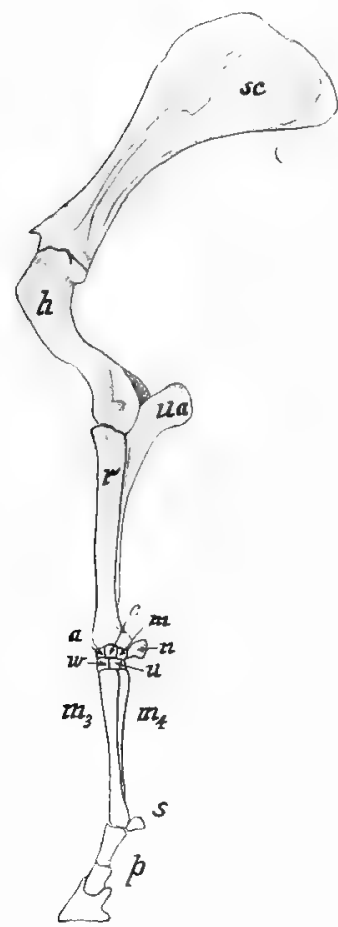

Fig. 37. Lateral AsPECT OF LEFT FORELIMB OF EQUUS.

$h$, Humerus; $n_{3}$, third metacarpal ; $m_{1}$, fourth metacarpal; $p$, phalanges ; $r$, radius; $s$, sesamoid; sc, scapula; $u a$, ulna; $a$, scaphoid; $c$, semilunar; $m$, cuneiform; $n$, pisiform; $w$, magnum; $u$, unciform. cartilaginous skeleton, but is a sesamoid bone. In all mammals possessing five digits, the anlage of three bones in the proximal row, five bones in the distal row, and a central element occurs in the embryo, but through fusion of elements a less number is present in most adults. Thus, in the cat the radiale and intermedium and centrale unite to form the scapholunar. In all forms carpalia 4 and 5 coalesce to form the unciform.

Metacarpus. - There are five metacarpal bones forming the middle region of the forefoot. They are named, beginning on the pollex side, first, second, third, fourth, and fifth metacarpals respectively. Each bone consists of a proximal extremity or base, a middle portion or shaft, and a distal extremity or head (Fig. 36). These bones are curved so as to be slightly convex on the dorsal aspect.

The number of metacarpals in mammals varies from one in Equus to five which are present in most orders. Nearly all the species of every order, except the Edentata and Ungulata, possess five metacarpals. In the pig and hippopotamus there are four metacarpals, in the rhinoceros three, and 
11 the camel, deer, sheep, and cow two. In the last three orms the metacarpals present are the third and fourth, which in the adult are coalesced into a single bone known s the cannon-bonc. Remnants of the second and fifth netacarpals are present in the deer, sheep, and cow, as the mall caudo-lateral hoofs indicate. The functional metaarpal present in the horse is the third. The reduction of netacarpals in the ancestral forms of the horse is shown in igure 35 , and will be referred to again in the description of he phalanges.

Phalanges.--The cat has five toes or digits on the foreoot, called pollcr, index, medius, anmulus, and minimus. Each digit, except the pollex, consists of three phalanges Fig. 36). The pollex or thumb has only two phalanges. The row of phalanges articulating with the metacarpals s called the proximal, the terminal row the distal, and he remaining row the middle phalanges. Two small esamoid bones are attached on the volar side of the juncion of each proximal phalanx with the metacarpal. Each listal phalanx has its proximal end produced caudal on the almar aspect so that its articular surface faces dorsal. The istal phalanges terminate in claws which are retractile.

The number of digits in the forefoot of Mammalia varies rom one to five. Nearly all the species of every order exept the Edentata and Ungulata possess five digits. The apir has four functional digits. The cow, deer, sheep, and ig also have four digits, but only two are functional, the econd and the fifth being atrophied and terminating in the mall caudo-lateral hoofs which do not touch the ground. The rhinoceros has three functional digits, and the Equida ossess only one digit (Fig. 37), the third, though the trophied remnants of the second and fourth metacarpals re present as splint bones which do not support phalanges. As before stated, the Ungulates are undoubtedly de- 
scendants of a five-toed ancestor of Eocene times. The evolution of the horse's limb and the reduction in the number of digits are shown in figure 35 . Fossil remains of the ancestors of the horse have been found in western United States, Europe, and South America. Orohippus lived in the region of Wyoming, Montana, and Idaho probably more than 5,000,ooo years ago, when that country was more or less marshy, and it was necessary that the mammals should possess a spreading foot which would not permit them to sink too deep into the mud. As the ground became firmer and preying Carnivora more numerous, the foot of the horse adapted itself to rapid flight over solid ground. Thus, through twe and natural selection the third digit was enlarged at the expense of the other digits. Confirmation of this ancestral history of the horse is found by an examination of the early embryonic stages. According to Ewart, a horse embryo $35 \mathrm{~cm}$. long possesses quite welldeveloped second and fourth metacarpals terminating with phalangeal structures. The ulna and radius of an embryo $50 \mathrm{~mm}$. long are strikingly similar to these same bones in Mesohippus. In a still younger embryo the ulna is complete and correspondingly as large as in Orohippus.

As to the method of walking, mammals are spoken of as plantigrade, digitigrade, and unguligrade. The first mode of progression is exemplified by the bear, which places its metacarpals and phalanges flat on the ground in walking. The cat is digitigrade, walking on its toes. The horse and cow are unguligrade, as they walk upon the hoof. In some cases, as in the Cetacea, the forefoot is adapted for swimming instead of walking, and the number of phalanges to each digit is more than three.

\section{PRACTICAL QUESTIONS AND SUGGESTIONS.}

I. What bones compose the shoulder girdle?

2. How is the thoracic limb attached to the trunk? 
3. What does the condition of the clavicle in the cat indicate as to its past history?

4. Draw the medial aspect of the scapula and label all parts.

5. What is the significance of the coracoid process?

6. Which processes of the scapula derive their names from their location and which from their shape?

7. How do you distinguish the right from the left scapula?

8. Draw the caudal aspect of the humerus and label all features.

9. Describe what is seen in looking directly at the distal articulating surfaces of the humerus.

ro. How do you distinguish the right from the left humerus?

II. What features of the humerus derive their names from their shape?

12. Draw the medial or inner aspect of the ulna and label all features.

I3. What features of the ulna derive their names from their form?

I4. How do you distinguish the right from the left ulna?

I5. Describe the articulations of the radius.

16. Draw lateral aspect of radius and label all features.

I7. Describe the condition of the bones of forearm in the horse and its ancestors.

I8. In a five-month fetus of the horse the ulna is distinct from radius and complete, while in the mature animal but little more than the distal third remains, and is anchylosed to the radius. Explain significance of this fact.

I9. Draw ventral aspect of carpus and label all parts.

20. Wherein is the chief difference between carpus of cat and man?

21. Draw the lateral aspect of the third metacarpal and label all features.

22. How do you distinguish the distal from the proximal end of the metacarpals?

23. Describe the variation in the number of metacarpals in mammals.

24. Describe the usual arrangement of the phalanges in mammals having five digits.

25. How do you distinguish a phalanx from a metacarpal?

26. Give the number of functional digits in forelimb of dog, pig, cow, sheep, horse, and rabbit.

27. Name some mammals with atrophied digits.

28. What is the significance of these?

29. In the evolution of the perissodactyls (odd-toed ungulates) describe the order in which the digits are lost.

3o. In the Bovidx and Cervidx which two digits are functional? 


\section{THE PELVIC LIMB.}

The pelvic or hind-limb of the cat is composed of the innominate bone, femur, patella, tibia, fibula, seven tarsals, five metatarsals, and twelve phalanges.

The innominate bone is composed of four parts, the ilium, ischinm, pubis (Figs. $2 \mathrm{I}$ and 38), and the small

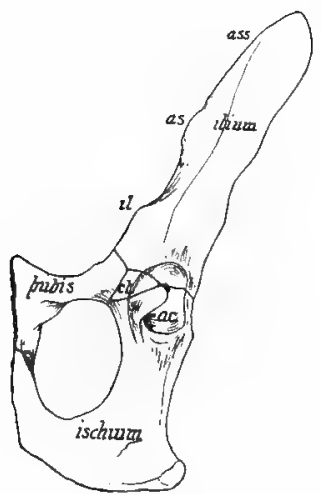

Fig. 38. Ventro Lateral Aspect of Left Innominate Bone of a KITTEN,

ct, Cotyloid bone; ac, acetabulum; $i l$, ileo-pectineal eminence; as, anterior inferior spine.-(Modified after Jayne.)

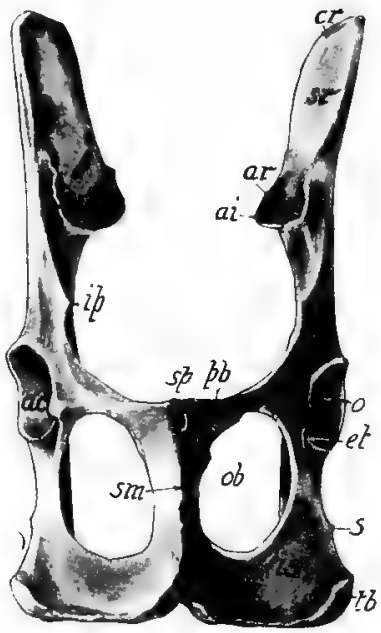

Fig. 39. Ventral Aspect of the INNOMINATE BONES.

ac, Acetabulum; ai, posterior inferior spine; $a r$, auricular surface; $c r$, crest; et, cotyloid notch; ip, ileopectineal eminence; is, body of ischium; $o b$, obturator foramen; $p b$, body of pubis; $s$, spine; $s m$, symphysis pubis; $s p$, spine of pubis; $s r$, surface of ilium for attachment of spinal muscles; $t b$, tuberosity of the ischium.

cotyloid bone. The ilium is the dorsal portion, extending down to and occupying about one-third of the acetabulum. The ischinm includes the caudal portion of the bone, extending ventral and forming two-thirds of the boundary of the 
obturator foramen. The pubis is the ventral portion, possessing two rami, one projecting laterad to unite with the ilium, cotyloid, and ischium, and the other projecting cattad along the mid-ventral line, joining its fellow and the ischium. In young kittens the junction of these parts is plainly visible, but in adult specimens it is wholly obliterated. In old specimens the ischium and pubis become more or less anchylosed with their fellows in the midventral line. The cranial and dorsal border of the ilium is the crest (Fig. 39). The rough crescentic area on the -medial aspect is the auricular surface for articulation with the sacrum. The cranial rounded angle of the crest is the anterior superior spine. The anterior inforior spine is the small prominence craniad from the ventral termination of the auricular surface.

The ischinm presents a spine on its dorsal border near the acetabulum. Between this spine and the posterior inferior spine of the ilium, is a shallow concavity termed the greater sciatic notch in distinction to the lesser sciatic notch between the spine of the ischium and the tuberosity. The acetabulum or cotyloid cavity forms the cup for the articulation of the femur. The interruption in its ventral border is the cotyloid notch, at whose base there is a depression for the attachment of the ligamentum teres holding the femur in place. The junction of the pubis with its fellow is known as the symphysis. The cranial portion of the bone lying on either side of this is called the body, the caudal part taking the name of ramus. The latter forms part of the boundary of the obturator foranen and meets the ramus of the ischium. This foramen gives passage to the obturator nerve and vessels.

In the Sirenia, which have no pelvic limbs, the innominate bones are rudimentary. In the Cetacea these bones are also rudimentary, which fact indicates that the ancestors of these forms possessed functional hind-limbs. 
The femur, or thigh-bone, may be recognized by its spherical head with a pit for the attachment of the liga-

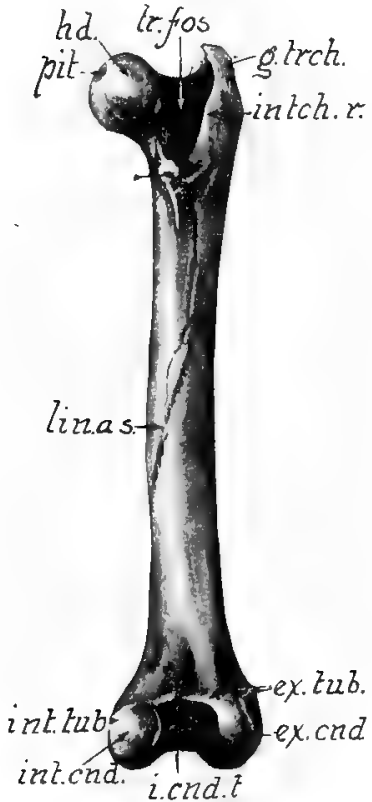

Fig. 40. Caudal Aspect of FEMUR.

$e x . t u b$, External tuberosity; int $t u b$, internal tuberosity; $e x$. cnd, external condyle; int. cnd, internal condyle; $i$. cnd. $t$, intercondylar notch or fossa; intch. $r$, intertrochanteric ridge; g. trch, greater trochanter; $h d$, head; lin. as, linea aspera; l. trch, lesser trochanter; $n k$, neck; pit, pit for the ligamentum teres; tr. fos, trochanteric fossa or digital fossa.

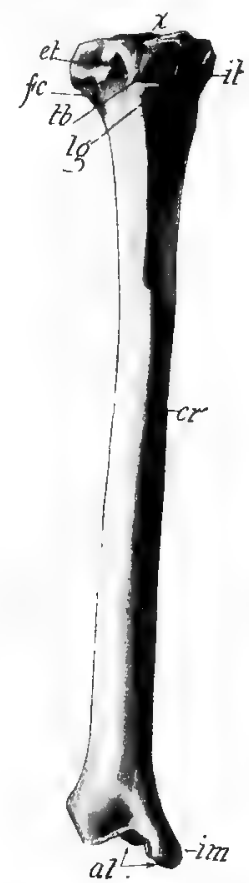

Fig. 4I. ANTERIOR OR Cranial Aspect of Right Tibia.

at, Articulatory surface for the astragalus; $c r$, crest; et, external tuberosity; $f c$, facet for articulation with the fibula : $i m$, internal malleolus; it, internal tuberosity; $l g$, ligament of the patella cut off; $t b$, tubercle.

mentum teres which aids in holding the head in the acetabulum. 
The greater trochanter projects from the proximal end of the bone to a level with the head. On this process are inserted the pyriformis, gluteus medius, and gluteus minimus muscles, all of which originate on the innominate bone. The lesser trochanter is the small projection on the caudal aspect of the proximal portion of the bone (Fig. 40). The intertrochanteric ridge or posterior intertrochanteric line extends between the two trochanters, and lying between this line and the neck is the digital fossa. The external and internal condyles are the articulatory processes on the distal end of the bone. The blunt projections at their roots are the external and internal tubcrosities. The intercondyloid notch forms the depression on the caudal aspect between the condyles. On the cranial aspect is the trochlear surface for articulation with the patella. Two small sesamoid bones, the fabellæ, are present on the caudal aspect of the condyles, but they are usually removed in preparing the skeleton. The linea aspera is the slightly roughened line beginning on the caudal side, distal to the middle and extending proximally a short distance, where it bifurcates.

The form of the femur varies but little among mammals having functional posterior limbs. No living Sirenia have any trace of a femur, but a vestigial femur is present in Halitherium, a fossil form. The hind-limbs are wanting among the Cetacea, but in a few forms nodules of bone or cartilage may represent the femur. In most Perissodactyla and Rodentia, and in some Insectivora and a few fossil Carnivora, a third trochanter is present.

The patella, or knee-cap (Fig. $2 \mathrm{I}$ ), is a sesamoid bone developed in the tendon of the quadriceps extensor muscle (Fig. 52). It is somewhat the shape of an almond and about half its size. It articulates with the trochlea of the femur.

The tibia is the larger bone of the crus. It presents two 
enlarged extremities and a shaft whose cross-section is triangtular. It articulates with the femur and fibula proximally and the fibula and astragalus distally

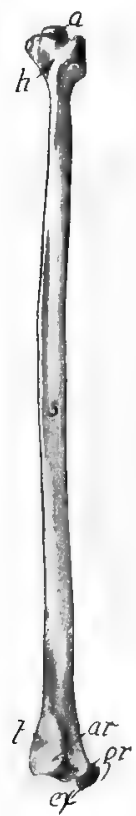

FIG. 42. INNER OR Medial Aspect of Right FibULA.

a, Facet for tibia; ar, facet for astragalus; $e x$, external malleolus; $h$, head; s, shaft; $t$, articular surface for tibia; gr, groove for peroneus longus muscle. (Fig. 2I). This is the longest bone in the cat's skeleton. Between the concave condyles on the proximal end is a notch giving attachment to the crucial ligament of the knee-joint (Figs. 4I, 46).

The prominences of the lateral and medial aspects of the proximal extremity are the external and internal tuberosities respectively. Beneath the former is the facet for articulation with the fibula (Fig. 4I). The tubercle, a prominence on the cranial side of this extremity, is for the insertion of the ligamentum patella, which is really the termination of the tendon of the quadriceps extensor muscle (Fig. 52 ). On the caudal aspect between the condyles is the popliteal notch. The sharp cranial border of the bone forms the crest. On the distal extremity is a process, the internal malleolus, bearing two grooves, the more caudal of which shelters the tendon of the flexor longus digitorum muscle while the other is for the tibialis posticus (Fig. 52). A facet is present on the lateral aspect of this extremity for articulation with the fibula.

The fibula in proportion to its length is the slenderest bone in the skeleton.

It is the outer or lateral bone of the crus, and articulates proximally with the tibia and distally with the tibia and astragalus (Fig. 2I). The proximal extremity is 
the head, upon which is a circular facet for articulation with the tibia. The sharp edge along the cranial aspect of the shaft furnishes attachment to the interosseous membrane uniting the two bones of the crus. The medial aspect of the distal extremity shows a prominent facet for articulation with the astragalus. Immediately proximal to this is the articular surface for the tibia. From the lateral aspect projects the external malleolus, on the caudal side of which is a groove for the peroneus brevis muscle, and on the cranial side is a slight depression for the peroneus longus (Fig. 52).

In many of the Mammalia the two bones of the crus are more or less united. In most of the Chiroptera and Ungulata the fibula is rudimentary. The middle portion of the fibula is absent in the horse and its distal portion is fused with the tibia (Fig. 35). The ancestor of the Equidx in Eocene times had a well-developed fibula, but in the evolution of the horse this bone has gradually diminished in size. as shown in the figure.

The tarsus is composed of seven bones in two rows. The proximal row contains the os calcis, astragalus, and navicular or scaphoid; the distal row the cuboid, and three cuneiform bones. The os calcis, or calcancum, is the largest bone of the tarsus, being twice as long as broad (Fig. 43). Its caudal end presents a groove for the tendon of the plantaris muscle. The poroneal tubcrcle is on the outer side of the distal extremity. The sustentaculum, a shelf-like process projecting from near the middle of the inner side, supports a facet for the tendon of the flexor longus digitorum muscle (Fig. 53).

The astragalus lies on the inner or medial side of the calcaneum and articulates with the tibia, fibula, calcaneum, and scaphoid. The bone is composed of a body, neck, and head. The body is proximal and bears a trochlear surface 
for articulation with the tibia. The head bears a convex

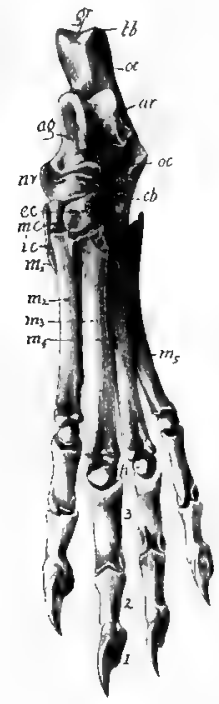

Fig. 43. Dorsal Aspect of LeFT Hind-Foot.

ag, Astragalus; ar, articillat surface of the tibia; $c b$, cuboid; $e c$, external cuneiform; $g r$, groove for the tendon of the plantaris; $h$, head of the fourth metatarsal; $i c$, internal cuneiform; $m c$, middle cuneiform; $m_{1}$, hallux or first metatarsal; $m_{z}$, $m_{3}, m_{4}$, and $m_{5}$, second, third, fourth, and fifth metatarsals; $n v$, navicular or scaphoid; oc, os calcis, or calcaneum ; 3, proximal row of phalanges; 2 , middle row of phalanges; $I$, distal row of phalanges. surface for articulation with the navicular. The neck is the constricted portion between the body and the head.

The scaphoid lies on the medial side of the foot and articulates with the remaining six bones of the tarsus. It may be recognized by its deep concave surface for articulation with the astragalus, and also by the tuberosity, a process on its medial plantar angle (Fig. 43).

The internal cuneiform is next to the smallest bone of the tarsus. It articulates with the navicular, middle cuneiform, and first and second metatarsals. The middle cuneiform is a wedge-shaped bone and the smallest element of the tarsus. It articulates with the other two cuneiforms, the scaphoid and second metatarsal. The external cuneiform may be recognized by a strong hooklike process on its plantar surface. It articulates with the scaphoid, middle cuneiform, cuboid, and second and third metatarsals.

The cuboid is the lateral bone of the distal row. It may be recognized by the deep groove on its plantar surface which shelters the tendon of the peroneus longus muscle.

The typical arrangement of the tarsal elements in ver- 
tebrates is similar to that of the carpus. Three bones, a tibiale, intermedium, and fibulare, compose the proximal row, while five tarsalia form the distal row. The centrale occupies the center of the tarsal region. In the adult mammal, fusion of some of these elements occurs, so that not more than seven distinct bones are present in any form. The astragalus contains the tibiale and intermedium, while the fourth and fifth tarsalia form the cuboid.

The metatarsus consists of five bones, the first of which is rudimentary, while the other four are longer than the metacarpus, which they resemble (Fig. 43). The first metatarsal is smaller than any bone of the tarsus. It articulates with the internal cuneiform and is also in contact with the second metatarsal. The four long metatarsals have a slight dorsal convexity, each one consisting of a base or enlarged proximal part, a shaft or middle portion, and a head or distal rounded articular process. On the plantar surface of the head of each metatarsal is a median spine, on each side of which is a concavity for a sesamoid bone. These sesamoid bones are frequently lost in cleaning the skeleton.

The number of functional metatarsals in mammals varies from one to five. Usually the number of metacarpals and metatarsals is the same, but in the tapir there are four metacarpals and but three metatarsals. All Monotremata, Carnivora, and Primates have five metatarsals, but in the cats, dogs, and hyenas the first metatarsal is vestigial. In early geological times all mammals possessed five metatarsals, the number of which in many cases has gradually diminished owing to environment, as is shown in the phylogeny of the horse (Fig. 35).

The Equidæ possess but one functional metatarsal and two rudimentary ones, although Orohippus, the ancestor of the horse, had three functional metatarsals.

The phalanges of the cat's foot are twelve in number. 
Each metatarsal except the first supports three phalanges. The proximal phalanges are the stoutest, and the distal the smallest. Each distal phalanx bears a claw.

In all five-toed animals, such as Primates, there are fourteen phalanges, each digit being composed of three, except the hallux, which has two.

\section{PRACTICAL QUESTIONS AND SUGGESTIONS.}

I. Describe the articulations of the innominate bone.

2. How do you distinguish the cranial from the caudal aspect of the os innominatum?

3. Which processes derive their names from their location?

4. Draw the lateral aspect of the os innominatum and label all features.

5. Name the four parts of the bone in order of size.

6. What two orders of mammals have no pelvic limbs?

7. Describe what is seen in viewing the femur from the cranial aspect.

8. Name the processes of the femur.

9. Draw the distal aspect of the femur.

Io. How do you distinguish the right from the left femur?

II. Describe the patella.

I2. Draw the caudal aspect of the tibia and label all features.

I3. How do you distinguish the right from the left tibia?

I4. Describe the articulations of the fibula.

I5. What features distinguish the proximal from the distal extremities of the fibula?

I6. Write Ioo words describing the crus in other mammals than the cat.

I7. Draw the ventral aspect of the tarsus and label all parts.

I8. Which of the tarsals support metatarsals?

I9. Name the tarsals in order of size.

20. Draw the lateral aspect of the third metatarsal.

21. How do you distinguish a metatarsal from a metacarpal?

22. How do you distinguish the proximal from the distal end of a metatarsal?

23. Describe the condition of the metatarsals in various mammals.

24. In most mammals how many phalanges to each digit?

25. What artiodactyls have you seen with only two functional digits on the posterior limbs? 


\section{THE JOINTS.}

The study of the articulation of the bones and the ligaments holding them in place is known as syndesmology. There are three general classes of articulations: Synarthroses, or immovable joints; amphiarthroses, or joints with slight motion; and diarthroses, or joints freely movable. A synarthrodal joint is exemplified in the sutures between the bones of the skull. The two surfaces of bone are separated by fibrous membrane only. An amphiarthrodal articulation occurs between the bodies of the vertebra and also in the union of the sacrum with the ilium. In the articulation of the vertebræ the contiguous surfaces of the bone are faced by flattened discs of fibrocartilage (Fig. 2I).

The diarthrodal articulation is exemplified in all joints allowing free motion. Such joints are composed of the following parts: the ends of two bones having their contiguous surfaces covered with cartilage; a synovial mem-

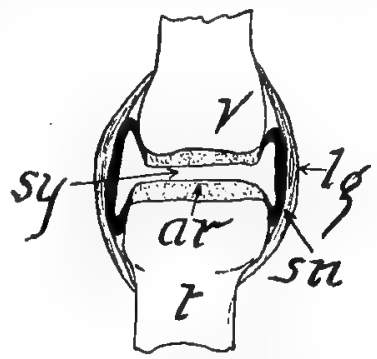

'Fig. 44. Diagram of a DiaRThRODAL JoINT.

ar, Articulatory cartilage; $l g$, ligament; sn, synovial membrane; sy, synovial fluid in synovial cavity; $t$, tibia; $v$, femur. brane forming a short tube whose ends are closed by the cartilaginous articulating surfaces; and several ligaments varying in number from two or three to a dozen (Fig. 44). There are four kinds of the diarthrosis: the arthrodia, or gliding joint, which occurs between the bones of the carpus; the enarthrosis, or ball-and-socket joint, such as at the hip or shoulder; the ginglymus, or hinge joint, exemplified at the elbow and knee; and the rotatoria, or pivot joint, formed by the articulation of the axis and atlas. 
As the knee-joint can be readily dissected and the parts well displayed, it is here described somewhat in detail. The leg should be detached at the hip-joint and the muscles largely removed, taking care in the immediate neighborhood of the knee that the ligaments are not cut. There are

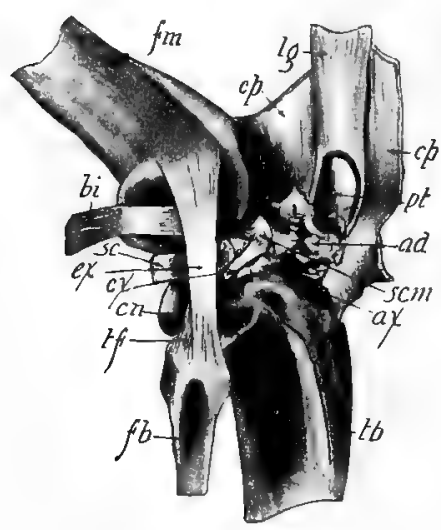

Fig. 45. Lateral Aspect of DisSECTED KNEE-JOINT.

$a d$, Adipose tissue; $a x$, antero-internal ligament of the meniscus; $c p$, capsular ligament cut and reflected mediad; $b i$, tendon of the popliteus muscle pulled proximad to display $s c$; $c n$, caudal projection of condyle of tibia; $c x$, antero-external ligament of the meniscus; $e x$, external lateral ligament; $f b$, fibula; $f m$, femur; $l g$, ligament of the quadriceps extensor muscle; $p t$, patella; $s c$, external or lateral meniscus; scm, medial or internal meniscus; tf, tibiofibular ligament; $t b$, tibia. eight ligaments to this joint. The anterior ligament or ligament of the patella (Fig. 45), extending from the patella to the anterior tubercle on the tibia, is the strongest ligament of the knee-joint, and is really a continuation of the tendon of the quadriceps extensor muscle. The capsular ligament, which entirely surrounds the joint except in the places occupied by the anterior and lateral ligaments, consists of two parts, a cranial and a caudal portion. The former is seen on either side of the anterior ligament, extending from the femur to the tibia as a thick membrane, and more laterally being attached to the menisci. The caudal part extends from the fabellix and the femur to the tibia and menisci.

The external lateral ligament proceeds from the external tuberosity of the femur to the head of the fibula. The internal lateral ligament, much shorter than the external 
one, extends from the internal tuberosity of the femur to the internal tuberosity of the tibia. The anterior and capsular ligaments must be cut in order to see the crucial ligaments, which are short, and cross each other in the region of the intercondylar notch. The posterior crucial extends from the caudal margin of the head of the tibia to the mediocranial angle of the intercondyloid notch of the femur. The anterior crucial extends from the summit of the tibia to the caudolateral angle of the intercondyloid notch. The tibio fibular ligament is very short, extending from the head of the fibula to the outer tuberosity of the tibia. In addition to these ligaments, there are four bands uniting the menisci to the bones. The menisci or semilumar cartilages are two biconcave cartilaginous plates, about one millimeter thick, interposed between the condyles of the femur and tibia.

The synovial membrane is a very thin transparent sheet lying within the capsular sheath of the joint. It secretes the white glairy synovia. for lubricating the joint. The synovial fluid and membrane may be demonstrated by cutting open a fresh joint

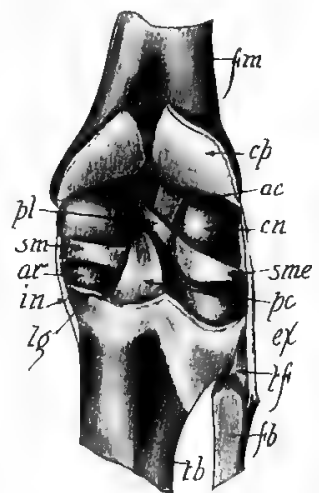

Fig, 46. Caudal Aspect OF KNEE-JOINT WITH Capsular Ligament Cut.

$a c$, Anterior crucial ligament; $a r$, articular surface of condyle of tibia; $c n$, condyle of femur; $c p$, capsular ligament cut along the line $l g$ and reflected proximad; ex, external lateral ligament; $f b$, fibula; $f m$, femur; in, internal lateral ligament; $l g$, cut edge of capsular ligament; $p c$, posterior crucial ligament; $p l$, posterior external ligament of the meniscus; sm, medial or internal meniscus; sme, lateral or external meniscus; $t f$, tibiofibular ligament; $t b$, tibia. obtained from the butcher-shop (Fig. 44).

All other freely movable joints are similar in structure to the knee-joint, but have no menisci and fewer ligaments. 
The shoulder-joint has only two or three ligaments, the most important of which is the capsular. The elbow-joint has four ligaments and the hip-joint only two. In the ankle-joint there are eight ligaments in addition to the capsular.

These ligaments which bind the joints consist of white fibrous connective tissue which under the microscope is seen to be composed of parallel and interlacing fibers. They are very tough and have but little elasticity, so that the joints are seldom dislocated (Fig. II).

\section{PRACTICAL QUESTIONS AND SUGGESTIONS.}

I. Give three examples of each of the three general classes of joints.

2. Explain difference in anatomy of the three classes of joints.

3. Without aid of the microscope can you detect any differences between a ligament and a tendon?

4. By removing the capsular ligament describe the ligaments that can be displayed on the lateral and caudal aspects of the knee-joint.

5. After bringing to view by dissection as many ligaments as possible on inner aspect of knee-joint, draw and label all parts.

6. Draw the menisci.

7. By careful dissection note the ligaments present in the hip-joint.

8. How many ligaments can you find in the shoulder-joint?

9. In what joints is synovia present?

ro. Cut a very thin slice of articular cartilage about a millimeter square, mount in dilute acetic acid, and make drawing as seen under the microscope. 


\section{THE MUSCLES.}

The study of the muscular system is known as myology. The muscles are of two kinds: voluntary, which are under the control of the will; and involuntary, which cannot be controlled by the will. All muscles moving the bones are voluntary and are supplied with branches of the cerebrospinal nerves. Examples of involuntary muscles are found in the walls of the alimentary canal, the ureter, bronchial tubes, and blood-vessels. These are supplied with nerves from the sympathetic nervous system (Fig. 9I). The structure of a voluntary muscle may be seen by teasing a small piece on a slide in a drop of water, covering with a cover-glass, and examining with the compound microscope. It is composed of striated fibers from one to fifteen centimeters in length, while involuntary muscle is composed of cells more or less spindle-shaped and non-striated, except in the heart (Figs. 8 and Io).

There are over five hundred voluntary muscles in the cat, each of which is usually attached at either end to the periosteum of a bone. The point of attachment on the unmoved bone is known as the origin of the muscle. The insertion of a muscle is its attachment to the bone which it moves. In the case of the biceps, its origin is on the scapula and its insertion on the radius. Usually a muscle originates and terminates in a white glistening cord called a tendon, composed for the most part of white fibrous tissue (Fig. I I).

Each muscle-fiber is surrounded by a transparent elastic sheath, the sarcolemma. A number of fibers bound together by a loose connective tissue, and the whole enveloped by an extension of the same, is a fasciculus. The tissue connect- 
ing the fibers is the endomysium, while that enveloping the fasciculus is the perimysium. A number of fasciculi bound together in a sheath, the epimysium, constitutes the entire muscle. The epimysium is merely a deflected portion of the sheath enveloping the fasciculus. It is visible to the naked eye as a thin shining sheath beneath the tougher fascia which covers the muscles and binds them together.

According to function, muscles are spoken of as flexors, extensors, adductors, abductors, rotators, elevators, depressors, and sphincters. A flexor muscle is one which by its contraction bends a limb or any portion of it. An extensor muscle is the antagonist of a flexor and serves to bring the two long bones into line. An abductor muscle is the one inserted on a long bone, which it draws laterad from the axis of the limb or the sagittal plane of the body. An abductor muscle is the antagonist of an abductor. The pectoral muscles are abductors of the forelimb. A rotator muscle is ont which produces more or less of a rotatory motion in the bone upon which it is inserted. A rotator muscle is exemplified in the obturators, which arise on the innominate bone and are inserted in the digital fossa of the femur. An elevator muscle is represented by the temporal, extending from the temporal bone to the mandible, which it elevates. A depressor muscle is the antagonist of an elevator. The digastric is a depressor of the mandible. A sphincter muscle is one surrounding an orifice which it closes by contraction. The orbictlaris oris in the lips is an example.

Muscles are named according to their function, shape, or part to which they are attached. Thus the sternomastoid muscle arises on the sternum and is inserted on the mastoid process of the skull. The latissimus dorsi is so named because it is a very broad muscle (Fig. 47) and occupies the clorsal part of the cat's body. The extensor 
communis digitorum muscle signifies by its name that it is the common extensor of the digits.

\section{DISSECTION OF THE MUSCLES.}

Since the other systems are of more importance from the standpoint of comparative anatomy and physiology than the muscular, only the more important muscles will be described. Great care should be exercised in removing the skin of the cat, in order that such superficial muscles as the platysma myoides on the neck and side of the face, and occipitofrontalis, may not be cut away. The skin is attached to the underlying muscles by the superficial fascia, a fibrous areolar tissue, which contains the subcutaneous fat more or less abundant in all specimens. The decp fascia is the fibrous and membranous layer of dense tissue lying close against the muscles and dipping down between them. The stronger parts of this fascia are called aponcuroses.

Directions for Dissection.-Dissection does not mean the cutting up, but the intelligent separation of one organ from another and the removing of known portions to study the deeper structures more carefully, The muscles should not be cut loose from their origin or insertion, but merely separated from each other by cutting the deep fascia in the longitudinal direction of the muscle. If it is necessary to remove a muscle for displaying those beneath, it should be cut transversely in the middle and the two parts reflected. No portion of a muscle or other tissue should be removed without knowing what it is and noticing carefully its relation to the surrounding parts. The specimen under dissection should be securely nailed to the tray so that the muscles are made tense. When the parts become dry, they should be thoroughly wet with water. If the formalin in which the specimen has been preserved is irritating to the mucous membrane of the dissector, a half liter of $5 \%$ ammonium hydrate should be poured over the specimen. 
The muscles of the following table are arranged according to location, but they need not be dissected in the order named. Some classes having time for the study of onehalf or even one-third of the muscles here described will be able by the use of the table and the illustrations to become familiar with the functions and the relations of any muscles the instructor may wish to assign for study. The student should note carefully the muscles which together effect a certain motion, such as the flexion of the forearm or the extension of the digits.

Fig. 47. Ventral Aspect of the Crantal Half of the Cat. The superficial muscles have been removed from the left side and the scapula reflected laterad to display the serratus and adjacent muscles.

$a$, Triceps; $b$, triceps; $c a r$, carotid artery; $c, c_{1}$, and $c_{2}$, scalene muscles; $c p h$, cephalohumeral; cre, coracobrachialis; $d g$, digastric; $d s$, cut end of the digastric; ext, external oblique; $f$, inferior constrictor; $g h$, geniohyoid; $h$, humerus; $i$, scalene; $i c$, triangularis sterni; int, internal oblique; $j$, hyoglossus; $k$, styloglossus ; $l$, rectus lateralis; $l d$, latissimus dorsi reflected lateral and much of the reflected portion cut off ; $l v$, levator anguli scapulæ; $m$, longus colli ; man, mandible; mas, masseter; mh, mylohyoid; md, median ventral line; $n$, fascial aponeurosis of the external oblique; $p c_{1}, p c_{2}, p c_{3}$, and $p c_{4}$, first, second, third, and fourth parts of the pectoralis muscle; pct, portion of the pectoral muscle of the left side; rct, left rectus abdominalis; $s h$, sternohyoid; $s h_{1}$, sternohyoid of the left side with its middle portion removed; std, sternothyroid; stm, sternomastoid; st, portion of left sternomastoid; sub, subscapularis; $s p s$, suprascapularis ; $t m$, teres major; $t r$, triceps; $x$, cleidomastoid; $1,2,3,7,8$, and 9 , ribs; 5 , trachea. 
THE MUSCLES.

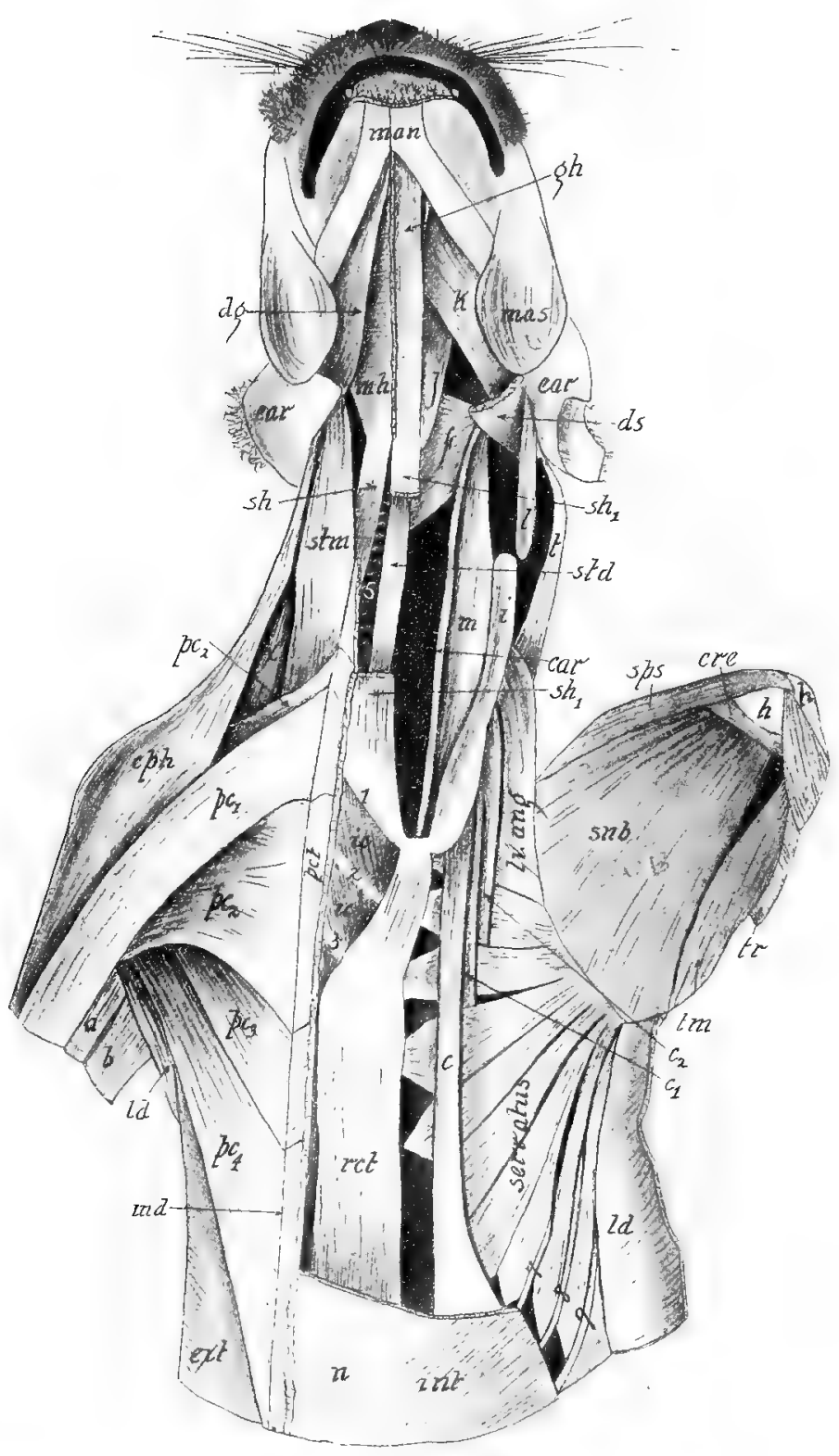

FIG. 47. 


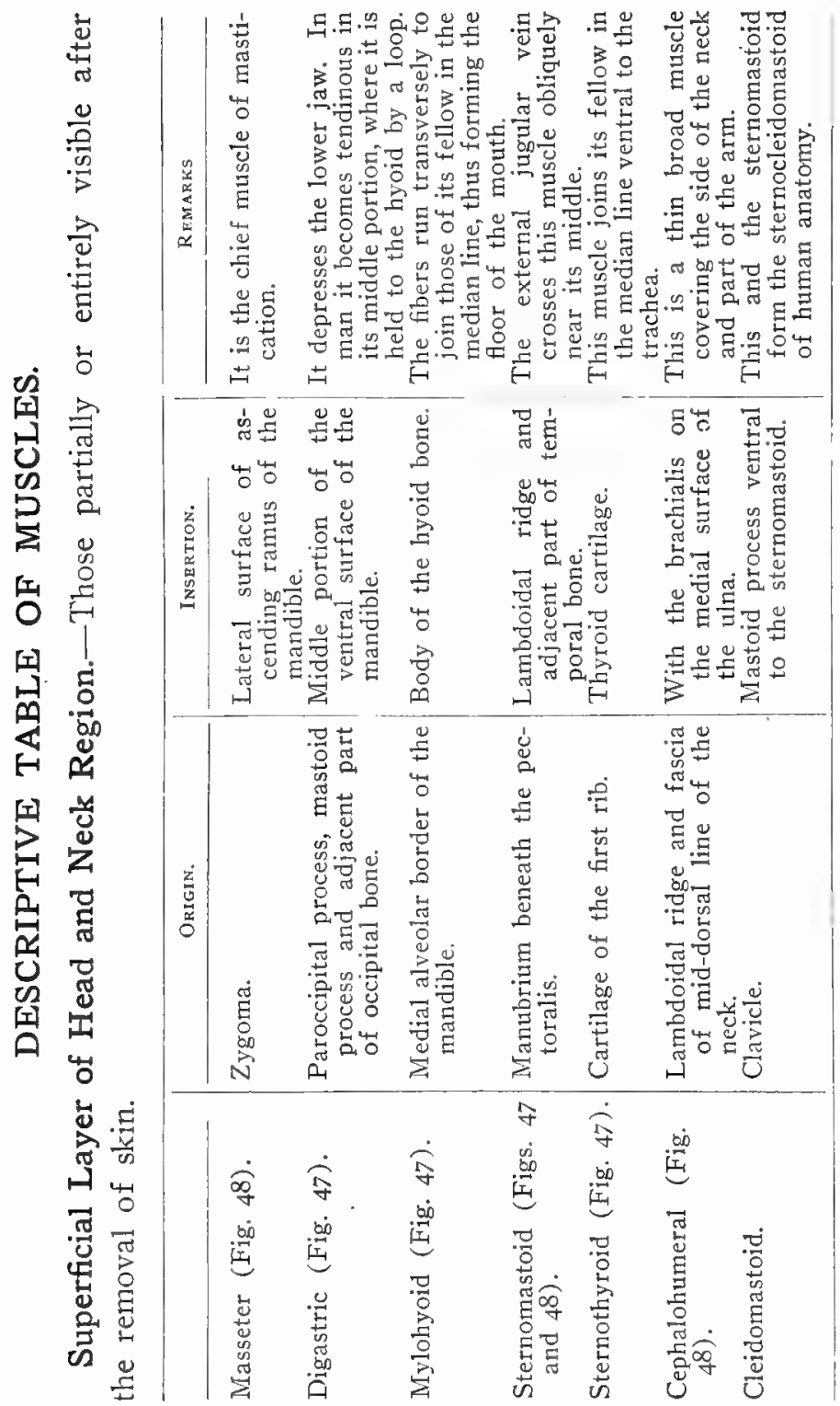




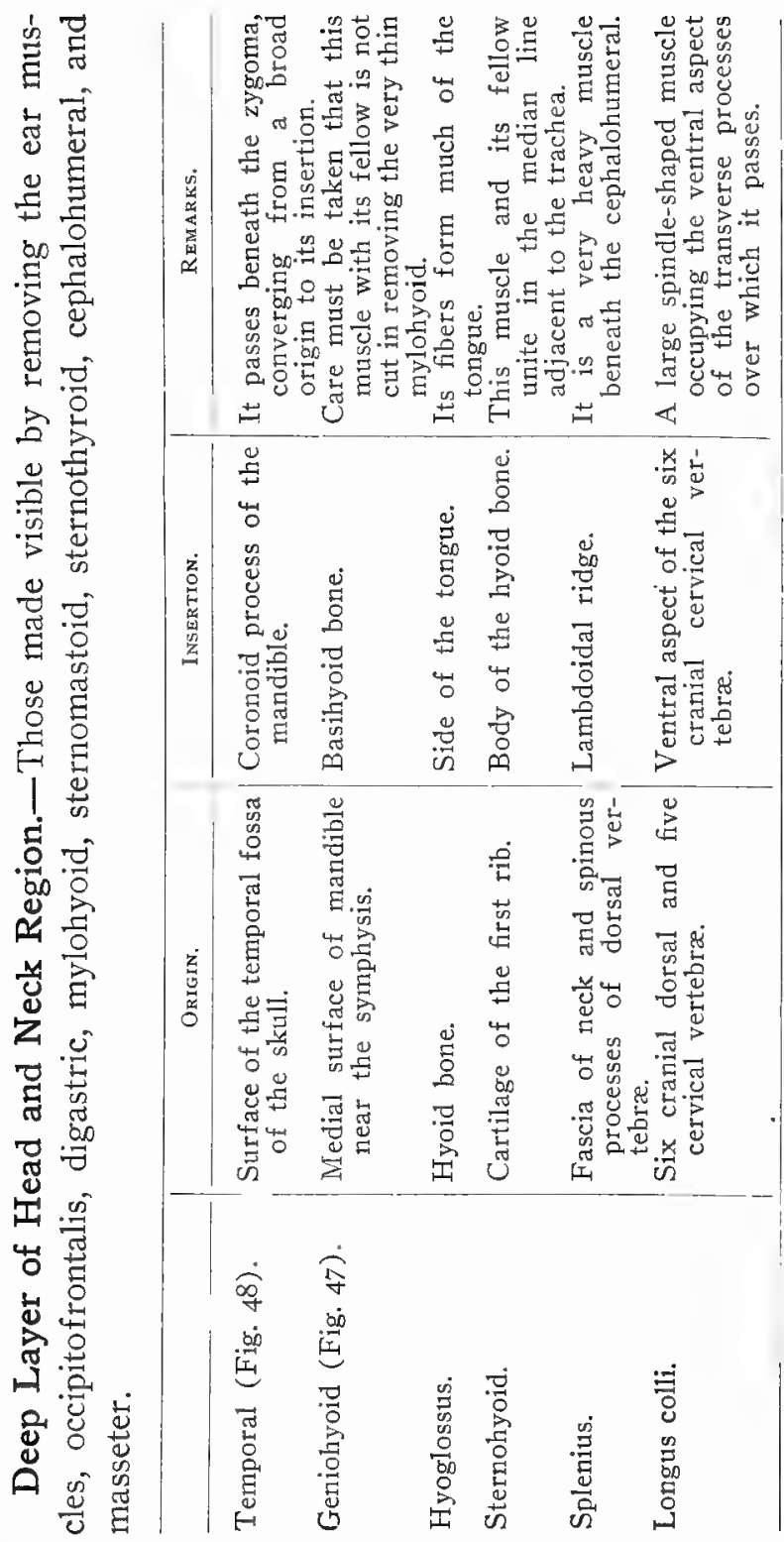


84 ELEMENTS OF MAMMALIAN ANATOMY.

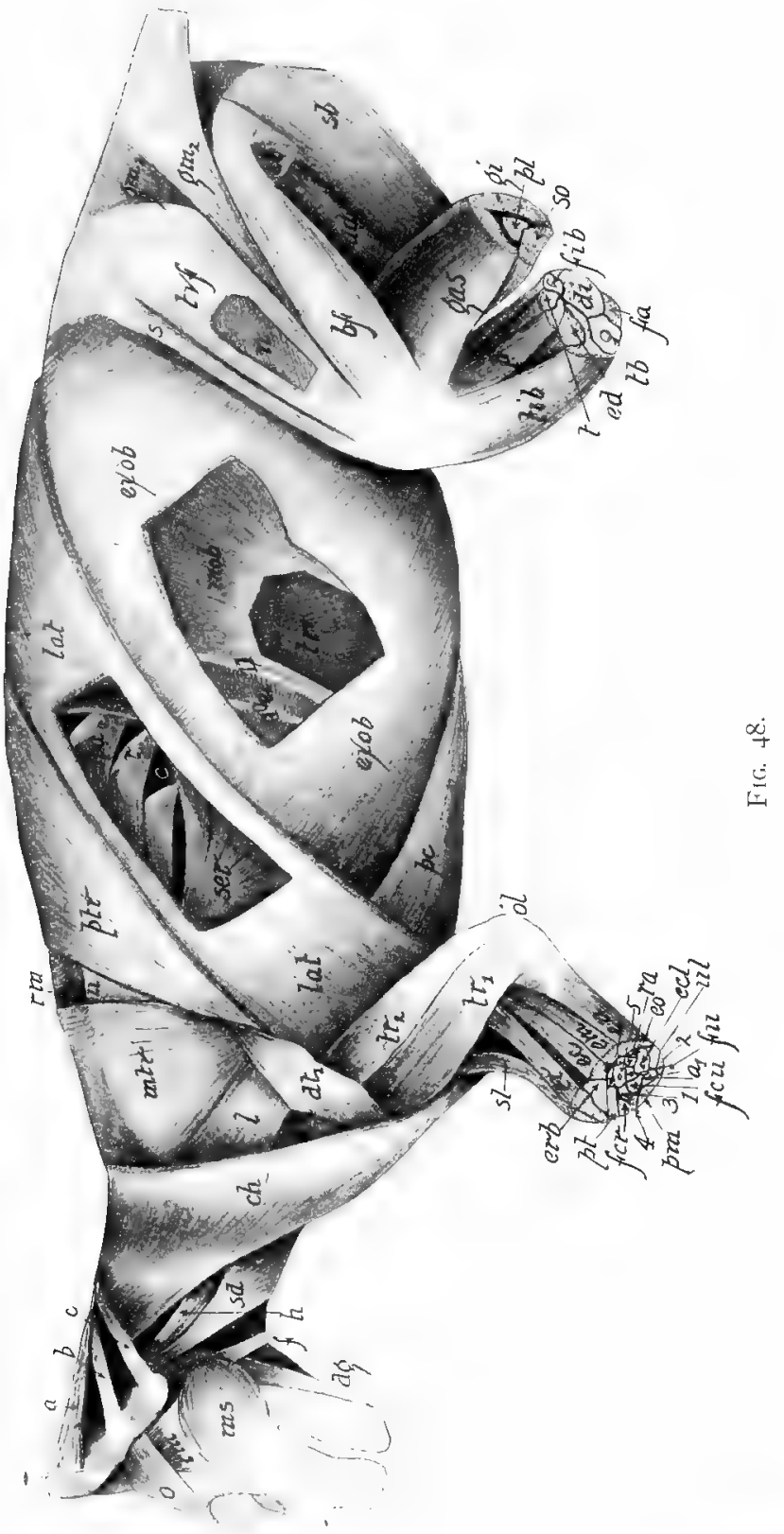




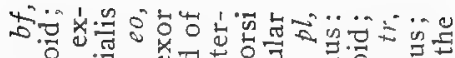

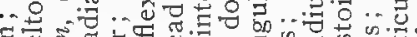

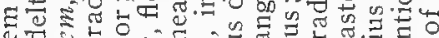

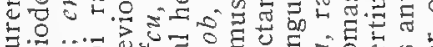

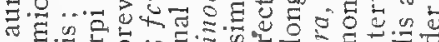
을.

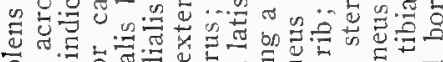

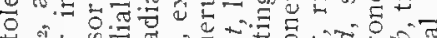

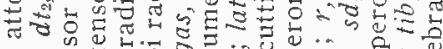
…ㄹ.

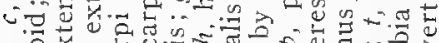

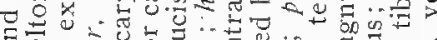

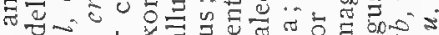
0马..t

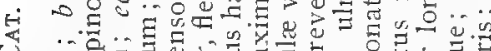

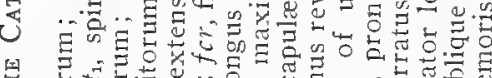

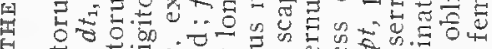
क

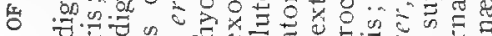
on

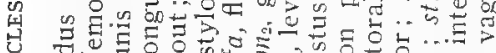

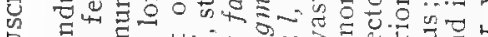

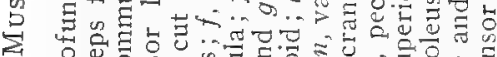

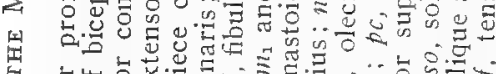
เ4

乎

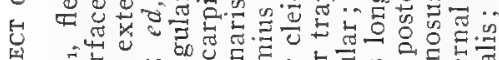

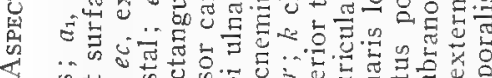

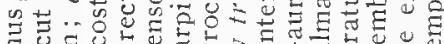
己 U

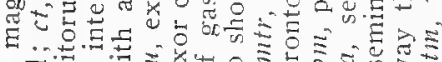

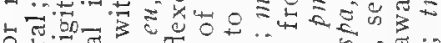

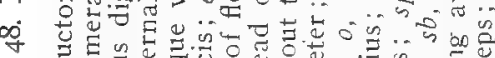

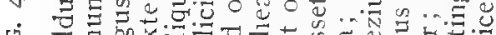

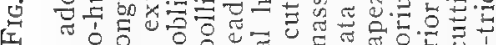

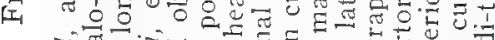

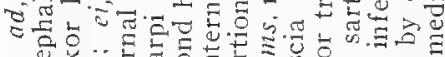
.. C . . E

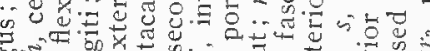
कos. …

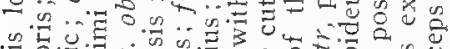
을.

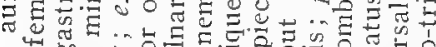
เ

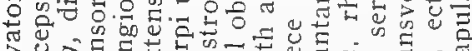

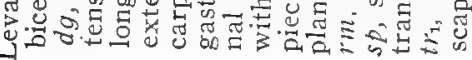




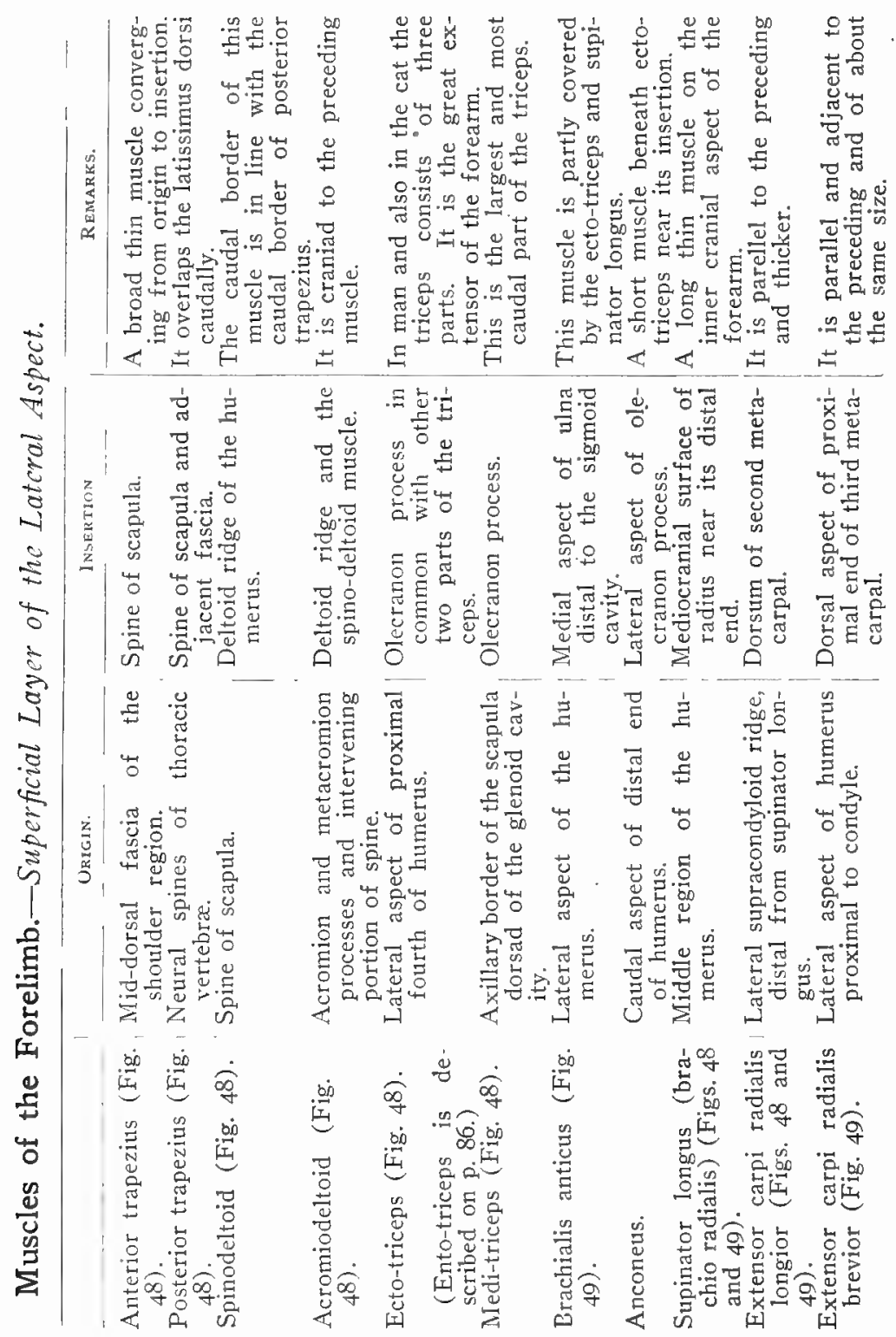




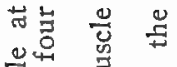 \\ 氙。 \\ 吉. \\ ․․ \\ 昰诺

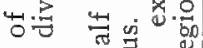

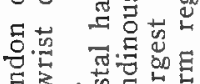

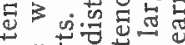 \\ 㝴灾。}

F

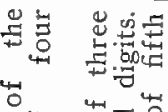

出岁苛

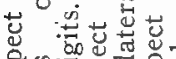

क口: v

ख

ส

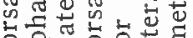

㟔的矛㟔曋

突 出

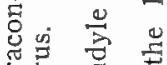

总䓌

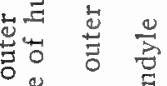

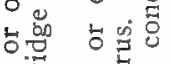

तี

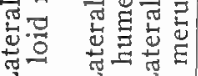

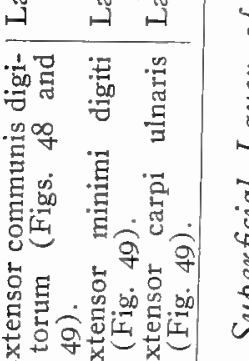

$\frac{-1}{3}$

N

\$

II

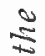

4

है

$\stackrel{5}{5}$

.

के

5

$\stackrel{2}{\infty}$

है

8

एँ

20

단 0

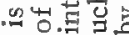

I0..

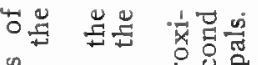

낭

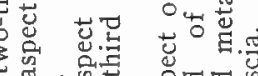

궁

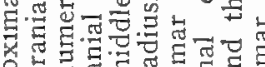

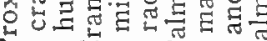

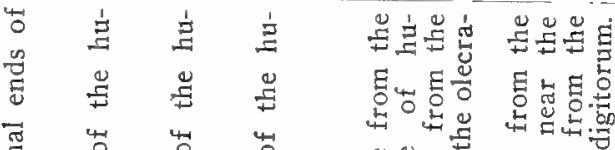

藏 出 㟧

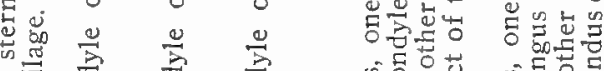

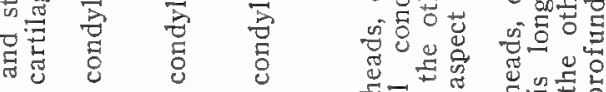

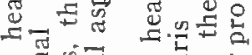

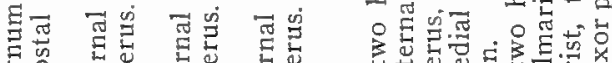

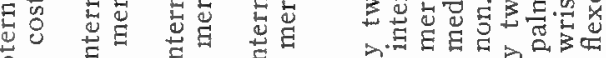

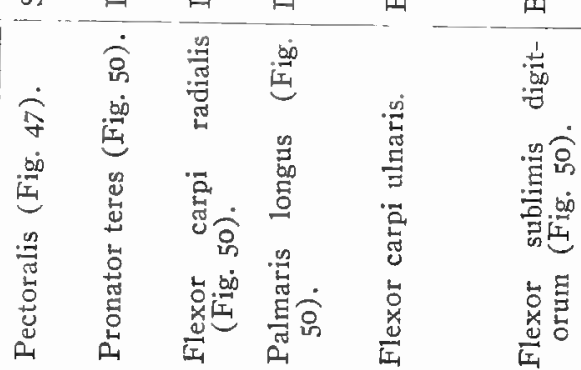




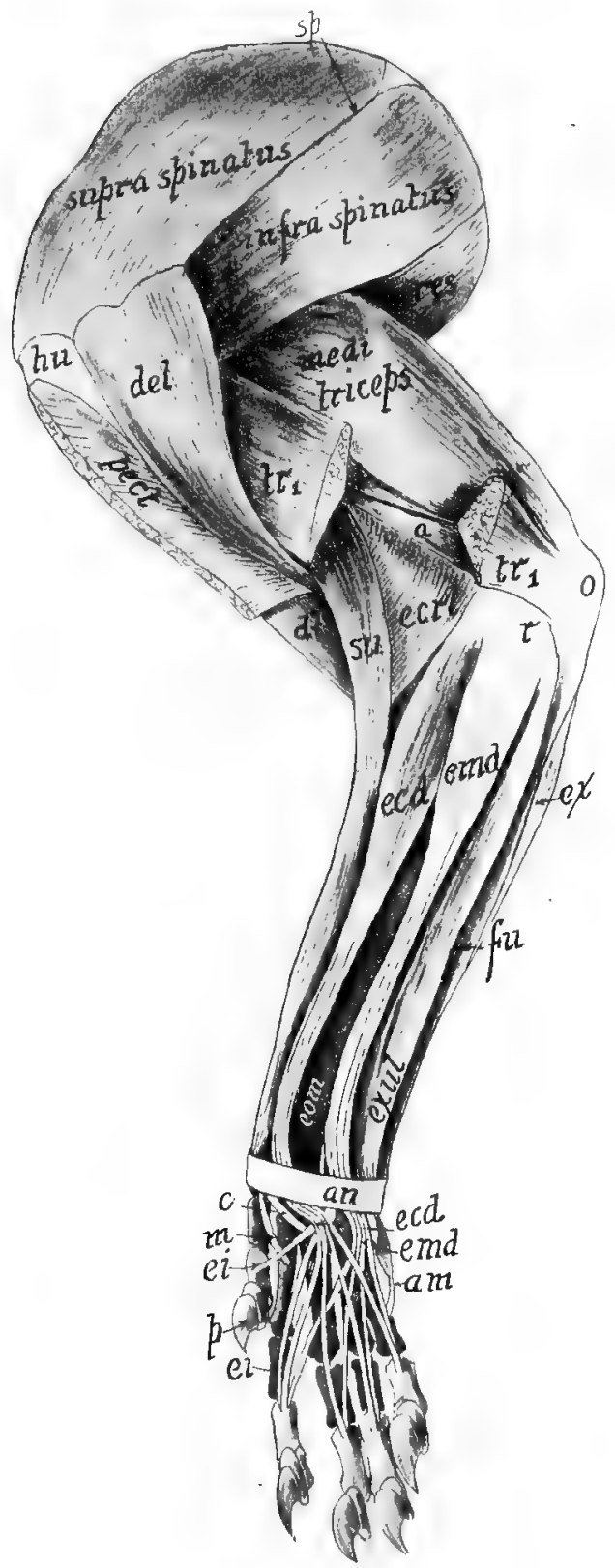

F1G. 49. 
Fig. 49. Lateral or Outer Aspect of Muscles of the Pectoral Limb.

$a$, Cranial part of the ento-triceps; an, annular liagment; am, abductor minimi digiti ; $c$, extensor carpi radialis brevior ; del, acromiodeltoid; $d l$, biceps; ecd, extensor communis digitorum; ecrl, extensor carpi radialis longior, whose tendon is marked $m$; emd, extensor minimi digiti; ei, extensor indicis; exul, extensor carpi ulnaris; eom, extensor ossis metacarpi pollicis; $e x$, ulnar head of the flexor carpi ulnaris ; $f u$, flexor profundus digitorum; $h u$, humerus; $i$, caudal part of the ento-triceps; 0 , olecranon process of the ulna; $p$, claw of first digit; pect, portion of the pectoralis; $r$, region of the head of the radius; $s p$, spine of the scapula; $s u$, supinator longus; $t r_{1}$ ectotriceps with its middle portion cut out. 


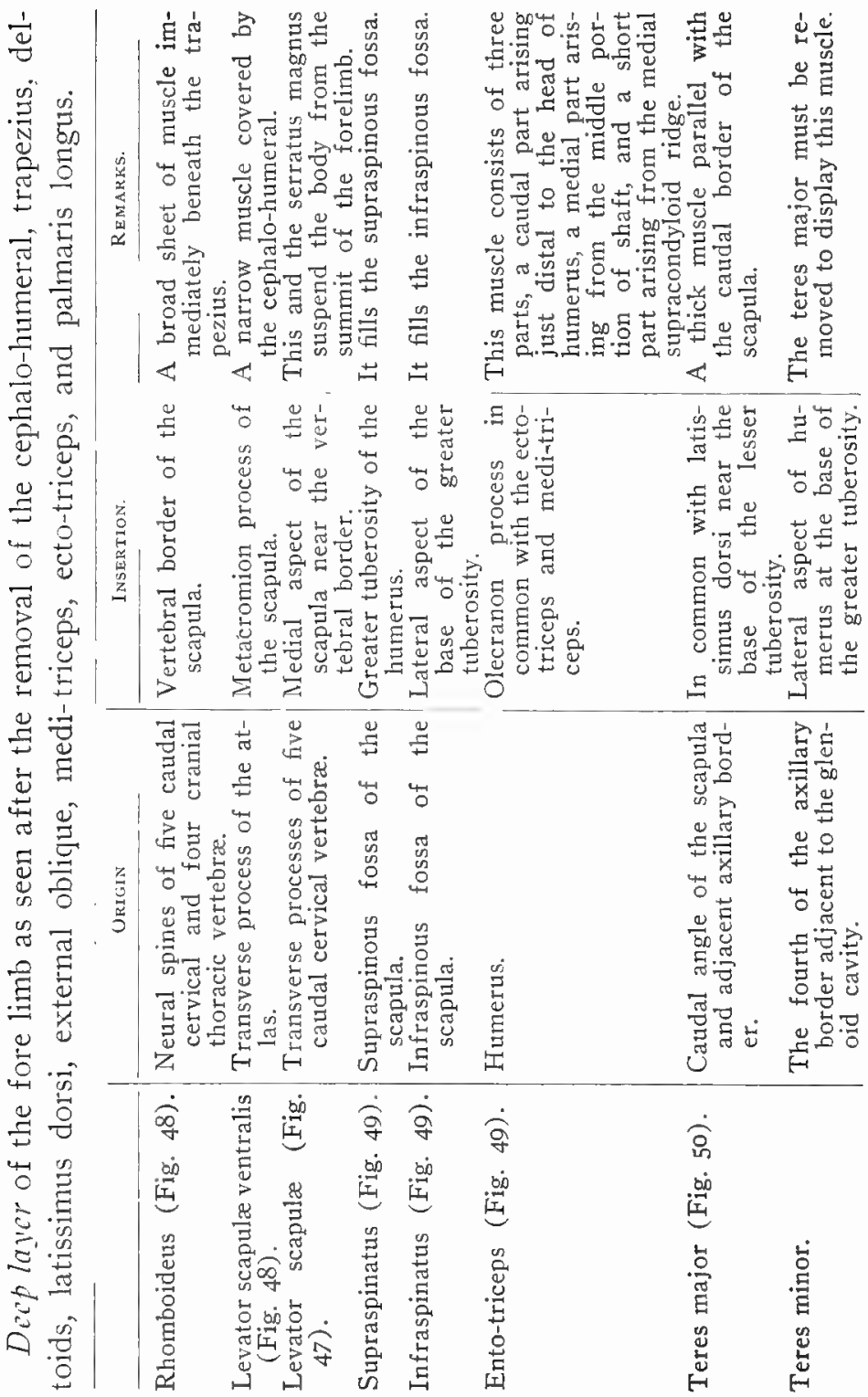




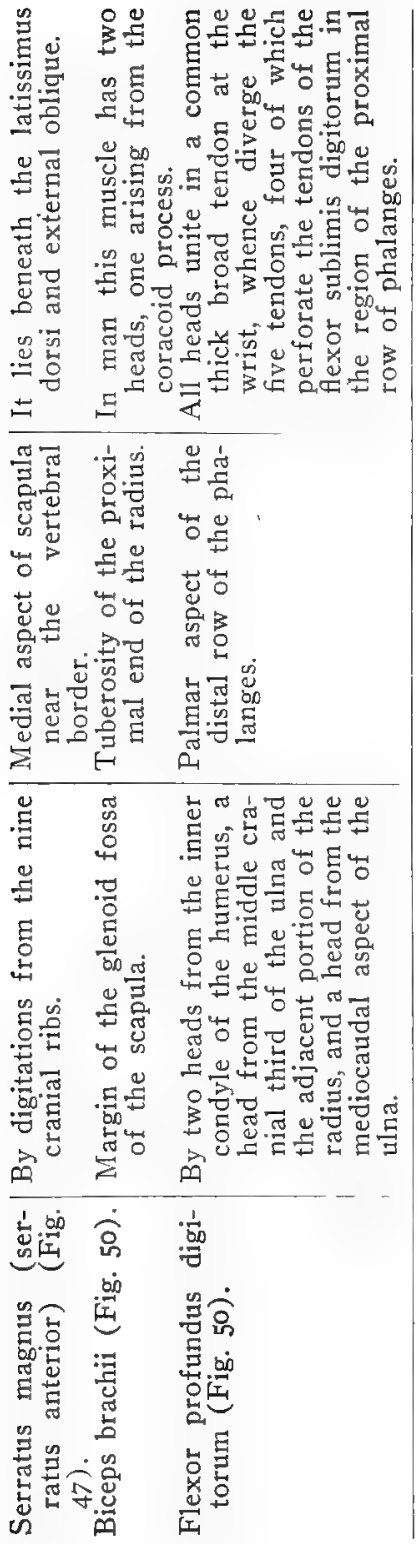




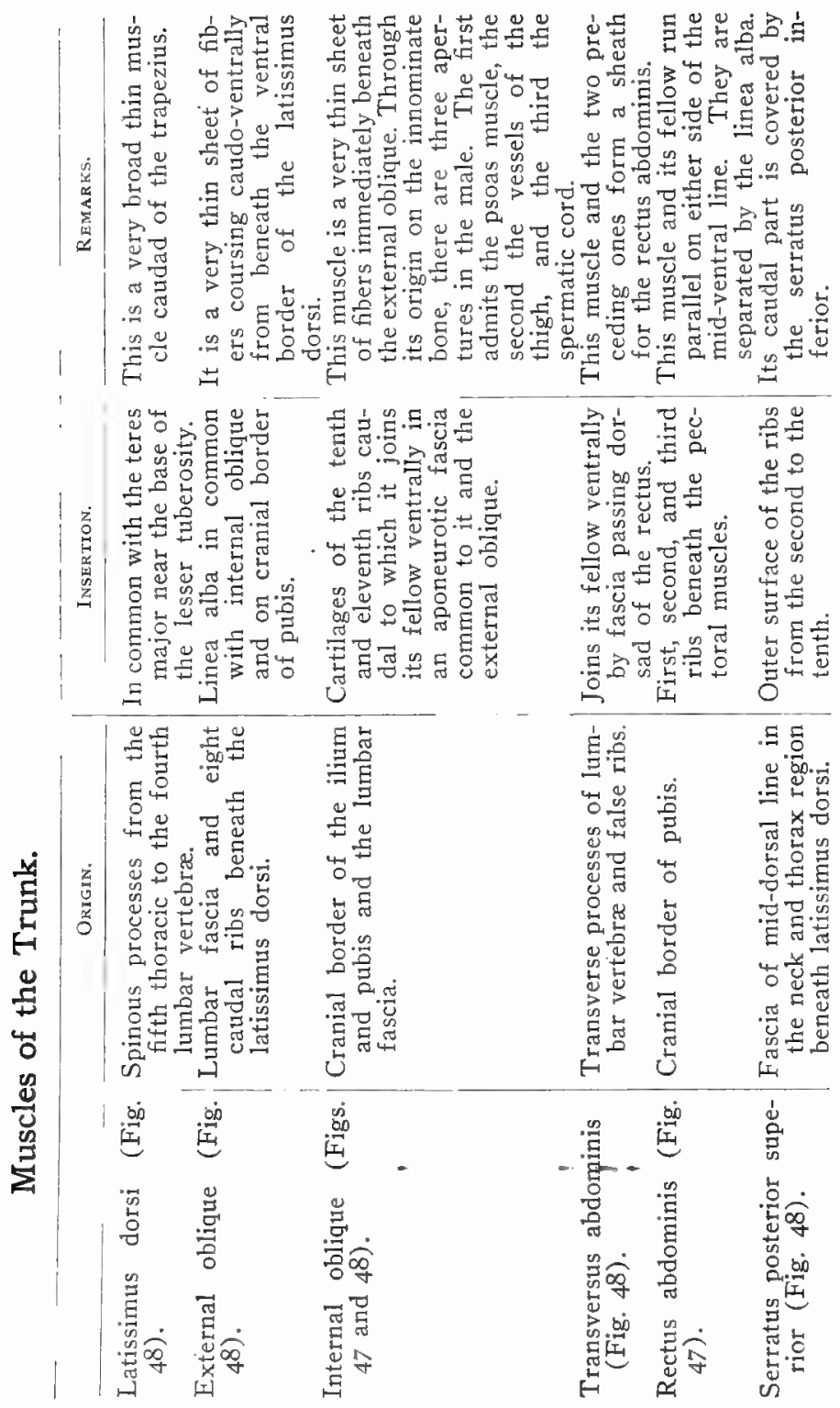




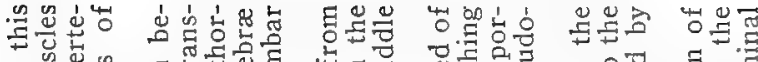

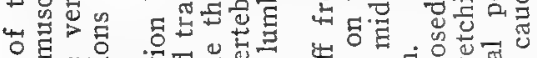
म

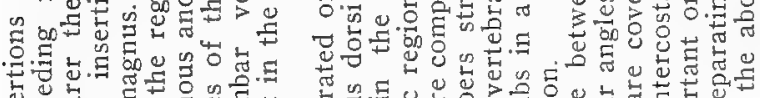

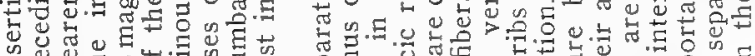
. न .

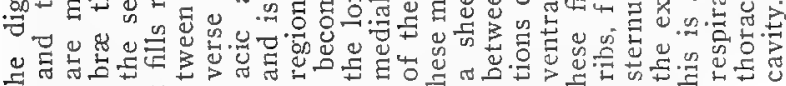
F

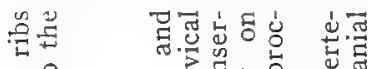

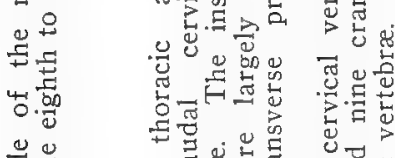

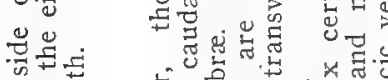
म हूँ

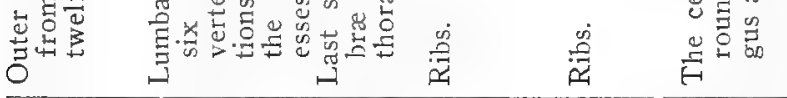

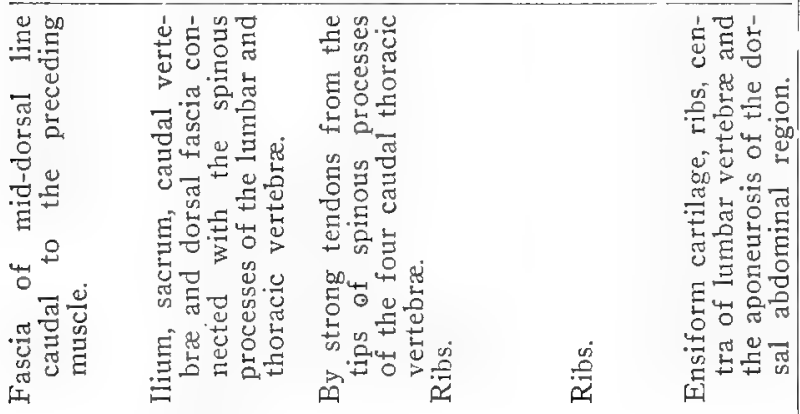

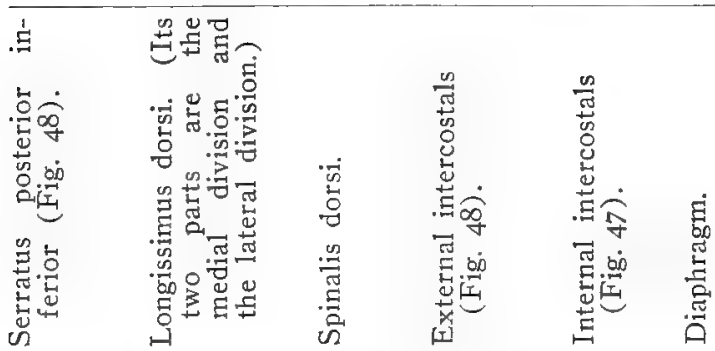


ELEMENTS OF MAMMALIAN ANATOMY.

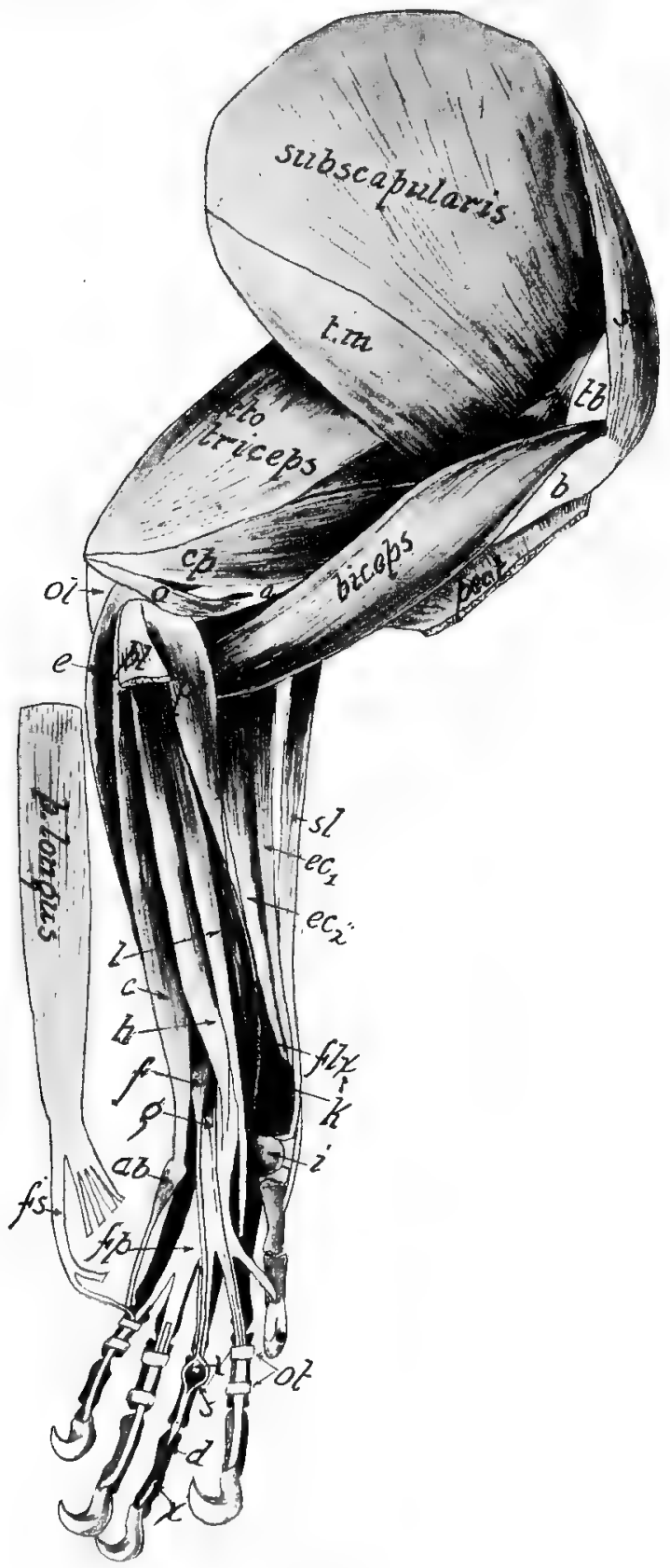

FIG. 50 . 
Fig. 50. Mediat or Inner Aspect of the Muscles of the Forelimb.

$a$, Supracondyloid ridge of humerus; $a b$, abductor pollicis; $b$, humerus ; $c$, humeral head of the flexor carpi ulnaris; $c p$, ento-triceps; $d$, insertion of a tendon of flexor sublimis digitorum; $e$, ulnar head of flexor carpi ulnaris; $e c_{1}$, extensor carpi radialis longior; $e c_{2}$, extensor carpi radialis brevior; $f$, portion of the flexor sublimis digitorum arising from the flexor profundus digitorum; $f s$, the portion of the flexor sublimis arising from the palmaris longus; $f p$, common tendon of the flexor profundus digitorum; $f x$, flexor profundus digitorum; $h$, flexor profundus digitorum; $k$, pronator quadratus; $l$, flexor carpi radialis; $o$, short part of the ento-triceps; $o l$, olecranon process; ot, tendinous loops; pect, pectoralis cut off; $p l$, origin of the palmaris longus which is reflected caudad; $p t$, pronator teres; $r$, ento-triceps; ro, coracobrachialis; $s$, split in the tendon of the flexor sublimis revealed by cutting a way the tendinous loop; ss, supraspinatus; $s l$, supinator longus; $t m$, teres major; $t b$, the head of the humerus; $x$, a tendon of the flexor profundus digitorum whose portion between the two letters is cut out to display the insertion of $d$. ("Ecto-triceps" in figure should be "meditriceps.") 


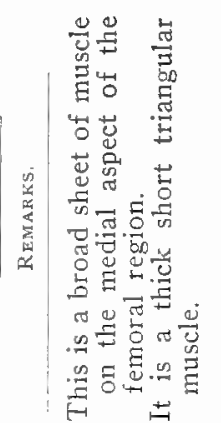

号总 藏

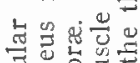

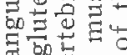

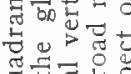

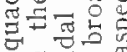
ज过氙

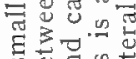

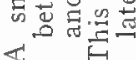

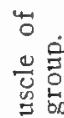

㶾 空焉 跑 突悬 竞 ....... 㴔 $\bar{A}^{+}$

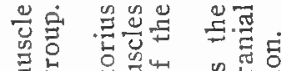

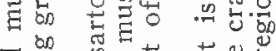

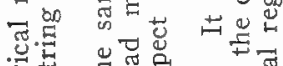

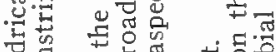
. 䲿

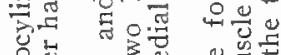

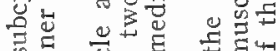
ज.

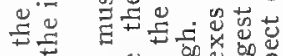
. n w 出

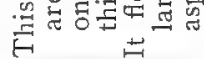

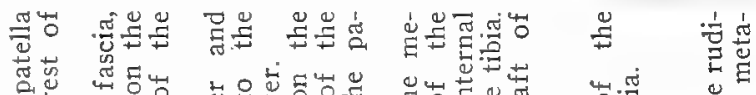

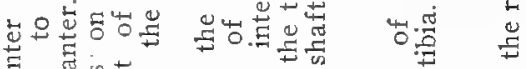

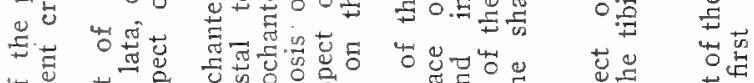

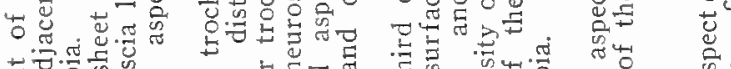

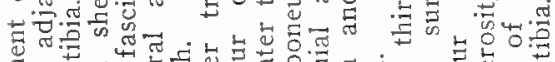

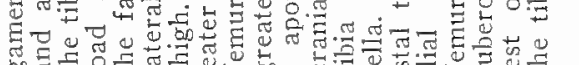

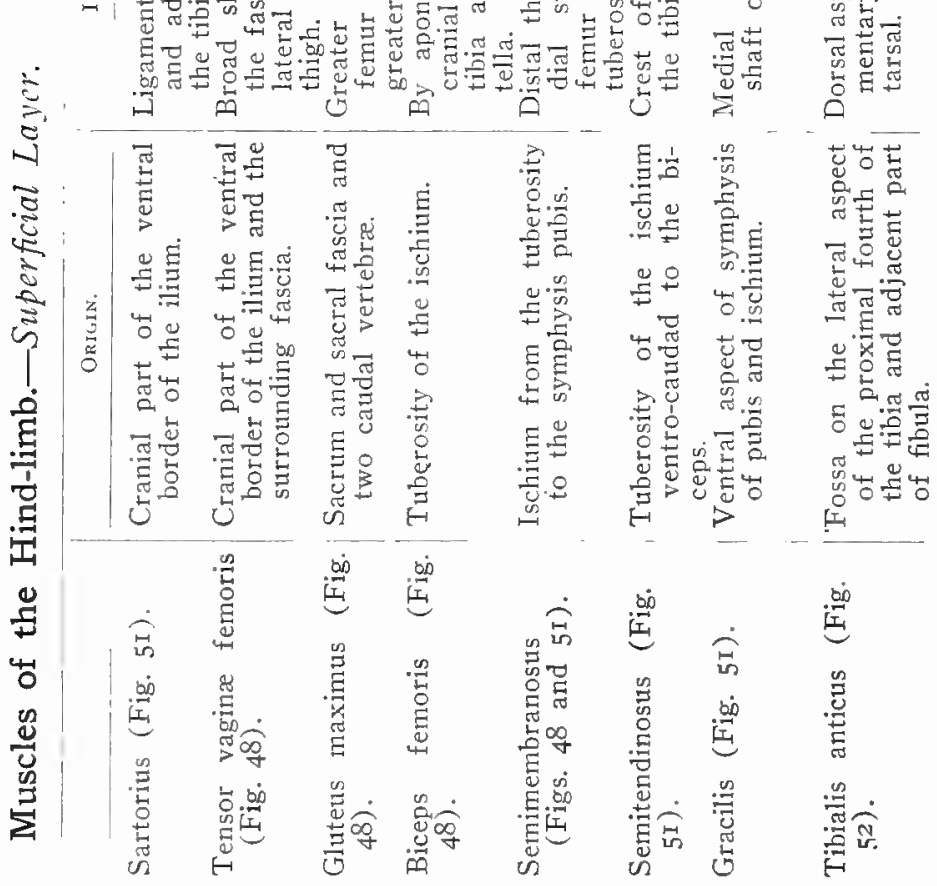




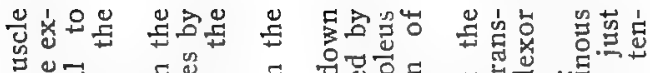

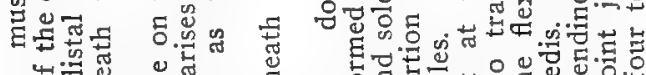

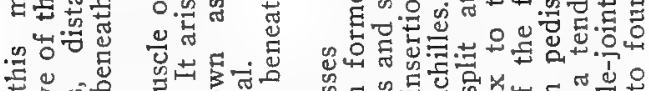

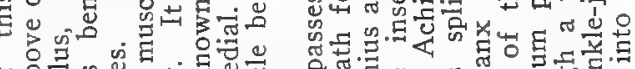

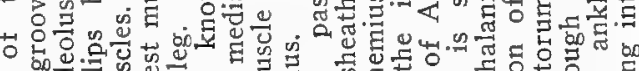

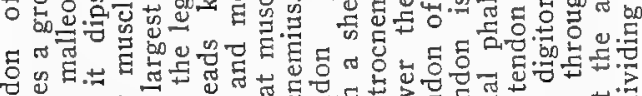

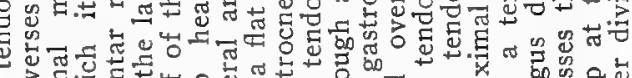

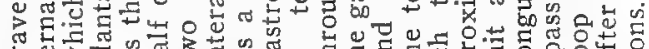

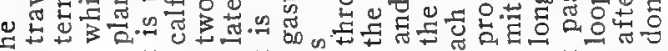
E

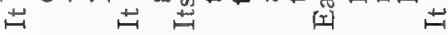

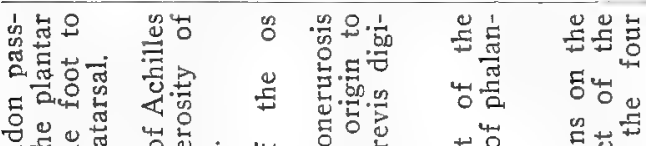

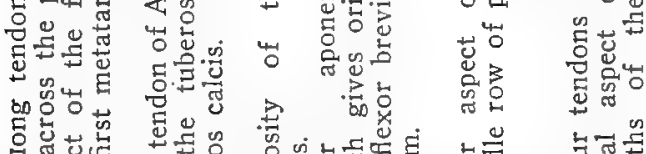

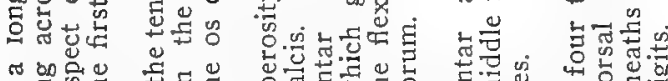
๙ म.

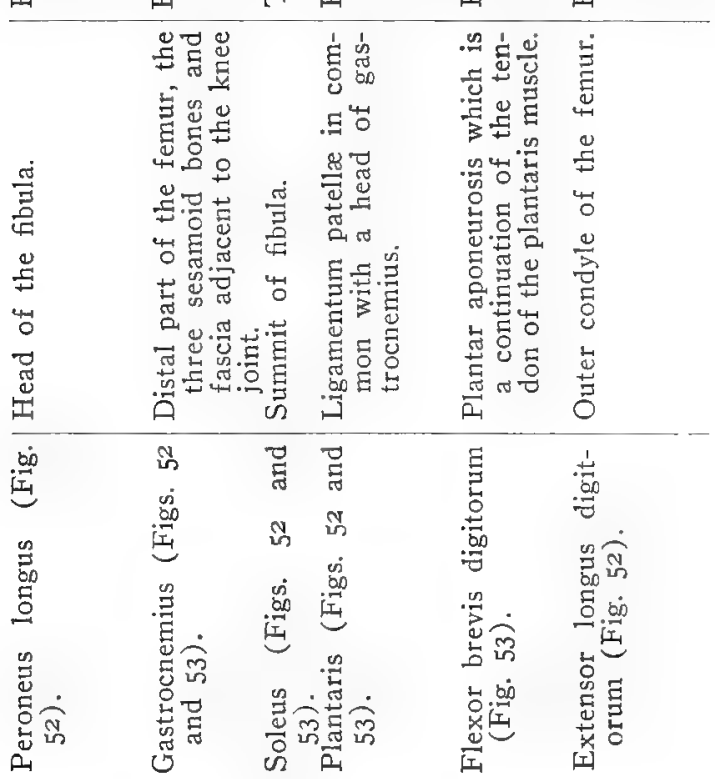




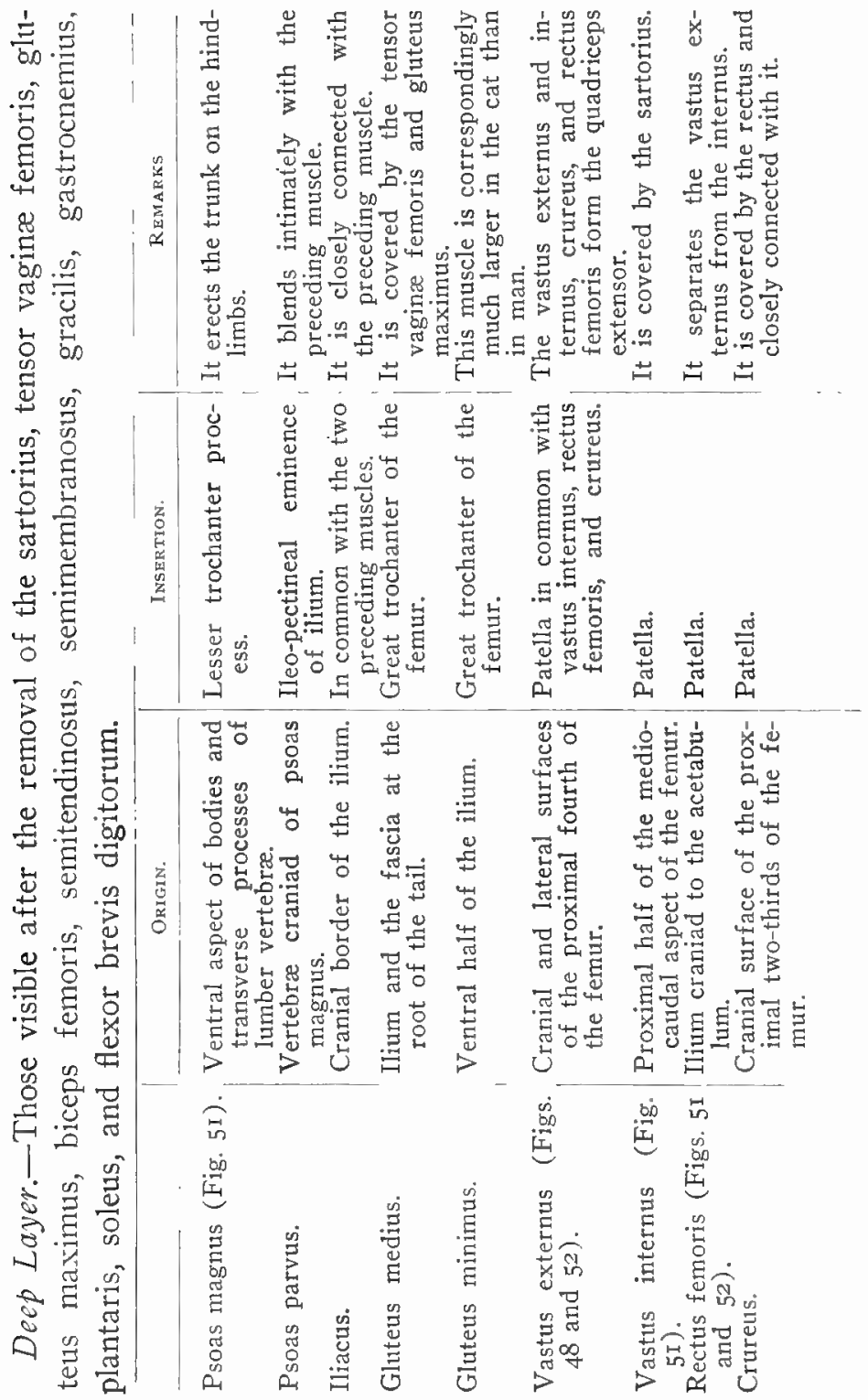




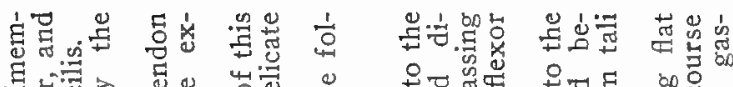

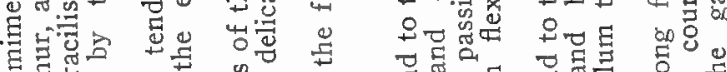

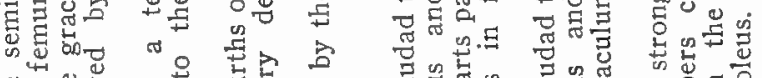
至至焉

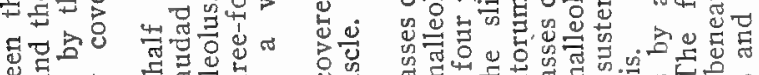

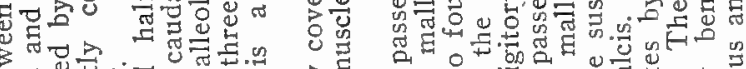

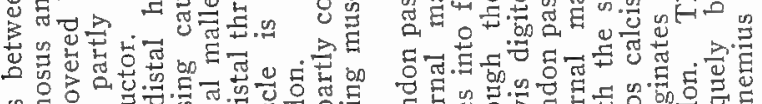

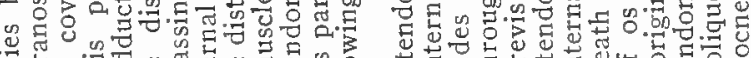

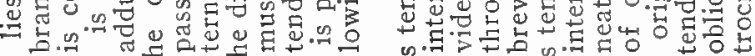

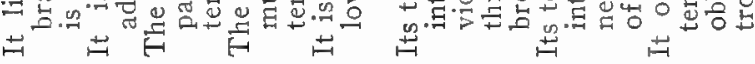

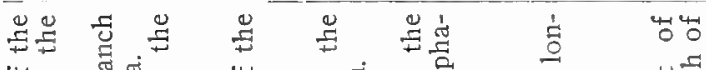

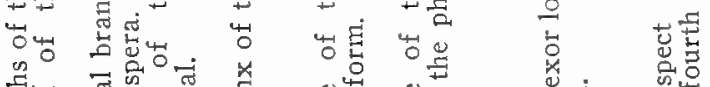

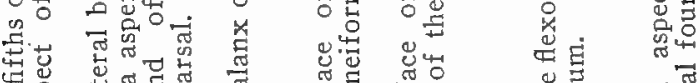

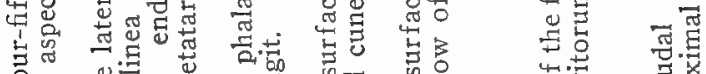

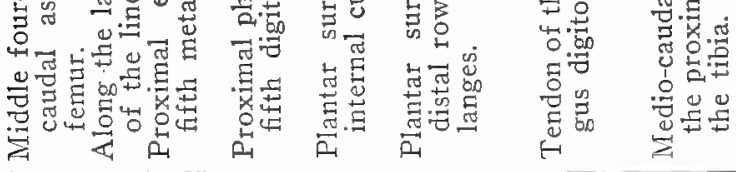

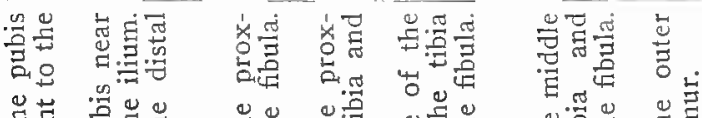

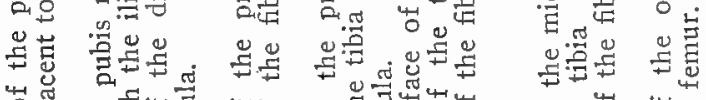
出㦹

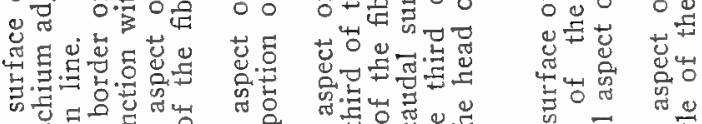

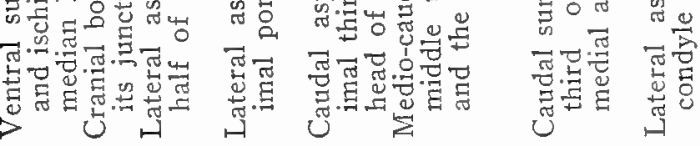

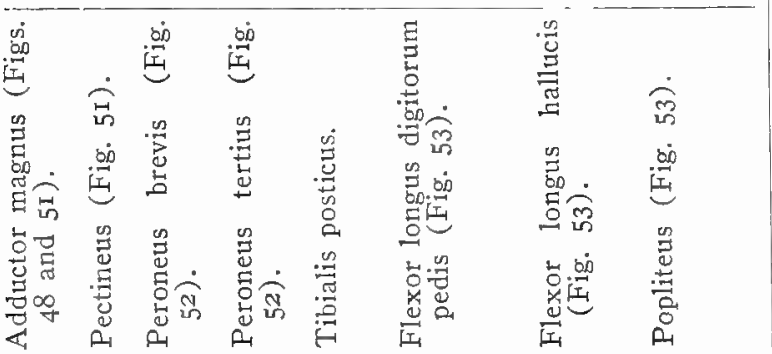


Fig. 5I. Ventral Aspect of Muscles of Caudal Portion of Trunk AND THIGH.

$a$, Transversalis abdominis becoming aponeurotic; adct, adductor magnus; $c$, pectineus; $e x . o b$, external oblique, whose aponeurosis on the left side is removed; $f$, aponeurosis of external oblique; grc, gracilis with its middle part cut out on the left side; $m$, median ventral line; $p s$, psoas magnus; $p$, penis; $r c f$, rectus femoris; rct, rectus abdominis; sar, sartorius with its middle part cut out on the left side; smb, semimembranosus; smt, semitendinosus; spmc, spermatic cord; $t$, aponeurosis; trs, internal oblique with a rectangular piece cut out to show the rectus and transversalis; tvg, tensor vaginæ femoris; $t s$, testicle; $v i$, vastus internus; $x$, external abdominal ring.

Fig. 52. Lateral Aspect of the Muscles of the Leg with the Glutei, Tensor Vagine Femoris, Semitendinosus, and Biceps FEMORIS REMOVED.

$a$, Portion of semimembranosus; $a b$, adductor magnus; $b$, peroneus tertius; $c$, abductor ossis metatarsi ; $c t$, cut surface of the vastus externus; $d$, peroneus brevis; eld, extensor longus digitorum; gas, gastrocnemius; $l$, tendinous loop; $l p$, annular ligament; $l$, external lateral ligament of the knee-joint; $l g$, tendon of the extensor longus digitorum; 0 , tendinous arch of the peroneus longus; oc, os calcis; $p l$, peroneus longus; $r c t$, rectus femoris; $t$, ligamentum patellæ; $t r$, greater trochanter; $t s$, soleus; $t g$, tendon of gastrocremius; $t p l$, tendon of the plantaris; $t b$, tibialis anticus; vex, vastus externus with a piece cut out. 


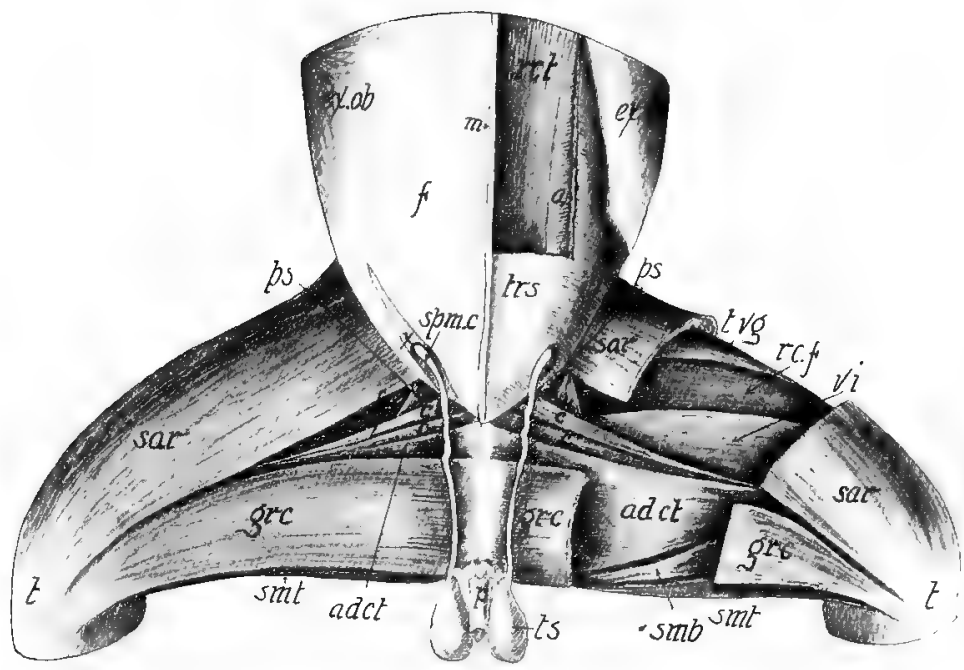

FIG. 5I.

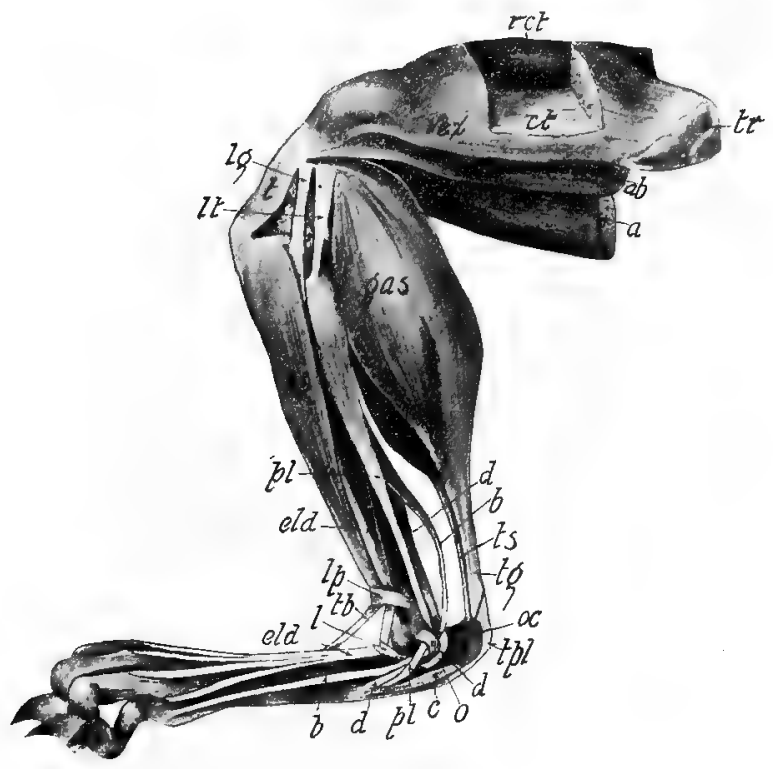

FIG. 52. 
The muscles in the different orders of mammals have the same general arrangement. Over four hundred muscles occurring in the cat are found in man and have approximately the same relative location and function, and the

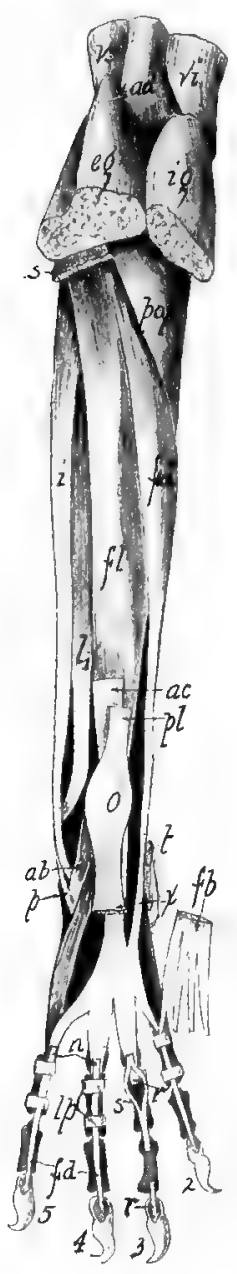
same nerve-supply. The size and the shape of the muscles may vary somewhat in accordance with the habits of the animal. The pectoralis in the cat consists of five parts, while in man there are only two parts. The biceps is a simple muscle in the cat, but in man it has two well defined heads. The muscles for moving the ear, which are well developed in the horse, cow, and cat, are exceedingly rudimentary in man. The Cetacea and Sirenia possess fewer muscles than the other orders of mammals, as they have no hind-limbs. These few remarks serve to show that a familiarity with the muscles

Fig. 53. Caudal Aspect of the Muscles of the Crus and Foot with the Gastrocnemius, Soleus, and Plantaris Removed.

$a d$, Adductor; $a c$, tendon of Achilles; $a b$, abductor ossis metatarsi; eg, external head of gastrocnemius; $f b$, flexor brevis digitorum cut at $x$ and turned aside; $f d$, flexor longus digitorum, $f$, flexor longus hallucis; $i$, peroneus longus; $l$, peroneus brevis; lp, tendinous loop through which pass the tendons of the flexor brevis digitorum and the flexor longus digitorum; $n$, cut tendons of $f b ; o$, plantaris over the tuberosity of the os calcis; $p$, tendon of the peroneus brevis; $p l$, tendon of the plantaris, whose proximal portion is cut away; $r$, tendon of the flexor longus digitorum pedis cut off as it passes through the slit in the flexor brevis digitorum; $s$, tendon of the flexor brevis digitorum split for the transmission of the tendon of the flexor longus digitorum pedis; so, soleus; $t$, tendon of the flexor longus hallucis; $x$, plantaris giving origin to the flexor brevis digitorum. 
of any one mammal guarantees a general knowledge of the muscular system of all mammals.

\section{PRACTICAL QUESTIONS AND SUGGESTIONS.}

I. Describe the two kinds of muscles.

2. Draw a diagrammatic cross-section of the palmaris longus muscle representing the relation of the fibers, fasciculi, sarcolemma, endomysium, and epimysium.

3. Describe an example of each class of muscles as to function.

4. Which muscles of the head and neck region derive their names from their function?

5. Describe the chief muscles moving the mandible.

6. Describe the muscles lying ventral to the trachea.

7. Name three important muscles attaching the thoracic limb to the trunk.

8. Draw the caudal aspect of the triceps muscle.

9. What muscles flex the forearm on the arm?

Io. Name the chief extensors and flexors of the digits.

II. On what process of the humerus do several of the flexors of the manus arise?

12. On what process of the humerus do most of the extensors of the manus arise?

I3. Draw the outline of the ventral aspect of the flexor profundus digitorum as it would appear detached from limb and with origins slightly separated.

I4. Draw cranial aspect of the radius and mark the areas to which the muscles are attached and the names of the same.

I5. What muscles flex the manus on the forearm?

r6. Describe the muscles extending the manus on the forearm.

17. What muscles in the forearm region derive their names from their function and location?

I8. Describe the large adductor of the thoracic limb. tions.

19. Describe the muscles serving to move the humerus in four direc-

20. Describe the location and the use of the tendinous loops in the manus.

2I. What muscles form the ventral and lateral walls of the abdomen?

22. Describe from your dissection four muscles causing the movement of the ribs.

23. After removing the biceps femoris and sartoritus, and dissecting the muscles on the lateral aspect of the thigh, draw the muscles visible on the lateral aspect, and label.

24. Name the muscles flexing the crus on the thigh. 
25. Describe from your dissection the muscles extending the crus on the thigh.

26. Describe the muscles forming the calf of the leg.

27. What muscles are the opponents of the adductor magnus?

28. Draw the plantar aspect of pes showing the superficial muscles, and label all the features.

29. Describe three muscles moving the digits.

30. Show by drawing the location of the muscles flexing the pes on the tibia and label all the features. 


\section{ORGANS OF DIGESTION.}

A young lean cat which has had no food for twenty-four hours is the best subject for the demonstration of the digestive system. Directions for preparing the specimen are given in the chapter on technique.

The digestive system (Figs. 55 and $5^{6}$ ) consists of the alimentary canal and the accessory glands of digestion.

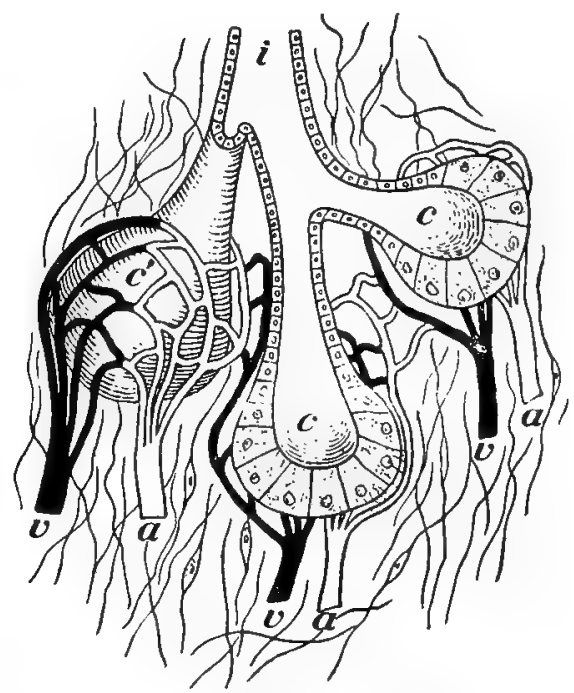

Fig. 54. Diagram of a Gland.

$a$, artery; $v$, vein; $c^{\prime}$, part of gland covered with capillaries; $c$, an acinus like $c^{\prime}$, cut open; $i$, duct.

The canal is made up of the mouth, pharynx, esophagus, stomach, small intestine, and large intestine. Its entire length is about five times that of the cat from the tip of the nose to the root of the tail. The accessory glands consist of five pairs of salivary glands, the liver, and the pancreas. 


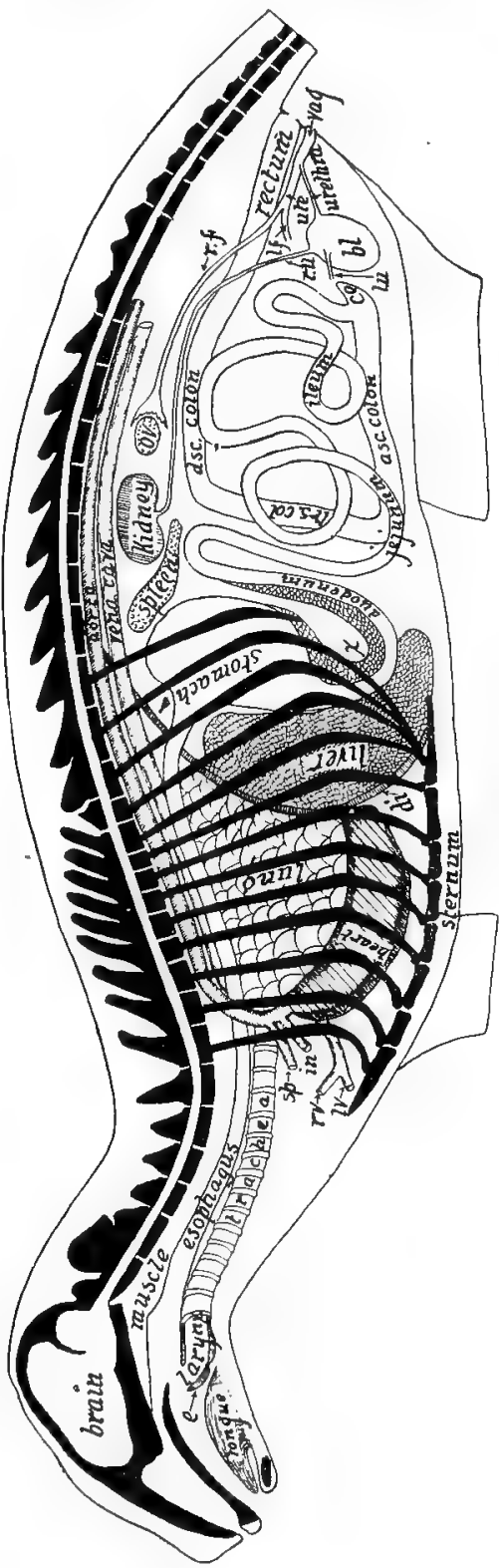

苟. 붕

$\rightarrow>$

乏ีษ

in.

อำ

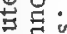

.

ज氮

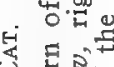

उ

불

$*$ 岕宫

동

$+5$

品

\& 30

近证司

๒

范前

บ

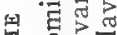

昰

约 .92

z. .5

$0 .+\infty$

4 is 0

एण

웅…

(i)

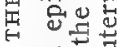

I 0

때욤

. 50

뚱ㅇำ

라

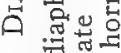

เ่

मे

I

E...

总跑

-

¿ล

…

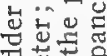

可证

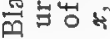

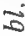


A gland is a tiny tube or collection of branching tubes which remove certain materials from the blood and manufacture them into a fluid useful to the body.

\section{THE MOUTH.}

The motth is bounded craniad by the lips, laterally by the cheeks, and dorsally by the palate, where the mucous membrane lies in seven or eight transverse ridges or rugæ, and caudally depends from the palatine bones forming the velum palati. To display the anatomy of the mouth, one should remove the right half of the mandible. From either side of the velum palati two folds of membrane diverge as they extend to the floor of the mouth at the root of the tongue. The cranial fold is the anterior pillar and the caudal one is the posterior pillar of the fauces (Fig. 56). The caudal portion of the mouth between these folds is known as the fauces. It opens into the pharynx. On either sicle of the tongue between the two pillars is a crescentic depression holding a tonsil. In man, the tonsils sometimes become inflamed an 1 enlarged, giving rise to a disease called tonsilitis. The tonsil is a compound lymphatic gland whose function is unknown.

Folds of mucous membrane calleciefrena bind the lips to the gums which are composed of derse fibrous tissue investing the alveolar margins of the jaw-inones. The mucous lining of the mouth contains many simple mucous glands invisible to the naked eye. Those of the lips are called labial, of the cheeks, buccal, and of the palate, palatine glands.

The tongue lying in the floor of the mouth is a muscular mass composed of the geniohyoglossus, lingualis superficialis superior and inferior, styloglossus, and hyoglossus muscles. Caudally it is attached to the hyoid bone. Its invest- 
ment of mucous membrane is formed into a fold beneath it, called the frenum linguce. The dorsal surface of the

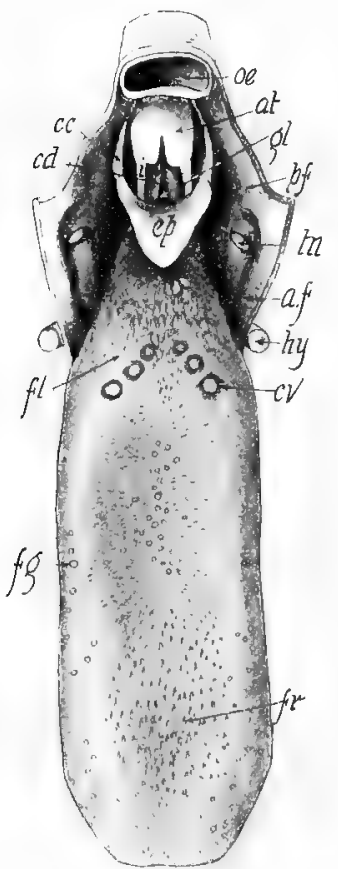

Fig. 56. DORSAL ASPECT G THE Tongue and Lary

at, Arytenoid cartilage; $a \boldsymbol{F}$, anterior pillar of the fouces; cc, crico-cpiglottic li tment; $c d$, true vocal cords; $c$, circumvallate papilla; ep, epiglottis; $f$, flat papilla; $f g$, fungiform papilla; $f r$, filiform papilla; $g l$, glottis; $h y$, epihyal bone cut off; $i$, false vocal cord; $\propto$, lumen of the esophagus, which is cut off just as it opens into the pharynx; pf, posterior pillar of the fauces; $t n$, tonsil. tongue displays four kinds of papillæ (Fig. 56) : The circumvallate, numbering from six to eight arranged in a $\mathrm{V}$ shape near the root; the flat, very numerous at the root; the conical, most numerous and thickly set over the entire dorsal aspect; and the fungiform, which are blunt and located more thickly on the sides and near the tip of the tongue (Fig. 56).

The Teeth.-During the first year the cat develops twenty-six teeth, known as the deciduous or temporary set, as they are later replaced by a crmanent set. The three parts of a tooth are the crown, neck, and fang (Fig. 58). The crown may be divided into several portions called cusps. A tooth split longitudinally presents the following four features (Fig. 57) : the enamel, a hard glistening substance covering the entire crown of the tooth down to the neck; the cement, a bony substance investing the fang; the dcntine, forming the interior hard portion of the torth; and the pulp cavity, containing in the 
recent state the nerve- and blood-vessels. The enamel consists mostly of the phosphate of lime. It is the covering which when broken permits the tooth to decay.

In an adult cat there are in each half of the upper jaw three incisors, one canine, three premolars, and one molar (Fig. 58). In each half of the lower jaw there are three incisors, one canine, two premolars, and one molar. The permanent dentition of the cat is therefore expressed by the formula i $3 / 3$, c $1 / 1$, pm $3 / 2, \mathrm{~m} 1 / 1$.

The upper incisor teeth are small and undivided both as to root and crown. They are scarcely one-third as long as the canine and are planted in the alveoli or sockets of the premaxillary. The remaining teeth of this jaw are in

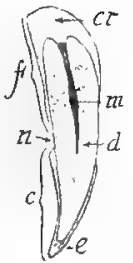

FIG. 57. LoNGITUDINAL Section of the Canine Tooth. $c$, Crown : $c r$, cement; $d$, dentine; $e$, enamel; $f$, fang; $m$, pulp-cavity; $n$, neck. the maxilla. The canine or eye tooth is the longest and likewise is undivided as to root and crown. The next three teeth are known as the premolars. They vary much in size. The anterior one is the smallest, being about the size of the incisors. Its crown is usually simple, although occasionally there is seen a small posterior cusp, called triticone, in distinction to the main cusp or protocone. The root is usually composed of only one fang. The second premolar is much larger than the first. Its crown presents a large median cusp, or protocone; a very small cusp, triticone, on the posterior side of the protocone half-way between its base and apex; and a basal cusp, the talon, on the posterior side of the base of the tooth. The prominent ridge encircling the tooth at its base is the cingulum. The root is composed of two fangs.

The third premolar or carnassial tooth is fully twice as large as the second premolar. Its protocone is the large 
central cusp, posterior to which is the large triticone. At the medial anterior angle is the deuterocone. The small projection at the lateral anterior angle is the protostyle.

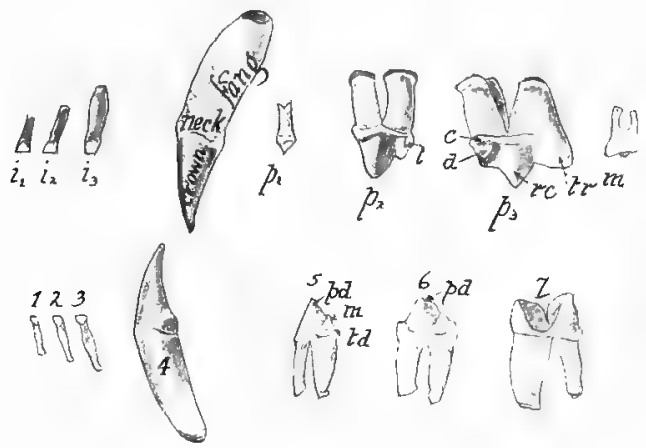

Fig. 58. Lateral Aspect of the Permanent Dentition of the Cat. $i_{1}, i_{2}, i_{3}$, First, second, and third incisors of the upper jaw; $c$, canine; $p_{1}$, $p_{2}$, and $p_{3}$, first, second, and third premolars; $m$, molar; $1,2,3$, the incisors of the lower jaw; 4 , canine; 5 and 6 first and second premolars; 7 , molar ; $c$, cingulum; $d$, deuterocone; $m$, metaconid; $m$, molar; $p t$, protoconid; $r c$, protocone; $t d$, talonid; $t$, talon; $t r$, triticone.

The root of the tooth usually consists of three fangs. The posterior tooth in the maxilla is called the molar, since it is the only one not preceded by a milk tooth. It is very small and its crown presents a grinding surface instead of a cutting one. Its root consists of two fangs.

Each half of the mandible holds three incisors, one canine, two premolars, and one molar. The incisors and canine are so similar to the upper ones that they need no further description. The first premolar presents a principal cusp or protoconid, a lower small cusp or metaconid, and a projection, on the posterior side of the base, known as the talonid. A cingulum or encircling ridge is also present at the base of the tooth. The root consists of two fangs.

The second premolar is very similar to the first except 
that it is larger and presents an anterior basal cusp in addition to the others. The lower molar, sometimes called the sectorial, because it shears against the upper sectorial or carnassial premolar, presents two nearly equal cusps, the protoconid and the paraconid. The root consists of two fangs, the anterior of which is the larger.

The deciduous or milk teeth begin to appear above the gums when the kitten is two weeks old. The incisors and the canine appear first, then the second and third molars. The first upper molars do not appear till the kitten is about six weeks old. According to Jayne, the deciduous dentition is complete at the end of the second month. At the end of the fourth month the milk incisors are being displaced by the permanent teeth. The formula for the temporary set is $\mathrm{di} 3 / 3, \mathrm{dc} 1 / 1, \mathrm{dm} 3 / 2$.

Teeth are present in nearly all adult mammals. The whalebone whales, the duck-bill, and some of the ant-eaters have no teeth in the adult state, but teeth are present during their embryonic life. The Echidna shows no evidence of teeth at any time. Most mammals have two distinct sets of teeth, known as the milk or deciduous set, and the permanent set. In the Marsupialia, "the milk dentition is in a degenerate condition. The milk teeth are present, but none become sufficiently developed to appear above the gums, except the last premolar, and in some cases the canine and the incisors. The sloths have only one set of teeth and are therefore Monophydont. Mammals having both a milk and a permanent set are termed Diphydont.

In the majority of mammals the teeth are divided according to form and function into four groups: incisors, canines, premolars, and molars. Such a dentition is known as Heterodont, in distinction to the Homodont dentition, in which all the teeth have the same form, as is the case in the dolphins. In mammals with a heterodont dentition the 
number of teeth in the different genera varies considerably, as seen by the following formula:

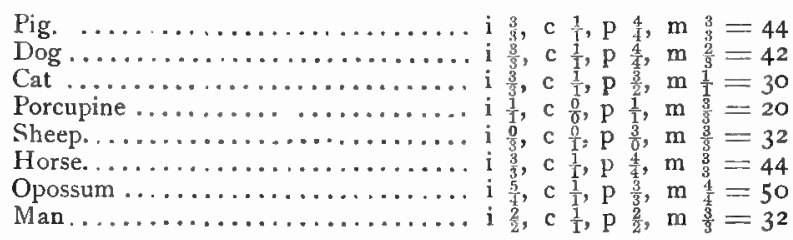

The elephant presents a very specialized dentition. It has no canines nor any lower incisors. The single pair of upper incisors is developed into long tusks, much prized for ivory. They continue to grow throughout the entire life of the animal. Six molars are present on each side, only one or two of which are functional at once. The posterior ones move forward to take the place of the anterior as these become worn out. The tusks of the walrus are its canines greatly developed. None of the typical modern Ruminants have upper incisors in the adult state, though they are present in the embryo. Palæontology has demonstrated that the ancestors of the Ruminants had well-developed upper incisors in the later Eocene times. The occurrence of the rudimentary upper incisors in the embryo furnishes evidence of a full dentition in the ancestors of the ruminants, since the individual embryological history is somewhat of a recapitulation of the ancestral history of the race.

\section{THE PHARYNX.}

The pharynx is that portion of the alimentary canal between the mouth and the esophagus. The structure is well shown by making a sagittal section through the head and neck. This is best done with a saw, after the specimen is frozen by placing it out-of-doors during one or two days of cold winter weather. 
There are seven openings into the pharynx: the two posterior nares (Fig. I8), opening anteriorly from the roof; a Eustachian tube on each side; the esophagus; and the laryn $x^{-}$leading into the trachea. The mucous membrane lining the pharynx contains many simple microscopic mucous glands.

\section{VISCERA.}

The body cavity known as the colom must be opened before the rest of the alimentary canal can be displayed. The entire ventral wall of the thoracic and abdominal cavi-

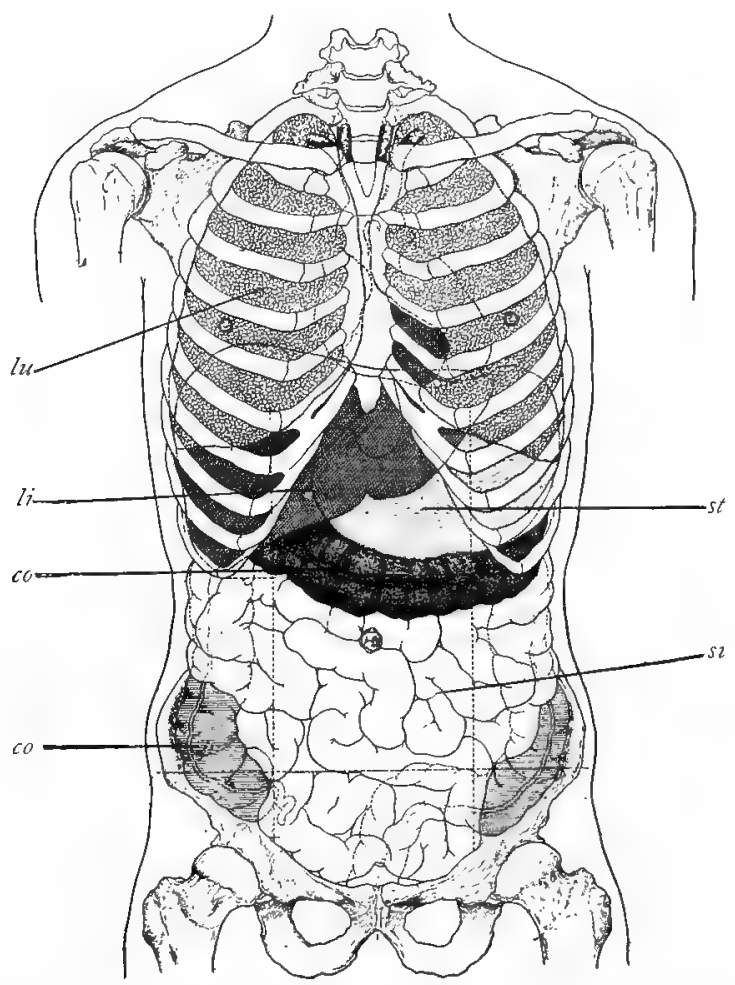

Fig. 59. Viscera of the Human Body.-(Deaver.) co, Colon; $l i$, liver; lu, lung; si, small intestine; st, stomach. 
ties should be cut away with the bone forceps and scalpel. The body cavity is divided into two parts by the diaphragm (Fig. 55). The cranial portion, the thoracic cavity, contains the esophagus, heart, blood-vessels, thoracic duct, trachea, and lungs. In the young cat there is present also the thymus gland, stretching craniad several centimeters from the base of the heart. The transparent membrane lining this cavity and investing the lungs is the pleura.

The caudal part of the colom is the abdominal cavity containing the abdominal viscera, which are here briefly described. The liver, a large brownish-red organ, is adjacent to the diaphragm on the right side, while the stomach (Fig. 55) lies close to the diaphragm on the left. The spleen is the dark red, flat, elongated organ caudad of the stomach on the left side. The sheet of thin transparent tissue more or less laden with fat, depending from the stomach and covering the intestines like an apron, is the greater omentum. It is a portion of the peritoneum which lines the abdominal cavity and invests most of the organs therein. The pancrcas is a pinkish elongate body, bent at a right angle near its middle, so that one portion lies in the bend of the duodenum and the other dorsal to the stomach. The kidncy's may be recognized by their well-known shape and dorsal location in the cranial lumbar region. The ovaries are small pinkish bodies lying near the kidneys, adjacent to the dorsal abdominal wall. The uterus is easily known by its two horns extending caudad from the ovaries to their junction at the body of the uterus. The bladder, if full of urine, is at once recognized; and if empty, appears as a small hard pear-shaped mass ventrad to the rectum (Fig. 55).

\section{ESOPHAGUS.}

The esophagus or gullet is that portion of the alimentary canal leading from the pharynx to the stomach. In the 
thoracic cavity it lies dorsal to the heart (Fig. 55) by the side of the aorta. Immediately caudad of the diaphragm it opens into the cardiac end of the stomach (Fig. 60).

\section{STOMACH.}

The stomach is that dilated portion of the canal lying immediately caudad of the diaphragm on the left side. The esophageal end of the stomach is known as the cardiac portion, and the intestinal end is the pyloric portion (Fig. 60). Here a circular fold of mucous membrane embraced by a sphincter muscle serves as a valve to open and close the pylorus or gateway to the intestine. The dorsal surface of the stomach is its lesser curvature and the ventral convex surface is its greater curvature. The structure of the walls of the stomach is described below.

\section{INTESTINE.}

The intestine is that much contorted portion of the cana! leading from the stomach to the external aperture or anus. The first portion, the small intestine (Fig. 6o), is about three feet long in a large cat, and is less in diameter and much more convoluted than the second portion, or large intestine.

The small intestine consists of three parts: the duodenum, the jejumum, and the ileum. The duodenum is the first twelve or fifteen centimeters. A duct from the liver and the gall-bladder and two ducts from the pancreas, empty into it. The former is the common bile duct and the latter are the pancreatic ducts. The jejunum is the portion of the small intestine next to the duodenum. It is about twenty-five centimeters long. No special mark indicates its limits. It is so called because that portion of the canal in man is frequently empty after death. The 
ilcum constitutes more than two-thirds of the small intestine, is much convoluted, and extends from the jejunum to the large intestine on the right side of the abdominal

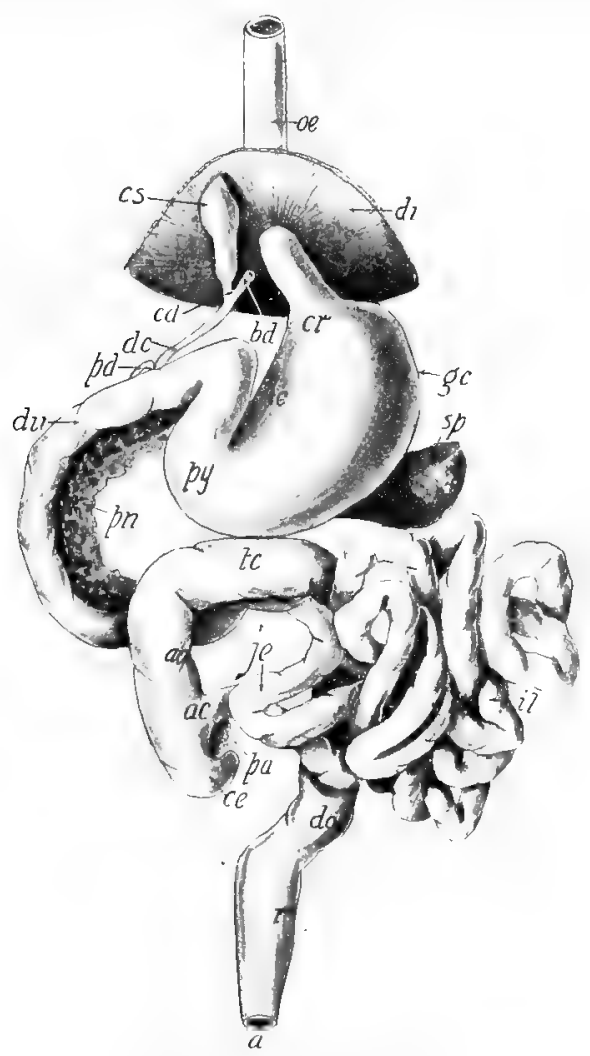

Fig. 6o. Ventral Aspect of the Alimentary Canal with the Ileum Pulled to ONe Side.

$a c$, Small intestine opening into the large intestine; $a$, antus; ao, ascending colon; $b d$, hepatic duct; $c e$, cæcum; $c d$, cystic duct; $c s$, bile-cyst or gall-bladder; $\mathrm{cr}$, cardiac portion of the stomach; di, diaphragm; $d u$, duodenum; do, caudal part of the descending colon; $d c$, common bile duct; $g \mathcal{c}$, greater curvature of the stomach; $i l$, ileum; $j e, j e j u n u m ; ~ l c$, lesser curvature of the stomach; $\alpha$, esophagus; $p n$, pancreas; $p y, p y l o r i c$ portion; $p a$, mesenteric gland; $p d$, pancreatic duct; $r$, rectum; $s p$, splecn; $t c$, transverse colon. 
cavity, near the iliac bone. The intestine is supported by the folds of the peritoneum known as the mesenteries.

The large intestine consists of the cacum, colon, and rectum. The cacum is the blind conical projection at the

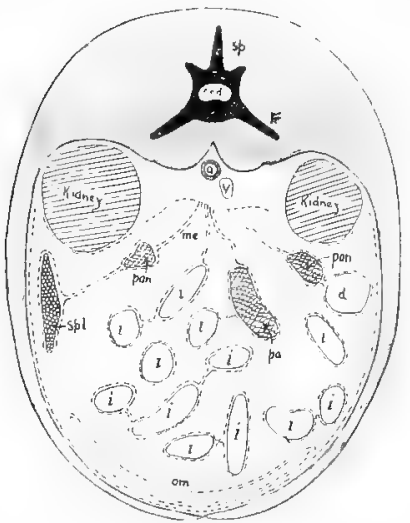

Fig. 6i. Transverse Section of THE CAT.

$i$, Sections of the intestine; $d$, duodenum; $a$, aorta; pan, pancreas; $p a$, pancreas Aselli; spl, spleen; $s p$, spinous process of the lumbar vertebra; $t r$, transverse process; $v$, post-cava or inferior vena cava; om, greater omentum; the broken line is the peritoneum.

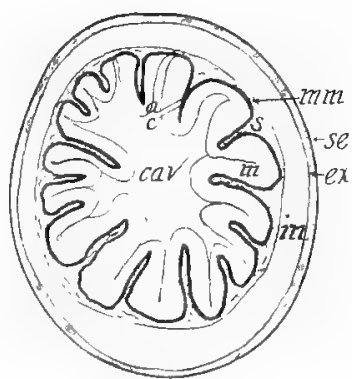

Fig. 62, Cross-section of the Cardiac End of the Stomach. $\times 3$.

cav, Cavity of the stomach; $e x$, external muscular coat; $i n$ in. ternal muscular coat; $m$, mucous coat; mm, muscularis mucosæ; $s$, submucous or are olar coat; se, serous or peritoneal coat.

beginning of the large intestine. It is only one or two centimeters long. There is no vermiform appendix in the cat. The ileum opens into the large intestine at the junction of the crecum and colon. An annular fold of mucous membrane, strengthened by a sphincter muscle, forms the ileocrecal valve, which retains the food in the small intestine until the nutriment is absorbed (Fig. 6o).

The colon, extending from the crecum to the rectum, is composed of the ascending, transverse, and descending parts. The ascending colon lies on the right side; the trans- 
verse extends crosswise, connecting the ascending with the descending, which lies on the left side. The descending

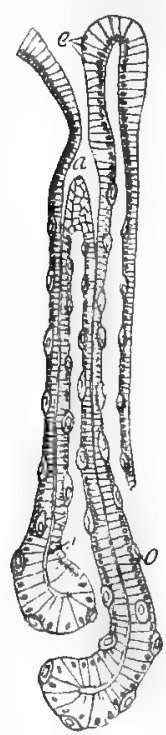

Fig. 63. A CrossSECTION OF THE MUCOUS COAT OF THE STOMACH BETWEEN THE LINES $a$ AND $c$ IN Fitg. 60 sHows a Gastric Gland. $\times 250$. Diagrammatic.

a, Mouth of gastric gland; $e$, columnar epithelial cells on the food surface of the stomach; $l$, lumen of a gland; $o$, uxyntic or acid cell. colon terminates in the rectum, which is five or six centimeters long.

The wall of the alimentary canal is composed of three chief coats-mucous, arcolar, and muscular. These coats may be seen by cutting transversely, with a sharp scalpel, a portion of the stomach hardened in formalin. The mucous coat (Fig. 62) lines the lumen and contains the numerous glands which vary much in the different portions of the canal. The esophagus contains the esophageal glands, whose secretion probably has no other effect on the food than to facilitate its passage. The mucous coat of the stomach contains the gastric glands, which yield pepsin and hydrochloric acid, the chief agents of the gastric digestive fluid (Fig. 63). The glands in the cardiac end of the stomach differ from those in the pyloric end in containing numerous parietal or acid cells which probably secrete the hydrochloric acid for digestion.

The mucous coat of the small intestine contains tube-like glands, the glands of Lieberkühn, whose secretion acts on the sugars. In the duodenum and jejunum the mucous membrane is thrown into numerous transverse folds, valuuli conniventes, which increase the surface for absorption. The villi are minute finger-like processes (Fig. 64), 
barely apparent to the naked eye, projecting into the lumen for the purpose of absorbing the nutriment from the chyle. They consist of a covering of columnar epithelial cells ( Fig. 65 ), within which ends a chyle vessel or lacteal surrounded by small blood-vessels held in place by connective tissue. The fatty portions of the food are carried by the lacteals (Fig. 65b) to the left thoracic duct, and thence to the jugular vein, while other portions of the food are taken up by the capillaries of the portal system, which begin in the villi (Fig. 65). The mucous membrane of the large intestine

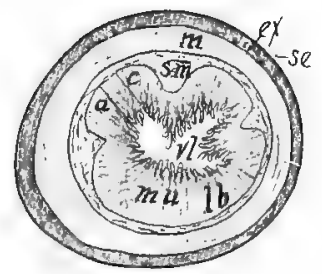

Fig. 64. CROSS-SECTION of the Small IntesTINE. $\times 5$.

$e x$, Longitudinal muscular coat; $m$, circular muscular coat; mu, mucous coat; $l b$, glands of Lieberkühn; se. serous or peritoneal coat; sm, submucous or areolar coat.

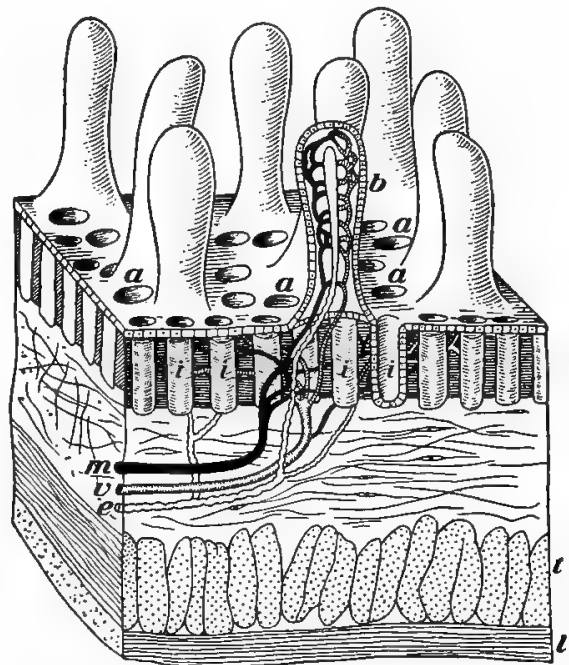

Fig. 65a. Diagram of a Small Cube cut from the Wall of the Jejunum.

$a$, Mouth of intestinal or Lieberkühn's glands; $b$, one of the nine villi cut open showing the network of capillaries and central white lacteal within; $e$, lacteal; $i$, intestinal glands; $m$, artery; $v$, vein; $l$ and $t$, muscular coats.

likewise contains tube-like glands similar to the glands of Lieberkühn, but no villi. 


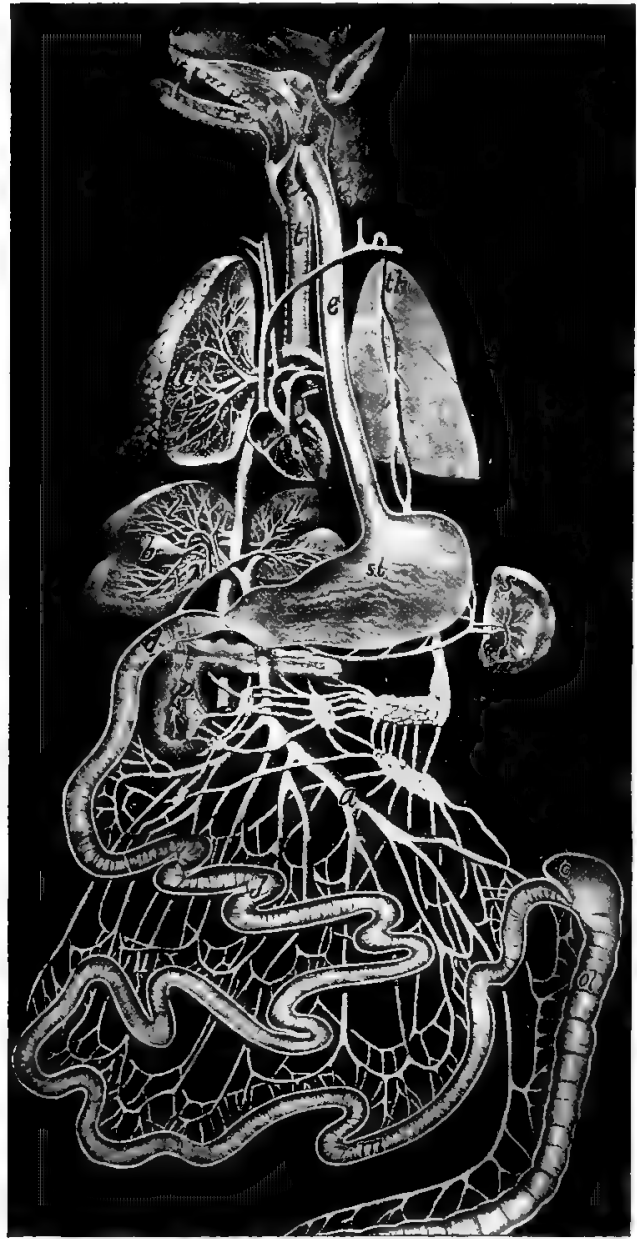

Fig. 65b. Lacteals and Portal System of Dog.

$a$, inferior mesenteric vein; $b$, gall bladder; $c$, cxcum; $d$, duodenum; $e$, esophagus; $i$, parotid gland; $j$, jejunum; $l$, branches of portal vein in liver; $l u$, branches of trachea and pulmonary artery in the lung; $m$, ilium; ol, colon; $p$, pancreas; $s$, spleen; st, stomach; $t h$, thoracic duct into which empty the white tubes, the lacteals. 
The submucous or areolar coat is adjacent to the mucous coat of the intestine, but in the stomach the muscularis mucosæ intervenes. Next to the submucous coat is the muscular coat, composed of two layers, one of circular fibers, the other of longitudinal fibers. An additional layer of oblique fibers is present in the cardiac end of the stomach, which aid in giving that organ the peculiar churning or peristaltic motion necessary for chymification of the food. A fourth coat or serous covering surrounds the muscular coat of the stomach and intestines. It is merely a reflected portion of the peritoneum which lines the entire abdominal cavity.

\section{THE ACCESSORY GLANDS OF DIGESTION.}

The salivary glands are five in number on each side of the head. They secrete the saliva, certain elements of which have the power of changing starch into sugar.

The parotid gland is the largest of the salivary group and lies just ventrad to the base of the external ear (Fig. 66) beneath the skin. It is flat and about two centimeters in diameter. Its secretion is poured into the mouth through Stenson's duct, which may be seen extending from the cranial margin of the gland over the masseter muscle, to near the angle of the mouth, where it perforates the buccinator muscle, and opens within the mouth on the cheek, opposite the prominent cusp of the last premolar. The duct and gland may be injected with Berlin blue by inserting the cannula into the orifice of the duct (Fig. 66).

The submaxillary gland is near the angle of the mandible and ventrad to the parotid. Wharton's duct extends from its anterior surface, between the digastric and masseter muscles, to its orifice on the floor of the mouth, opposite the last tooth of the mandible.

The sublingual gland is quite small, elongated, and lies 
craniad of the submaxillary. Its duct extends parallel with that of the submaxillary and opens within the mouth upon the same papilla beneath the tongue. The molar gland is

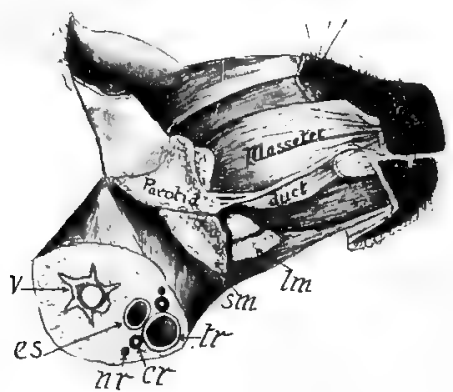

Fig. 66. Lateral Aspect of the Head with the Skin Removed.

cr, Carotid artery; es, esophagus; lm, lymphatic gland; $n r$, vagus and sympathetic nerves; sm, submaxillary gland; $t r$, trachea ; $v$, cervical vertebra. very small and lies near the angle of the mouth ventrad of Stenson's duct. Its several ducts, which are not easily demonstrated, pass through the cheek to open within the mouth. The zygomatic or infraorbital gland lies on the lateral part of the orbit on the ventro-lateral surface of the eyeball. It may be seen by cutting away the zygomatic arch and the masseter muscle. From near the ventral angle of the gland a duct leads to the roof of the mouth posterior to the molar tooth.

The liver is the largest gland in the body and is situated immediately caudad of the diaphragm (Fig. 55), and in contact with the right lateral and cranial surfaces of the stomach. It is strongly convex on its cranial aspect while its opposite surface presents a deep concavity occupied by the stomach. Several deep incisions named fissures divide the liver into five parts called lobes. The falciform or suspensory ligament which is a fold of peritoneum joins the liver to the diaphragm and extends into the large median fissure known as the umbilical notch because during fetal life it shelters the vein leading through the umbilical cord to receive nourishment from the mother.

On the right side of the body from the umbilical notch is the large right median lobe enfolding the gall bladder. 
On the other side of the notch is a small left median lobe and a much larger left lateral lobe. The right lateral lobe is dorsal of the right median lobe, and is divided into two parts by a deep cleft. A fifth lobe known as the Spigelian or caudate lobe is a small triangular portion of the liver connected to the base of the right lateral lobe and lying between the neck of the gall bladder and the end of the stomach joining the esophagus.

The bile secreted by the liver passes through the several ducts from the various lobes, to the main hepatic duct, which may be seen by cutting away the liver from the right side of the gall-cyst, and carefully picking off the peritoneum ensheathing the vessels between the Spigelian lobe and the cystic duct. The latter is somewhat convoluted in its course from the deeply imbedded end of the cyst, to a point on the duodenum about three centimeters from the pylorus. The main hepatic duct joins the cystic duct (Fig. $60)$ near its middle. The common duct thus formed is known as the common bile duct. When the bile is secreted faster than it is permitted to enter the intestine, it passes backward from the common bile duct into the cyst.

The bile aids in the absorption of the fats by the villi, and renders the chyme alkaline. The formation of red blood-corpuscles takes place in the liver of the embryo, while in the adult, the liver destroys these corpuscles. The chief function of this organ, however, is the formation of glycogen from the sugars and starches eaten and the gradual transformation of this glycogen into sugar as demanded for the nutrition of the body. Diabetes mellitus is caused by a diseased liver or pancreas which permits sugar to accumulate in the blood.

The pancreas (Fig. 60) is an elongated gland bent at a right angle near its middle. The body of it lies dorsal to the pyloric portion of the stomach, and the head lies 
close along the concavity of the duodenum. It has two ducts, one of which enters the duodenum in common with the common bile duct, while the other enters about three centimeters further caudad. The pancreatic juice acts on the starches, proteids, and fats.

\section{THE PERITONEUM.}

The peritoneum (Fig. 6I) is the serous sac lining the abdominal cavity and investing most of the organs therein contained. The four portions of the peritoneum are known as the omenta, the mosinterics, parietes, and ligaments.

The omenta are three in number, the largest of which is the great or gastrocolic omentum, stretching caudad from the dorsal abdominal wall and the greater curvature of the stomach, so as to cover the intestine like an apron. It is composed of four layers of peritoneum forming a closed sac, and bearing more or less fat. Two layers form the ventral wall of the sac attached to the stomach, and two layers are also present in the dorsal wall of the sac which invests the pancreas.

The lesser omentum, or gastrolucpatic omentum, extends caudad from the liver to the pyloric part of the stomach and duodenum. Its two folds extend from the two sides of the portal fissure, ensheathing the portal vein, hepatic artery, and cystic duct. The gastrosplenic omentum stretches from the cardiac region of the stomach to the spleen, which it embraces, and then proceeds to the diaphragm.

The mesenteries are the two layers of peritoneum suspending the intestine from the dorsal abdominal wall. There are four mesenteries: the true mesentery, suspending the jejunum and ileum; the mesoduodenum, suspending the duodenum; the mesocolon, suspending the colon; and the mesorectum, suspending the rectum.

The parietes or parietal peritoneum is that portion lining 
the walls of the abdominal cavity. It is a closed sac in the male, but in the female the Fallopian tubes open into it.

The ligaments are the layers of the peritoneum suspending other organs than parts of the alimentary canal. The suspensory or falciform ligament extends from the caudal surface of the diaphragm and the abdominal wall, to the surface of the liver, which its line of attachment divides into halves. The round ligament is the thickened free caudal border of the suspensory ligament. It is the remains of a vein which in fetal life joined the offspring to the mother. A third ligament connects the dorsal border of the liver with the diaphragm. The broad ligaments of the uterus are the folds of peritoneum which embrace the uterus, the Fallopian tubes, and the ovaries. The ovarian ligaments are short cords extending from the ends of the uterine cornua to the ovaries. The round ligaments of the uterus pass from the sides of the uterus to the brim of the pelvis.

The peritoneum is called a serons membrane because of the colorless serum secreted by it. Other serous membranes are the pericardium of the heart, the pleura lining the thoracic cavity and investing the lungs, and the synovial membranes of the joints. Serous membranes invest only such cavities as are not exposed to the air. All other cavities are lined by mucous membrane. A serous membrane consists of a layer of fibrous connective tissue covered by platelike endothelial cells.

\section{REMARKS ON THE MAMMALIAN DIGESTIVE SYSTEM.}

The digestive system of mammals varies somewhat among the different groups. In carnivorous animals, as a rule, the alimentary canal is much shorter than in herbivorous. In the wildcat the canal is four times the length of the body, while the canal of the sheep is twenty times as 
long as the body. In man it is about nine times as long as the distance from the crown of the head to the coccyx. In Ruminants, such as the cow and the sheep, the stomach is very large and divided into four chambers-the rumen or paunch, reticulum, psalterium or manyplies, and abomasum

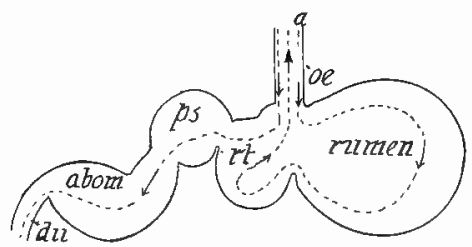

Fig. 67. Diagram of the Stomach of a Ruminant.

$a$, Dotted line showing the direction of the food in the process of digestion; abom, abomasum; $d u$, duodenum; $a$, esophagus ; $p s$, psalteritum; $r$, reticulum.

(Fig. 67). The rumen and reticulum serve as mere storage cavities, from which the food returns to the mouth for thorough mastication, and then passes direct, by means of a groove in the esophagus, into the psalterium, and finally on to the abomasum. The latter is the true stomach, and is provided with gastric glands. In the camels the rumen and reticulum have connected with them pouch-like diverticula for the storage of water. The constricted openings of the pouches into the rumen or reticulum may be entirely closed by sphincter muscles.

In man and the higher apes there is present an attenuated extension of the crecum known as the vormiform appendix. In the fetus of man it is proportionally longer than in the adult. In the herbivorous mammals, such as the cow and rabbit, the crecum is greatly enlarged, so as to play an important part in digestion. In a few forms, stuch as the sloths, some Cetacea, and a few Carnivora, the cæcum is absent.

The lowest mammals, the Monotremata, resemble birds 
and reptiles in possessing a cloaca into which open the rectum and the urinary and genital ducts. The cloaca opens externally through the anus. Salivary and thyroid glands, pancreas, and liver are present in all mammals, but the gall-cyst is absent in Cetacea, the Perissodactyla, Hyracoidea, and a few Rodentia. The liver is usually relatively larger in fat-eating animals.

\section{PRACTICAL QUESTIONS AND SUGGESTIONS.}

I. Describe the fauces.

2. Describe in detail every feature visible on the dorsal surface of the tongue.

3. Give the number of fangs in each tooth of the permanent set.

4. Give the number of each kind of teeth in the two sets.

5. Draw two aspects of the sectorial tooth.

6. How thick is the enamel of the teeth?

7. Name some mammals which do not have enamel on the teeth.

8. Name some toothless mammals.

9. Name some mammals having only one set of teeth.

Io. Give the dental formulæ for three ungulates.

II. In what animals are some of the teeth greatly enlarged?

I2. Do any ruminants have upper incisors?

I3. Name the important features of the pharynx.

I4. Name every organ in the abdominal cavity, telling with what other organs it is in contact.

I5. Describe as much of the peritoneum as you can see in your snecimen.

I6. Draw the alimentary canal in its natural position, showing all ducts leading into it, and label all parts.

I7. How much longer is the small intestine than the large one?

18. On what does the length of the canal in different mammals largely depend?

I9. Make a section of a portion of the wall of the stomach and draw what is seen, labelling all parts.

20. Make a section of the small intestine, draw what can be seen by naked eye or simple microscope.

21. About how many villi to each square millimeter?

22. Describe the two channels through which the food passes from the intestines to the heart.

23. Make a somewhat diagrammatic drawing representing that part of the venous system conveying the food from the intestines to the heart. 
24. What is the size of the crecum in other mammals than the cat?

25. Give the location, size, and form of the salivary glands.

26. Name the lobes of the liver in order of their size.

27. How is the liver held in place?

28. Draw the pancreas, showing ducts leading to the intestine.

29. Draw the complex stomach characteristic of many ruminants.

30. What is the cloaca and in what mammals is it present? 


\section{THE VASCULAR SYSTEM.}

The vascular system is composed of the central forcing muscular organ, the heart; a system of vessels, the arteries, carrying the blood from the ventricles to the lungs and all parts of the body; a system of vessels, the veins, returning the blood to the auricles; and numerous microscopic vessels. the capillaries, connecting the termination of the arteries with the origin of the veins.

\section{THE HEART.}

The location of the heart in the cat may be seen by removing the ventral thoracic wall, but for the study of the parts, the heart of an ox or a sheep will be found more satisfactory. The heart of the cat lies between the lungs (Fig. 82) in the thoracic cavity a little to the left of the median line. The caudal end is the apex, and the cranial end is the base. The entire organ is invested by a tough membrane, the pericardium, which when cut permits the pericardial fluid to run out. All the blood-vessels originate from the dorsocranial aspect of the heart.

It is composed of a right and left half, each of which consists of an auricle and a ventricle. The separation between the two halves is apparent on the ventral surface. The auricles receive the blood from the veins and pass it to the ventricles, which disperse it through the arteries. There is no aperture between the auricles or the ventricles. The aperture between the right auricle and the right ventricle is guarded by the tricuspid valve which prevents the blood from returning into the auricle when the systole or contraction pushes the blood into the pulmonary artery. 
The opening between the left atricle and the left ventricle is guarded by the bicuspid or mitral valve. These valves

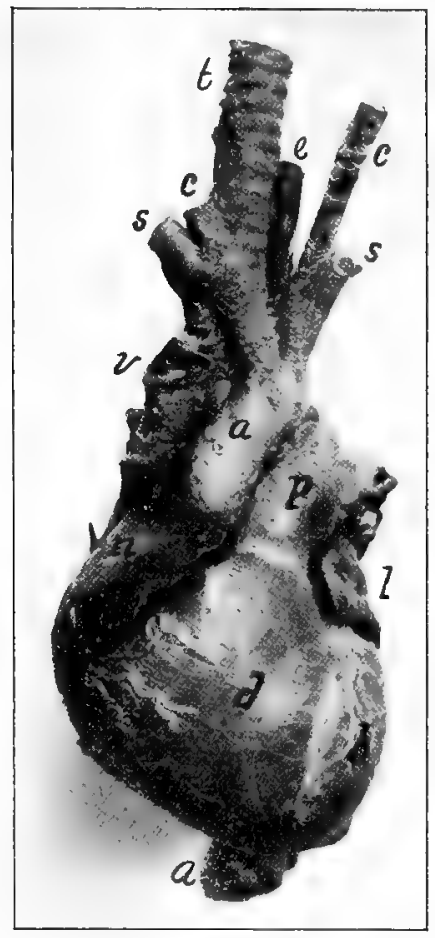

Fig. 68. Photograph of the Ventral Aspect of the Human Heart In JeCted.

$a$, aorta ; $b$, left ventricle; $c$, carotid arteries; $d$, right auricle; $e$, esophagus; $l$, left auricle; $n$, right auricle; $s$, subclavian attery; $t$, trachea; $v$, superior vena cava. $\frac{1}{3}$ natural size.

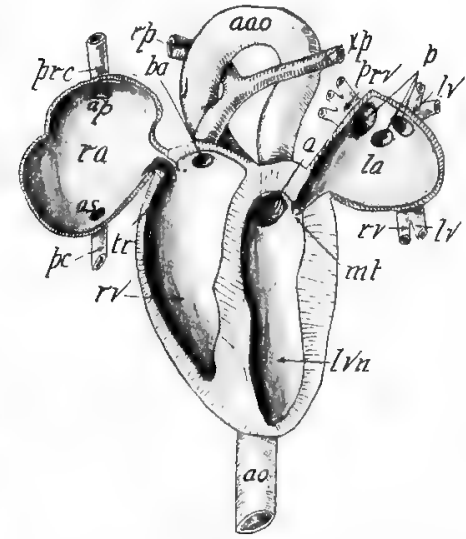

Fig. 69. IIEart Viewed Ventrally, With Ventral Half of THE AURICLES AND VENTRICLES Cut Away and the Auricles Drawn Laterad. Partly diagrammatic.

a, Orifice of the aorta; ao, aorta; aao, arch of the aorta; $a p$, orifice of the precava; as, orifice of the postcava; $l v$, left pulmonary veins; lvn, left ventricle; $m t$, mitral or bicuspid valve; la, left auricle; $p$, orifice of the pulmonary veins; $p c$, inferior vena cava; prc, superior vena cava; $b a$, orifice of the pulmonary artery; prv, right pulmonary veins; $r v$, right ventricle and one of the right pulmonary veins; $r a$, right auricle; $p p$, right pulmonary artery; $t r$, tricuspid valve; $x p$, left pulmonary artery.

may be displayed by cutting away the caudal half of the ventral wall of the ventricles, when the chorda tendinea, delicate tendinous cords, will be seen extending from the 
margins of the translucent membranous valves to the columna carnex or muscular projections on the walls of the ventricles. The walls of the auricles are thin in comparison with the walls of the left ventricle, which are twice as thick as the walls of the right ventricle (Fig. 70).

The auricles are very small when not injected, and may

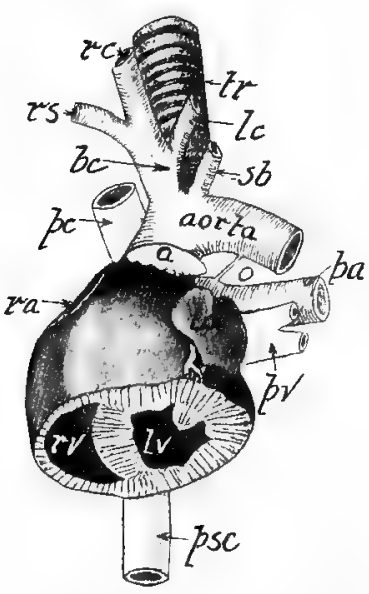

Fig. 70. Ventral Aspect of the Heart with its Caudal Third Cut off Transversely.

$a$, Adipose tissue; $b c$, innominate artery; la, left auricle; $l v$, left ventricle; $l c$, left carotid artery; $o$, ductus arteriosus; $p v$, pulmonary vein; $b a$, pulmonary artery; $p c$, stuperior vena cava; psc, inferior vena cava; ra, right auricle; $r c$, right carotid artery; $r s$, right subclavian artery; $r v$, right ventricle; $s b$, left subclavian artery; $t r$, trachea.

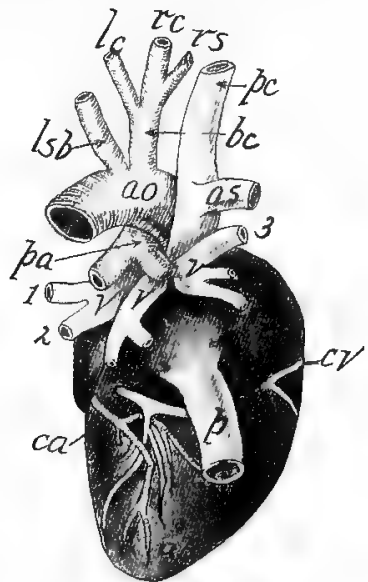

Fig. 7i. Dorsal Aspect of the Heart of the Cat.

ao, Aorta; $a p$, apex; as, azygos vein; $b c$, innominate artery; $c a$, coronary artery; cv, coronary vein; $l$, left auricle; $l c$, left carotid artery; $l s b$, left subclavian artery; $p$, inferior vena cava; $p c$, superior vena cava; $p a$, pulmonary artery dividing into its right and left branches; $r a$, right at1ricle; $r c$, right carotid; $r s$, right subclavian; $v$, pulmonary veins.

by the beginner be cut away with the pericardium and surrounding adipose tissue. The right auricle receives three veins, the superior vena cava, inferior vena cava and coronary veins, all of which enter its dorsal aspect. The portion 
of the auricle into which the above veins open is the simus icnosus. At the dorsal part of the septum which divides this auricle from the adjoining one is an oval depression, the fossa ovalis, where, in the embryo, the two auricles communicated. The left auricle is in contact with the right dorsally, and receives three pulmonary veins (Fig. 7I).

From the right ventricle arises the pulmonary artery which carries the impure blood to both lungs. Its mouth is guarded by three semilmar ralves which prevent the return of the blood. The left ventricle gives origin to only one important vessel, the aorta, which arches dorsally around the left auricle, and at the apex of the arch gives off two branches, the imnominatc, and the left subclavian. Three semilunar valves also guard the mouth of the aorta. The arteries of the heart may easily be distinguished from the veins by the fact that the walls of the former are much thicker.

\section{THE ARTERIES OF THE TRUNK.}

The blood-vessels form two systems of circulation; the one known as the pulmonary circulation includes the arteries carrying blood from the right ventricle to the lungs, and the veins returning the blood from the lungs to the left auricle; the other, known as the systemic circulation, includes the arteries conveying the blood from the left ventricle to all parts of the body, and the veins returning the blood to the right auricle.

The main artery of the systemic circulation is the aorta, which, leginning in the left ventricle, arches dorsad to the heart and extends along the spinal coltumn to the tail. That portion in the thoracic cavity is termed the thoracic aorta, while that portion in the abdominal cavity is the abdominal aorta. Three semilunar valves guard the mouth of the aorta at its opening from the ventricle, in order that the 
blood may not be forced back into the heart by the contraction of the muscular coat of the arteries.

The branches of the thoracic aorta are as follows: the right and left coronary, arising from the aorta immediately beyond its exit from the ventricle, are distributed to the walls of the heart. From the arch of the aorta arise two large branches; first, the innominate, giving origin to the right subclazian supplying blood to the arm, and the right and left carotids supplying the head and neck; and second, the left subclavian, supplying the left arm, brain, and sternum (Fig. 72). Ten pairs of intercostal arteries supply the intercostal spaces, muscles, of the back, and the spinal cord. Two bronchial arteries go to the lung tissue. Two to four esophageal arteries are distributed to the esophagus. Two or three pairs of lumbar arteries pierce the muscles of the back.

Fig. 72. Chief Arteries of the Trunis, Ventral Aspect.

$a r$, Arch of the aorta; $b c$, innominate; $c e$, coliac axis; $c d$, cautdal; $e$, gastric; $f$, gastric; $g r$, gastric; gas, gastroduodenalis; $h p$, hepatic; ht, location of heart; icn, intercostals; $i c$, external iliac; it, internal iliac; il, iliolumbar; im, inferior mesenteric; $l s$, left subclavian; $l p l$, left pulmonary; $m$, splenic; $o$, splenic; $r$, right pulmonary; $r e$, renal; sp, splenic trunk; sms, superior mesenteric; $s m$, spermatic or ovarian; $s$, adrenolumbalis; $1,2,3,4,5$, and 6 , lumbar arteries.

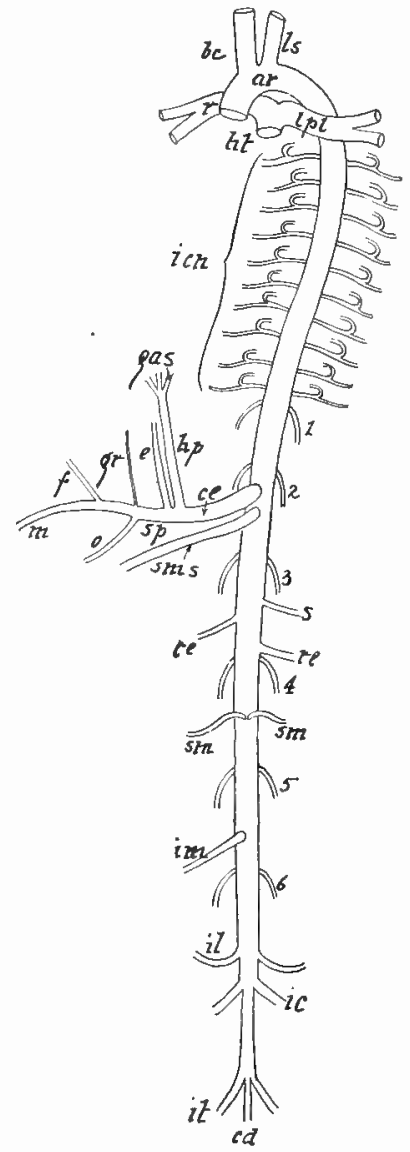


The abdominal aorta gives off the following branches: the coeliac axis, the superior mesenteric, the adrenolumbalis, a pair of renal, a pair of genital, an inferior mesenteric, a pair of iliolumbar, seven or eight pairs of lumbar, a pair of external iliacs, a pair of internal iliacs, and a caudal artery (Fig. 72).

The coliac axis is a large branch arising just caudad to the diaphragm and gives off the hepatic branch to the liver, pancreas, and duodenum, the gastric to the stomach, and is continued as the splcnic, supplying the pancreas and the spleen. The phrenic artery, supplying the diaphragm. sometimes arises from the cœliac axis, but usually from the adrenolumbalis.

The superior mesenteric is about the same size as the coliac axis, and arises within one centimeter caudad. It sends branches to the pancreas and both intestines. The adrenolumbalis is a small branch on the left side dividing into the adrenal, phrenic, and muscular. The renal arteries supply the kidneys and usually the suprarenal bodies. The genital arteries are small, and arise from one to two centimeters caudad of the renal arteries. They pass obliquely caudad to the ovaries in the female, and the testes in the male. The inferior mesenteric is almost as large as the superior mesenteric. It is distributed to the large intestine. The pair of iliolumbar arteries are small branches supplying the muscles of the iliac region.

Four or five pairs of lumbar arteries are given off from the dorsal side of the aorta at regular intervals between the diaphragm and the origin of the external iliac arteries. They supply the muscles of the back and spinal cord. The external iliac arteries are the largest branches of the abdominal aorta and carry blood to the hind-limbs. The internal iliac arteries arise more than a centimeter caudad to the external iliacs and furnish blood to the pelvic viscera 
and the muscles of the innominate region. The caudal artery is the continuation of the aorta beyond the origin of the internal iliacs. It extends into the tail (Fig. 72).

\section{ARTERIES OF THE HEAD AND NECK.}

From the arch of the aorta arise the innominate and left subclavian, which supply the sternum, neck, head, and anterior extremities with blood. The innominate gives off the left carotid and then divides into the right carotid and right subclavian (Fig. 73). Sometimes the two carotids arise as a single trunk from the innominate, which is then continued as the right subclavian. In this case the common trunk of the carotid usually bifurcates within one or two centimeters of its origin, forming the right common carotid and the left common carotid, lying on the respective sides of the trachea beneath the sternomastoid and the sternohyoid muscles. The vagus or tenth cranial nerve and the sympathetic trunk lie in the same sheath with the carotid (Fig. 66).

Each carotid artery in the neck region gives off the following branches: a thyroid to the thyroid cartilage and gland, and a muscular to the muscles of the neck. At the base of the skull, about the middle of the bulla of the temporal bone, a slight enlargement of the vessel is seen, from which arises the very small internal carotid, leading through the foramen lacerum medius to the base of the brain, where it joins the circle of Willis. The continuation of the common carotid is now known as the external carotid. This, after giving off a lingual branch to the tongue, an external maxillary branch to the lower jaw, a post-auricular branch, and a temporal branch, turns to pass along the medial aspect of the mandible, where it is named the internal maxillary, whose main branches are the inferior alveolar, the middle meningeal supplying the dura mater, several 
branches to form the carotid plexus, a palatine, sphenopalatine, and infraorbital. The latter is the direct continuation of the internal maxillary. It supplies the upper teeth, lower eyelid, parts of the nose, and upper lip. An ophthalmic branch, supplying structures in the orbit, may arise from the carotid plexus or the internal maxillary.

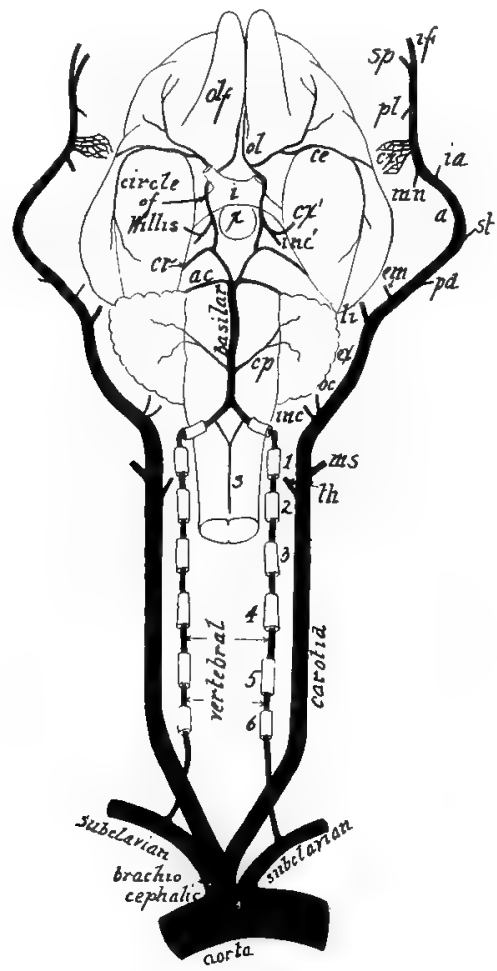

Fig. 73. Ventral Aspect of the Arteries of the Head and Neck. The carotids with their branches have been drawn laterad.

$a$, Internal maxillary; $a c$, anterior cerebellar; $c e$, median cerebral; $c r$, posterior cerebral; $c p$, posterior cerebellar; $c x$, carotid plexus, many of whose branches reunite in one, $c x^{\prime}$, which is cut off; $\varepsilon x$, external carotid; $e m$, external maxillary; inc, origin of internal carotid; inc', union of internal carotid with circle of Willis; $i a$, inferior alveolar; if, infraorbital; $i$, optic chiasma; $l i$, lingual; $m m$, middle meningeal; $m s$, muscular; oc, occipital; ol, anterior cerebral; $p l$, palatine; $p a$, posterior auricular; $s$, anterior spinal; th, thyroid; $x$, hypophysis: $\mathrm{I}, 2,3,4,5$, and 6 , transverse foramina in cervical vertebræ. 
The vcrtebral artery is the first branch given off by either strbclavian. It proceeds dorsad and craniad to the sixth cervical vertebra, whence it extends through the transverse foramina of the cervical vertebræ and foramen magnum, to a junction with its fellow in the median line on the ventral aspect of the medulla oblongata. The union of the two vertebral arteries forms the basilar artery, which, after giving off several branches to the medulla and cerebellum. divides craniad of the pons Varolii, forming the circle of Willis around the infundibulum and the optic chiasma at the base of the brain. The circle of Willis receives the internal carotid and gives off several arteries to the cerebrum. In man the internal carotid is much larger proportionately than in the cat (Fig. 73).

\section{THE ARTERIES OF THE THORACIC LIMB.}

There is more or less variation in the branching of the arteries in the limbs. No two cats are found exactly alike as to their arteries or veins. The same is true of all other mammals.

The subclavian artery, which on the right side springs from, or is merely a continuation of, the innominate and on the left side arises from the arch of the aorta, supplies the forelimbs with blood (Figs. 73 and 74). When the subclavian reaches the armpit, it is called the axillary artery, and its continuation along the humerus is the brachial artery. A continuation of the same artery along the radius is the radial artery, furnishing a large part of the blood to the fingers.

Four branches arise from the subclavian: the vertebral artery, extending to the brain through the transverse foramina of the cervical vertebræ; the internal mammary artery, arising from the ventral side of the subclavian op- 
posite the origin of the vertebral, and extending along the visceral surface of the sternum, and sometimes supplying the pericardium of the heart; the superior intercostal, arising near the vertebral artery and supplying the first and second intercostal spaces, the deep muscles of the back, and the serratus magnus; and the thyroid axis, extending craniad to supply some muscles of the neck and the lateral aspect of the scapula (Fig. 74).

The axillary artery gives origin to three branches: the anterior thoracic, the long thoracic, and the circumflex. The antcrior thoracic supplies the pectoral muscles. The

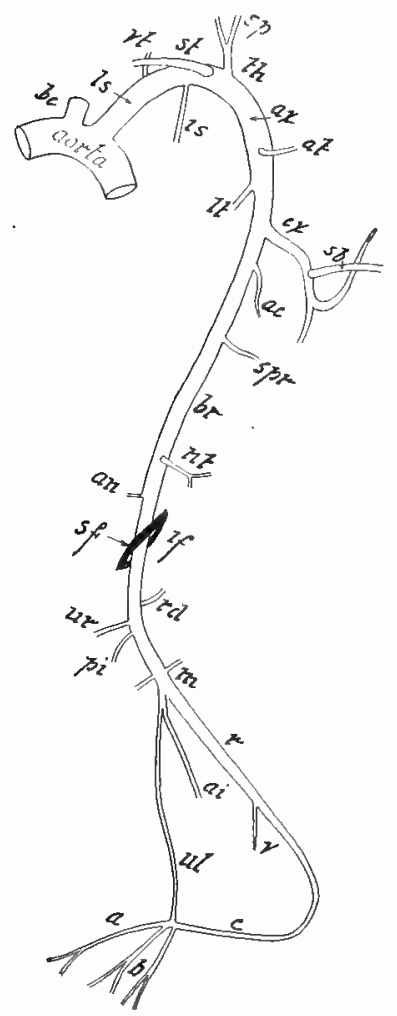
long thoracic is distributed chiefly to the latissimus dorsi. The circumflex artery is almost as large as the continuation of the axillary, which beyond this point is called the brachial. The circumflex, about a centimeter from its origin, after giving off the subscapular, which is distributed mainly to

Fig. 74. Arteries of the Forelimb. Ventral Aspect.

a, Digital artery; an, anastomotica magna; $a c$, anterior circumflex; $a i$, anterior interosseous; $a x$, axillary; $a t$, anterior thoracic; $b$, digital artery; $b c$, innominate; $b r$, brachial; $c$, dorsal branch of the radial where it passes between the second and third metacarpals to the palmar side; $c x$, circumflex; is, superior intercostal; $l s$, left subclavian; $l t$, long thoracic; $m$, branch to extensor muscles; nt, nutrient; pi, posterior interosseous; $r$, radial; $r d$, radial recurrent; $s f$, supracondyloid foramen of the humerus; $s p r$, superior profunda; $s b$, subscapularis; $s p$, suprascapularis; st, sternal ; $t h$, thyroid axis; $u l$, ulnar; $u r$, ulnar recurrent; vt, vertebral. 
structures in the subscapular fossa, winds around the neck of the humerus to its distribution in the triceps and deltoid muscles.

The brachial artery, in addition to several muscular branches, gives origin to the anterior circumflex, superior profunda, the nutrient, and anastomotica magna. The anterior circumflex supplies the biceps and head of the humerus. The superior profunda is distributed to the muscles on the caudal aspect of the humerus. The nutrient artery enters the nutrient foramen of the humerus. The anastomotica magna is the small branch supplying the convexity of the elbow. The brachial artery after passing through the supracondyloid foramen takes the name of radial.

The radial artery, which lies deep beneath the flexor muscles on the caudal aspect of the proximal half of the radius (Fig. 74), becomes superficial along its distal half, where the vessel is covered by skin and fascia only. In the region of the wrist, it curves dorsad and then pierces between the second and third metacarpals to the palmar side, where it sends branches to each of the digits, and forms the palmar arch by anastomosing with the ulnar artery beneath the flexor muscles. In addition to a few small branches, the radial gives off the following: the radial recurrens, supplying the concavity of the elbow; the ulnar recurrens, supplying the convexity of the elbow; the posterior interosseons, passing caudad between the radius and the ulna to the extensor muscles; the anterior interosseous, passing along the cranial sicle of the interosseous membrane; the unar, extending beneath the flexor muscles, which it supplies, to the palm, where it anastomoses with the radial to form the palmar arch; and the volar branch, supplying the superficial palmar region. The ulnar and anterior interosseous frequently arise from the same trunk, as shown in the figure. The ulnar artery in the cat is so 
small that it is frequently not filled by the starch injection. but in man it is larger than the radial.

\section{THE ARTERIES OF THE HIND-LIMB.}

As in the forelimb, the branching of the arteries in the hind-limb varies considerably in different specimens. The main artery of the leg lies on the ventral or medial aspect of the femur, passing obliquely to the caudal side of the knee-joint, where it divides into two branches (Fig. 75), one extending along the cranial, the other along the caudal

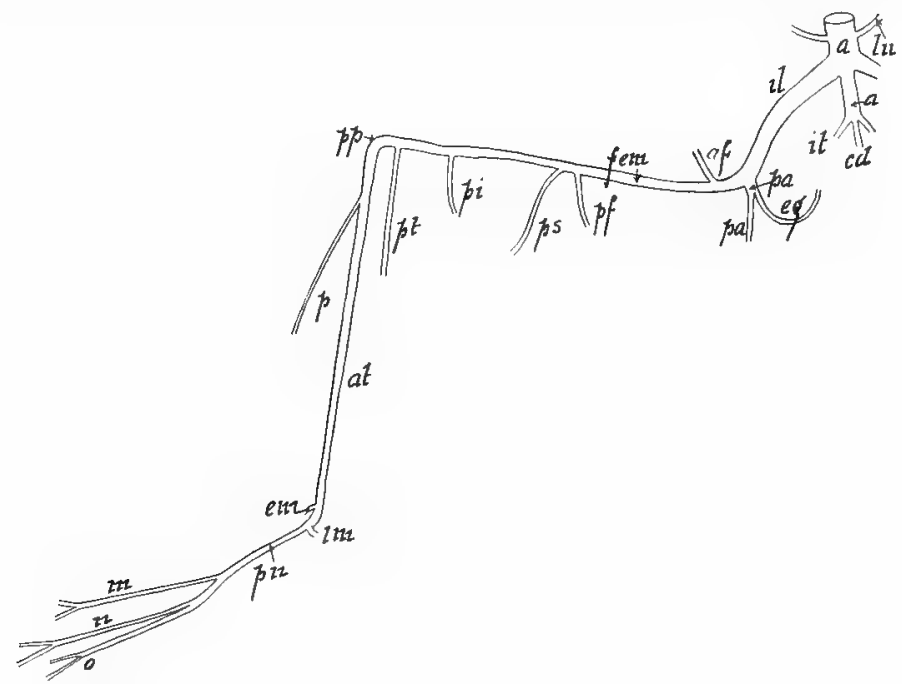

Fig. 75. Arteries of the Right Leg. Ventral Aspect.

$a$, Aorta; at, anterior tibial; $a f$, anterior femoral ; $c d$, caudal; $c g$, epigastric; em, external malleolar; fom, femoral; ime internal malleolar; $i l$, external iliac; it, internal iliac; $l u$, iliolumbar; $m$, digital; $n$, digital; $o$, digital; $p$, peroneal ; $p a$, profunda ; $p f$, posterior superior femoral; $p i$, posterior inferior femoral; $p n$, plantar; $p p$, popliteal; pt, posterior tibial; $p s$, saphenous.

aspect of the crus. The cat, or at least the caudal half of a cat, should be fastened to the dissecting tray on its back, 
the abdominal wall removed, and the viscera pushed laterad to demonstrate the origin of the artery of this limb. As in the forelimb, the main artery in different portions of the leg takes the name of the corresponding region.

The cxternal iliac is the largest artery arising from the aorta in the lumbar region. It gives off but one important branch, the profunda, which, extending caudad, soon gives off a large epigastric artery to the abdominal wall, then smaller branches to the external genital organs, and numerous branches to the muscles on the caudal aspect of the femur.

The femoral artery, which is a continuation of the external iliac, extends along the medial aspect of the femur. In the proximal half of its course it is quite superficial, but the distal portion is covered by the gracilis, sartorius, and semimembranosus muscles. It furnishes four important branches: the anterior femoral, supplying mainly the quadriceps extensor muscle; the superior posterior femoral, supplying the adductor and hamstring muscles; the saphenous, accompanying the saphenous nerve and vein to the foot, where it branches and anastomoses with the plantar artery; and the posterior inferior fomoral, supplying mainly the gastrocnemius group of muscles (Fig. 52).

The popliteal artery is the continuation of the femoral artery in the popliteal region on the caudal aspect of the knee-joint. One or two articular branches are given off here to the joint, in addition to the posterior tibial, which supplies the deep muscles of the crus.

The anterior tibial artery is the continuation of the popliteal on the lateral cranial aspect of the tibia, adjacent to the bone. By separating the tibialis anticus and extensor longus digitorum muscles, this artery is well displayed. Near the knee-joint a small branch, the peroneal, is given off, and passes to the dorsal aspect of the foot, where it 
anastomoses with the dorsal branch of the saphenous, forming a superficial arch sending branches to the digitis. The peroneal is so small that it is frequently not injected. In the tarsal region two branches, an external malleolar and an internal malleolar, are given off. A centimeter or two distal to the latter branch, the main artery passes between

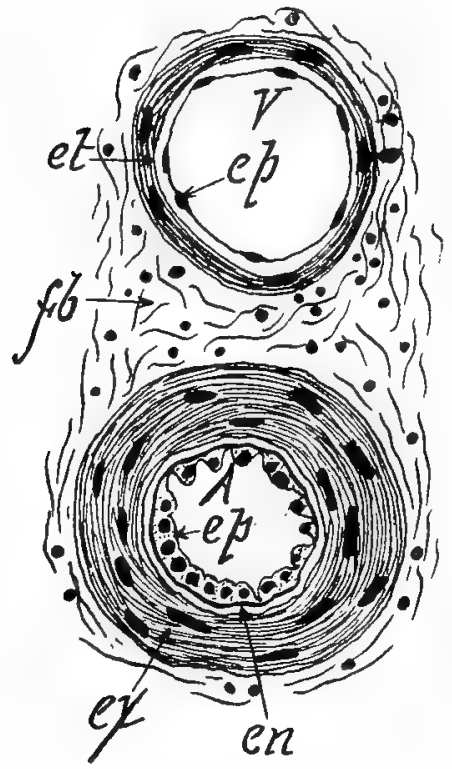

Fig. 76. Cross-Section of ARTERY AND VEIN. $\times 350$.

$V$, Vein ; $A$, artery ; en, inner coat ; $e p$, epithelium lining the vessels; et, middle or muscular coat of vein; ex, muscular coat of artery; $f b$, fibro-areolar coat.(From Martin's "Human Body.") the second and third metatarsals to the deep plantar region, where it receives an anastomosing branch from the saphenous, and sends off branches to the digits.

\section{THE VENOUS SYSTEM}

The veins are the vessels returning the blood to the heart. As a rule, veins carry only impure blood, but the pulmonary veins returning blood from the lungs to the left auricle carry pure blood. After death the veins can readily be distinguished from the arteries by the fact that they have much thinner walls than the arteries and are usually full of blood, while the arteries are empty (Fig. 76). This is due to the fact that the thick muscular coat of the arteries, by its contraction tends to drive the blood into the veins, whose muscular coat is very thin. The three coats composing the walls of the veins are the epithelial, or tunica intima; the middle, or muscular; 
and the tunica adrentitia, or outer elastic coat of fibro-areolar tissue. The veins of the central nervous system and its membranes have no muscular coat. While the only valves in the arteries are found at their origin from the heart, the veins of the limbs, neck, and the head possess numerous valves. These valves are formed by semilunar folds of the epithelial coat, strengthened by fibrous tissue (Fig. 77).

The main deep veins of the limbs accompany the arteries and take the same names as the arteries. $\Lambda$ superficial set of veins is present also in the limbs. The large superficial vein on the lateral aspect of the forelimb is the ccphalic. The superficial vein extending along the medial aspect of the hind-limb is the saphenous.

\section{The Veins of the Trunk, Head, and} Neck.-There are two chief venous trunks: the precava, or superior vena cava, and the postcava, or inferior vena cava. Both vessels open into the dorsal aspect of the right auricle. The veins received by the inferior vena cava are thirteen in number. The phronic veins collect the blood from the diaphragm and empty into the vena cava immediately caudad of the diaphragm. The several

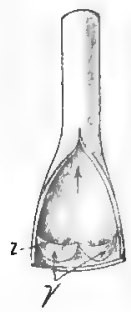

FIG. 77. VEIN CUT OPEN. ARROW SHOWS THE DIRECTION OF THE BIIOOD.

$v$, Semilunar valves: $i$, free edge of the valve. hcpatic veins collect the blood from the liver, which must be partly dissected away to see their entrance into the vena cava. The two suprarcnal a'eins return the blood from the suprarenal bodies and two renal veins carry the blood from the kidneys. The left owarian or spermatic vein is a tributary to the left renal, but the right orarian empties directly into the vena cava. A pair of small iliolumbar veins collecting blood from the lumbar muscles empty into the vena cava a centimeter or more craniad to the large common 
iliacs. The union of the common iliac roins collecting the blood from the hind-limbs and the pelvic region, and the catclal rein, forms the beginning of the inferior vena cava. The common iliac is formed by the union of the external and internal iliac veins in the pelvis. The former is much the larger of the two.

The portal system begins with the veins collecting the blood from the intestines, pancreas, spleen, and stomach, and terminates where the hepatic veins enter the vena cava. The inferior mescutcric vein collects the blood from the large intestine; the superior mescnteric, from the small intestines; the gastrosplcnic, from the spleen, stomach, and pancreas; the coronary, from the lesser curvature of the stomach; the gastro-cpiploica, from the greater curvature of the stomach; and the pancrcatoduodenalis, from the pancreas and duodenum. The last three may empty directly into the portal vein or into one of the three branches first named (Fig. 78).

The supcrior icna car'a extends from the union of the innominate reins to the right auricle. Three important veins empty into the superior vena cava: the asygos, collecting blood from the intercostal spaces; the sternal, lying on the visceral surface of the sternum; and the right vertebral, which, with its fellow, collects the blood from the deep muscles and spinal cord in the region of the atlas, and after making a strong anastomosis with the internal jugular vein, descends in company with the vertebral artery through the transverse foramina canal of the first six cervical vertebræ. The lcft vortcbral vein is a tributary of the left innominate (Fig. 78 ).

The innominate a'cin is formed by the union of the subclavian and the external jugular. Sometimes the vertebral vein joins also in the union instead of emptying into the superior vena cava. The subclavian vein returns the blood from the 
arm, and accompanies the subclavian artery. The external jugular veins are large vessels lying on either side of the neck beneath the platysma myoides muscle. When the skin is removed, the veins are plainly seen through this very thin muscle. The external jugular is formed ventral to the angle of the mandible by the union of the internal and exter-

Fig. 78. Ventral View OF THE Chief Veins of the Trunk, Neci, and Head.

$a z$, Azygos; au, anterior auricular; $b r$, innominate; $c d$, caudal; $c p h$, cephalic; em, anterior facial; $e x, \quad e x-$ ternal jugular; eic, external iliac; $h p$, hepatic; im, posterior facial; ij, internal jugular; ims, inferior mesenteric; ilm, iliolumbar; ilc, common iliac; iic, internal iliac; 一, inferior labial; na, anterior facial; ov, ovarian or spermatic; pan, posterior auricular; $p d$, pancreatoduodenalis; $p s v$, superior vena cava; $p s t$, inferior vena cava; prt, portal; phrn, phrenic; $m$, renal; ste, superficial temporal ; $s t$, gastro-epiploica and coronary; $s r$, suprarenal; str, sternal or internal mammary; $s p$, gastrosplenic; $s m$, superior mesenteric; $s b c l$, subclavian; $t r$, transverse; $t g$, submental; vtr, vertebral; 1, 2, 3, 4, 5, 6 , the transverse foramina of the first six cervical vertcbr $x$; $w$, intercostals; $x$, superior intercostals.

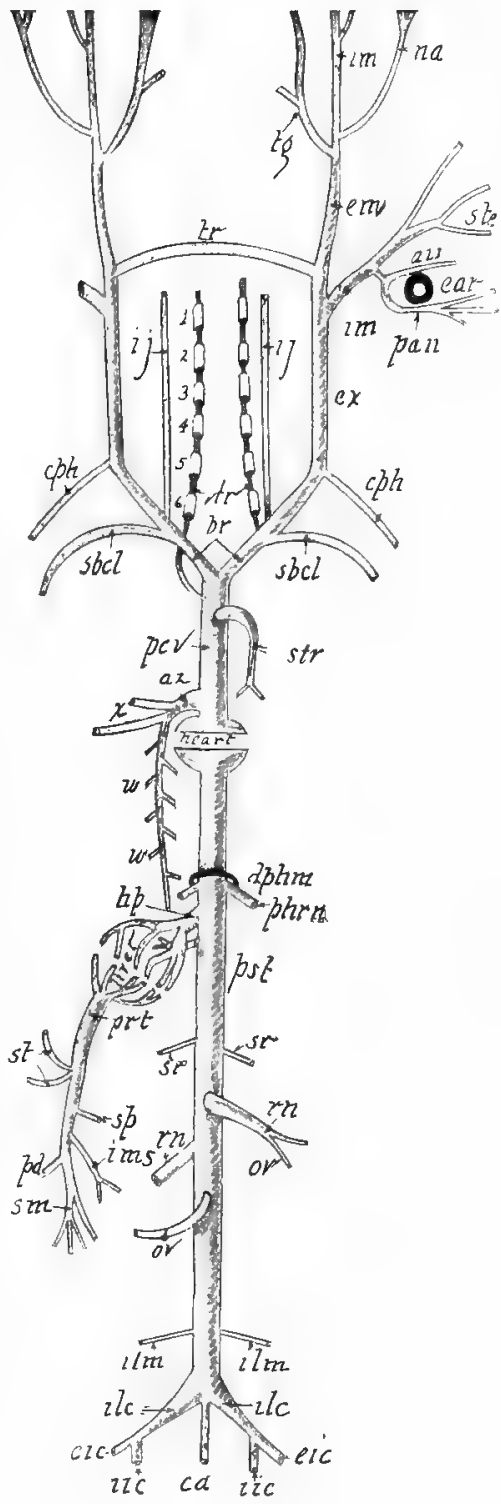


nal mavillary veins. The external maxillaries are united by a large transverse vein. The two tributaries of the external jugular are the cophalic and the internal jugular. The former is the superficial vein on the lateral aspect of the arm, and the latter is the small vein returning blood from the brain.

A system of tube-like spaces, called simuses, whose walls are formed by the dura mater lined with epithelium, takes the place of the large venous trunks within the cranial cavity. These sinuses are usually not filled by a starch injection, but may be filled by a gelatin mass. They cannot be dissected by the beginner. The superior longitudinal sinus extends in the median line beneath the roof of the skull, from the ethmoid region to the tentorium cerebelli, where it bifurcates to form the lateral sinuses, which proceed laterad and ventrad in the substance of the tentorium. The lateral simus emerges from the tentorium just caudad to the petrosal bone, where it follows the groove to the jugular foramen. This groove may be seen in a bisected or unroofed skull.

The supcrior petrosal sinus lies in the angle formed by the junction of the tentorium and the petrosal bone, and unites with the lateral sinus just before it reaches the jugular foramen. The infcrior petrosal simus, collecting blood from the base of the brain, lies in the groove ventral to the petrosal bone, and unites with the lateral sinus at the jugular foramen. The union of these sinuses at this foramen forms the internal jugular vein, which extends deep beneath the muscles of the neck with the carotid artery. It joins the external jugtular opposite the shoulderjoint. $\Lambda$ the base of the skull the internal jugular gives off a large transverse anastomosing vein to the vertebral, so that the blood from the vein may return partly by the latter vessel. 
The pulmonary veins convey the pure blood from the lungs to the left auricle. There are three main trunks from each lung. These six veins are arranged in pairs (Fig. 7I), constituting a left pair from the left lung; a median pair,
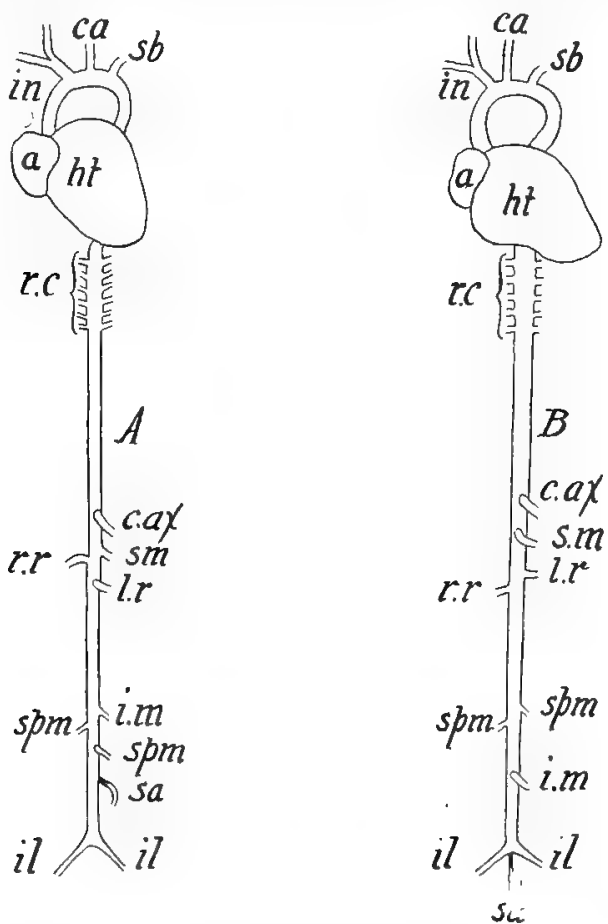

Fig. 79. $A$, Ventral View of Heart and Main Arteries in the Trunk of the Rabeit. $B$, Arteries of Man.

$n$, Right auricle; $c a$, left carotid; $c$. $a x$, coliac axis; $i . n$, innominate; il, common iliac; $i$. $m$, inferior mesenteric; $l . r$, left renal; $r$. $r$, right renal; r. $c$, right intercostals; sm, superior mesenteric; spm, spermatic; $s a$, sacral; $s b$, left subclavian.

composed of one branch from the right and one from the left lung; and a right pair from the right lung. Each pair forms a common trunk before entering the auricle. In order to demonstrate these veins one must remove the heart 
and lungs from an injected cat, and carefully dissect away the fatty and connective tissues enveloping the vessels.

The peripheral connection between the arteries and veins is by means of capillaries, which are microscopic vessels with an extremely thin wall composed of a single layer of epithelial cells. These capillaries are so abundant everywhere in the flesh that a needle cannot be inserted without penetrating some. They form a kind of mesh or network, so that every cell may be supplied with oxygen and food and discharge its waste matter. All the blood carried to any portion of the body by the arteries is not returned by the veins, as a considerable amount of the plasma and some of the white corpuscles escape through the thin capillary walls and are returned to the circulation by a system of vessels called lymphatics (Fig. 80).

\section{PRACTICAL QUESTIONS AND SUGGESTIONS.}

I. What holds the heart in place?

2. Draw the ventral aspect of the heart with the pericardium removed and label all features.

3. When the heart is detached from the body, how do you distinguish the dorsal from the ventral aspect?

4. How many veins open into each auricle?

5. What arteries lead from each ventricle?

6. After dissecting write a detailed description of the valves of the heart.

7. Describe the differences in the appearance of the walls of the aorta and vena cava.

8. From your dissection write a description of the features seen in each cavity of the heart.

9. Name the branches of the thoracic aorta in order.

Io. Name the branches of the abdominal aorta and tell what organs each supplies.

II. Draw the coeliac axis and its branches throughout their course and label all parts.

12. Show by a drawing the relations of the aorta and venæ cavæ throughout.

I3. Make a diagrammatic cross-section of the neck, showing location of arteries and veins. 
I4. Describe the three routes by which blood may reach the brain and the two rotites by which it may be returned to the heart.

I5. Name the arteries arising from the arch of the aorta.

I6. Draw the inner or medial aspect of your dissection of the arteries of the thoracic limb and label all parts.

I7. Draw cross-section of arm at middle of humerus to show location of main artery and vein.

18. Draw cross-section of the middle region of the forearm to show location of chief arteries.

19. Draw outline of the bones of the manus and show relation of arteries to bones as seen from palmar aspect.

20. Draw outline of femur and show course of main artery in relation to the bone as seen from medial aspect.

2I. Draw outline of bones of the pes and show relations of the arteries to the bones as seen from the plantar aspect.

22. At what points in its course is the chief artery of the pelvic limb most superficial?

23. Describe the difference in structure of a vein and an artery.

24. What veins open into each auricle of the heart?

25. Name the veins returning the blood from each organ of the abdominal cavity.

26. Draw the portal system and label all vessels.

27. Describe the veins returning the blood from the head.

28. Describe the chief blood sinuses in the skull.

29. Where are the valves found in the blood-vessels?

30. If the brachial vein were cut, how could the blood from the manus reach the heart?

\section{THE LYMPHATIC SYSTEM.}

The lymphatics constitute that part of the vascular system which collects the colorless fluid called lymph from the tissues, and the chyle from the small intestine, and conveys them to the external jugular veins. The portion of the lymphatic system originating in the villi of the small intestine and conveying the chyle to the left thoracic duct is known as the lacteals (Fig. 65, b).

The lymphatic system consists of four parts: (I) the - lymphatic spaces between the skin and muscles in all parts of the body, the spaces between the muscles adjacent to the bones, and internal spaces such as those enclosed by 
the peritoneum and pleura; (2) minute thin-walled vessels beginning by capillary mouth in the spaces just described and leading to larger vessels which empty into the tracheal trunks or thoracic duct; (3) the glands, which vary in size from a mustard-seed to two centimeters in diameter, and are located chiefly on the side of the neck, in the axillary region, at the bifurcation of the trachea; in the inguinal region, lumbar region, and mesentery; (4) the two tracheal trunks and thoracic duct (Fig. 80).

One of the largest of the lymphatic spaces is the greater cavity of the peritoneum. The cavity of the lesser peritoneum, a large lymphatic space, may be shown by separating the layers of the great omentum carefully. The cavity of the pleura within the chest is also a large lymphatic space. Numerous small lymph spaces are present in all parts of the body. The lymphatic capillaries originating in these spaces are invisible to the naked eye, but their union into larger vessels may be demonstrater satisfactorily in a cat just killed, by pulling forward the tongue, and injecting very slowly beneath the skin, on its ventral aspect five or ten centimeters of a two per cent. solution of Berlin blue in warm water.

The lymph glands (Fig. 8o) of the cat are not nearly so numerous as in man. The largest lymph gland is the pancreas Aselli in the mesentery. It is considerably flattened and about two centimeters long. A few other very small lymphatic glands are also present in the mesentery. The two largest lymph glands of the head are just beneath the skin craniad of the submaxillary gland. On the side of the neck beneath the cephalohumeral muscle are three large lymph glands at the cranial border of the scapula. A small axillary gland lies on the caudal side of the axillary vein beneath the scapula. A single popliteal gland is in the popliteal space, an inguinal gland lies on each side of the 
penis, two or three iliac glands are near the origin of the femoral artery, and a few small lumbar glands lie in the lumbar region of the abdominal cavity.

All parts of the body have communication with the lymphatic vessels, which for the most part are so small as to be invisible unless injected, when they are easily recognized by their beaded appearance caused by the numerous valves within them. There are two systems of vessels in the head and extremities-the superficial and the deep. The former accompany mainly the superficial veins, and the latter follow the deep veins. On the outer aspect of the thoracic limb just beneath the skin two vessels are present, which flow into the cervical glands. They carry the lymph from the ball of the foot and the skin of the foot and forearm. One or two deep lymph-vessels are found accompanying the brachial vein and artery, which convey the lymph from the bones and muscles of the arm to the axillary gland.

In the pelvic limb two or three superficial vessels are present transmitting the lymph from the foot to the popliteal gland, whence two vessels proceed to the deep lymphatic system. The lymph from the bones and muscles of the leg reaches the iliac glands through two or three deep vessels lying near the femoral vein and artery. The inguinal glands receive most of the lymph from the skin of the leg.

The lymph from the superficial parts of the head flows largely into the submaxillary glands, while that from the brain, tongue, esophagus, and larynx empties into the laryngeal glands.

The lymph of the right forelimb, right side of the neck and head, and right side of the thoracic wall is received by the right tracheal trunk. The left tracheal trunk receives the lymph from the left side of the head, neck and thoracic 
wall, and the left forelimb. The thoracic duct receives the lymph from the lungs, heart, all the abdominal viscera, and muscles, and the hind-limbs. With but few exceptions, all

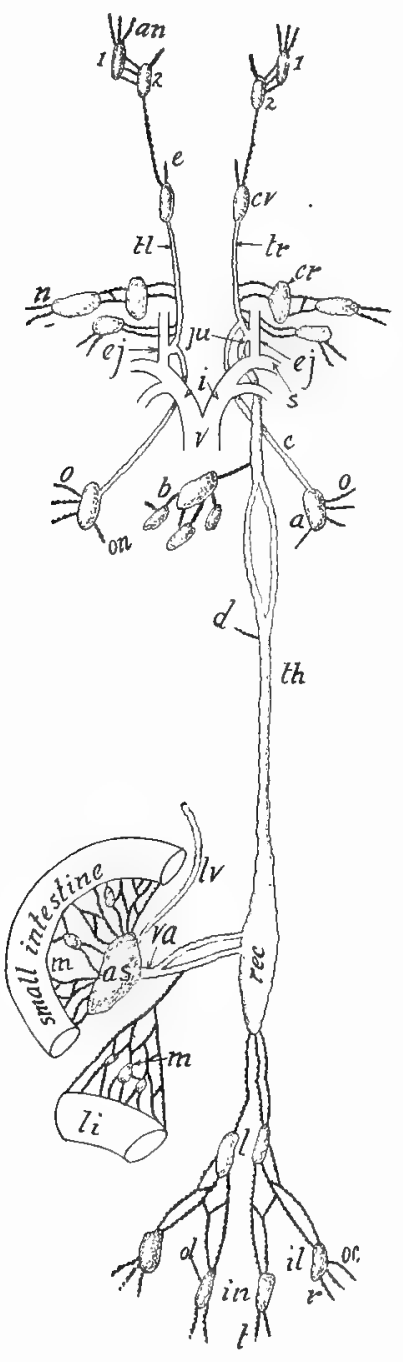

the main lymphatic vessels pass through lymphatic glands before reaching one of the three main trunks. In fact, the vessels bringing the lymph to the glands may be said to terminate there. They are called afferent lymphatics. The lymph moves free through the tissue of the gland, and on the opposite side is taken up by the efferent lymphatics.

The right and left tracheal trunks lie on their respective sides of the trachea and empty into the external jugular vein just be-

Fig. 80. Ventral Aspect of Chief Lymphatic Vessels of the Cat.

a, Axillary gland; as, pancreas Aselli; an, superficial lymphatics from the head; $b$, bronchial glands receiving lymph from lungs; $c$, lymphatic trunk; $c r$, cervical glands; $c v$, laryngeal glands; $d$, vessel from diaphragm; $e j$, external jugular vein; in, inguinal glands; $i l$, iliac glands; $j u$, junction of thoracic duct with tracheal trunk; $l$, lumbar glands; $l i$, large intestine; $l v$, lymph-vessel from liver; $m$, lacteal vessel and glands of mesentery; $n$, superficial lymphatics from limb; $o$, deep lymph-vessels from limb; on, lymphatics from thoracic wall; ol, vessel from abdominal wall; oc, vessels from limb; rec, receptaculum chyli; $s$, subclavian vein; $t$, lymphatics from skin of leg; $t r, t l$, tracheal trunks; va, lymph trunk from pancreas Aselli to thoracic duct; $v$, superior vena cava; I and 2, submaxillary lymph glands. 
fore its junction with the subclavian. The opening is guarded by a valve which prevents the blood from entering the lymphatic trunk.

The thoracic duct (Fig. 80) is the largest vessel of the lymphatic system, but is usually invisible unless injected. It extends from the region of the kidneys on the dorsal

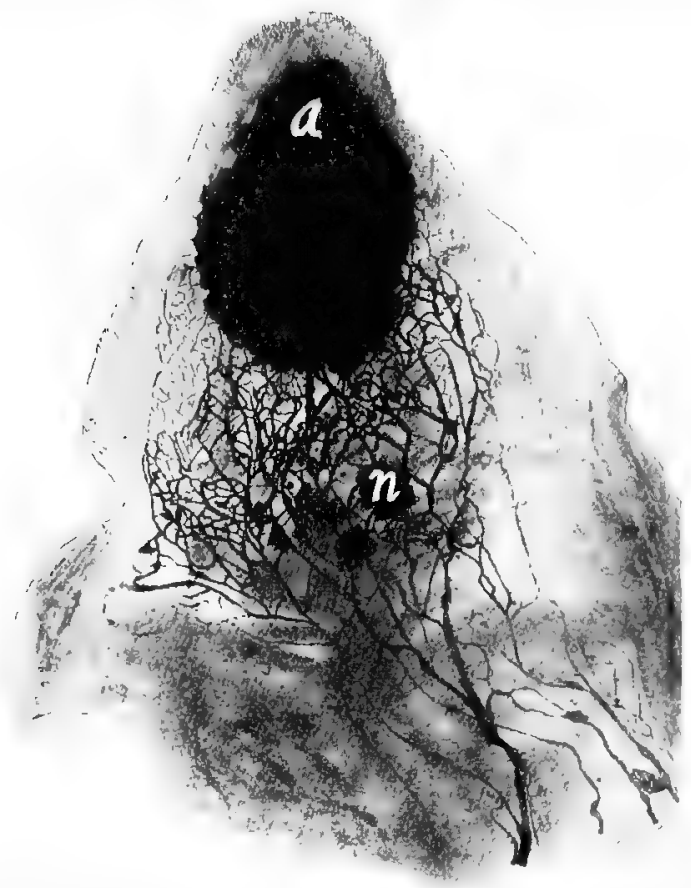

Fig. 8i. Photograph of Lymphatic Capillaries Injected with Berlin BLUE. They lie immediately beneath the skin on the outer aspect of the ear.

a, Point of injection; the black area is Berlin blue lying in the connective-tissue spaces from which the capillaries arise; $n$, injection escaped from ruptured vessel.

aspect of the body cavity, along the left side of the spinal column, to its opening into the external jugular vein near where the latter joins the subclavian vein. The caudal end 
of the thoracic duct is expanded, forming the receptaculum chyli. Numerous valves are present in the duct, and give to it a moniliform or beaded appearance. It receives all the lymph from the left abdominal wall, both pelvic extremities, a large part of the thoracic wall, and the thoracic and abdominal viscera.

\section{DUCTLESS GLANDS.}

The splcon, thyroid gland, thymus gland, and suprarenal bodies are ductless glands whose functions are imperfectly known. The largest of these is the spleen, which is of a deep red color in a fresh specimen, and lies in the abdominal cavity on the left side caudad to the stomach (Fig. 55). It is about five centimeters long, two centimeters wide, and less than a centimeter thick. It is composed of lymphoid tissue of two forms, supported by connective-tissue trabeculæ which are merely prolongations of the enveloping capsule. The two forms of tissue can be seen by cutting the organ transversely. The dense lymphoid tissue appears as white spots less than the size of a pin-head. They are the Malpighian corpuscles. The intervening looser lymphoid tissue forms the greater part of the spleen, and is known as the splenic pulp. The splenic artery, a branch of the coeliac axis, enters the spleen at its hilus and divides into capillaries which terminate in irregular spaces, thus permitting the blood to flow freely through the splenic pulp, whence it is taken up by the capillaries of the splenic vein leading to the portal vein. In embryonic life the spleen forms blood-corpuscles, but in postnatal life it seems to destroy blood-corpuscles. An animal from which the spleen has been removed may live many years in good health.

The thyroid gland is composed of two parts lying on the lateral aspects of the trachea, just caudad to the larynx. 
Each part is less than two centimeters long. The two parts are sometimes connected by a small isthmus extending ventrally across the trachea, as in man. An enlargement of this gland in man is called goiter. An animal can live only a short time after the removal of the thyroid unless it is fed thyroids or an extract of thyroid gland. The function of the gland is to supply iodin compounds to the system.

The thymus gland is a median structure varying in size according to age. In a cat about one-third grown it is very large, extending craniad from the heart along the ventral aspect of the trachea three or four centimeters. As the cat grows older, it gradually dwindles, and is entirely absent in aged specimens. Its function is unknown. It persists throughout life in the lower vertebrates.

The suprarenal bodies are small, somewhat bean-shaped organs lying craniad of the kidneys. An animal from which they have been removed can live but a short time. Their function is not known. They are sometimes spoken of as suprarenal capsules or adrenal bodies.

The above-named ductless glands occur in all mammals in the same relative locations. The anatomy of the lymphatic system is also exceedingly similar throughout the various orders of mammals. In some animals, especially man, the lymphatic glands are more numerous than in the cat. The tracheal trunks are also wanting in man and a right thoracic duct about two centimeters long is usually present. A failure of the lymphatics to do their work results in dropsy.

\section{PRACTICAL QUESTIONS AND SUGGESTIONS.}

I. Which of the four parts of the lymphatic system are visible in your specimen?

2. Describe size and number of lymphatic glands in the mesentery.

3. Describe the location of lymph glands present in any other portion of your specimen. 
4. How do you distinguish a lymph gland from other glands?

5. What causes the lymph to flow in one direction only?

6. What is meant by afferent and efferent lymphatics?

7. Which kind of blood-corpuscles are found within the lymphvessels?

8. From what regions does the thoracic duct receive the lymph?

9. What glands receive the lymph from the thoracic limb?

Io. What glands receive the lymph from the pelvic limb?

II. Describe location of spleen, thyroid and thymus glands, and suprarenal capsules by naming the organs with which they are in contact.

12. Draw a cross-section of the spleen and label all features visible.

I3. Draw a cross-section of the suprarenal body and label parts.

I4. Tell what you know of the functions of the ductless glands.

15. What is a gland? 


\section{THE RESPIRATORY SYSTEM.}

Respiration is the process whereby the tissues are supplied with oxygen and relieved of their carbon dioxid. In mammals, the special organs of respiration are the lungs, wherein the carbon dioxid is received from the blood, while at the same time the oxygen of the air passes through the thin-walled capillaries to the red blood-corpuscles capable of conveying it to the cells throughout the body. Each cell is composed largely of carbon, hydrogen, oxygen, and nitrogen, and any activity on the part of the cell is the result of the chemical union of some of its elements, whereby several waste products are formed, one of which is the gas, $\mathrm{CO}_{2}$ (carbon dioxid). This gas is a poison and therefore must be eliminated. It passes through the thin walls of the capillaries adjacent to every cell, and is transferred through the veins to the heart and thence to the lungs. Here the pulmonary artery divides up into capillaries ramifying over the air sacs (Fig. 84), thus permitting the carbon dioxid to escape into the air sacs. Other waste products resulting from chemical activity within the cells are carried away by the kidneys and.sweat glands.

The respiratory system consists of the nasal passages, pharynx, larynx, trachea, and lungs. The air taken in at the anterior nares is warmed in passing over the mucous membrane of the turbinated bones, after which it goes on through the posterior nares (Fig. I8) to the pharynx, and thence into the larynx.

The larynx is the cartilaginous expansion of the cranial end of the trachea, at the base of the tongue. The basihyal bone is attached to the cranial ventral margin of the larynx and on each side is a thyrohyal bone (Fig. 20). Dorsal 
to the larynx is the esophagus. By removing carefully the muscles and fibrous tissue from the cartilage the larynx is seen to be composed of five pieces: the epiglottis, thyroid cartilage, two arytenoid cartilages, and the cricoid cartilage (Fig. 20). The epiglottis is the small triangular cartilage that closes the glottis when food passes into the esophagus (Fig. 56). The thyroid cartilage constitutes the largest part of the larynx. In man it forms the prominence known as Adam's apple. Dorsally the two halves of the thyroid cartilage are separated, each projecting craniad into a process known as a cornu. The arytenoid cartilages are the two small paired pieces caudad to the thyroid, on the dorsal side. The cricoid cartilage forms a complete ring at the caudal end of the larynx (Fig. 20).

There are a number of ligaments connecting the various parts of the larynx, the most important of which are the

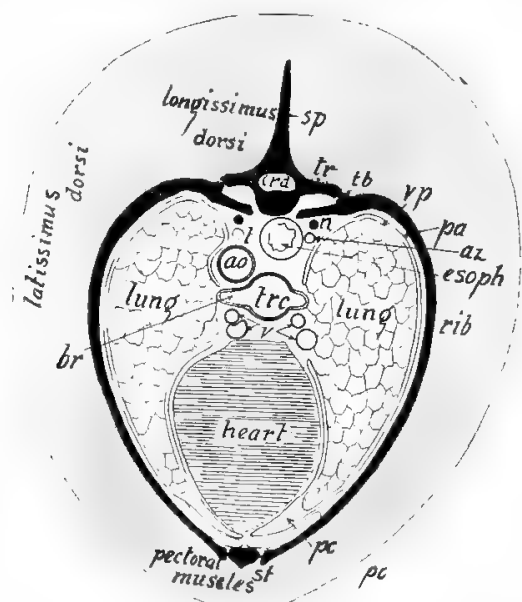

Fig. 82, Diagrammatic Transverse Section of the Chest.

ao, Aorta; br, bronchus; crd, spinal cord; csoph, esophagus; hd, head of rib; $p a$, parietal pleura; $p c$, cavity of the pleura; $s p$, spinous process; $s t$, sternum; $t b$, tubercle of rib; $t r$, transverse process; $v p$, visceral pleura; $t$, thoracic duct; $n$, sympathetic nerve cord; $a z$ azygos vein; trc, trachea; $v$, pulmonary veins. 


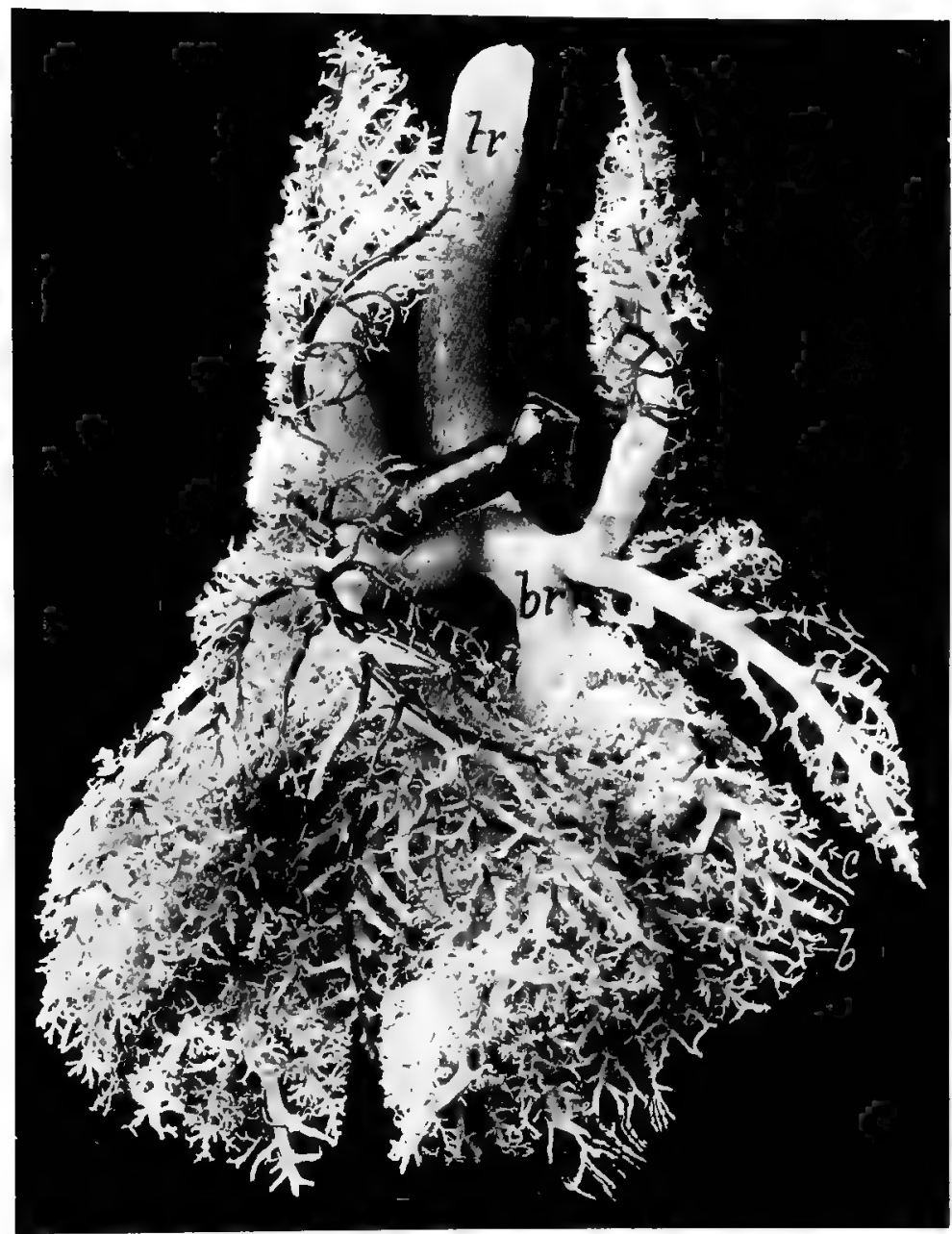

Fig. 83. Photograph of a Lung Corrosion of a Puma in Morphologic Museum of Princeton University. The specimen was prepared by Mr. Sylvester. The trachea with all its ramifications was injected with white paraffin, and the pulmonary artery with red paraffin, after which the lung substance was eaten away with acid. $t r$, Trachea; $b r$, bronchus; $b$, bronchial tube; $c$, bronchiole. The pulmonary artery and its branches are much darker than the air tubes. 
rocal cords. These are of two kinds-true and false. They are best demonstrated by dividing the larynx, sagittally. The superior or false vocal cords are the two superior thyro-arytenoid ligaments passing from the arytenoid to the thyroid cartilage, at the base of the epiglottis. The cat is said to use these cords in purring. The inferior or true vocal cords are the inferior thyro-arytenoid ligaments, consisting, as in man, of a fold of mucous membrane on either side, just caudad to the false vocal cords (Fig. 56). The depression on either side between the true and false vocal cords is the ventricle. By means of the muscles attached to the arytenoid and thyroid cartilages, the tenseness of the vocal cords is regulated, and the various pitches of voice produced.

The trachea, or windpipe, is the tube leading from the larynx to the lungs (Fig. 55). Its walls are prevented from collapsing by the presence of about forty-five cartilaginous rings which are incomplete dorsally. Before passing into the lungs the trachea bifurcates into a right and a left bronchus. The trachea and bronchi are lined by ciliated columnar cpithelium. The cilia project freely into the lumen from the columnar walls, and are always waving in such a manner as to carry the secreted mucus lodged thereon toward the mouth, thereby preventing the lungs from becoming clogged with foreign material. Ciliated cells with the cilia in action may be easily demonstrated by scraping very lightly a little mucus from the posterior part of the roof of the frog's mouth, and mounting the same in a drop of saliva on a glass slip, which is then to be examined with a microscope magnifying about 300 diameters. The diaphragm of the microscope should be arranged so as to admit but little light.

The lungs together with the heart fill up the greater part of the thoracic cavity. In a cat recently killed the lungs 
may be expanded by tying a piece of glass tubing on the trachea and blowing into it strongly for a few seconds. Each lung is completely invested by a sac of delicate transparent serous membrane called pleura (Fig. 82). Each sac is reflected at the root or the lung, where the bloodvessels and bronchus enter, so as to form a parietal layer lining its half of the thoracic cavity. The median space between the two sacs is called the mediastinum. The anterior or ventral mediastinum contains blood vessels and the thymus gland. The dorsal or posterior

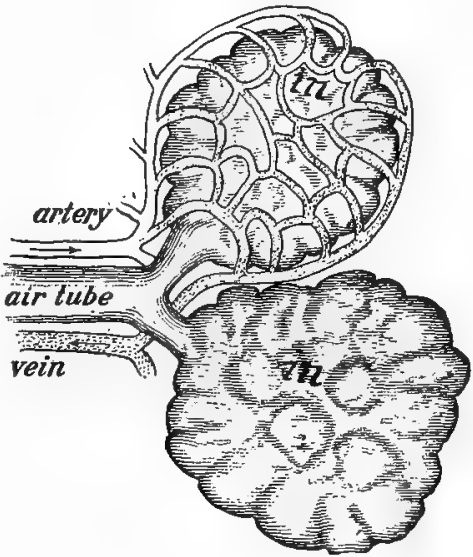

Fig. 84. Diagram Showing how THE Air Tube or Bron'ChIOle TermiNATES IN INFUNDIBULA.

in, infundibulum with air sacs over which numerous capillaries lie. mediastinum lodges the trachea, esophagus and aorta and the heart occupies the middle mediastinum.

Each lung is divided by deep clefts into several lobes. The left lung is composed of two large lobes and a small one. The right lung consists of four unequal lobes. The cranial end of the lung is the apex and the caudal end, resting against the diaphragm, is the base. The bronchi, as they are continued into the lungs, subdivide into smaller tubes, whose later subdivisions are the bronchioles. The latter, dividing like the branches of a tree, finally terminate in blind pouches known as infundibula or alveoli, the walls of which are thickly beset with microscopic sac-like evaginations named air sacs (Figs. 83 and 84 ). The walls of these air sacs are very thin, somewhat like the peritoneum. 
Over them course numerous thin-walled capillaries, so that the carbon dioxid of the blood passes out into the air as the oxygen passes into the blood. Expiration is the process

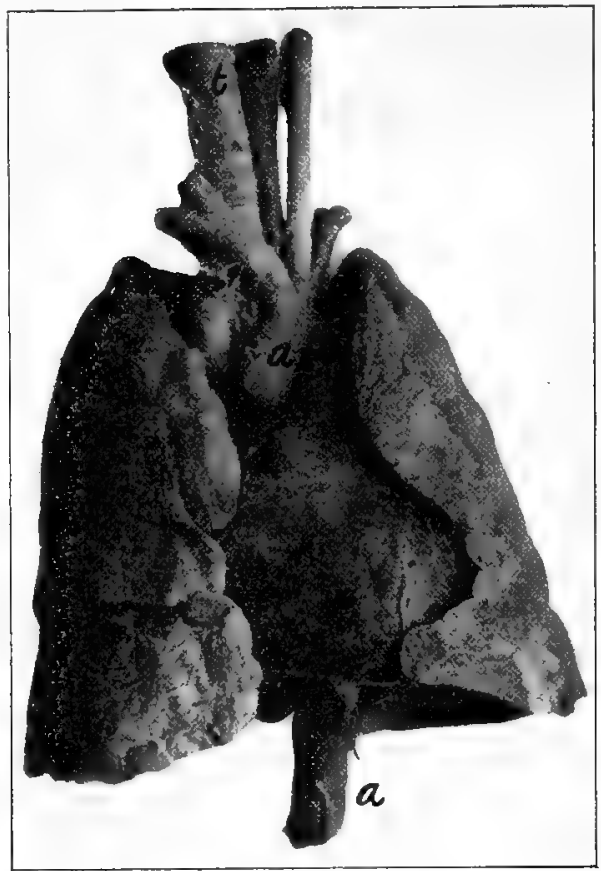

Fig. 85. Photograph of Human Heart and Lungs from Ventral ASPECT.

$a$, aorta; $t$, trachea.

of forcing the air out of the lungs which have been filled by an inspiration chiefly effected by depressing the diaphragm and elevating the ribs. The two processes together are spoken of as a respiration.

PRACTICAL QUESTIONS AND SUGGESTIONS.

I. Of what four elements are the soft parts of the body largely composed? 
2. What waste gas is formed in every part of the body exercised? blood?

3. Through what three channels do waste materials pass from the blood.

4. Describe the manner in which the oxygen of the air reaches the

5. Write a description of the pharynx.

6. Bisect the larynx in the sagittal plane, make a drawing of the cut aspect, and label all features. t1se?

7. How many cartilaginous rings in the trachea and what is their

8. Describe as much of the pleura as can be seen in your specimen.

9. Do the right and left bronchi have the same number of main branches?

Io. Why do the air cells seldom become clogged?

II. What muscles are largely used in respiration?

I2. Describe the hyoid bone as seen from your dissection.

I3. What part of this bone can you feel beneath your mandible?

I4. How does the carbon dioxid given off by the cells in the foot reach the lungs?

I5. What causes the air to enter the lungs?

I6. Inflate the lungs of a freshly killed animal by forcing air from your lungs into a glass tube tied into its trachea.

I7. After retaining a full inspiration of air as long as possible, expire it through a glass tube into the bottom of a two-liter bottle and insert into the bottle a lighted splinter.

I8. Describe the pulmonary circulation 


\section{THE EXCRETORY AND REPRODUCTIVE SYSTEM.}

As explained in the last section, a portion of the waste products produced by the activity of the cells of the body is passed off through the lungs, but some other outlet must be provided for the excretions that are not in the form of gases. These liquid excretions, containing various salts and urea, pass off through the kidneys and the glands of the skin.

The latter are of two kinds, sudoriparous or sweat glands. and sebaceous or oil glands, with ducts opening into the hair follicles near the surface. The sweat glands lie deeper than the sebaceous glands. The former are subcutaneous and consist of a more or less coiled tube with a straight duct opening on the surface. They are most abundant on the tip of the nose and the balls of the feet. The sebaceons glands are very numerous all over the body. Both are of microscopic size.

A still more important part of the excretory system is the urinary system, consisting of the kidneys, two ureters leading from the kidneys to the bladder, the bladder, and the urethra.

The student should note that the kidney is not enveloped by the peritoneum, like the other abdominal organs, but lies dorsad to it and is encased by a fibrous covering known as the capsule. The hilus is that portion of the concave surface where the renal artery and vein and ureter enter. A median longitudinal section of the kidney will show that the ureter within the kidney enlarges, forming the pelvis, into which projects the renal papilla (Fig. 87). This is better demonstrated in a transverse section. 
The substance of the kidney is composed of an outer cortical layer, about a half centimeter thick, and an inner medullary substance adjacent to the pelvis, and projecting into the latter in the form of a papilla. In the cortical substance are hundreds of Malpighian bodies, each composed of a ball of capillaries (Fig. 87) enveloped by the invaginated enlarged extremity of a tubule which carries away the urine by a tortuous course to the papilla (Fig. 88). In the Malpighian bodies the water and other mineral substances of the urine are extracted from the blood by means of the epithelial cells forming the inner wall of the capsule of Bowman. These urinary products pass through the proximal convoluted tubule and the loop of Henle to the distal convoluted tubule, where they are mingled with the urea extracted from the blood by the columnar epithelial cells of the tubule. From this point the excretions flow into the collecting tube which empties into the pelvis at the papilla. In a prepared microscopic section of the kidney, these Malpighian bodies and uriniferous tubules may be seen with a microscope magnifying about 200 diameters. 
The ureter is a small tube leading from the pelvis of each kidney along the dorsal aspect of the abdominal cavity to the dorsal and caudal end of the bladder.

The bladder is the sac for retaining the urine. It lies ventrad

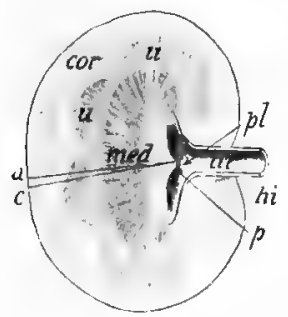

Fig. 87. Median Longitudinal Section of A Kidney.

cor, Cortical substance; hi, hilus; med, medullary portion; $p$, papilla; $p l$, pelvis; $u$, pyramids; $u r$, ureter.

to the rectum, a little to the right of the median line, being held in place by the ligamentum suspensorium, a fold of the peritoneum attached to the mid-ventral line. It is also attached by lateral ligaments. On its dorsocaudal aspect near where the ureters empty, the urethra originates and passes along the ventral surface of the vagina to the vestibule, within which it opens (Fig. 86). In the male it passes directly from the bladder

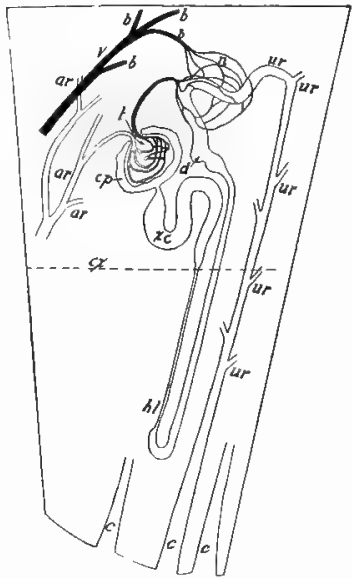

Fig. 88. Diagram of the Structure of THE KidNEY BETWEEN THE LINES $a$ AND $c$ IN FIG. 87.

ar, Arteries leading to the Malpighian bodies, only one capsule being shown; $b$, veins leading from the capillary network about a convoluted tubule as at $n ; c x$, line marking the boundary between the cortical and medullary portions of the kidney; $c p$, capsule of Bowman enveloping the bunch of capillaries; $d$, distal convoluted tubule; $h l$, Henle's loop; $n$, capillary network about the tubule; $t$, the bunch of capillaries or Malpighian tuft; $u r$, portions of uriniferous tubules emptying into the collecting tubule $c ; x c$, proximal convoluted tubule. along the ventral surface of the rectum to the root of the penis at the pubic symphysis, and thence on through the 
corpus spongiosum to the point of the penis. The ureter, bladder, and urethra consist largely of muscular tissue, the lining being formed by mucous membrane.

\section{THE FEMALE REPRODUCTIVE SYSTEM.}

The female reproductive organs are the two oz'aries, a pair of Fallopian tubes, a uterus, and a ragina. To demonstrate these, the entire ventral abdominal wall must be removed and the pubic symphysis severed with the bonecutters. The ovaries are the small yellowish oval bodies about one centimeter long lying just caudad of the kidneys, against the dorsal abdominal wall. From the vicinity of each extends a tube caudad to join its fellow in the median line ventrad to the rectum (Figs. 55 and 86 ). The crania1 portions of these are the Fallopian tubes, and the larger caudal portions are the cornua of the uterus. The junction of the cornua in the median line forms the body of the uterus.

The Fallopian tube is smaller in diameter than the cornu of the uterus, generally more or less contorted, and terminates by a fimbriated expansion or mouth opening freely into the abdominal cavity.

The Fallopian tubes and uterus are suspended by the broad ligament, or ligamentum latum, which is a fold of the peritoneum attached to the dorsal abdominal wall. The round ligament, or ligamentum rotundum, also aids in keeping the uterus in place. This appears as a thickening of the broad ligament when the latter is looked through toward the light. The round ligament extends from about the middle of the horn or cornu of the uterus ventrad of Poupart's ligament, and through the muscles of the abdominal wall beneath the skin of the inguinal region, where it gradually loses itself. It is exceedingly delicate and thread-like. 
The vagina extends from the uterus to the vestibule, opening on the surface ventrad to the anus. The small papilla just caudad of the orifice of the urethra on the ventral surface of the vestibule is the clitoris, the homologue of a part of the penis in the male. The prominent circular fold of mucous membrane craniad of the orifice of the urethra represents the hymen, which marks the separation between the vagina and vestibule. This structure may be shown by making a median longitudinal section through the vagina. Bartholin's glands lie on the lateral aspect of the vestibule, into which their ducts open. Each one is about the size of a small pea. The vagina, uterus, and Fallopian tubes are lined with mucous membrane in which are many glands. The mucous lining is surrounded by a muscular coat especially thick in the uterus.

The ovaries are the organs producing the female germ cells or ova which when fertilized are known as the eggs (Figs. 55 and 86). One lies caudad of the kidney on each sicle and is invested by peritoneum, which should be carefully dissected away. A microscopically prepared section of the adult ovary magnified about Ioo diameters will reveal a number of ova in a more or less mature state. Usually a peripheral ring of very young ova is present, more mature ones are near the center, while one or two quite ripe ova are very near the circumference. As the ova develop, a follicle or sac known as the Graafian follicle is formed about them. This is lined with several layers of epithelial cells forming the membrana granulosa. At one side of the follicle the membrana granulosa thickens and envelops the ormm, forming the discus proligerus. The cavity of the follicle is filled with liquor folliculi. When the ovum becomes almost mature, the walls of the follicle have grown peripherad, so as to cause a pin-head protuberance on the surface of the ovary clearly visible to the 
naked eye. In a fresh specimen this protuberance may be picked open and the ovum expelled on a slide for ex-

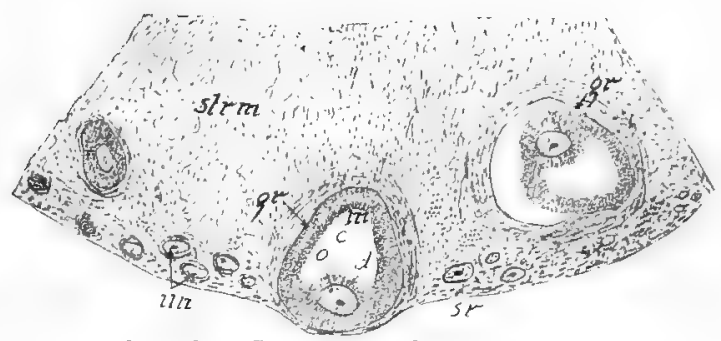

Fig. 89. Section of Ovary. $\times 40$.

$s r$, Surface of the ovary; $g r$, Graafian follicle with mature ovum; 0 , ovum; $c$, cavity of the follicle; un, undeveloped ova; strm, stroma or connective elements of the ovary; $m$, membrana granulosa; $d$, discus proligerus.

amination with the microscope. The ovum is scarcely visible to the unaided eye. The human ovum is still smaller.

The ova of all mammals, except the duck-bill and spiny ant-eater, are very small. When the ovum becomes mature, the protruding wall of the follicle bursts, permitting its contents to be received by the expanded end of the Fallopian tube, whence it passes to the uterus. If the male element, the spermatozoon, enters the ovum, the latter is soon enveloped by a growth of mucous membrane and retained in the uterus for development. Ripe ova occur near the close of the first year of the cat's life and new ones probably continue to mature during the next ten years. The discharge of the ova from the ovary is accompanied by a constitutional disturbance, during which an extra amount of blood is sent to the sexual organs, and the sexual appetite becomes very marked. In the human species this disturbance occurs about every twenty-eight days. Mature ova occur in the human ovary between the thirteenth and forty-eighth years. 
The mammary glands of the adult fenale cat reach their full development when it gives birth to young. They may be seen by carefully removing the skin from the ventral aspect of the body, when they will appear somewhat like a thin layer of adipose tissue extending from near the axilla to the pubic symphysis. There are four teats or nipples on each side. In some mammals the nipples are less numerous and confined either to the thoracic or inguinal region. In the elephant, Chiroptera, and Primates there are but two nipples, and they are thoracic. In most Ungulates the nipples are inguinal.

\section{THE MALE REPRODUCTIVE SYSTEM.}

The organs of generation in the male consist of the testes, the ducts leading from the testes to the urethra, the prostate gland, Cowper's gland, and the penis.

The testes are two in number, contained in a pouch of integument called the scrotum, which hangs beneath the anus. Internally the scrotum is divided into two chambers. By dissecting away the adipose tissue covering the spermatic cord in the inguinal region (Fig. 5I) it may be seen that the cord and the testes are enveloped by a tough sheath. This is composed of cremasteric fascia derived from the aponeurosis of the external oblique muscle, and of the tunica vaginalis.

During the fetal life the testes lie in the abdominal cavity, and when they descend into the scrotum about the time of birth, a double layer of peritoneum is pushed down before them through the inguinal canal, forming a diverticulum whose blind end lies within the scrotum, while the constricted portion forms a channel for the vas deferens, spermatic nerve, and vessels. These three structures form the spermatic cord (Fig. 5I). The fascia propria (tunica vaginalis communis) is inseparably united with the adjacent 
parietal layer of the peritoneum. The visceral layer of peritoneum is quite delicate and transparent and lies close to the testis. Immediately surrounding the latter is a dense capsule, the tunica albuginea, sending septa into the interior. Within the tunica vaginalis is the tunica albuginea, closely investing the testicle and adjacent to the epididymis, penetrating the substance of the gland, forming a septum known as the mediastinum testis or corpus Highmorianum (Fig. 90).

The testis is about $\mathrm{I} / 2$ centimeters long by I centimeter thick. On its dorsal surface lies the epididymis, an elongated body composed of an enlarged extremity, the globus major, and an attenuated portion, the globus minor. The main portion of a testicle is composed of many minute coiled tubules, tubuli seminiferi, which unite into a few tubules near the surface of the testis beneath the globus major, into which they extend. These tubules are the rasa

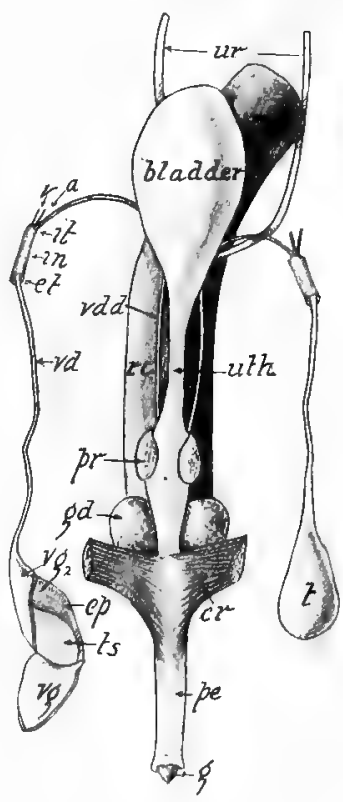

Fig. 90. Ventral Aspect of the Male Rerroductive Organs.

$c r$, One of the crura of the penis; $e p$, epididymis revealed by cutting and reflecting $v g$, a piece of the tunica vaginalis and albuginea; et, external abdominal ring; it, internal abdominal ring; in, inguinal canal; $g$, glans penis; $g d$, Cowper's glands; $p e$, penis; $p r$, prostate gland; $r c$, rectum; $t$, testis from which the tough sheath composed of the levator scroti muscle and cremaster fascia has been removed, leaving it enveloped by the tunica vaginalis; $t s$, testicle from which a portion of the tunica vaginalis and albuginea has been reflected; uth, urethra; ur, ureters; vd, spermatic cord; $v d d$, vas deferens within the abdominal cavity; $v g$, tunica albuginea reflected; $v_{2}$, tunica albuginea; $v$, spermatic vein. 
effercntia. The epididymis is composed of a single greatly convoluted tubule of which the vas deferens is a continuation. The latter proceeds craniad to the external abdominal ring, which it enters to traverse the inguinal canal into the abdominal cavity. It then curves caudad and enters the urethra on its dorsal aspect in the region of the prostate gland.

The inguinal canal begins with the external abdominal ring, which is an opening in the tendon of the external

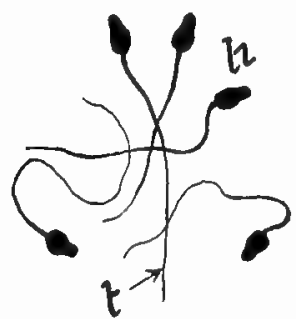

Fig. 9i. Spermatozoa or Male Germ Cells. $\times 500$.

$h$, Head; $t$, tail. oblique muscle, and ends with the internal abdominal ring, which is an opening in the fascia of the transversalis muscle (Fig. 5I). By accident, a fold of the small intestine in man sometimes descends through the inguinal canal, which condition is known as hernia or rupture.

The penis is a cylindrical pointed body about three centimeters long when in repose. It is composed of two kinds of tissues arranged in three bundles. The corpus spongiosum is the median ventral bundle, extending throughout the length of the organ, and at the end forms the glans or head. The two dorsal lateral bundles are the corpora cavernosa. They form the greater part of the penis proximad of the glans, and by diverging somewhat before their attachment on either side to the pubis and ischium form the crura. The penis is suspended from the wall of the abdomen by a fold of integument inserted at the base of the glans, and forming the prepuce. The latter is a free projection of skin covering the glans. In the midst of the penis is a small bone. The penis is the organ of copulation, and is composed of a spongy mass of elastic and muscular fibers richly supplied with highly distensible blood-vessels which when filled render the organ erect. 
The prostate gland surrounds the urethra dorsally and laterally about two or three centimeters from the bladder. This gland secretes a milky fluid which is poured into the urethra through many ducts, during copulation, and serves as a medium for the spermatozoa (Fig. 90).

Cowper's glands are two in number, about the size of a pea, and lie in the angles formed by the urethra and the crura of the corpora cavernosa. These glands secrete a viscid fluid of unknown function. One duct from each gland opens into the urethra.

\section{REMARKS ON THE MAMMALIAN UROGENITAL SYSTEM.}

The urogenital system is subject to some variations in the different orders of Mammalia. In the Ornithodelphia, the mammary glands are devoid of teats and the oviducts corresponding to the Fallopian tubes and horns of the uterus do not unite in the median line to form the body of the uterus, but unite with the urethra, forming the urogenital canal. The latter opens into an enlarged terminal portion of the rectum, called the cloaca. The ureters also open directly into the cloaca, so that there is but one external opening for the genital and excretory products. In the above features the Monotremes resemble the Amphibia and reptiles. All mammals are viviparous except the Monotremata, which are oviparous, laying eggs as large as those of the robin. The Ornithorhynchus incubates its eggs in an underground nest, while the Echidna carries her single egg in a temporary abdominal pouch.

The Marsupialia bring forth their young in a very immature condition. They are then carried for several months in an abdominal integumentary pouch, the marsupium, within which are the nipples. In the Monotremata, Cetacea, Sirenia, and elephant the testes do not descend into a scrotum, but are retained in the primitive location 
within the abdomen. In Primates and some Edentates, the uterus is merely a pear-shaped body without any cornua, the Fallopian tubes leading directly into the body of the uterus.

In the ox, bears, seals, and cetaceans the kidneys are distinctly lobulated. Internal evidence of lobulation is presented in most mammals by the renal papillæ. In the embryo, the kidneys of all mammals are lobulated.

\section{PRACTICAL QUESTIONS AND SUGGESTIONS.}

I. What other waste products besides $\mathrm{CO}_{2}$ result from the chemical action in the tissues of the body?

2. Write a description of all parts of the urinary system visible in your dissection.

3. Bisect a kidncy longitudinally in the horizontal plane, draw the cut surface, and label all features.

4. Explain the parts of a uriniferous tubule.

5. Wherein does the male urinary system differ from the female?

6. Make a drawing of the Fallopian tubes and uterus and label all parts.

7. Describe location, size, external appearance, etc., of the ovary as seen in your specimen.

8. How are the female reproductive organs held in place?

9. Can you distinguish externally the termination of the uterus and the beginning of the vagina?

Io. Are there any eggs protruding from the ovary or any cavities from which eggs have been recently discharged?

II. Describe a Graafian follicle.

I2. What must be added to the ovum to produce another animal?

I3. Name the parts of the male reproductive system present in your specimen and locate them.

I4. Describe the course of the spermatozoon from the testis to the exterior.

I5. Do all mammals nourish their young in the same manner?

I6. What mammals incubate their eggs externally? 


\section{THE NERVOUS SYSTEM.}

The nervous elements of the cat form three systems, known as the central, peripheral, and sympathetic. The central nervous system includes the brain and spinal cord. The peripheral system includes the twelve pairs of nerves emanating from the brain and the forty pairs of nerves emanating from the spinal cord to supply the extremities and trunk. The sympathetic system is composed of two ganglionated nerve cords extending throughout the trunk within the body cavity, one on either side of the vertebral column, and their various branches to all the viscera, bloodvessels, etc., of the body (Figs. 94 and 95).

\section{THE BRAIN.}

The central nervous system is known as the cerebro-spinal axis. It is composed of the brain and spinal cord. The brain lies within the cranial cavity and is protected by three membranes called the meninges. These may be demonstrated by cutting away the roof of the skull with the bone forceps. The dura mater is the tough fibrous membrane lining the interior of the skull. It dips down between the two halves of the cerebrum, forming the falx cerebri. Between the cerebrum and cerebellum in the cat it is ossified, thus forming the bony shelf or tentorium cerebelli (Fig. I8). The second membrane of the brain is the arachnoid. Between the dura mater and the arachnoid is the subdural space, containing a fluid having the nature of lymph. The arachnoid is a very delicate membrane which does not dip down into the clefts between the folds of the brain, as is the case with the pia mater, but passes across these depressions, where it may be easily demonstrated (Fig. 98). 
The subarachnoidal space lies between the arachnoid and pia mater. The pia mater is the delicate vascular membrane following so closely the folds and clefts of the brain that it becomes apparent only when lifted carefully by the forceps.

In order to study the brain satisfactorily each student should have a specimen hardened according to directions on page Io, and also should be permitted to examine a series of sections cut transversely about a centimeter thick. The brain of a calf or sheep serves the learner's purpose better than that of a cat, as the parts are larger, and they are also easier to procure. An additional advantage is also found in the fact that there is some difference between the brains of the cat and calf, and the student must therefore rely more on his own observations.

External Features.-The brain is composed of five parts: the medulla oblongata, or myelencephalon; the pons Varolii and cerebellum, forming the metencephalon; the corpora quadrigemina and crura cerebri, composing the mesencephalon; the diencephalon, including the optic thalami and other parts bounding the third ventricle; and the telcncephalon, or cerebral hemispheres. The medulla oblongata, sometimes called the bulb or stem of the brain. is the expansion of the spinal cord as it passes through the foramen magnum. The pons Varolii is the bridge of transverse fibers seen on the ventral aspect of the brain just craniad of the medulla (Fig. 93). The cerebellum or little brain lies on the dorsal side of the medulla and is partly covered by the caudal part of the cerebrum. The mesencephalon is not visible externally on the dorsal aspect, but may be seen immediately craniad of the cerebellum by cutting away the cerebrum (Fig. 96). The diencephalon is visible externally only on the ventral aspect of the uncut brain, where it forms the floor of the third ventricle. It 
may be viewed as a whole if the dorsal half of the cerebrum including the corpus callosum is cut away. The telencephalon or end brain is composed of the two large hemispheres partially surrounding the diencephalon and mesencephalon.

The brain is composed of two kinds of matter, white and gray. The former is constructed for the most part of fibers, while the latter is formed largely of cells. The outer or cortical portion of the cerebrum and cerebellum is a layer of gray matter less than a half centimeter thick, and is disposed in folds called gyri or convolutions with intervening slit-like depressions termed sulci, the more important of which are called fissures.

The four different portions of the cerebrum are known as frontal, parietal, occipital, and temporal lobes, which occupy the respective regions of the cranial cavity. The frontal and parietal lobes are separated by the crucial fissure, extending transversely between them. The olfactory lobe (usually torn off in removing the brain from the skull) projects from the cranial portion of the frontal lobe. The parietal lobe is marked by three gyri, named according to location gyrus marginalis, gyrus suprasylvius,

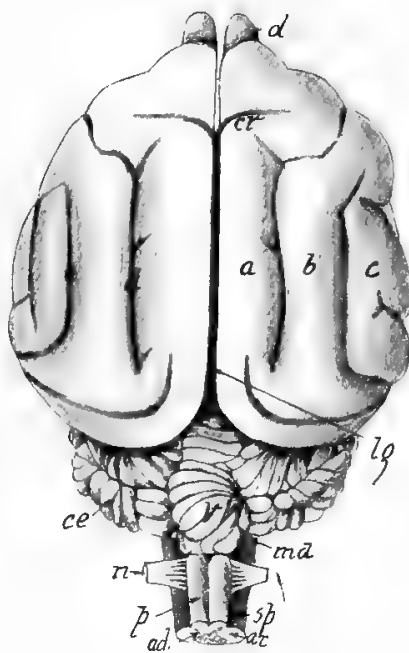

Fig. 92. Dorsal Aspect of THE BRAIN.

$a$, Gyrus marginalis; $a c$, white matter of the cord; $a d$, gray matter of the cord; $b$, gyrus suprasylvius; $c$, gyrus ectosylvius; $c r$, crucial fissure; $c e$, lateral lobe of cerebellum; $d$, lateral sulcus; $e$, suprasylvian sulcus; $l g$, great longitudinal fissure; $m d$, medulla oblongata; $n$, first spinal nerve; $o l$, olfactory lobe; $p$, posterior pyramids; $s p$, spinal cord; $v$, vermis of cerebellum. and gyrus ectosylvius (Figs. 92 and 93). The caudal 
portions of the gyri marginalis and suprasylvius constitute a portion of the occipital lobe. These two gyri are separated by the lateral sulcus. The suprasylvian sulcus extends between the gyrus suprasylvius and the gyrus ectosylvius. The splenial sulcus (Fig. 95) separates the gyrus marginalis from the gyrus fornicatus on the medial aspect of the parietal and occipital lobes. There are no definite sulci or fissures separating the parietal, occipital, and temporal lobes. The postrhinal fissure, extending caudad from the fissure of Sylvitu, divides the temporal lobe into two portions on the ventral aspect.

The ventral surface (Fig. 93) of the brain also presents important features which should be noted by the student before investigating the internal structure. The anterior pyramids, two indistinctly differentiated bundles of fibers, occupy the middle of the ventral region of the medulla, and craniad of the pons help form the peduncles of the cerebrum. Laterad of each pyramid is the olivary projection. A broad band of transverse fibers appearing just cautad of the pons Varolii and laterad of the anterior pyramids is the corpus trapezoideum.

The pons Varolii is itself composed of a band of transverse fibers which on either side forms the middle peduncle of the cerebellum. The fibers originate either in cells of the medulla or those of the cerebellum.

The crura cercbri, or peduncles of the cerebrum, the ventral portions of which are continued as the anterior pyramids (Fig. 93), are seen just craniad of the pons. Their fibers unite the cerebrum to the rest of the brain and the spinal cord. In the space between the crura and the optic chiasm is a prominent projection, the terminal nodular portion of which is the pituitary body or hypophysis. It occupies the pituitary fossa of the skull and is usually torn off in removing the brain. Caudad of the hypophysis are 


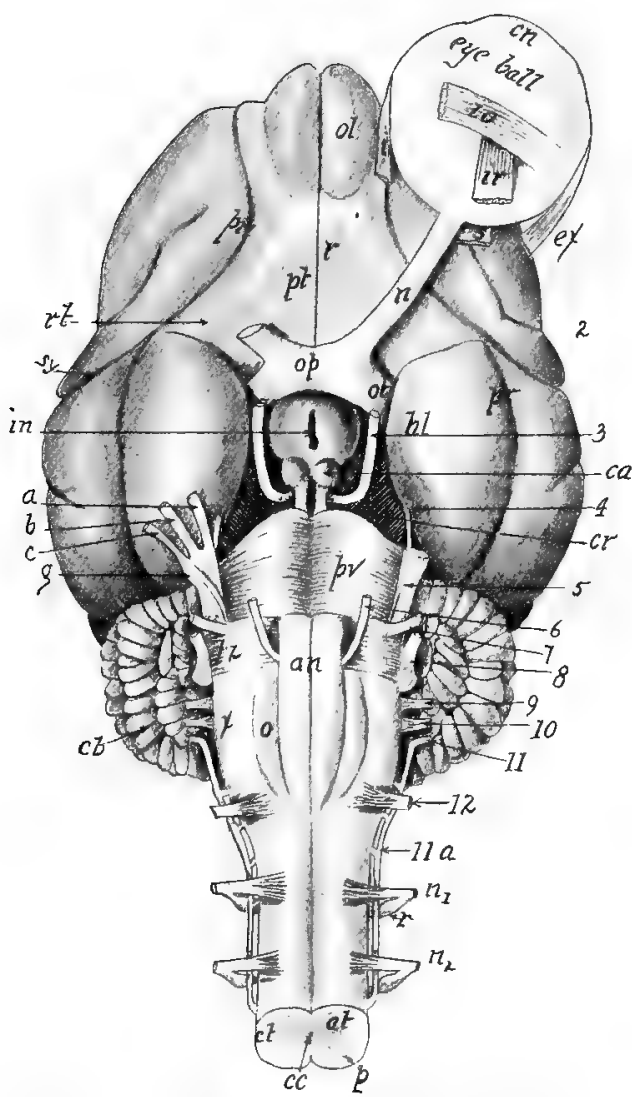

Fig. 93. Ventral Aspect of the Brain.

$2,3,4,5,6,7,8$, 9, IO, II, I2, The cranial nerves; $a$, ophthalmic branch of the trigeminal nerve; an, anterior pyramids; at, anterior horn of gray matter; $b$, superior maxillary branch of the trigeminal nerve; II $a$ eleventh cranial nerve with roots from the spinal cord; $c$, mandibular branch of the trigeminal nerve; $c a$, corpus albicans; $c b$, cerebellum; $c c$, canalis centralis; $c n$, cornea; $c t$, cut surface of spinal cord; ex, external rectus muscle; $c r$, peduncle of the cerebrum; $g$, Gasserian ganglion of the trigeminal nerve; $h l$, pyriform lobe; in, opening into the tuber cinereum revealed by removal of the infundibulum and pituitary body; $i$, internal rectus; $i o$, inferior oblique; $i r$, inferior rectus; $n_{1}$ and $n_{2}$, first and second spinal nerves; ol, olfactory lobe; $a p$, optic commissure; ot, optic tract; $p$, posterior horn of gray matter; pt, anterior perforated space; $p v$, pons Varolii; $r$, medial or inner root of olfactory nerve; $r t$, lateral root of olfactory nerve; $p r$, postrhinal fissure; $s y$, Sylvian fissure; $s$, superior rectus nutscle; $t z$, corpus trapezoideum; $x$, external arciform fibers. 
two small rounded white bodies, the corpora albicantia. The tuber cinereum, a slightly elevated mass of gray matter behind the optic chiasm, bears on its surface the funnelshaped stalk, the infundibulum, to which the hypophysis is attached. If the two latter parts are removed, there is seen a small elongated aperture through the tuber cinereum into the third ventricle (Figs. 93 and 95).

The optic commissure, or optic chiasm, is the commissure formed by the crossing of the optic nerves just craniad of the tuber cinereum. The prolongation of the optic nerves dorsad from the optic commissure forms the optic tracts, partly covered by the temporal lobes. On either side of the median fissure just craniad of the optic chiasm is a somewhat triangular area known as the anterior perforated space because of the numerous vessels that enter the brain in this region. Laterally this space is bounded by the lateral olfactory tract or lateral root of the olfactory nerve, which presents the appearance of a band of white fibers extending from the olfactory lobe into the temporal lobe. The medial or inner root of the olfactory nerve is seen adjacent to the median ventral line craniad of the anterior perforated space. The olfactory lobes project from the cranial ventral portion of the cerebrum and give origin to the first pair of cranial nerves.

Internal Structure.-The canalis centralis, a small canal extending throughout the center of the spinal cord, enlarges in the region of the brain, forming four cavities or ventricles communicating with each other by narrow channels. The brain is therefore to be considered as a hollow structure. The first and second ventricles, also known as lateral ventricles, occupy the cerebral hemispheres (Fig. 94). The third and fourth ventricles lie in the median line, and are therefore well seen in a sagittal section of the brain (Fig. 95). 
The Ventricles of the Brain.-The fourth ventricle is visible on the dorsal aspect of the medulla oblongata (Fig. 95). It is about three centimeters long by one centimeter wide, and lies ventral to the cerebellum. This ventricle is merely an expansion of the canalis centralis of the spinal cord. Its roof is very thin and consists of two portions, one of which, the superior medullary velum, sometimes called the valve of Vieussens, covers the cranial half of the ventricle; the other portion is the inferior medullary velum, lying over the caudal half. The latter velum is composed of a fold of pia mater tucked in between the cerebellum and medulla, in addition to a layer of epithelial cells on the ventricular aspect of the pia mater. Some nervous matter in addition to the pia mater and epithelium forms the superior velum. Two longitudinal vascular fringes hanging from the roof of the

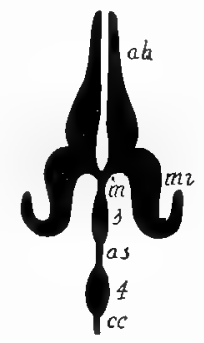

Fig. 94. DiAgram of VENTRICLES OF THE BRAIN VIEWED DORSALLY.

ah, Anterior horn of the right lateral ventricle; as, aqueduct of Sylvius; $c c$, canalis centralis of the spinal cord; 3 and 4 , third and fourth ventricles; $m$, foramen of Monro; $m i$, middle horn or cornu of the ventricle. ventricle on either side of the mid-line, form the choroid plexus, which is merely a network of blood-vessels carried by a reflected portion of the pia mater.

Craniad the fourth ventricle is continued as a small canal, the iter, or aqueduct of Sylvius, which lies ventrad to the corpora quadrigemina and opens into the third ventricle (Fig. 95). The latter is a narrow, vertical, cleft-like space between the optic thalami. The two thalami are united by the soft or middle commissure, better designated as the massa intermedia, extending through the ventricle. Unless this ventricle has been injected with a starch mass through the infundibulum before the brain was hardened, its cavity 
will not exceed a millimeter in width. The roof is formed much in the same manner as that of the fourth ventricle, by a reflection of the pia mater lined with epithelium (Figs. 95 and 97). A sagittal section of the brain placed in a pan of water will show the fold of pia mater called velum interpositum extending craniad from the pineal gland. Two folds of the pia mater hanging on either side from near the median line form the choroid plexus as in the fourth ventricle. The body of the fornix lies dorsad of the membranous roof of the ventricle. In the floor lie the corpora albicantia, the infundibulum, the tuber cinereum, and the optic commissure. Craniad the third ventricie communicates with the lateral ventricles by slit-like apertures, the foramina of Monro, passing laterad and ventrad of the anterior pillars of the fornix (Figs. 95 and 96).

The lateral ventricles are found in the cerebral hemispheres ventrad to the corpus callosum. They are the largest ventricles of the brain. In order to view them satisfactorily, the entire dorsal portion of the brain down to the corpus callosum must be cut away, and a hole cut through the corpus callosum. A number of cross-sections of the cerebral hemispheres should also be studied.

Each ventricle is composed of a body from which projects an anterior cornu and a middle or descending cornu. The former extends into the frontal lobe and thence into the olfactory lobe, and the latter descends into the temporal lobe. The roof of the body of the lateral ventricle is formed by the corpus callosum (Figs. 95, 96 and 97) and the medial wall by the septum lucidum, a mass of gray matter lying between the fornix and the corpus callosum. A fringe of pia mater projects through the foramen of Monro into the lateral ventricle, where it forms the choroid plexus. The lateral ventricles are lined with the epithelial layer common to the other ventricles. 
These cavities within the central nervous system result from the manner in which the brain and cord are formed. In the embryonic life of most vertebrates the nervous system appears as a trough of matter extending dorsally

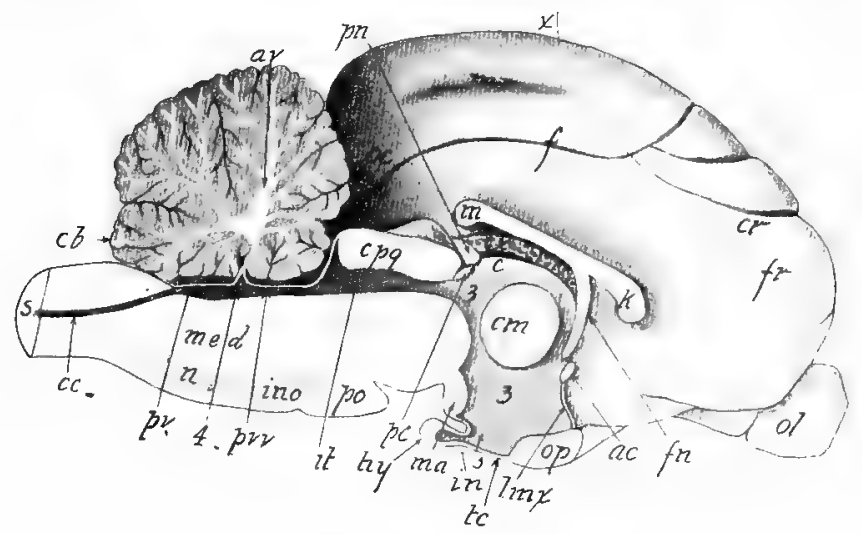

Fig. 95. Sagittal Section of the Brain.

$a c$, Anterior commissure; av, arbor vitx; $c$, habena; $c c$, canalis centralis; $c b$, cerebellum; $c m$, middle commissure or massa intermedia; $c r$, sulcus crucialis; $c p q$, corpus quadrigemina; $c x$, choroid plexus of third ventricle-the dark line dorsad of $c x$ is the velum interpositum; $f$, sulcus splenialis; $f r$, frontal lobe of cerebrum; $f n$, anterior pillars of the fornix; in, infundibulum; it, iter, or aqueduct of Sylvius; $k$, genu of corpus callosum; $\ln x$, lamina terminalis; $m$, splenium; nr, sulcus marginalis; med, medulla; op, optic chiasm; $o c$, occipital lobe; ol, olfactory lobe; $p n$, pineal gland; po, pons Varolii; $p c$, posterior commissure; $p a$, inferior medullary velum; pwr, superior medullary velum or valve of Vieussens; 3 and 4 , third and fourth ventricles.

throughout the length of the body. The sides of this trough grow dorso-mediad, thus forming a roof and thereby converting the trough into a canal which in the spinal cord becomes the canalis centralis, and in the brain the ventricles. This continuous cavity of the central nervous system contains a fluid having the nature of lymph.

The Commissures of the Brain.-The paired portions of the brain are united across the median line by bands of 
fibers known as commissures, two of which are visible on the ventral surface of the brain, and the others may be seen in a sagittal section (Fig. 95).

The pons Varolii is the commissure on the ventral aspect of the medulla. Its fibers pass into the cerebellum on either side, forming the middle peduncle or crus cerebelli ad pontem. The optic commissure or optic chiasm is formed by the crossing of the optic nerves, craniad of the tuber cinereum. Some of the fibers originating in the cells of the retina of one eye pass by this commissure directly to the cells in the retina of the other eye, while a second set passes from the eye to the optic tract on the opposite side of the brain, and still a third set, originating in one corpus quadrigeminum, passes by the optic commissure direct to the opposite corpus quadrigeminum (Figs. 95, I04).

The corpus callosum is the largest commissure of the brain. It joins the two cerebral hemispheres, and forms the roof of the lateral ventricles. This broad plate of fibers (Figs. 95, 96, 97, 98), which may be seen at the bottom of the great longitudinal fissure by pressing the hemispheres slightly apart, is about one millimeter thick and three centimeters wide. Laterally the fibers radiate in all directions to the gray matter of the cortex. The ventral bend of the median cranial portion of the callosum is the genu or knee. The caudal border is the splenium.

The fornix lies ventral to the callosum (Figs. 95 and 97) and consists of a median plate of fibers, the body, two posterior columns, and two anterior columns or pillars. The median plate or body of the fornix sends some fibers into the ventral surface of the callosum. From the cranial border of the body near the median line the two anterior columns, or pillars, descend in a curve, forming the cranial boundary of the third ventricle as far ventrad as 
the anterior commissure. Here the two columns diverge slightly from the median line, but continue their descent, curving caudad to their termination in the corpora albicantia. The posterior columns, or crura, descend from the caudal border of the body, curving laterad into the median cornu of the lateral ventricle, and gradually unite with the cornu ammonis. The cornu ammonis, or hippocampus major, is a thickened projecting fold of the wall of the

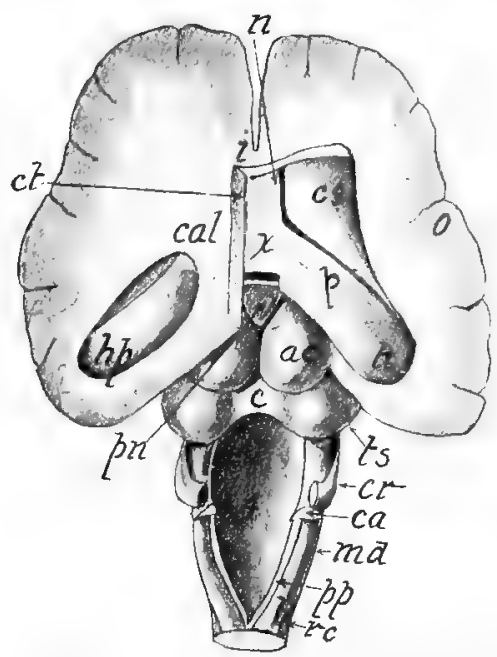

Fig. 96. Dorsal Aspect of the Brain with the Cerebellum and the Dorsal Third of the Cerebrum Removed and Most of the Corpus Callosum Cut Away from the Right Half.

$a c$, Right anterior corpus quadrigeminum; $c$, commissure of the quadrigemina; $c a$, the united superior and inferior peduncles of the cerebellum; $c r$, the middle peduncle of the cerebellum; $c s$, corpus striatum; ct, edge of corpus callosum cut slightly to the left of the median line; cal, dorsal surface of the callosum into which a hole has been cut; $h p$, hippocampus major, or cornu ammonis, in the median cornu of the lateral ventricle; $h$, hippocampus major near where it is joined by the fibers of the crus of the fornix; $i$, uncut portion of the callosum; $m d$, medulla oblongata; $n$, anterior columns or pillars of the fornix; 0 , gray cortex of the cerebrum; $p$, posterior crus of the fornix; $p n$, pineal gland, craniad to which is the heavy white line, the commissure of the habenæ or tæniæ thalami; $p p$, funiculus gracilis; $r c$, funiculus of Rolando; $l$, funiculus cuneatus; $t s$, posterior corpora quadrigemina; $x$, body of the fornix. 
median cornu of the lateral ventricle (Fig. 96). The free lateral margin of the posterior pillar or crus of the fornix is the fimbria, or tenia hippocampi. Adjacent to the median line in either hemisphere, a thick lamina of matter, the septum lucidum, stretches from the cranial part of the fornix dorsad to the callosum. The very narrow cavity formed by the adherence of the margins of the septum of one hemisphere to those of the septum in the other hemisphere is sometimes called the fifth ventricle. Between each anterior pillar of the fornix and the optic thalamus is a cleft, the foramen of Monro, leading from the third ventricle, laterad of the septum lucidum, into the lateral ventricle.

The three remaining commissures are known according to their location as the anterior, middle, and posterior. The anterior commissure (Figs. 95 and 98) perforates the corpora striata, extending across the median line immediately craniad of the anterior pillars of the fornix. It is about two millimeters in diameter. The middle commissure, or massa intermedia, lies between the optic thalami. It is sometimes called the soft or gray commissure. It is nearly one centimeter in diameter and passes through the third ventricle (Fig. 95). The posterior commissure is a cord of fibers about a millimeter in diameter connecting the caudal portions of the optic thalami.

The Basal Ganglia.-A semi-independent group of nerve cells forming a definite mass is known as a ganglion. In the ventral portion of the brain lie three pairs of large ganglia, called corpora quadrigemina, optic thalami, and corpora striata. To study them, the entire dorsal surface of the brain down to and including the corpus callosum should be removed.

The corpora quadrigemina (Fig. 96) forming the dorsal part of the mesencephalon lie craniad of the medulla, and consist of an anterior pair and a posterior pair. The former are known as the superior colliculi and the latter as 
inferior colliculi. The anterior pair lie nearer to the midline than the posterior pair, which are slightly separated by a depression occupied by the middle portion of the central lobe of the cerebellum. The posterior pair are united by a white commissure. The posterior commissure of the brain unites the cranial portions of the anterior pair (Fig. 95). Its cut end may be seen ventrad to the base of the pineal gland.

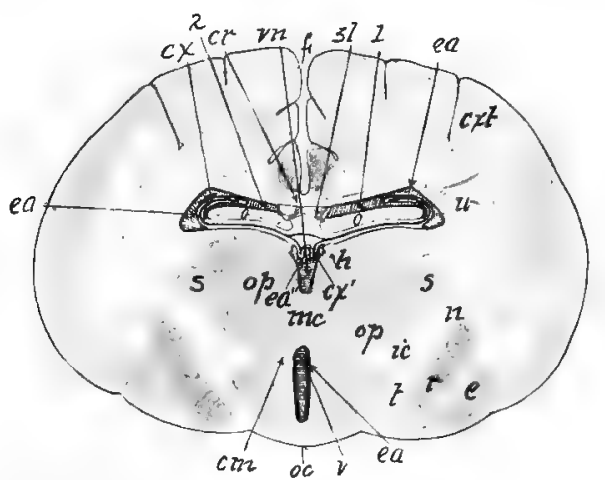

Fig. 97. Cross-section of the Brain in the Plane $x$ in Fig. 95.

The plane is just caudad of the optic chiasm.

I and 2, First and second or lateral ventricles; $\mathrm{cr}$, corpus callosum; $\mathrm{cm}$, anterior pillars of fornix ; $c x$, choroid plexus of lateral ventricle; $c x^{\prime}$, choroid plexus of third ventricle; $c x t$, gray cortex; ea, ependyma lining the ventricles; $f$, median longitudinal fissure; $h$, tænia thalami; mc, middle commissure, or massa intermedia; $n$, fibers of the optic tract as they enter the lateral geniculate body $s$; $o$, fornix; $r$, caudal portion of nucleus lenticularis; $o p$, optic thalamus; oc, optic tract as it leaves the chiasm; sl, septum lucidum; vn, part of third ventricle dorsad to the commissure; $v$, third ventricle; $t$. fibers of optic tract.

Laterally each pair of the corpora quadrigemina is prolonged into two white bands, the anterior and posterior brachia. The latter are about a half centimeter long, and pass forward beneath a pisiform ganglion, the corpus geniculatum intermm or mediale. The anterior brachia pass from the cranial end of the posterior pair laterad beneath the caudal projections of the optic thalami, where they join the optic tracts. 
Homologues of the corpora quadrigemina exist in all vertebrates. In these bodies originate partly the optic nerves, and therefore their size is in proportion to the animal's power of sight. In the mole, which has little use for eyes, the anterior pair is rudimentary.

The optic thalami forming the sides of the diencephalon or tween brain are the largest pair of basal ganglia, and lie craniad of the corpora quadrigemina and form the lateral walls of the third ventricle, across which they meet, forming the massa intermedia, or middle commissure.

On the dorsal aspect of each thalamus, near the median line, is a longitudinal band of white fibers called the tania thalami, which at its caudal limit is united to its fellow by the commissura habenæ. The thalamus is composed largely of gray matter, but there are two important bundles of fibers, known as the optic tract and internal capsule (Fig. 97), appearing on its lateral surface. The optic tract, of which the optic nerve is a continuation, arises by two roots, the larger of which comes from the cells forming the lateral geniculate body, which is the lateral and caudal projection of the thalamus. The internal capsule, well shown in a transverse section, is composed of the fibers forming a communication between the cells of the cortex and those in the lower brain centres and spinal cord.

The pineal gland, or pineal body (Fig. 95), is a conical projection about a half centimeter long, from the caudal part of the clorsal surface of the thalamus. It is a vestigial structure which in some of the lower vertebrates in early geological time functioned as a third eye. In Hatteria, a New Zealand lizard about a foot long, the eye is present, projecting slightly through a foramen in the parietal bone. Traces of this third eye with a lens have also been noticed in the embryo of the viper and some of the lizards.

The corpora striata lie deep in the telencephalon. They 
are the most anterior of the basal ganglia and are somewhat pear-shaped, the larger ends being craniad and nearer the median line than the caudal portions, which curve laterad around the optic thalami (Fig. 96). They form a part of the floor of the lateral ventricles, and are pierced by the anterior commissure (Fig. 98), a small cord of white fibers.

The corpus striatum consists of both white and gray matter. The latter, composed of cells, is disposed in two chief nuclei or masses, known as the nucleus caudatus, lying anterior and nearer the median line than the mucleus lenticularis, which is more lateral and caudal (Fig. 98).

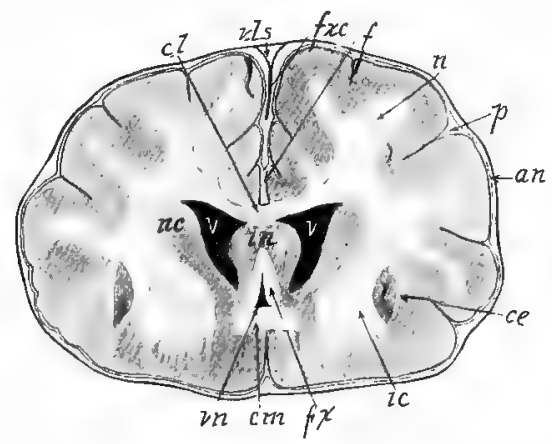

Fig. 98. Cross-section of the Brain through the Antertor ComMISSURE.

an, Arachnoid; ce, external capsule; $\mathrm{cl}$, corpus callosum; $\mathrm{cm}$, anterior commissure; $f x c$, falx cerebri; $f$, great longitudinal fissure; $f x$, anterior pillars of the fornix; ic, internal capsule; $n$, radiating fibers of callosum; in, septum lucidum; $n c$, nucleus caudatus of corpus striatum; $l$, nucleus lenticularis; $p$, pia mater; $v l s$, superior longitudinal sinus; $v n$, third ventricle; $v$, lateral ventricle.

The center of the nucleus lenticularis is laterad of the optic thalamus and dorsad of the crus cerebri. A thin layer of white matter, the lamina semicircularis, separates the optic thalamus from the nucleus caudatus. A few fibers from the cerebral peduncles form the lamina semicircularis, whose edge may be seen in the floor of the lateral ventricle on the lateral boundary of the nucleus caudatus. A group of 
fibers, known as the internal capsule, separates the optic thalamus from the nucleus lenticularis, laterad of which is the external capsule, a group of fibers probably descending from the cells of the cerebral cortex. The two nuclei of the corpus striatum are connected by fibers, and other fibers connect these nuclei with the cortex of the cerebrum and the optic thalamus.

The Medulla Oblongata.-The medulla oblongata, or myelencephalon, is the stem of the true brain and extends from the point of origin of the first spinal nerve to the pons Varolii. The cerebellum must be removed in order to study carefully the features of the medulla, and as it is cut away the student should notice just ventrad to it the very thin roof of the fourth ventricle. Its caudal portion, composed of a reflection of the pia mater lined with epithelium, takes the name of inferior medullary velum, and the cranial part, formed of pia and a thin layer of nervous matter, is called the anterior medullary velum (Fig. 95).

The fourth ventricle (Figs. 95 and 96) is an enlargement of the canalis centralis of the cord. Two bands of fibers called clava, the three peduncles or crura of the cerebellum, and the posterior corpora quadrigemina form its lateral boundaries. Its cavity is shallow and pointed at either extremity. The floor, called fossa rhomboidea, is formed by the continuation of the gray matter of the spinal cord. Where the ventricle is widest a tract of fibers, the stria medullaris, arises from the midline and proceeds laterad to help form the auditory nerve.

Laterad of the clava a larger band of fibers, the funiculus cuneatus, runs parallel with a more lateral lying bundle, the funiculus cuneatus lateralis, or funiculus of Rolando. The band of fibers on either side uniting the cerebellum to the medulla oblongata is the restiform body, or inferior peduncle of the cerebellum. On the ventral aspect of the medulla 
may be seen the anterior pyramids, composed of a band of fibers lying on either side of the median line and apparently emerging from the pons. They form a section of the crossed pyramidal or motor tract connecting the brain with the cord. The olivary eminence lies just laterad of the pyramid. The fact that seven posterior cranial nerves originate from the medulla shows the importance of this part of the brain. The destruction of the respiratory centers, or vital knot, lying ventrad to the caudal end of the fourth ventricle causes instant death.

The Cerebellum, or Little Brain.-The cerebellum, which in the cat lies caudad of the cerebrum and dorsad of the medulla, resembles the cerebrum in being composed of an outer layer of gray matter or cells and an inner mass of white matter made up of fibers. While within the cerebrum there are several important ganglia or masses of gray matter, in the cerebellum only one chief mass of gray matter, the corpus dentatum, is present in each hemisphere.

The outer layer of gray matter, known as the cortex, is folded into numerous convolutions, between which are deep strlci (Fig. 95). The central core of white matter forms an arborescence known as the arbor vitce.

The cerebellum (Fig. 92) is seen to consist externally of two lateral portions, the cerebellar hemispheres, a median vermiform process and three pairs of peduncles or crura which are bands of fibers uniting it with other parts of the brain and cord (Fig. 96). The separation between the hemispheres and vermis or vermiform process is most marked on the cranial aspect.

The peduncles are named, according to their location, superior, middle, and inferior. The middle peduncle, or brachium pontis, is a dorsal prolongation of the fibers of the pons Varolii (Fig. 93). In order to display the other peduncles a portion of the cerebellum must be cut or picked 
away with the forceps. The superior one, known also as the brachium conjunctioum, extends as a cord of fibers along the cranial half of the fourth ventricle and then beneath the corpus quadrigeminum. The inferior peduncle, or restiform body, forms part of the boundary of the caudal half of the fourth ventricle and enters the cerebellum between the other two peduncles. It is composed of fibers from the spinal cord and medulla.

\section{PRACTICAL QUESTIONS AND SUGGESTIONS.}

I. Describe the meninges of the central nervous system.

2. Which of the five parts of the brain are exposed dorsally?

3. Draw the lateral aspect of the brain and label all features.

4. Draw the ventral aspect of the brain and label all features.

5. Draw the dorsal aspect of the brain after the dorsal portion, including corpus callosum and fornix, has been removed.

6. Describe the differences existing between the gyri and stlci of your specimen and the one described in the text.

7. Write a description of the ventricles, giving dimensions and boundaries.

8. Describe the attachment of the pineal body. tion?

9. Which of the cranial nerves derive their name from their func-

Io. Name the foramina giving passage to one or more of the cranial nerves.

II. From which of the five parts of the brain do most of the cranial nerves originate?

12. Describe the choroid plexus.

13. What is the internal capsule?

I4. Draw a cross-section of the brain made by cutting through the optic commissure and label all parts.

I5. Draw a cross-section of the brain made by cutting through the middle commissure and label all parts.

I6. Draw a cross-section of the brain made by cutting through the corpora quadrigemina and label all parts.

I7. Write a description of the corpus callosum.

18. Which is the smallest commissure of the brain?

19. Explain the difference in structure between the white and gray matter.

20. Describe the cerebellum. 


\section{THE SPINAL CORD.}

The spinal cord extends from the foramen magnum through the vertebral canal. It is more or less cylindrical throughout and has a diameter of about one centimeter except in the lumbosacral region, where it grows gradually smaller until it is only one or two millimeters in diameter. In order to study the cord, one should have a

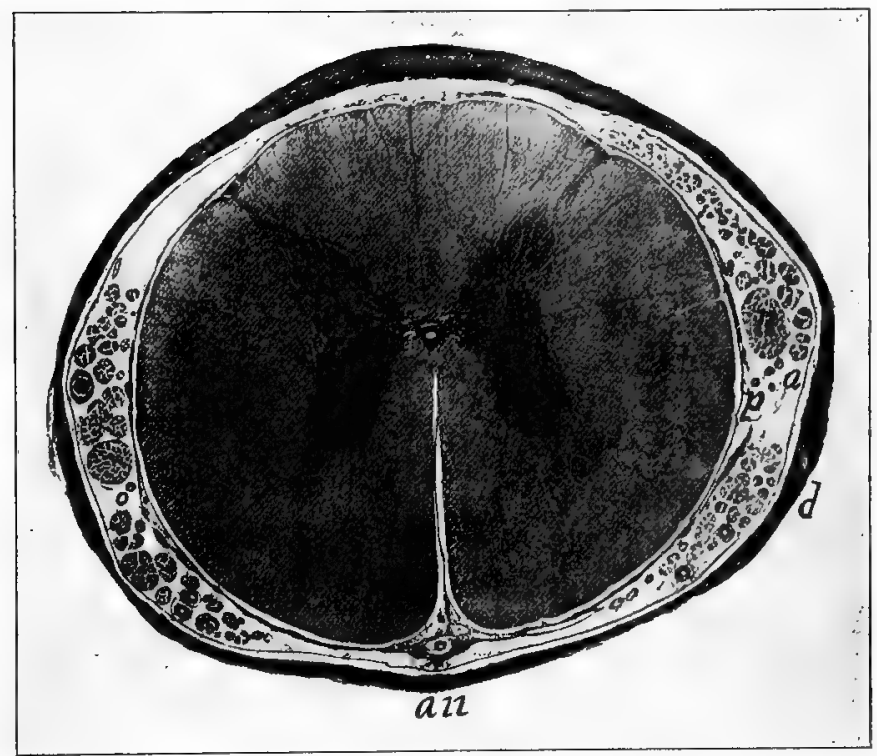

Fig. 99. Photomicrograph of Cross Section of Human Spinal Cord. $a$, Arachnoid membrane; an, ventral side in which appears the deep anterior fissure; $d$, dura mater; $n$, one of several nerve bundles; the tiny white spot in the center of the dark gray matter is the canalis centralis; $p$, pia mater. $\times 5$.

mounted transverse microscopic section, and an entire cord in situ with the dorsal wall of the vertebral canal removed, so that the exit of the spinal nerves may be seen.

The membranes (Fig. 99) which envelop the spinal cord 
are the same as those that envelop the brain. The dura mater is the external tough coat; the pia matcr, the internal delicate vascular coat sending a process deep into the anterior fissure on the ventral side; and the arachnoid, the very thin membrane between the two preceding. The arachnoid lies close against the dura mater, but is separated from the pia mater by the subarachnoid space, which is filled with a serous fluid called the cerebrospinal fluid. It is apparently the same as that in the ventricles of the brain, and seems to be of a lymphoid nature. In fact, the subarachnoidean space is merely a large lymph space similar to the cavities of the pleura and peritoneum. This lymph, or cerebrospinal fluid, probably escapes from the thin walls of the capillaries covering the pia mater and is taken up by lymphatic vessels which begin in open mouths on the walls of the space.

The cord presents two enlargements, the cervical, whence issue the nerves of the forelimbs, and the lumbar, giving origin to the nerves of the posterior limbs. Two deep fissures, the anterior median and the posterior median, penetrate about one-third through the cord, incompletely dividing it into halves longitudinally. The pia mater is prolonged into the anterior fissure, but not into the posterior fissure. Slightly laterad of the anterior median fissure issue the anterior roots of the spinal nerves, and at about the same distance from the posterior median fissure are the posterior roots of the spinal nerves. These two roots unite about one centimeter from their origin (Fig. 93). On the posterior or sensory root is a small ganglion located very near the junction of the two roots. The common spinal nerve, formed by the union of the two roots, almost immediately divides into four branches, one of which, the dorsal, supplies the muscles and skin along the vertebral column; a second, the ventral branch, supplies the limbs or intercostal spaces; while the other two branches, 
rami communicantes, join the adjacent ganglion of the sympathetic cord (Fig. ro7). Each of the four branches contains both motor and sensory fibers, or, in other words, fibers from both roots.

The exit and entrance of the nerve roots divide the white matter of the lateral half into three columns named, according to their location, the anterior column, the lateral column, and the posterior columm. The first is ventral to the anterior nerve roots, the last is dorsal to the posterior nerve roots, while the lateral column is between the roots.

The elements of the spinal cord, like those of the brain, are of two kinds - the cells composing the gray matter and

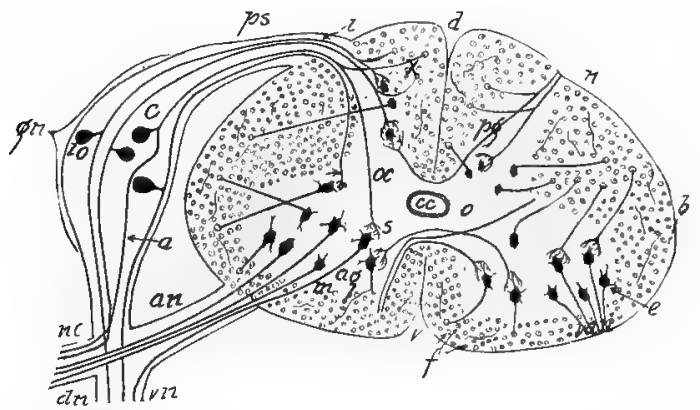

Fig. 100. Diagrammatic Cross-section of the Spinal Cord. The cells and fibers are represented too few and too large in proportion to the size of the cord.

$a g$, Anterior horn or column of gray matter; $a$, nerve process of the cell $c$; an, anterior root; $c c$, canalis centralis; $c$, one of many cells forming the ganglion on the posterior root; $d$, posterior fissure; $e$, cell giving off an axone into the anterior root; $d n$, dorsal branch; $f$, cut-off fibers; $g n$, ganglion of posterior root; $i$, axone of the cell io; $n c$, junction of anterior and posterior roots; $p s$, posterior root of nerve; $p g$, posterior horn of gray matter; $s$, terminal arborization of part of fiber from $c$; $v$, anterior median fissure; $v n$, ventral branch of nerve; van, axone of anterior horn cells; $x$, the part of the posterior root fiber extending caudad in the cord.

the fibers composing the white matter. While in the brain the gray matter is largely on the surface, forming the cortex, in the cord it occupies the central region. A canal, 
the canalis centralis, about one-half a millimeter in diameter, extends throughout the cord, opening into the fourth ventricle of the brain. A cross-section of the cord shows the gray matter arranged in the shape of a letter $H$. The ventral columns of gray matter are the anterior horns, and the posterior columns, the posterior horns (Fig. IOO).

Many of the fibers extend in a longitudinal direction throughout the cord, but the roots of the spinal nerves upon entering the cord run transversely a longer or shorter dis-

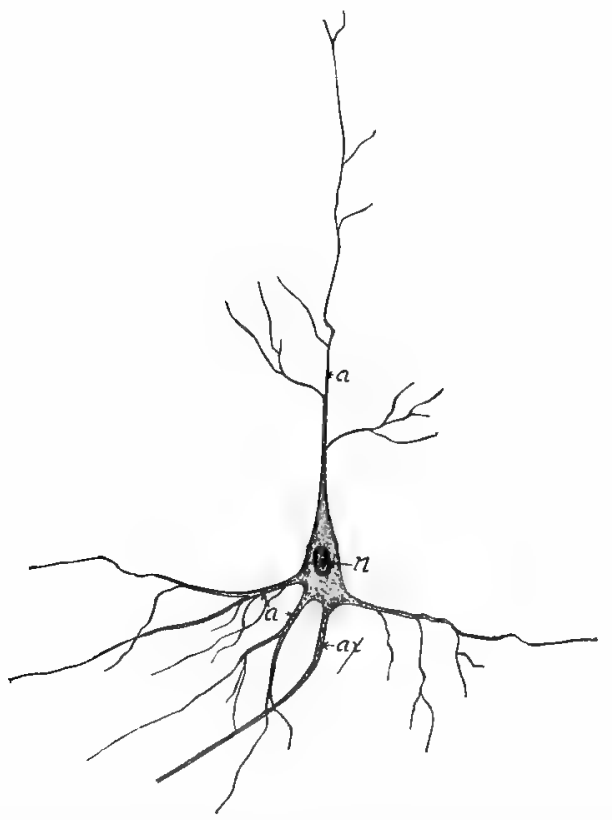

Fig. ioi. Celll from the Central Neryous System. $\times$ ioo.

$a$, Dendrites or protoplasmic processes; $a x$, axone; $n$, nucleus of the cell body.

tance, and in many cases cross to the opposite side. Numerous experiments show that the anterior root fibers are, for the most part, the axones of the cells in the anterior horn (Fig. IO2). 


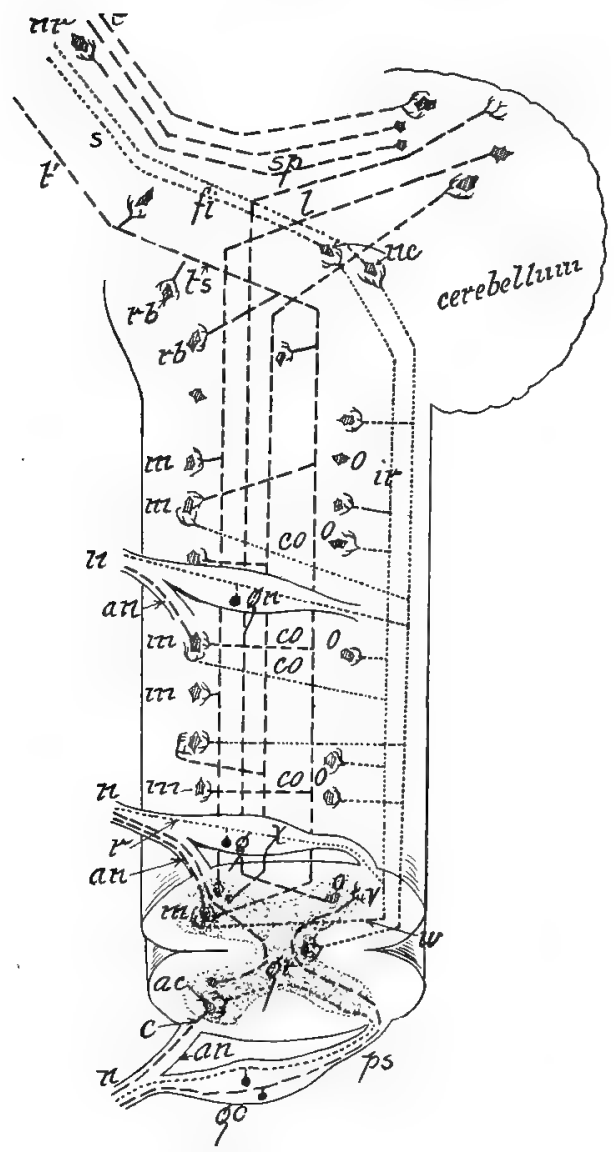

Fig. to2. Diagram showing the Relation of some of the Cells and Fibers of the Spinal Cord. Lateral aspect of the cord.

$a$, Anterior median fissure; $a c$, cells of the anterior horn; an, anterior root of spinal nerve; $c$, axone; $c o$, collateral fibers; $e$, fibers connecting higher brain centers with cerebellum; $f$, sensory fibers of fillet to the brain; $g, g n, g o$, ganglion of posterior root; $g r$, gray matter; ir, fibers of the posterior sensory tract; $l$, fibers to cerebellum; $m$, cell in the anterior horn or column of gray matter; $n$, spinal nerves; $o$, cells in the posterior horn or column of gray matter; $n c$, nucleus gracilis and nucleus cuneatus; $n r$, nucleus ruber; $r$, a fiber of posterior root; $r b$, ganglion cells of medulla; $s$, tract of fillet to the brain; $s p$, fibers of superior peduncle of the cerebellum; $t^{\prime}$, fiber of crossed pyramidal tract; $t s$, point of decussation; $v$, division of fiber $x$ into its cranial and caudal extensions; $w$, a collateral of the longitudinal fiber $i r$. 
Each posterior root fiber after passing into the cord separates into two parts one of which extends craniad, the other caudad (Fig. IO2). Both give off branches at right angles, called collaterals, which terminate in arborizations about the cells of the cord.

Each nerve cell with all its processes is called a neurone. It presents two kinds of processes, protoplasmic processes or dendrites and an axis-cylinder process or axone (Fig. IOI). The dendrites, except in the ganglia outside of the central nervous system, are usually several in number and comparatively short, while there is but one axone from each cell, which may be more than a foot in length. A number of axones (nerve fibers), each of which is surrounded by a sheath, the neurilemma, constitutes a nerve bundle or nerve. Every axone or nerve fiber originates in a cell, but terminates freely either within the central nervous system or in some other part of the body (Figs. IOr, ro2). Within the central nervous system a fiber usually ends in an arborescence which may be contiguous but not continuous with the dendrites of another cell. The nerve processes have the power of conducting impulses whether derived from the cell itself or an external stimulus. The dendrites conduct impulses toward the cell, while the axone conducts them from the cell.

The sensory fiber $r$ (Fig. I02) leads from the dermis of the cat's paw. A pin-prick in the paw causes an impulse to be transmitted along the fiber to the cell $g$, and thence by its axone, $x$, to the point $v$ within the cord where the fiber splits. From the point $v$ the impulse will proceed both through the ascending portion of the fiber, ir, and the collateral, w. By the latter route it will stimulate the cell $m$, whose axone terminates in the foreleg muscles, which are thereby made to contract and pull the paw away from the irritating object. This process may take place without con- 
sciousness, and is then known as reflex action. If, however, the impulse travels along the fiber ir, and thence through the fiber $s$ to the brain, whence an impulse descends through the fiber $t^{\prime}, t s$, the process is known as voluntary reaction.

\section{THE FIBER TRACTS OF THE CENTRAL NERVOUS SYSTEM.}

As before stated, the white matter of each half of the cord is divided by the exit and entrance of the nerve roots into three columns-anterior, lateral, and posterior. Each of these columns is subdivided into tracts which have special names and special functions (Fig. IO3).

In the posterior column two tracts are recognized: the fasciculus gracilis, occupying the medial third of the column, and the fasciculus cuneatus, composing the remainder. In the medulla of the cat these two tracts may be distinguished by the unaided eye (Fig. 96). They are here called the funiculi of Goll and Burdach, or funiculi gracilis and cuneatus. Their fibers are largely, if not entirely, the axones of the ganglion cells on the posterior roots of the spinal nerves. They terminate in the nuclei gracilis and cuneatus, two small masses of nerve cells in the medulla laterad of the fourth ventricle (Fig. I02). That these fibers are processes of the spinal ganglion cells is proved by the fact that they degenerate if the posterior nerve roots are severed close to the cord. In whales, where the pelvic extremities are wanting, the fasciculi gracilis and cuneatus are very small.

The lateral column is composed of five tracts: the direct cerebellar tract, the antero-lateral descending cerebellar tract, the antero-lateral ascending cercbellar tract or Gower's tract, the lateral ground bundle, and the crossed pyramidal tract. 
The direct cercbellar tract occupies the superficial region of the cord laterad of the posterior cornu of gray matter.

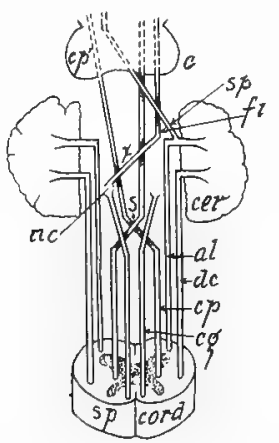

Fig. ro3. Diagram of SOME FIBER TRACTS. DORSAL ASPECT.

al, Antero-lateral ascending cerebellar tract; $c$, posterior corpus quadrigeminum ; cer, lateral lobe of cerebellum, whose median portion is removed; $c g$, the two fasciculi gracilis and cuneatus represented as one; $c p$, crossed pyramidal or chief motor tract; $c p^{\prime}$, crossed pyramidal tract in the region of the cerebral peduncle; $d c$, direct cerebellar tract; $f$, the large part of the fillet derived from $n c$; $n c$, nuclei gracilis and cuneatus; $s$, decussation of pyramidal tracts; $x$, sensory or superior pyramidal decussation; $s p$, superior pecluncle of cerebellum. Its fibers originate from the cells of the more central portion of the gray matter throughout the cord and terminate in the cerebellum. Its fibers help to form the inferior peduncle of the cerebellum.

The antero-lateral descending cerebellar tract occupies the superficial area ventrad of the anterior horn of gray matter. Its fibers originate in the cells of the cerebellum and extend caudad in the cord.

The antero-lateral ascending cerebellar or Gowers's tract occupies the superficial area laterad of the anterior horn. Its fibers probably originate in the cells of central gray matter throughout the cord, and largely terminate in the cerebellum. The lateral ground bundle consists largely of fibers with a short course, many of which are commissural, connecting the two halves of the spinal cord.

The crossed pyramidal tract contains the longest fibers of any of the tracts of the central nervous system and occupies a large area just laterad of the posterior horn of gray matter. Its fibers originate in the cortical cells of the brain near the crucial sulcus (Fig. 92), and descend as part of the internal capsule, through the corpus striatum and laterad of 
the optic thalamus to the base of the brain. Here it is one of the three main tracts forming the crus or peduncle of the cerebrum, whence it extends through the pons Varolii, appearing along the median ventral line of the medulla as the pyramid (Fig. 93). At the caudal end of the medulla it crosses dorsad to the opposite side of the cord to occupy the area laterad of the posterior horn of gray matter. Its fibers terminate largely in arborizations around motor cells of the cranial nerves in the brain, and the cells in the anterior horn of gray matter, from which originate the motor fibers for the muscles of the body. Therefore it is apparent that this tract controls largely the muscular activities of the entire body (Figs. IO2, I03, and I04). The crossing of the fibers of this tract in the caudal region of the medulla is known as the motor decussation or the decussation of the pyramidal tract.

The limits of these various fiber tracts of the central nervous system cannot be determined by dissection. They have been worked out largely by experimental physiology and pathology, and by studying their embryonic development when the fibers of different tracts are seen to acquire their sheaths (neurilemma) at different periods. The portion of a nerve fiber separated from its cell degenerates, so that if the fibers of the crossed pyramidal tract were injured by accident or disease in the region of the medulla, all that part of the tract in the cord would degenerate, in consequence of which the subject would suffer paralysis.

The larger portions of the tracts thus far described have been confined to the cord, while the remaining tracts to be discussed concern chiefly the brain. In order to understand these it is necessary to remember that the cortex of the brain is composed of millions of nerve cells which give origin to nerve fibers extending to other portions of the cortex, to the basal ganglia, the cerebellum, medulla, and 
spinal cord (Fig. 104). Likewise some of the fibers originating in the cells of the cord, medulla, cerebellum, and basal ganglia terminate about the cells of the cortex. The cord, medulla, and cerebellum are connected with the higher brain centers by the fibers of the cerebral peduncles (Figs. 93 and 104). Each peduncle is separted into two longitudinal parts by an elongated mass of gray matter, the substantia nigra. The dorsal part is known as the tegmentum, while the ventral part is the crusta.

The fibers of the brain are of three kinds-the commissural fibers, the projection fibers, and the association fibers.

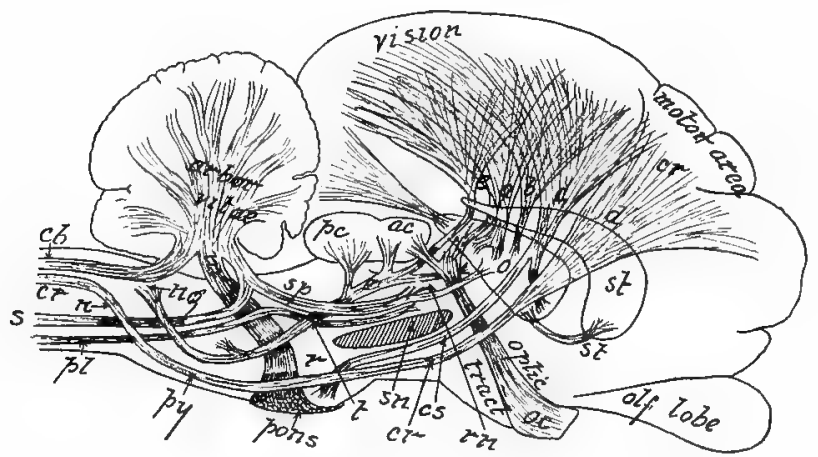

Fig. i04. Diagram of Chief Fiber Tract of the Mammalian Brain. Lateral Aspect.

$a, b, c, d, e$, Fibers forming internal capsule; $a c$, anterior corpus quadrigeminum; $c b$, direct cerebellar tract; $c r$, crossed pyramidal or chief motor tract; $c s$, cortico-pontine or secondary motor tract; $m$, middle peduncle of cerebellum; $n g$, nuclei gracilis and cuneatus; $n$. decussation of crossed pyramidal tract; $o$, optic thalamus; $o c$, optic chiasm; $p c$, posterior corpus quadrigeminum; pons, transverse fibers of pons Varolii; py,-pyramids formed by pyramidal tract; $r n$. nucleus ruber; $s$, antero-lateral cerebellar tract; $s n$, substantia nigra; $s p$, superior cerebellar peduncle; $s t$, corpus striatum; $t$, fibers of the fillet or great sensory tract.

The commissural fibers constitute the commissures of the brain previously described (Figs. 93, 95). In addition to these commissures, numerous other fibers cross to the 
opposite half in that portion of the brain caudad of the optic thalami. The internal portion of the medulla oblongata possesses numerous transverse fibers which, with the longitudinal fibers, form a kind of reticulum in the midst of the gray matter, known as the formatio reticularis.

The projection fibers (Fig. I04) are those connecting the cortex with the lower brain centers and the cord. The chief motor tract is the crossed pyramidal tract already described in the cord. It may be traced from the pyramids to its origin in the cortex in the region of the crucial sulcus (Fig. 92), by slicing away the ventral portion of the brain obliquely in a plane joining the cranial margin of the pons and the crucial sulcus. Numerous fibers are given off by this tract to the motor roots of the cranial as well as the spinal nerves.

The secondary motor tract, cortico pontine tract, carries motor impulses from the frontal cortex to the medulla, whence other fibers convey them to the opposite half of the cerebellum. The axis-cylinders of the cells here transmit the impulses through the inferior peduncle to the cells in the anterior horn of gray matter of the cord.

The great sensory tract of the brain is the fillet. Its fibers originate largely in the cells of the nuclei gracilis and cuneatus of the medulla (Figs. I02, I03, I04) and cross over to the opposite side of the medulla, forming the sensory or superior pyramidal decussation. This tract receives also fibers from the spinal cord, the cerebellum, and the medulla oblongata.

These projection fibers, after leaving the peduncular region, turn dorsad to pass with others through the corpus striatum and laterad of the optic thalamus. In this part of their course they form what is known as the internal capsule (Fig. 98). The spreading out of the projection fibers just beneath the cortex of the cerebrum forms the corona radiata. 
The association fibers are those which connect different portions of the same cerebral hemisphere. Two kinds are recognized. The short fibers connect adjacent convolittions, while the long ones place in communication two remote portions of a hemisphere.

\section{PRACTICAL QUESTIONS AND SUGGESTIONS.}

I. Describe the membranes of the cord.

2. What difference in the size of the nerve roots in the various regions of the cord?

3. Draw a cross-section of the cord showing all features visible to the naked eye.

4. How does the arrangement of the gray matter of the cord and brain differ?

5. Describe the processes of nerve cells.

6. In what portions of the body are nerve cells found?

7. What is the location of the cells whose protoplasmic processes largely make up the fasciculi cuneatus and gracilis.

8. What part of the cord is occupied by the chief motor tract?

9. What tracts of the cord originate or terminate within the cerebellum?

Io. Describe the course of the crossed pyramidal tract throughout the axial nervous system.

II. Describe three bundles of commissural fibers in the brain.

I2. Which tract of the projection fibers contains the longest axones?

13. Describe the great sensory tract of the brain.

14. What do the association fibers connect?

I5. Tell what is known of the functions of various regions of the cortex.

16. Explain why paralysis of the left side of the body would result from an injury to the right motor region of the cortex.

I7. Procure a piece of spinal cord from the butcher-shop. Smear a bit of the gray matter on a glass slip, dry, then stain in hematoxylin, wash, and after drying mount in balsam. Draw and describe nerve cells thus found.

\section{THE PERIPHERAL NERVES.}

All portions of the head, trunk, and limbs of the cat are supplierl with nerve fibers which are in communication with the central nervous system by means of fifty-two pairs of 


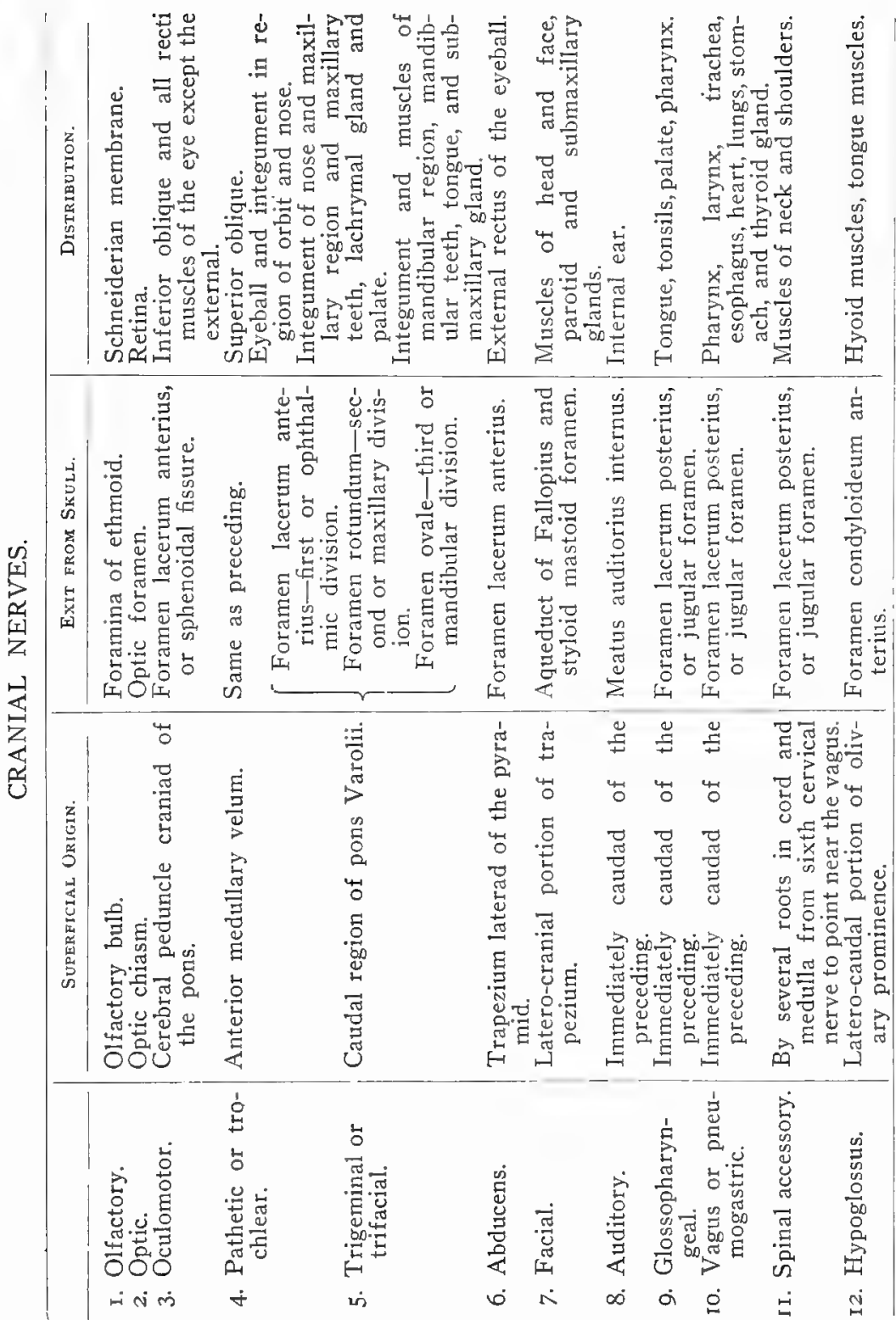


nerve bundles, forming what are known in the brain region as the cranial neres and in the region of the cord as the spinal nerves.

The Cranial Nerves.-There are twelve pairs of cranial nerves, all of which pass through foramina in the base of the skull, and all except one, the tenth or vagus, are distributed to structures of the head and neck. They are divided according to function into motor and sensory. Some of the nerves communicate with the brain by more than one root, and in such cases the same nerve may have sensory fibers in one root and motor fibers in another. For example, the trigeminal nerve transmits a stimulus causing the muscles of mastication to contract and also supplies the teeth with sensory fibers (Fig. 93).

The olfactory, optic and auditory are the only cranial nerves wholly sensory. The oculomotor, patheticus or trochlearis, abducens, spinal accessory, and hypoglossal are wholly motor. The trigeminal, facial, glossopharyngeal and vagus contain both motor and sensory fibers.

The dissection of the cranial nerves is very difficult. A head, containing a brain hardened by a formalin injection, should be placed in 500 c.c. of $5 \%$ nitric acid, which will decalcify the bone in about a week. After washing out the acid by soaking the specimen in running water twenty-four hours, the dissector may with much care follow the course of the nerves peripherad from their origin at the base of the brain. The vagus nerve must of course be traced in an entire specimen, where it may be easily followed in the neck region along with the carotid artery, whence it passes to the lungs and stomach (Fig. 66).

Some of the sensory nerve roots bear ganglia, the largest of which is the Gasserian ganglion, more than a half centimeter in diameter, forming a knot on the sensory root of the trigeminal, within the cranial cavity (Fig. 93). 
The Spinal Nerves.-There are forty pairs of nerves connected with the spinal cord. They issue from the vertebral canal through the intervertebral foramina. Each nerve is connected to the cord by a ventral and dorsal root (Figs. 93 and I02). The former is also known as the motor root, since its fibers are almost entirely motor, while the latter is the sensory root, as it is composed of fibers transmitting' impulses to the central nervous system. A ganglion about the size of a pinhead is located on the dorsal root immediately proximad of its junction with the ventral root, within the intervertebral foramen. This anatomy can be displayed by cutting away the dorsal muscles on either side of the column, and then, with the bone-cutters, severing the laminæ of several of the arches of the vertebræ, so that the roof may be removed from the vertebral canal (Fig. 22).

Immediately beyond the intervertebral foramen each nerve gives off a dorsal branch to the muscles of the back, and a small connecting twig to the sympathetic system. The main nerve is then spoken of as the ventral branch. These main nerves or ventral branches, in various regions of the trunk, anastomose with each other, forming plexuses. In the region of the neck there is formed the cervical plexus; in the region of the shoulder, the brachial plexus; in the region of the loins, the lumbar plexus; and in the region of the sacrum, the sacral plexus (Figs. I05 and I06).

There are eight cervical nerves, the first of which does not make its exit through the intervertebral foramen, as do all the other spinal nerves, but traverses a foramen in the atlas. The first five cervical nerves, the three posterior cranial nerves, and branches from the sympathetic trunk, form the cervical plexus. These five cervical nerves supply mainly the structures of the neck.

There are thirteen pairs of thoracic nerves. The ventral 
branches of the sixth, seventh, and eighth cervical nerves and the first thoracic nerve form the brachial plexus. This may be displayed by removing the cephalo-humeral muscle and cutting through the pectoral muscles about two

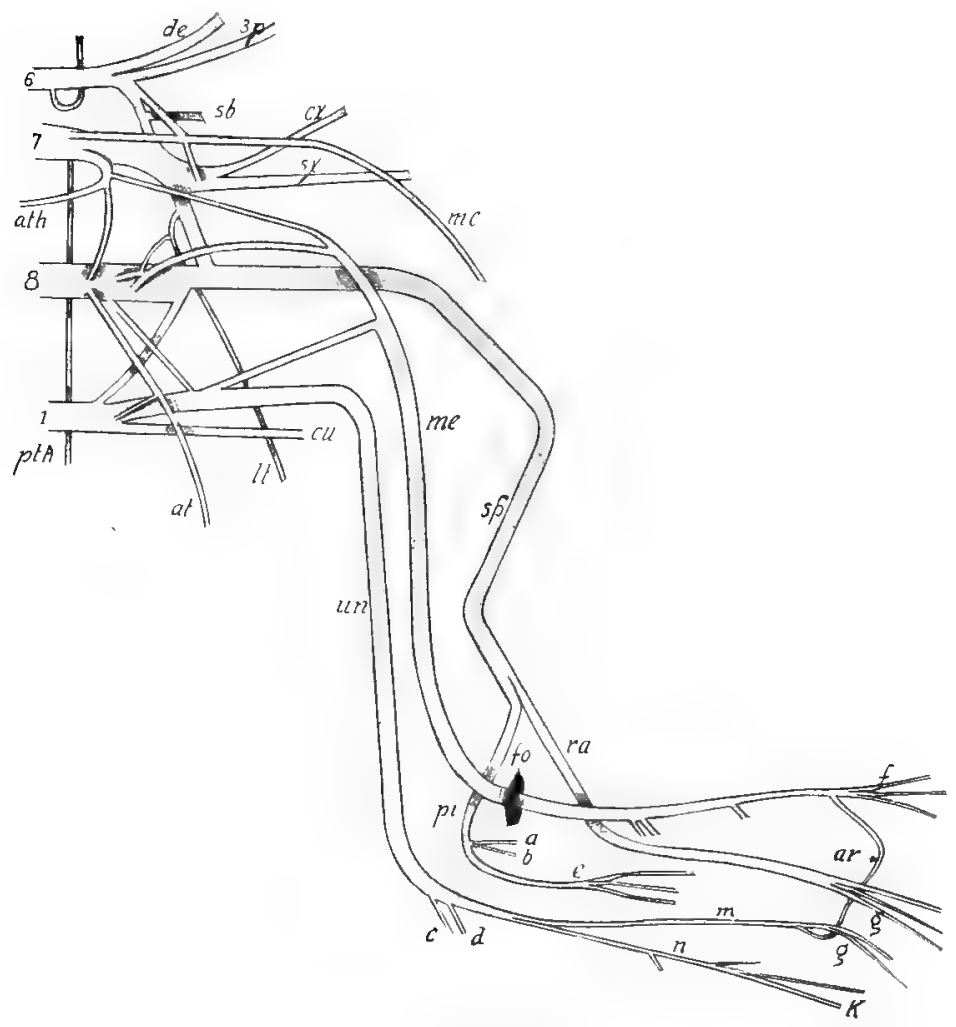

Fig. 105. Ventral Aspect of the Brachial Plexus and Chief Nerves OF THE ARM.

$6,7,8$ and I, Sixth, seventh, and eighth cervical and first dorsal nerves; $a t$, ath, anterior thoracic nerves; $a$ and $b$, to muscles of the forearm; $c$ and $d$, to the joint; $c x$, circumflex nerve; $c u$, internal cutaneous; $d e$, to the deltoid; $g$, to the digits; $f$, to the digits; $f o$, supracondyloid foramen; $l t$, long thoracic; $m c$, musculocutaneous; me, median nerve; $p i$, postcrior interosseous; $p t h$, posterior thoracic; $s p$, musculospiral; $s p$, to suprascapular region; $s b$, to subscapular region: $s x$, subscapular; ra, radial; un, ulnar nerve. 
centimeters from their origin (Fig. 47). The manner in which the nerves anastomose varies somewhat, but the following will be found approximately correct:

The sixth cervical nerve gives off a small branch to the rhomboideus and levator anguli muscles of the shoulder, and then divides into two nearly equal branches, one of which supplies the muscles on the lateral aspect of the scapula, and the other joins with the seventh cervical nerve. Small branches from the fifth and sixth cervical nerves unite to form the phrenic nerve supplying the diaphragm.

The seventh cervical nerve gives off three small branches at about the same point, one of which is the posterior thoracic supplying the serratus magnus muscle, a second helps to form the musculocutaneous, and the third forms part of the median and anterior thoracic. The main portion of the seventh cervical unites with the eighth and first thoracic, to form the musculospiral nerve. The circumflex and subscapular branches supplying the deltoid and subscapular muscles are also derived from the seventh.

The eighth cervical nerve, after giving off a snall branch to the pectoral muscle, a small twig to the median nerve, and a large branch to the first thoracic nerve, is continued as the main part of the musculospiral nerve.

The first thoracic nerve gives first a large branch to the musculospiral nerve, a second small branch to the anterior thoracic, and a third branch forming the internal cutaneous nerve supplying the skin of the arm and forearm on the caudal aspect. The main portion of the first thoracic nerve then continues as the main part of the ulnar nerve.

The nerves of the forelimb are five in number (Fig. I05): the external cutaneous or musculo-cutaneous, the internal cutaneous, the musculospiral, the median, and the ulnar. The external cutaneous arises from the sixth and seventh cervical nerves and passes distad along the caudal 
aspect of the biceps to the cranial aspect of the forearm, where it becomes subcutaneous. It supplies the biceps and coracoid muscles and the skin of the forearm. The internal cutaneous arises from the first thoracic and passes along the ventral side of the arm, becoming subcutaneous just proximad of the elbow, where it is distributed to the skin of the arm and forearm on the caudal and ventral aspects.

The musculospiral arises from the seventh and eighth cervical and first thoracic nerves. It is the largest component of the brachial plexts. It winds obliquely around the humerus to the cranial aspect, where it divides into two branches, the radial and the posterior interosseous. The radial nerve is the smaller and becomes subcutaneous near the elbow, and passes along the radial region. The posterior interosseous proceeds along the dorsal aspect of the forearm to the wrist, where it divides into branches supplying the digits.

The median nevve arises from the seventh and eighth cervical and first thoracic. It follows the course of the brachial artery, passing through the supracondylar foramen to the elbow, where it passes beneath the pronator teres to the carpal region, and supplies the first, second, and third digits. It also supplies the pronator teres and flexor muscles of the forearm.

The ulnar nerve (Fig. I05) is derived from the eighth cervical and first thoracic. It courses with the brachial artery to the middle of the humerus, where it turns caudad to pass between the olecranon process and internal condyle of the humerus. It is here subcutaneous and furnishes the sensation experienced when one strikes what is popularly called his "funny bone," but what is really the ulnar nerve. It then passes down the ulnar side of the forearm, supply. ing some of the flexor muscles, and finally divides to supply the fourth and fifth digits. The ventral branches of the 
remaining thoracic nerves encircle the body, supplying the muscles and skin of those regions.

The lumbar plexus (Fig. 106) is composed of the anastomosing of the ventral branches of the four caudal lumbar nerves. As in the cervical and thoracic nerves, the lumbar nerves divide into dorsal and ventral branches immediately without the intervertebral foramen. The former supply the muscles and skin of the back. In order to display the lumbar nerves, the entire ventral and lateral abdominal wall should be cut away and the specimen securely nailed to the tray on its back. The adipose tissue and muscles lying on either side of the bodies of the lumbar vertebra must be carefully picked away until the roots of the nerves are apparent. They may then be easily followed distad.

The first three lumbar nerves of the cat are represented in man by the ilio-hypogastric and ilio-inguinal. The first nerve supplies the rectus muscle and skin of the abdomen. This nerve and the two next described are scarcely as large in diameter as an ordinary pin. The ventral branch of the second lumbar nerve divides into two branches, and supplies the skin of the caudal part of the abdomen, and structures in the inguinal region. The ventral branch of the third lumbar nerve supplies the inguinal region and is also distributed to the transverse and rectus muscles. The fourth lumbar nerve divides into two parts, one of which is the genito-crural nerve, supplying the skin and other structures of the ventral abdominal wall and thigh, the other branch together with part of the fifth nerve forms the $e x$ ternal cutaneous, supplying the lateral surface of the thigh region.

The anterior crural nerve is composed mainly of branches of the fifth and sixth lumbar. It receives a small branch from the fourth. It supplies the psoas muscles, which it 


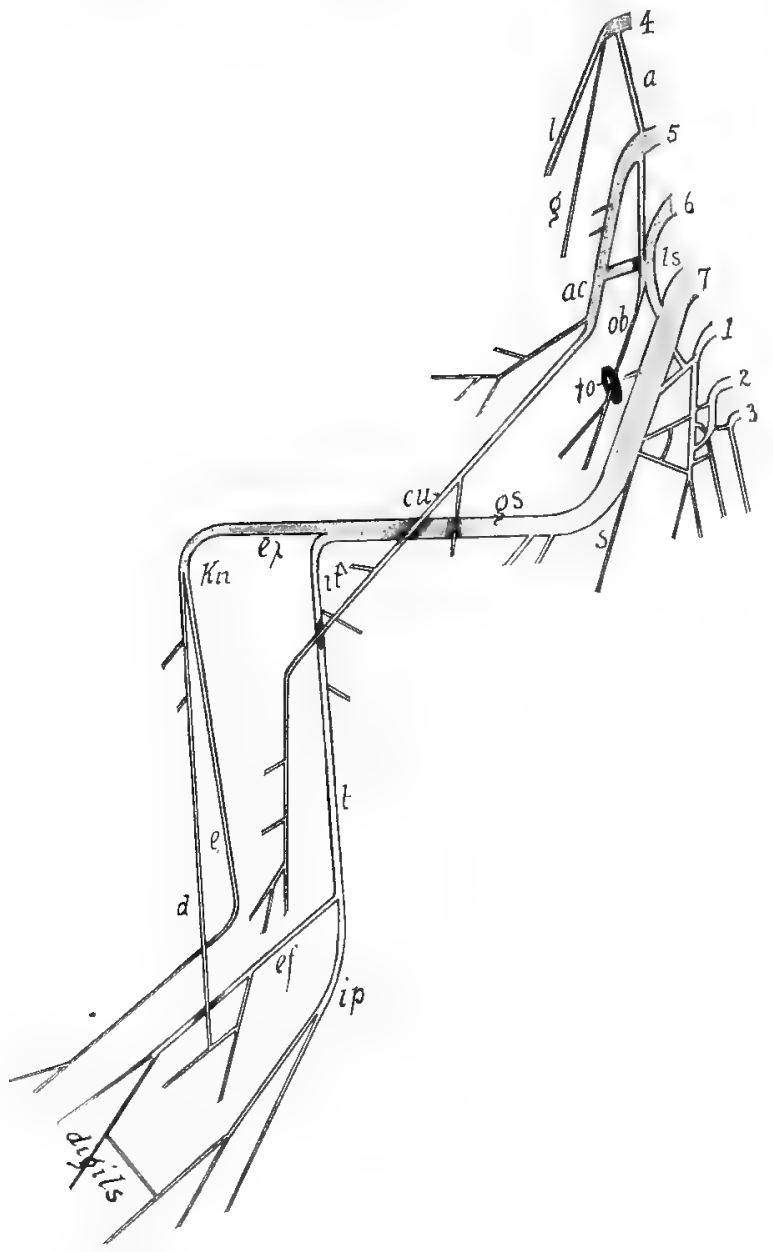

Fig. io6. Ventral Aspect of the Nerves of Hind-Limb.

$4,5,6,7,1,2$, and 3 , Fourth, fifth, sixth, and seventh lumbar, and first, second, and third sacral nerves; $a$, branch from the fourth to the fifth; $a c$, anterior crural; $c u$, saphenous; $d$, anterior tibial; $e$, peroneal or musculocutaneous; $e x$, external poplitcal or peroneal; ef, external plantar; fo, obturator foramen; $g s$, greater sciatic; $g$, genito-crural; it, internal popliteal; $i p$, internal plantar; $k n$, knee; $l$, external cutaneous; $l s$, lumbosacral cord; $t$, posterior tibial: $s$, small sciatic. 
pierces, and then divides into several branches, one of which is the saphenous, passing subcutaneously along the medial aspect of the leg. The other nerves supply the muscles of the thigh on the cranial and medial aspect. The obturator nerve is composed of branches from the sixth and seventh lumbar. It is smaller than the preceding, and passes through the obturator foramen to supply the obturator, adductor, gracilis and pectineus muscles.

The sacral plexus is formed of the three sacral nerves with branches from the sixth and seventh lumbar nerves.

The great sciatic nerve is composed mainly of the ventral branches of the seventh lumbar and first sacral nerves. It usually receives accessions from the other sacral nerves and the sixth lumbar. The great sciatic is the largest peripheral nerve in the body. It passes caudad from its origin around the greater sciatic notch and thence along the caudal aspect of the thigh to the popliteal space, where it divides into the internal and external popliteal nerves. The former continues down the caudal side of the tibia as the posterior tibial nerve to the internal malleolus, where it divides into internal and external plantar nerves, which supply the digits. The external popliteal or peroneal nerve extends to the outer cranial aspect of the leg, where it divides into the musculocutaneous and anterior tibial nerves. The former extends between the extensor longus digitorum and peronei muscles to its ramification on the dorsum of the foot. It supplies the skin along its course and the peronei muscles. The anterior tibial nerve passes down on the cranial aspect of the tibia beneath the extensor longus digitorum muscle to the tarsal region, where it anastomoses with a branch of the external cutaneous, and supplies the skin, tibialis anticus, and the extensor muscles.

The lesser sciatic nerve comes chiefly from the second and third sacral nerves. It supplies the region of the ants and the biceps muscle. 
Other nerves given off from the sacral plexus are the glutci and pudic nerves supplying the buttock muscles and external genital organs.

\section{THE SYMPATHETIC NERVOUS SYSTEM.}

The sympathetic nervous system is composed chiefly of a pair of nerve-cords extending from the base of the skull to the root of the tail, a number of ganglia and branches supplying the thoracic and abdominal viscera, and numerous minute fibers supplying the muscular walls of the bloodvessels in all parts of the body. The sympathetic system supplies all non-striped or involuntary muscles in any part of the body. The two branches connecting each spinal nerve with a sympathetic nerve cord are called rami communicantes.

In order to demonstrate this system successfully, one should use a lean injected specimen. After the cat has been securely nailed on its back to the tray, the entire ventral half of the thoracic and abdominal walls should be removed. By pushing the heart and lungs to the left side a white cord about one millimeter in diameter may be seen lying near the median dorsal line (Fig. I07). The left cord may be found in a similar manner and both followed craniad and caudad, noting their numerous branches in accordance with the fol. lowing description.

The sympathetic nerve-cord begins in the superior cervical ganglion lying near the angle of the mandible, beneath the submaxillary and lymphatic glands. This ganglion is about the shape of a grain of wheat, but not more than half so large, and is adjacent to the small vagus ganglion on the dorsal side of the carotid artery. The ganglia are masses of large nerve cells and occur at regular intervals on the sympathetic cords in the body cavity, and are present also on some of the branches of the cords (Fig. I08). On the 
cords there are three pairs of cervical ganglia, thirteen pairs of thoracic ganglia, seven pairs of lumbar ganglia, and one or two pairs of sacral ganglia, in addition to two median unpaired sacral ganglia.

In the cervical region the sympathetic and vagus, or tenth cranial nerve, are bound in a common sheath lying along the lateral aspect of the carotid artery. One or two centimeters craniad of the first rib is the thyroid or middle cervical ganglion, whence the nerve proceeds in two cords, enclosing the subclavian artery, to the

Fig. 107. Chief Part of Lefet Half of Sympathetic System Crantad of the Diaphragm. Semidiagrammatic.

$5,6,7,8,9$, and ro, Fifth, sixth, seventh and eighth cervical nerves, and first and second thoracic spinal nerves; $a$, the dorsal branch of the left vagus ln; an, dorsal branch of the right vagus; $a x$, common dorsal vagus formed by $a$ and $a n$; $a v b$, ventral vagus; $b c$, cardiac branch of $s g$, cr, carotid plexus; car, carotid artery; cm, rami communicantes; $c p$, cardiac plexus; dia, diaphragm; $g$, ganglia in the thoracic cavity; ig, middle cervical ganglion; $l g$, portion of left lung; $l n$, left vagus nerve; $n v$, cranial nerve; $p n$, phrenic nerve; $p p$, pulmonary plexus; $s n$, sympathetic cord; sm, superior cervical ganglion; $s b$, left subclavian artery; $s g$, stellate ganglion or inferior cervical; spm, splanchnic major nerve; $v g$, vagus ganglion; v, vagus

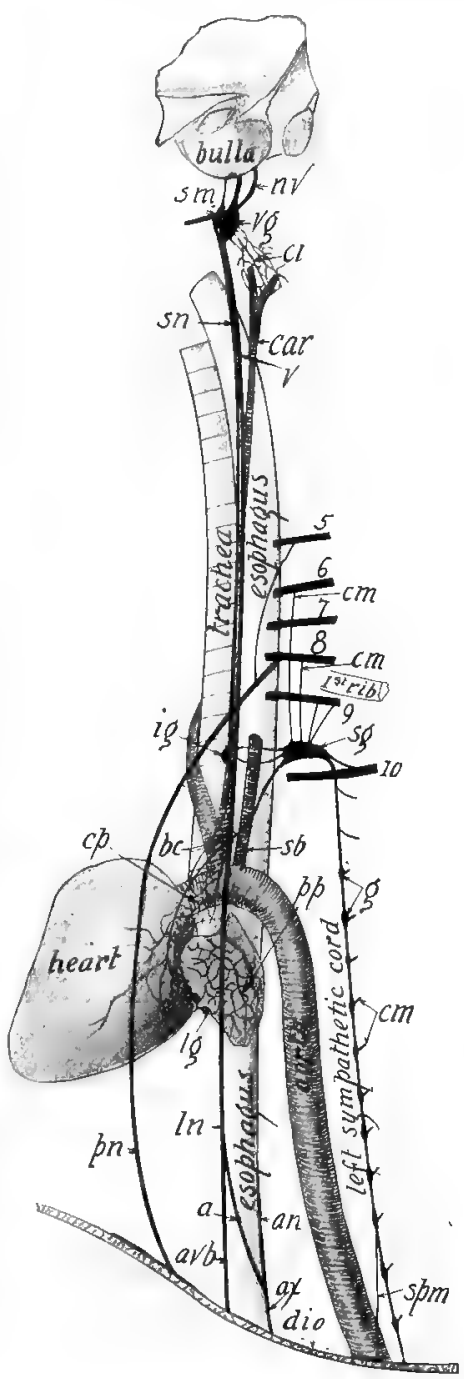
nerve. 
large inferior cervical ganglion just caudad of the first rib. From the cervical portions of the sympathetic cord are given off numerous delicate branches, forming the carotid plexus on the carotid artery, and uniting with the eight posterior cranial nerves and the first spinal nerve. From the inferior cervical ganglion a branch goes to the vagus nerve, several branches to the brachial plexus, and a branch to the heart, forming the cardiac plexus, while the main sympathetic cord continues along the dorsal thoracic wall. A ganglion occurs opposite each vertebral body, from which it gives off a branch to the corresponding spinal nerve. The great splanchnic arises from the main cord just craniad of the diaphragm and extends to a group of ganglia in the region of the trunk of the coliac axis (Figs. Io7 and I08). These ganglia and anastomosing branches constitute the solar or epigastric plexus, lying dorsad of the stomach, to which it sends numerous branches. This plexus also receives the lesser splanchnic nerve coming from the sympathetic cord just craniad of the diaphragm, and branches from the tenth cranial nerve.

The largest ganglion of the solar plexus is the semilunar. The solar and its allied plexuses send nerves to the diaphragm, suprarenal bodies, many of the blood-vessels of the abdominal cavity, stomach, kidneys, ureters, testes or ovaries, uterus, liver, gall-bladder, spleen, pancreas, and intestines.

The hypogastric plexus is the third great sympathetic plexus. It lies on the ventral aspect of the two caudal lumbar vertebra and is formed by branches from the solar plexus and a few twigs from the sympathetic cords. It supplies the blood-vessels of the pelvic region and all the organs of the pelvis. The sympathetic cords in the lumbar region lie near together and the communicating branches between them and the spinal nerves are longer than in the 
thoracic region. In the sacral region there are no rami communicantes, and the ganglia are irregularly arranged. A median ganglion in the sacral region is known as the ganglion impar. There may be two median ganglia. The sympathetic cords terminate in the tail.

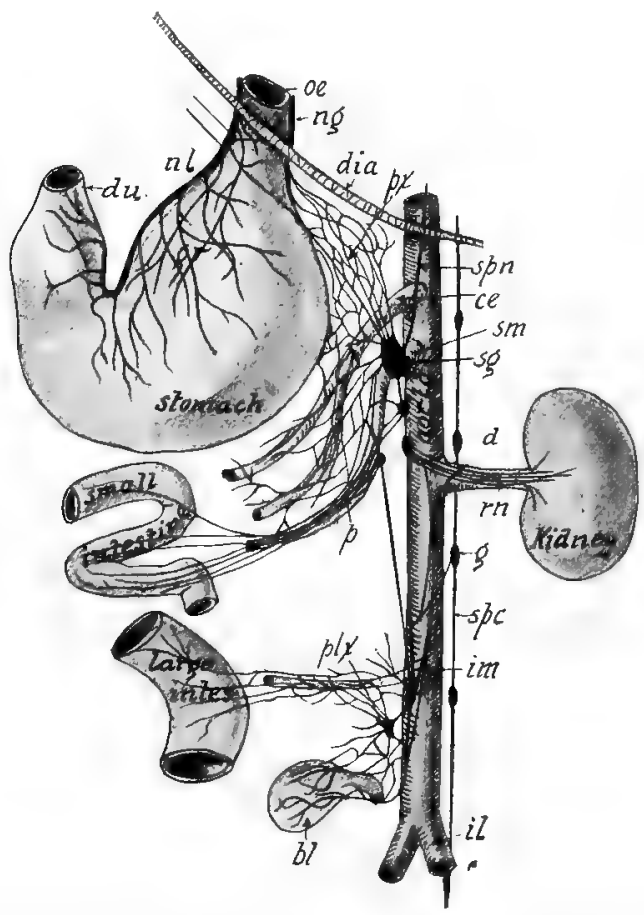

Fig. 108. Chief Part of Left Half of Sympathetic System Caudad of the Diaphragm. Semidiagrammatic.

$b l$, Bladder ; $c e$, cœliac axis; du, duodenum cut off ; dia, diaphragm; gr, anterior gastric plexus; $g$, ganglion; $i m$, inferior mesenteric artery; $i l$, external iliac artery; $n g$, dorsal branch of vagus (Fig. I03, ax); $n l$, ventral branch of vagus; $o e$, esophagus cut off; $p$, superior mesenteric plexus; $p l x$, inferior mesenteric plexus; $p x$, branches to dorsal gastric plexus; $r n$, renal plexus; sm, superior mesenteric artery; spn, splanchnic major or greater splanchnic nerve from the sympathetic cord; $s g$, semilunar ganglion; $s p c$, sympathetic cord of left side. 


\section{PRACTICAL QUESTIONS AND SUGGESTIONS.}

I. Name the foramina of the skull giving passage to one or more cranial nerves.

2. From a study of one or more specimens and the description in the book make a diagrammatic drawing of each cranial nerve.

3. Which cranial nerves have their roots in the medulla?

4. Name the cranial nerves which are wholly motor.

5. Which of the cranial nerves do not supply structures of the head?

6. Of what are ganglia composed?

7. Make a drawing of your dissection showing the connection between the spinal and sympathetic nerves.

8. Which spinal nerves form the several plexuses?

9. Make a drawing showing wherein the brachial plexus in your specimen differs from that described in the text.

Io. Write a description of your dissection of the nerves of the thoracic limb.

II. Mention in what way the lumbar plexus differs from the description in the book.

12. Draw the great sciatic nerve and its branches as seen from the caudal aspect.

I3. What nerves supply the digits?

14. Describe the chief plexuses of the sympathetic system.

15. How do stimuli from the viscera reach the brain?

I6. What portion of the body is not supplied with nerves from the sympathetic system?

\section{THE ORGANS OF SENSE.}

The organs of sense are the specialized peripheral terminations of the sensory nerves, and are so constructed as to be capable of receiving only a certain kind of stimulus. The stimuli for the eye are ether vibrations; those for the ear are vibrations of the air. The stimulation of the sensory nerves produces sensations in the cells of the cerebral cortex to which they lead.

The external stimuli giving rise to the internal sensations of seeing, hearing, smelling, and tasting are transmitted by only four pairs of cranial nerves, while the stimuli of cutaneous sensations are transmitted by three pairs of cranial nerves and all the spinal nerves. 
Cutaneous Sense Organs.-The cutaneous sense organs are composed of the endings of the sensory nerves in all parts of the skin and the mucous membrane of the mouth, nose, arms, vagina, and urethra. One kind of sense organs, those of pain, are present in every organ of the body. The sense organ of pain is probably an unmodified free nerveending.

While all portions of the skin and perhaps other parts of the body are supplied with organs capable of receiving stimuli giving rise to tactile sensation, the soles of the feet and the skin at the base of the vibrissæ are specially sensitive regions. The nerves terminate in a kind of wreath formation about the base of the vibrissæ.

All of these sense organs are invisible to the naked eye except the Pacinian corpuscles. If the mesentery is held up and looked through toward the light, the Pacinian corpuscles or sensory nerve terminations appear as translucent oval bulbs about two millimeters long. If a piece of the mesentery containing a corpuscle is pinned tense on a piece of cork and then cut out and placed ten minutes in $3 \%$ acetic acid, the termination of the nerve within the corpuscle may be seen with a microscope magnifying thirty diameters. All the spinal sensory nerve fibers enter the cord by the posterior root (Figs. 93 and roo).

The Olfactory Organ.-The organ of smell lies in that part of the mucous

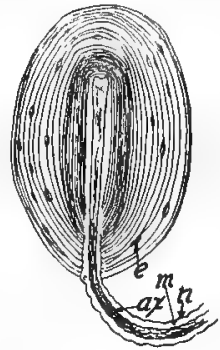

Fig. Iog. Pacinian CORPUSCLE FROM The Mesentery. $X$ 20.

$a x$, Axis-cylinder; $n$, neurilemma; $m$, the white substance of Schwann; $e$, epithelial cell. membrane lining the caudal part of the nasal cavity and the basal third of the ethmoturbinal bones (Fig. I8). That part of the mucous membrane containing the olfactory cells 
is known as the Schneiderian membrane. In a fresh specimen it is of a grayish color while the other mucous membrane is red. The first pair of cranial nerves convey the olfactory impulse to the brain. They pass through the foramina in the cribriform plate of the ethmoid bone, to the olfactory bulbs, from each of which two roots extend to the base of the cerebrum (Fig. 93).

The Gustatory Organ.-The organ of taste is located chiefly in the mucous membrane on the dorsum of the tongue, the soft palate, the pillars of the fauces, epiglottis, and part of the cheek. On the dorsum of the tongue are seen four kinds of papillæ- the circumvallate, the fungiform, the filiform, and flat. The circumvallate papilla are from eight to twelve in number, forming two sides of a triangle on the caudal portion of the dorsum of the tongue. The fungiform are blunt papillæe scattered sparsely in the midst of the numerous filiform or pointed papillæ (Fig. 56). The special organs of taste, known as taste-buds, are very numerous in the fungiform and circumvallate papillæe of most mammals, but in the cat they are few and not well differentiated. These tastebuds occur in many parts of the mucous membrane of the mouth cavity, each being supplied with a branch of the glossopharyngeal nerve.

The Visual Organ.-The special organ of sight is the eye, which occupies the orbital cavity of the skull. The ball of the eye is protected above and below by extensions of skin called the eyelids or palpebræ, which are lined with mucous membrane, a transparent layer of which, known as the conjunctiva, extends over the front of the eyeball between the two licls. The dorsal lid is raised by the levator palpebræ muscle, which has its origin in the occipitofrontalis muscle. A sphincter muscle, the orbicularis palpebrarum, lies on the margin of the lids, and by its contraction closes the eye. 
The point on either side where the two eyelids meet is termed the canthus or angle. At the medial or inner canthus are two minute apertures, the puncta lachrymalia, leading into two short canals which unite to form the nasal duct. The lachrymal canal, which forms the channel for this duct, is clearly visible in the lachrymal bone of the dried skull. At the medial eanthus there is a prominent fold of mucous membrane, the membrana nictitans, or plica semilunaris, which is a rudimentary structure in the cat, but is found well developed in birds, which have the power of sweeping it rapidly across the eyeball, thereby removing dust.

On the inner surface of each lid are the Meibomian glands. The lachrymal gland lies in the dorso-lateral region of the orbit, and its ducts open on the ventral surface of the upper lid, whence the tears flow over the conjunctiva ventrad to the puncta lachrymalia. The Harderian gland is the very small gland at the medial canthus.

The muscles controlling the movements of the eyeball are seven in number: four are recti muscles, two are oblique, and one is a retractor. The recti muscles (Fig. 93) originate on the bone around the optic foramen, and are inserted on the sclerotic coat, caudad of the equatorial ring. The extcrnal rectus is inserted on the lateral aspect; the internal rectus, on the medial aspect; the superior rectus, on the dorsal aspect; and the inferior rectus on the ventral aspect. The superior oblique muscle arises from the sphenoid bone medial of the optic foramen, extends along the medial wall of the orbital cavity to its dorso-medial margin, where it passes through a tendinous loop fastened to the frontal bone and then turns laterad to its insertion in the sclerotic beneath the superior rectus. The inferior oblique arises from the lachrymal bone and is inserted on the sclerotic between the external and inferior recti muscles. The above muscles may be demonstrated by cutting away the lateral and dorsal 
walls of the orbital cavity. The retractor oculi originates on the boundary of the optic foramen and is inserted into the sclerotic around the entrance of the optic nerve. This muscle is completely hidden by the recti muscles.

The eyeball is composed of three membranes and three humors. The outer coat, the sclerotic, consists of the opaque portion forming the caudal two-thirds, and the transparent portion, or cornea, forming the remainder (Fig. I ro). The optic nerve pierces the sclerotic a little mediad of the longitudinal axis of the eye. The surface of the cornea is more strongly curved than that of the opaque por-

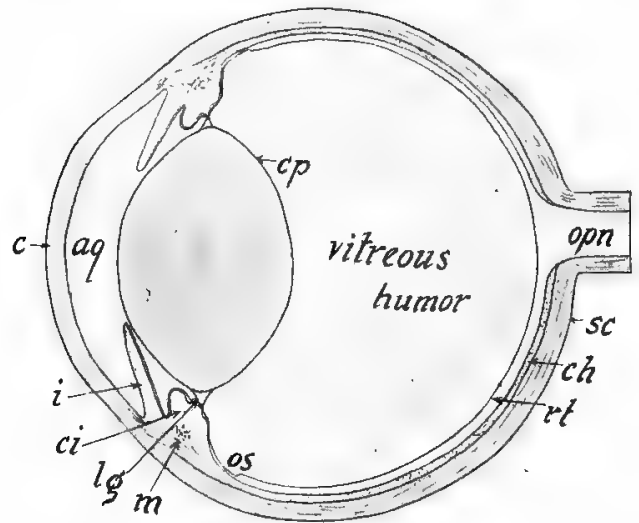

Fig. ilo. Longitudinal Section of the Eye.

$a q$, Aqueous humor; $c$, cornea; $c p$, capsule of the lens; $c h$, choroid; $c i$, ciliary process; $i$, iris; $l g$, ligament of lens; $m$, ciliary muscle; opn, optic nerve: $r t$, retina; $s c$, sclerotic coat; os, ora sertata.

tion of the sclerotic, and contains no blood-vessels. The second or middle coat of the eye is formed by the choroid membrane and its extension, the iris. This coat is incomplete, as there is an aperture, the pupil, through the iris for the admission of light. The choroid appears as a jet-black membrane, less than half as thick as the sclerotic, lying closely appressed to the latter. The choroid is lined in- 
ternally by dark pigment cells, except in the caudal area around the optic nerve, which has a metallic luster. This portion is called the tapetum. It causes the shining appearance of the cat's eyes in the dark. The choroid is a vascular membrane, being supplied by the ophthalmic artery, a branch of the internal carotid.

The iris is attached by its peripheral margin to the sclerotic and choroid coats, and hangs free in the aqueous humor. It gives color to the eye. In the cat it is yellowish, while in man it is frequently blue or black. The iris is merely a curtain to regulate the amount of light admitted to the retina. There is a sphincter muscle lying in it, which by contraction renders the pupil very small. There is probably no dilating nuscle of the iris present in the cat. The short, thickened, radial projecting folds of the choroid are the ciliary processes, which contain numerous blood-vessels. and in some mammals a gland. The ciliary muscle arises from the sclerotic coat near its junction with the cornea, and is inserted into the cranial part of the choroid coat.

The inner membrane of the eye is the retina, which is of a light gray color in a fresh specimen and seems quite free from the choroid. It is thickest in the caudal two-thirds of the cavity of the eyeball (Fig. IIO). At the base of the ciliary bodies it seems to end with a free margin, called the ora serrata. In reality it becomes very thin here and is prolonged over the ciliary bodies and covers the caudal aspect of the iris. The blind spot is the point of entrance of the optic nerve, laterad of which is the yellow spot, or macula lutea, containing the fovea centralis, or acute point of vision. This is the point on which the rays of light are focused when the cat sees distinctly.

The three humors of the eye are the aqueous, the crystalline lens, and the vitreous humor. The aqueous humor is a watery fluid occupying the cavity between the cornea and 
crystalline lens. It always escapes as soon as the cornea is punctured. The vitreous humor is of a jelly-like consistency, filling the part of the eyeball caudad of the lens. It is perfectly transparent and is surrounded by a delicate capsule, the hyaline membrane.

The crystalline lcns is a transparent biconvex tissue having a vertical diameter of about one centimeter and a shorter diameter through its optical axis. It is enclosed in a transparent elastic capsule, some of whose fibers are continued peripherad as the susponsory ligamont which is inserted in the choroid coat (Fig. I IO).

The Auditory Organ.-The organ of hearing is composed of three parts-the external ear, middle ear, and internal ear. The first consists of the pinna and the auditorius meatus externus. The pinna is the projecting portion of the ear capable of being moved by muscles, and is composed of integument strengthened by fibrocartilage. The auditorius meatus extermus extends from the base of the pinna to the tympanic membrane (Fig. I I I). Its outer or lateral third is formed by cartilage, and the remainder by the tympanic portion of the temporal bone (Fig. I 7 ). The meatus is lined with mucous membrane in which are numerous sebaceous and oleaginous glands. The latter secrete the wax of the ear.

The middle ear, or tympanmm, is an irregular cavity about one centimeter in diameter contained in the lateral chamber of the bulla (Fig. I I I). It is separated from the external auditory meatus by the delicate translucent membrane, the membrana tympani. The petrous bone containing the internal ear forms part of the inner or medial wall. In the petrous bone are two foramina which may be seen in a dry skull by looking through the external auditory meatus. The more clorsal foramen is the fenestra ovalis, which in the recent state is closed by a membrane to which the foot 
of the stapes is attached. The ventral one is the fenestra rotundum, also closed by a membrane in the recent state. In the dry skull the fenestra ovalis opens into the first or basal whorl of the cochlea, and the fenestra rotundum opens into the vestibule of the internal ear. The Eustachian tube (Fig. I8), whose opening may be seen craniad of the auditory bulla, connects the middle ear with the posterior nares and thus admits air to the tympanic cavity.

To demonstrate further the anatomy of the middle ear, one should clean the flesh from a fresh or preserved head and carefully cut away the ventral walls of both chambers of the auditory bulla (Fig. I7).

In the middle ear are three bones, the malleus, incus, and stapes, commonly called hammer, anvil, and stirrup. They form a crooked chain across the cavity. The long process of the malleus is fastened throughout nearly its whole length to the inner surface of the membrana tympani, and its enlarged extremity articulates with the body of the incus. The latter has two legs, to one of which the stapes is attached. The base of the stapes is inserted in

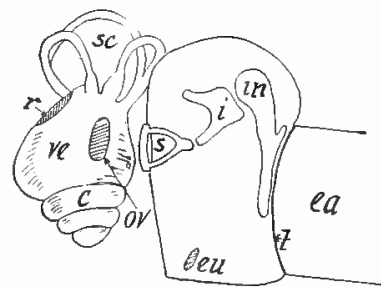

Fig. iII. DiAgram OF THE MammaLian EAR.

The internal ear is represented removed about a centimeter from the middle ear and slightly rotated to the left. The base of the stapes, $s$, in nature, covers the fenestra ovalis, ov; $c$, basal whorl of the cochlea; ea, external auditory meatus; eu, opening of the Eustachian tube; $i$, incus; $i n$, malleus; $s c$, semicircular canals; ve, vestibule; $t$, tympanum. the membrane closing the fenestra ovalis (Figs. I7 and I I I).

The internal ear, or labyrinth, consists of three partsthe vestibule, cochlea, and semicircular canals (Figs. I8 and III). All of these parts are of membrane and lie in cavities of corresponding shape within the petrous bone. 
A lymphoid fluid, the perilymph, floats the delicate membranous internal ear within its bony cavity, while within the membrane is a similar fluid, the cndolymph. The vestibule is a small sac adjacent to the tympanum, and may be seen by looking through the fenestra ovalis. From the dorso-caudal aspect of the vestibule, arch three semicircular canals at nearly right angles to one another. The external semicircular canal is in a horizontal plane and surrounds a small fossa almost caudad of the fenestra ovalis. The superior semicircular canal lies in a transverse plane caudad

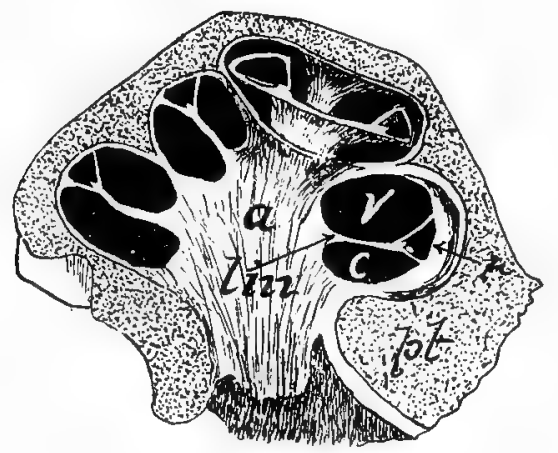

Fig. il2. Section of the Cochlea of the Calf. $\times$ 10.-(From Ellenberger, after Kölliker.)

$a$, Modiolus ; $c$, scala tympani; $v$, scala vestibuli ; $l m$, lamina spiralis; $p t$, portion of the petrons bone; $r$, scala media, or ductus cochlearis.

to the preceding. The posterior semicircular canal lies in a vertical longitudinal plane, immediately laterad from the jugular foramen.

The cochlea is a coiled canal lying within the coiled cavity, the bony cochlea, extending craniad from the vestibule. If both chambers of the auditory bulla are removed and a bristle thrust into the fenestra rotundum (Fig. I7), it will enter the basal whorl of the bony cochlea. A line drawn from the lateral margin of the foramen ovale to the 
medial margin of the fenestra rotundum passes through the apex and middle of the base of the cochlea, which may be rendered visible by carefully clipping off with the boneforceps the ventral portion of the petrous bone along the line indicated. This coiled canal, the cochlea, is divided into two channels by a shelf of bone, the lamina spiralis, projecting from the central axis or modiolus of the coil (Fig. II 2 ). The bony lamina extends but partly across the canal, the remaining distance being bridged by membrane. The cranial channel, or the one nearer the apex of the cochlea, is called the scala vestibuli. The other is the scala tympani.

The semicircular canals probably have nothing to do with hearing, as they are well developed in fishes, some of which do not hear at all. They may aid in helping the cat to maintain its equilibrium. The auditory nerve, however, is distributed to the vestibule and semicircular canals as well as to the cochlea upon the lamina spiralis, where the organ of Corti, the essential organ of hearing, is located.

\section{REMARKS ON THE MAMMALIAN NERVOUS SYSTEM.}

So far as known, the relation of the sympathetic to the peripheral and central nervous systems is the same in all mammals. The number of spinal nerves varies with the number of vertebræ. The distribution of these nerves, however, is approximately the same in all forms with five digits. In those having a less number of digits the nerve branch corresponding to the lacking digit or digits is wanting. The arrangement of the columns or tracts of fibers in the spinal cord is very similar in all the orders. The anterior or direct pyramidal tract, however, is partially or wholly absent in most orders below the Primates. It is best devel- 
oped in man, although in a number of cases it has been found entirely wanting in the human. The number of the cranial

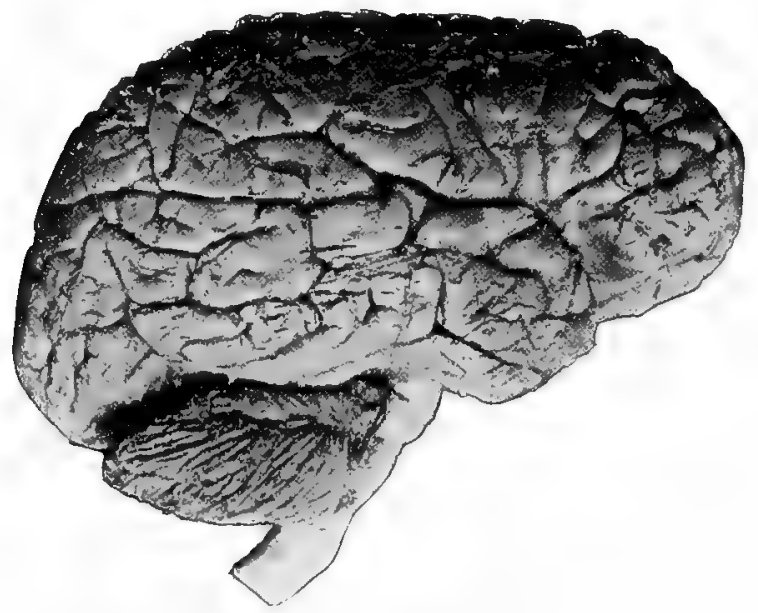

Fig. iI3. Photograph of the Human Brain from the Lateral Aspect. Two fifths natural size.

nerves is always twelve and their distribution is very similar in all forms investigated.

The structure of the brain in the Ornithodelphia and Didelphia differs considerably from that of the Monodelphia. In the two former subclasses the corpus callosum and fornix are very rudimentary, but the anterior commissure piercing the corpora striata is unusually large. The fibers, which in the Monodelphia arise from the cells of the hippocampus, and extend craniad to form the fornix, cross transversely to the opposite hippocampus in the two lower subclasses.

In all higher mammals the cerebrum is greatly convoluted, but in the lower ones the convolutions are few or almost absent, as in Ornithorhynchus. The above-mentioned features show that the ornithodelphian brain presents a 
striking similarity to the brains of reptiles and birds. The brains of Rodentia possess but few convolutions, while the brain of man is the most highly convoluted.

The size of the brain varies widely. As a rule, the larger the brain in proportion to the size of the animal, the greater is its intelligence. However, in man this statement does not always hold true, as an individual with a small brain may be much more capable mentally than one with a large brain. Mental power in man seems to depend upon the development of the cells and fibers of the brain.

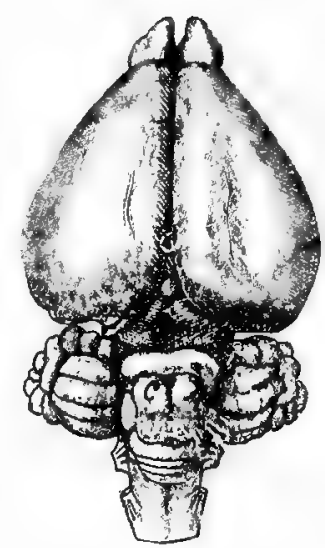

FIG. II4. BRAIN OF THE RABBIT FROM DORSAL ASPECT.

$c$, cerebellum. Three fifths natural size.

The average weight of a male human brain is about three pounds; of a female, about two and two-thirds pounds. The human brain is $\frac{1}{4}$ the weight of the body; the ape's, $\frac{1}{29}$; the rat's, $\frac{1}{82}$; the sheep's, $\frac{1}{5} \overline{1}$; and the elephant's, 500 . The brain of man is larger than that of any other mammal except the whale and elephant. The brain of a large whale weighs over four pounds, while that of a large elephant will weigh about ten pounds.

\section{PRACTICAL QUESTIONS AND SUGGESTIONS.}

x. How many nerves transmit the stimuli received by the organs of special sense?

2. Where are the sense organs of pain located?

3. How many sense organs are visible in the mesentery of your specimen?

4. Describe the path of a stimulus from the index finger to the brain.

5. Through which nerve roots would the stimuli received by the cutaneous sense organs pass into the cord?

6. Describe the nerves transmitting the stimuli from the olfactory organ. 
7. Describe the gland secreting the tears and how they reach the nasal cavity.

8. By cutting away the lateral and dorsal walls of the orbit dissect the muscles of the eyeball and make a drawing of them, labelling all parts.

9. What nerves control the movements of the eyeball?

Io. Procure the eyes of any mammal from the butcher-shop or slaughterhouse; bisect one in the meridional and the other in the equatorial direction. Make a drawing of the features seen and label.

II. Remove the crystalline lens from a fresh eye, describe its size, shape, structure, length of focus, and power of magnification.

12. Describe the path of a stimulus from the retina to the area of sight in the brain.

13. Name every feature visible in the eyes you have dissected.

I4. What nerve supplies the auditory organ?

15. Describe the middle ear.

I6. In what part of the temporal bone is the internal ear located?

I7. By looking into the auditorius meatus of the dried skull two openings are seen. Into which portions of the internal ear do these lead?

I8. Write a description of the internal ear.

I9. Mention some important points of difference in the nervous system of various mammals.

20. What relation, if any, between intellectual ability and brain development? 


\section{GLOSSARY.}

$\mathrm{Ab} d \mathbf{u}^{\prime}$ cens ( $a b$, from; ducens, leading): the sixth cranial nerve.

$\mathrm{Ab} \mathrm{duc}^{\prime}$ tor ( $a b$, from; duco, I lead) : a muscle drawing a part outward.

Ac e tab' u lum (small cup) : cavity of the innominate bone for articulation with the femur.

A cro'mi on (summit of shoulder): name of certain parts at the shoulder.

Ad: a Latin prefix of words; signifying to, toward or at.

Ad duc' tor ( $a d$, to; duco, I draw) : a muscle drawing a part inward.

Af' fer ent ( $a d$, to; fero, I carry) : the name of a nerve carrying an impulse to the brain or cord, and also applied to a vessel conveying fluid to the organ in which a physiologic process is to occur.

An æs thet' ic (want of feeling) : any drug which when used externally or internally causes loss of feeling.

Al isphen' oid (ala, wing; sphen, wedge; oid, like): the wing-like part of the sphenoid bone.

Alve' olar (alveolus, small hollow): relating to the sockets of the teeth.

Al ve' o lus : the socket of a tooth.

Am phi ar thro' sis (amphi, around; arthron, a joint) : a joint in which there is limited movement in every direction.

Am phib' i ans (amphi, both; bios, life) : a class of vertebrates including frogs which spend part of the life in water and part on land.

A nas to $\mathrm{mo}^{\prime}$ sis: the intercommunication of vessels.

An chy $10^{\prime}$ sis (stiff joint) : a firm union of the bones forming a joint.

$\mathbf{A n}^{\prime} \mathbf{n u}$ lar (annulus, a ring) : a name given to the encircling ligaments at the wrist and ankle.

Ap o neu ro' sis (apo, from; neuron, a tendon): a membranous expansion of a tendon.

A rach' noid (like a spider's web) : the delicate middle membrane enveloping the brain and spinal cord.

A re' o lar (open space): relating to connective tissue loosely woven.

Ar ti o dac' ty la (even-fingered) : those ungulates having an even number of digits on each foot.

A ryt' e noid (arutaina, pitcher;' oid, like): the name of a pair of cartilages of the larynx.

Au ric' ular (auricula, outer ear) : relating to the ear.

$\mathrm{Au}^{\prime}$ ditory (audire, to hear): pertaining to the act or the organs of hearing. 
Axil' la (axilla, armpit).

Ax' il la ry: a name given to several structures in the region of the armpit.

$A x^{\prime}$ one: the process which carries the impulse away from a nerve cell.

$\mathbf{B i}^{\prime}$ ceps (bis, twice; caput, head) : a term applied to muscles having two origins.

Brach (brachium, arm).

Brach' $^{\prime}$ al : a name given to several structures in the upper arm region. Bron' chi : plural of bronchus.

Bron' chus (brogkos, windpipe) : the two tubes into which the trachea divides.

Buc' cal (bucca, cheek) : pertaining to the cheek.

Cæ' cum (blind) : first part of large intestine.

Cal ca' ne um (calcaneum, the heel) : the os calcis or heel-bone.

Cal lo' sum (callosus, thick-skinned) : the largest commissure of the brain.

Can a lic' $\mathbf{u}$ li : the small canals opening into the lacunx of bone.

Can' nu la (canna, a tube) : a small tube.

Ca pit' ulum (capitulum, a small head) : the enlarged terminal portion of an organ.

Car' di ac (kardia, the heart): pertaining to the heart.

Ca rot' id: the chief artery lying on either side of the windpipe.

Car' pal (karpos, wrist) : pertaining to the wrist.

Cau' dad: toward the tail.

Cau'dal (cauda, tail) : relating to the tail.

Cen' trum: the body of a vertebra.

Ceph' a lic (kephala, head) : relating to the head.

Cer a to hy' al: a part of the hyoid apparatus.

Cer' vic al (cervix, neck) : a name applied to strutctures in the region of the neck.

Cer' vi dæ: the name of the deer family.

Chev'ron bones: the bones on the underside of some of the caudal vertebræ.

Chi' asm (ki' azm, mark crosswise) : the optic commissure.

Chi rop' te ra (cheir, hand; pteron, wing) : an order of mammals including the bats.

Cho an' $æ$ : the posterior nares.

Cho' roid: the middle lining of the eyeball.

Cir cumval' late (circumvallere, to surround with a wall) : the name of the large papille at the base of the tongue.

Clit' or is: a small erectile organ occupying the same relative position in the female as the penis occupies in the male.

Coc' cyx (kokkux, the cuckoo, resembling the bill): the several united vertebra forming the tail in man. 
Coch' le a (kok'leah) (kochlos, a conch-shell): the coiled canal of the internal ear.

Cœ'li ac (se'le ak) (koilia, belly) : a name applied to a large artery and a nerve plexus in the abdomen.

$\mathrm{C}^{\prime}$ lom ( $e^{\prime}$ lum $)$ : the body cavity.

Con' dyle (kondulos, a knuckle) : a paired rounded eminence of a bone for articulation.

Cor' nu (a horn): a name given certain structures resembling a horn.

Cor' nu a: the plural of cornu.

Cor' o noid (corona, crown; oid, like).

Cor' por a (corpus, body): a name given to certain parts having a rounded or ovoid shape.

Cor' pus : singular of corpora.

Cos' ta (costa, rib).

$\operatorname{Cos}^{\prime}$ tal : pertaining to the ribs.

Cot' yl oid (kotula, a cup; oid, like): relating to the articular cavity in the innominate bone.

Cra' ni ad: toward the plane in front of the cranium and perpendicular to the spinal axis.

Cra' ni al: pertaining to the cranium.

$\mathrm{Cra}^{\prime}$ ni um: those bones of the skull encasing the brain.

Cru' ra: plural of crus.

Crus (crus, a leg) : the part of the leg between the knee and ankle. It is also applied to structures resembling the leg.

$\mathrm{Cu}^{\prime}$ boid (like a cube): one of the tarsal bones.

Cu ne $\mathbf{a}^{\prime}$ tus (kuneus, a wedge) : a fiber tract in the spinal cord.

Cu ne' i form (wedge-shaped) : bones of the ankle and wrist.

Cu ta' ne ous (cutis, the skin): relating to the skin.

De cus sa' tion (decussatus, crossed) : an oblique crossing of the nerves. Dem i fac' et (demi, half; facette, little face) : the articular surface on the body of a vertebra for the articulation of half the head of a rib.

Den' drites (dendron, a tree): the processes of a nerve cell which transmit the impulse toward the cell-body.

Di aph'y sis (dia, between; phuein, to grow): the shaft of a long bone.

Di a ste' ma (diastema, a distance) : a space between any two consecutive teeth.

Di ar thro' sis (dia, throughout; arthrosis, articulation): a form of articulation giving much freedom of motion.

Di del' phi a (dis, twice; delphus, uterus) : an order of mammals including the kangaroos and opossums in which a paired uterus is present.

Di en ceph' a lon (dia, between; egkcphalos, the brain): the tween brain formed largely by the optic thalami.

Di gas' tric (dis, double; gaster, belly): the muscle depressing the lower jaw. 
Dig' it (digitus, a finger): the name of a finger or toe.

Dig it or' um: of digits.

Diph' y o dont (diphus, twofold; odous, tooth): mammals having two sets of teeth.

Dis' tad: away from the axis of the body.

Dis' tal: the part farther from the axis of the body.

Dor'sad (dorsum, the back): toward the line passing from head to tail along the tips of the spinous processes.

Duode' num (duodeni, twelve each) : first part of the small intestine; in man it is twelve finger-breadths.

Du ra ma'ter (durus, hard; mater, mother): the outer membrane of the brain and cord.

E den ta' ta (e, without; dens, a tooth): an order of mammals some of which have no teeth.

Ef' fer ent (efferens, carrying from): the opposite of afferent.

$\mathrm{Em}^{\prime}$ bry o: the undeveloped young.

En ceph' a lon (en, in; kephala, the head): the brain.

En do mys'i um (cndon, within; mus, muscle): the extension of the perimysium between the muscular fibers.

$\mathrm{En}^{\prime}$ si form (ensis, sword; forma, form) : the cartilaginous process at the caudal end of the sternum.

Epi did'y mis (epi, upon; didumoi, the testes): the contorted tubule forming the small body lying against the testis.

Ep i mys'i um (epi, upon; mus, muscle) : the delicate membrane enve!oping muscle.

E piph' $^{\prime}$ y ses (epi, upon; phucin, to grow) : a process of bone attached for a time to another bone by cartilage, but later becoming firmly united to it.

Ep i the' li um: the outer layer of the skin and all mucons surface. Eth' moid (ethmos, a sieve; oid, like) : the bone at the root of the nose. Eu sta' chi an ( $u$ sta ke an) (named after the anatomist Eustachio).

Eu the' ria (eus, good; therion, beast) : a subclass including all mammals above the marsupials.

Fac' et (facette, a little face) : a small plane surface ustrally on a bone for articulation.

Fal lo' pi an tube: the canal conducting the eggs from the ovary to the uterus.

Fal lo' pi us: a noted Italian anatomist.

Fas' cia (fash'eah): the membranous fibrous covering of muscles.

Fas cic' u lus (fascis, a bundle) : a little bundle of fibers forming part of a nerve or muscle.

Fau'ces ( $\left.f a v w^{\prime} s c z\right)$ : that part of the throat surrounded by the palate, tonsils and uvula. 
Fe nes' tra (a rindors).

Fil' i form (filum, thread; forma, form) : name of papillæ on tongue.

Fora'men (forare, to pierce): a passage or opening, usually in bone, for the transmission of nerves or vessels.

Fo ram'i na: the plural of foramen.

For mal' de hyde: an excellent disinfectant.

For' mal in: a 40 per cent. solution of formaldehyde in water.

For' nix (an arch): the projecting bundle of fibers from the gyrus hippocampus, beneath the corpus callosum.

Fos'sa (a ditch): a depression or furrow.

Fu nic' u lus ( $f$ unis, a cord) : applied to various cord-like structures.

Gas' tric (gaster, stomach) : relating to the stomach.

Gas troc ne' mi us (gastcr, stomach; knema, leg): large muscle in the calf of the leg.

Gen'e ra: plural of genus.

Ge nic u la' tum (geniculare, to bend the knee) : a name applied to certain bodies in the brain.

Gen' us : a species or collection of species marked by one or more common characteristics distinguishing them from other groups.

Ging' ly mus (gigglumos, a hinge) : a kind of joint having free motion in two directions.

Glen' oid (glena, a cavity; oid, like): pertaining to a shallow cavity.

Glos' sa: the tongue.

Glu' te al: pertaining to the buttocks.

Glu' te us (gloutos, buttock)

Gly' co gen (glukos, sweet) : animal starch.

$\mathrm{Grac}^{\prime} \mathrm{i}$ lis (slender): the name of a muscle in the leg.

Gy'ri: plural of gyrus.

Gy' rus (guros, a circle): a convolution of the brain.

Hal' lu cis (from hallux, the great toe).

He pat' ic (hepar, liver): pertaining to the liver.

Het' er o dont (heteros, other; odous, tooth): having teeth of mere than one kind.

Hom' o dont (homos, the same; odous, tooth): having teeth all of one form.

$\mathrm{Hy}^{\prime}$ oid: the name of the bone at the root of the tongue.

$\mathrm{Hy}^{\prime}$ po: under.

Hy po gas' tric: under the stomach.

Hy po glos' sus: under the tongue.

In' fra: below.

In fra or' bit al : under the orbit. 
Il' e um (eilo, twist): the last part of the small intestine.

Il'i ac (ilia, the flanks) : pertaining to the region of the ilium or hip bone.

In' guin al (in' gwin al): pertaining to the groin or ventral region where the pelvic limb joins the body.

In'ter: a Latin prefix meaning between.

In ter $\cos ^{\prime}$ tal : between the ribs.

In ter os' se ous: between the bones.

In ter ver' te bral: between the vertebra.

Is' chi um (is' ki um) : the middle part of the innominate bone.

Je jun' um (jejunus, empty) : the two fifths of the small intestine extending between the duodenum and ileum.

$\mathrm{Ju}^{\prime}$ gal (jugum, a yoke) : the malar bone.

$\mathrm{Ju}^{\prime}$ gu lar (jugulum, throat): the name of the large veins in the neck.

Lac' er um (laceros, torn): name of foramina in the skull.

Lach' ry mal (lachryma, a tear) : pertaining to the lachrymal apparatus.

Lac'te als (lac, milk): the lymphatics of the small intestine which take up the chyle and carry it to the thoracic duct.

Lamb doi' dal (after a Greek letter) : pertaining to the suture between the parietal and occipital bones.

Lam'i na (a plate or scale): a term designating a thin layer of tissue. Lar' ynx: the cartilaginous tube at the cranial end of the trachea.

Lat' er ad (latus, side; ad, to) : toward one side.

Lat' er al: pertaining to the side.

La tis' si mus (broadest): a name applied to certain muscles.

Le va' tor (a lifter): a name given to muscles which raise parts.

Lin' gual (lingua, tongue) : pertaining to the tongue.

Lum' bar (lumbus, the loin): relating to the region of the loins which is the lower part of the back.

Lym phat' ics (lympha, water): the absorbent system.

Mag' num (great).

Ma'lar (mala, cheek).

Mal le' olus (malleus, hammer): a process of bone.

Mal pigh' i: an Italian anatomist.

Mam ma' li a (mamma, breast) : the highest class of vertebrates.

Ma nu' bri um (a handle): the cranial piece of the breastbone.

$\mathbf{M a}^{\prime}$ nus (hand) : the hand.

Mar su pi a' li a (marsupos, a pouch): a subclass of mammals having a pouch beneath the belly in which they carry the young.

Ma' ter (mother).

Mas' toid (mastos, breast; oid, like): the process of bone behind the ear. 
Me $\mathbf{a}^{\prime}$ tus (passage) : a channel or canal.

$\mathrm{Me}^{\prime}$ di ad (medius, middle): toward the middle.

$\mathrm{Me}^{\prime}$ di al : pertaining to the middle.

Me di as ti' num (standing in the middle): the space between the lungs, including the heart and other organs.

Med' ul la ry (medulla, marrow) : pertaining to the marrow within the bones.

Men in ge' al (menigx, membrane): pertaining to the membranes of the brain or cord.

Men'tal (mentum, chin): pertaining to structures about the chin.

Mes en ter ${ }^{\prime}$ ic (mesos, middle; cnteron, intestine): pertaining to the mesentery.

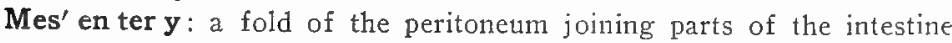
to the dorsal part of the abdominal cavity.

Met' a (beyond).

Mes en ceph' a lon (mesos, middle; encephalon, brain): the mid-brair, consisting of the corpora quadrigemina and crura cerebri.

Met en ceph' a lon: the pons Varolii and cerebellum.

Mo di' olus: the central pillar or axis of the cochlea.

Mon' o phy dont (monos, single; phuein, to grow; odous, tooth): having only one set of teeth during life.

Mon o tre' ma ta (monos, single; tremos, hole) : the lowest subclass of mammals. The intestinal and urinary products are voided through one opening as in birds; duck bill and spiny ant eater.

Mor phol' o gy (morpha, form; logos, discourse) : that part of biology dealing specially with form and structure.

My el en ceph' a lon (myelos, marrow; encephalon, brain): the medulla oblongata.

Mo' tor (movere, to move): a name given nerves stimulating muscles.

Neu' ral (neuron, nerve) : pertaining to a nerve.

Neu'rone: a nerve cell with all its processes.

$\mathrm{Nu}$ ' clei : plural of nucleus.

$\mathrm{Nu}^{\prime}$ cle us (nux, a nut) : the essential part of every cell; also applied to a definite bunch of nerve cells.

$\mathrm{Ob}^{\prime}$ tu rator: the name of the large foramen in the innominate bone or of structures near to it.

Oc cip' ital ( $o b$, against; caput, the head) : relating to structures in the region of the back part of the head.

Oc' u lar (oculus, the eye) : pertaining to the eye.

O don' toid (odous, tooth; oid, like) : relating to the tooth-like process of the axis.

Oid: a common suffix derived from Greek cidos and signifying like.

O lec'ran on (olea, elbow; kranion, head) : process of the ulna. 
O men' tum : a fold of the peritoneum connecting the abdominal viscera.

Ol fac' to ry (olfacere, to smell): pertaining to the nose.

Oph thal' mic (ophthalmos, eye) : pertaining to the eye.

Op' tic (optikos, to see) : relating to the eye.

$\mathrm{O}^{\prime}$ ra: mouth.

$\mathrm{Or}^{\prime}$ bit al (orbis, circle) : pertaining to the cavity for the eye.

$\mathrm{Or}^{\prime}$ gan: any part having a definite function.

Or nith o del' phi a (ornis, bird; delphus, womb): the oviparous mammals.

Os: bone.

$\mathbf{O}^{\prime}$ va: plural of ovum.

O va'le: oval.

O vip' a rous (ovum, egg; parere, to bring forth) : those animals which deposit eggs instead of bringing forth living young.

$\mathrm{O}^{\prime}$ vum : egg.

Pa ri' e tal (paries, a wall).

Par ot' id (para, near; ous, ear): the name of a salivary gland.

$\mathrm{Pec}^{\prime}$ to ral (pectus, breast): pertaining to structures in the region of the breast.

Ped'icles (pediculus, a little foot) : the foot of the neural arch.

$\mathrm{Pe}^{\prime}$ dun cles (pedunculus, a little foot) : bands of fibers uniting certain parts of the brain.

Pel' vic: relating to the cavity between the innominate bones.

Per i mys' i um (peri, around; mus, a muscle) : the tissue which envelops the primary bundles of muscle fibers.

Per is so dac' ty la (perissos, odd; dactyl, finger): those ungulates having an odd number of digits.

Pe riph' e ral: pertaining to the ottside.

Per i to ne' um (peri, around; teinein, to stretch): the serous membrane lining the abdominal cavity and surrounding most of the organs within it.

Per o ne' al (perone, a pin) : relating to the fibula.

$\mathrm{Pe}^{\prime}$ des : plural of pes.

Pes : foot.

Pha lan' ges: plural of phalanx.

Phal' anx: one of the bones of the fingers or toes.

Phar' ynx (throat): the cavity back of the mouth.

Phren' ic (phren, diaphragm): pertaining to the diaphragm.

Phy log' e ny (phula, tribe; genas, producing): that science treating of the evolution of a group.

$\mathbf{P i}^{\prime}$ a $\mathbf{m a}^{\prime}$ ter (soft mother): the delicate membrane next to the brain and cord.

Pneu mo gas' tric (pneuma, air; gaster, stomach): the vagus nerve.

Pons : bridge. 
Pop lit' e al (poples, knee): pertaining to the caudal region of the knee-joint.

Post : a common prefix meaning after or behind.

Pri ma' tes (prinus, first): the highest order of mammals, including man and the monkeys.

Profun' da (profundus, deep) : a term given to a part deep-seated.

Pro to chor da' ta (protos, first; chorda, cord): those forms between the invertebrates and vertebrates. Seasquirts.

Pro to the' ri a (protos, first; therion, beast): the oviparous mammals.

Prox'i mad: toward the central axis of the body.

Prox' i mal: that part nearest to the central axis of the body.

Pter' y goid (pteron, wing; oid, like) : part of the sphenoid bone.

$\mathrm{Pul}^{\prime}$ mo na ry (pulmo, lung): pertaining to the lung.

Pylor' ic (pyloros, gate-keeper): the opening of the stomach into the duodenum.

Quad'ri ceps (quadri, four; caput, head).

Quad ri gem' i na : plural of quadrigeminum.

Quad ri gem' i num (quadri, four; geminus, twin born): part of the brain.

$\mathrm{Ra}^{\prime}$ mi: plural of ramus.

$\mathrm{Ra}^{\prime}$ mus: the branch of an organ.

Rec' tus : straight.

Rhin' al: pertaining to the nose.

Ro lan' do: an anatomist.

Ro tun' dum: round.

$\mathrm{Ru}^{\prime}$ mi nant (ruminare, to chew the cud); any of the ungulates which chew the cud.

$\mathrm{Sa}^{\prime}$ crum (sacer, sacred) : the part of the backbone between the innominate bones.

Sag' it tal (sagitta, an arrow): a name given to a vertical longitudinal plane of the body.

Scaph' oid (skapha, a boat): a bone in the wrist and also the ankle.

Sci at' ic $\left(\right.$ si $\left.a t^{\prime} i c\right)$ : relating to structures in the region of the ischium.

Scle rot' ic (skleros, hard): relating to the outer coat of the eye.

Se ba' ce ous (sebum, suet or fat): the name of glands in the skin.

Sec to' ri al (secare, to cut): the carnassial or last premolar tooth in many of the carnivora.

Sem i lu' nar (semi, half; luna, moon).

Ses' a moid (sesamon, a grain; oid, like): the name of small bones developed in tendons.

Sig' moid: shaped like the Greek letter sigma.

$\mathrm{Si}^{\prime}$ nus (simus, a hollow) : a cavity or channel. 
So' le us (flat).

Sper mat' ic (sperma, seed) : pertaining to the reproductive fluid called semen.

Sper ma to $z 0^{\prime}$ a (spcrma, seed; zoa, animals) : plural of spermatozoön. Sper ma to $\mathbf{z o}^{\prime}$ ön: the male reproductive cell developed in the testis.

Sphen' oid (sphen, wedge; oid, like).

Sphinc' ter (to squeeze): the name of a muscle surrounding and capable of closing an orifice.

Splanch' nic : pertaining to the viscera.

Sub: a common prefix denoting under or beneath.

Sty' loid (stulos, a pillar).

Su' pra: a prefix denoting above.

Sul' ci : plural of sulcus.

Sul' cus (sulcus, a furrow) : a cleft or furrow in the brain.

Syl' vi us: a noted anatomist.

Sym' phy sis (sun, together; phucin, to grow): the junction of bones, usually in the median line of the body.

Syn arthro' sis (sun, together; arthron, a joint) : a form of articulation in which the bones are immovably united.

Sys' tem: a collection of organs for one general purpose.

Tel en ceph' a lon (telos, end; encephalon, brain): the cerebral hemispheres and corpora striata; the end brain.

Te' res: round.

Thal' a mus (thalamos, bed) : the optic thalami form the chief part of the tween brain.

Thy' roid (thureos, a shield; oid, like) : the name of structures in the region of the thyroid cartilage.

$\mathrm{Tib}^{\prime} \mathbf{i}$ al (tibia, shin) : pertaining to the tibia or shin bone.

Tri' ceps (tres, three; caput, head).

Tri cus' pid: having three points or cusps.

Tri gem' inal: the fifth cranial nerve, so called because of its three divisions.

Tro chan' ter: the name of two processes on the femur.

Troch'le ar (trochilia, a pulley).

Tur' bin al: one of the turbinated or lateral ethmoid bones.

Tym' pan um (tumpanum, a drum) : the middle ear.

Umbil'i cus (navel): the depressed cicatrix in the center of the abdomen marking the hole giving passage to the vessels formerly connecting the young with the mother.

$\mathrm{Un}^{\prime}$ ci form (uncus, a hook; forma, form) : a bone of the carpus.

Un gu la' ta (ungula, a hoof) : an order of mammals characterized by hoofs.

U re' ter: the tube from the kidney to the bladder. 
$\mathrm{U}$ re' thra: the tube from the bladder to the exterior.

$\mathrm{U}^{\prime}$ ter us: the womb or cavity in which the young are developed.

Ven'trad (vcnter, stomach) : toward a plane passing along the underside.

Ver' te bra (vertere, to turn): a bone of the spinal column.

Ver'te bræ: plural of vertebra.

Ves tig' i al : rudimentary; existing only as a trace.

Vis' ce ra: the organs within the body cavity.

Whar' ton: name of the duct from the sublingual gland.

Wil' lis : an anatomist.

Wir'sung : an anatomist; name of a duct from the pancreas.

Xiph' oid : same as ensiform.

Zy go' ma (zugoma, cheek-bone): the arch formed by a process of the temporal bone and the malar. 



\section{INDEX.}

Air sacs, I6I

Alimentary canal, i I6 walls of, II8

Alveoli, I6I

Amphibia, 2

Anæsthetizing, 5

Anatomy, I

Antibrachium, 56 .

Aorta, 132

Appendix vermiformis, II7, I26

Arteries

head and neck, I35

pelvic limb, I40

thoracic limb, I37

trunk, I32

Artiodactyla, 23I

Association fibers, 204

Atlas, 44

Auditory organ, 224

Axis, 44

Bile, I23

Bile cyst, I27

Bone, structure of, 25

Lones, ear, 225

head, 26

method of cleaning, II, I2

number of, 2I

pelvic limb, 64

table of, 22

thoracic limb, 52

Brachial plexus, 208

Brain, I75

arteries, I 36

basal ganglia, I 86

commissures, 183

external features, 176

extraction of, Io-I2

fibers of, 202

human, 228

internal structure, I 80

mammalian, 228

parts of, 176

rabbit's, 229

ventricles of, I $8 \mathrm{I}$ weight of in mammals, 220

Bronchial tubes, I 59

Cacum, 232

Capillaries, 148

Carpus, 57

Cartilage cells, I4

Cerebellar tracts, 200

C'erebellum, I9I

Cerebrum, I77

Clievron bones, 48

Chiroptera, 232

Classification, 2

Clavicle, 53

Clitoris, 232

Cloaca, I73

Coccyx, 232

Cochlea, 225, 226

Colon, 233

Conjunctiva, 220

Connective tissue, I6

Corona radiata, 203

Corpora quadrigemina, I86 striata, I 88

Corpus callosum, I84

Cranium, 26

Crossed pyramidal tract, I9I, 197. I99, 200, 202

Crus, 69

Cutaneous sense organs, 219

Decussation, motor, 200

$$
\text { sensory, } 203
$$

Dermis, I8

Didelphia, 233 care of young, I73

Diencephalon, I88, 233

Digestive system, I05

Digit, 234 of mammals, I 25

Digitigrade, 62

Dissection, preparation for, 5-I2

Ear, 224

bones containing, 30 
Edentata, 234

Embryology, I

Epithelium, I3

Esophagus, II4

Ethmoid, 26

Eutheria, 234

Eye, 220

muscles of, 22I

nerves of, 205

structure of, 222

Excretory system, I64

Fallopian tube, I67

Families, 3

Fasciculus, muscle, 77

Feces, I6

Goll and Burdach, I99

Femur, 66

Fiber tracts, 199

Fibula, 68

Fillet, 197, 203

Foot, bones of, 70 of horse, 57,58

Foramina of skull, 34

Formaldehyde, 4

Formalin, 4, 235

Formatio reticularis, 203

Gall bladder, I23

Ganglia, sympathetic, 2r4

Genera, 3

Gland, I05

Cowper's, I53

digestive, I 2 I

ductless, I 54

lachrymal, 22I

lymphatic, I 50

mammary, I7o

prostate, 173

sebaceous, I64

Glands, I20

salivary, I2I

stomach, II 8

sudiparous, 164

Gustatory organ, 220

Hair, 20

Hand, bones of, 59

Heart, I29

Histology, I

Horns, 26

Horse, evolution of, 62

limbs of, 56,60

Humerus, 54
Hymen, I 68

Hyoid bones, 40

Inguinal canal, I72

Injection method of, 5-8

Innominate, 64

Internal capsule, I89, I90, 200, 203

Intestine, II5

Invertebrata, 2

Involuntary muscle, 13

Joints, kinds, 74

ligaments of, 76

structure of, 75

Kidney, parts, I64 structure, 165

Kidneys of mammals, I74

Knee-joint, 75

Lachrymal bones, 38

Lacteals, I I9, I20

Larynx, I57

Lateral ground bundle, 200

Ligaments, 74, 125

Liver, I20, 122

Lumbar plexus, 2I I

Lungs, I 58 , I60

Lymphatic system, I 49 injection of, 8,9

Lymph glands, I50

Malar bone, 39

Mandible, 39

Marsupialia, 3, I73

Maxillary bone, $3^{6}$

Maxillo-turbinal, 37

Mediastinum, I6 I

Medulla oblongata, Igo

Meninges, 175

Mesencephalon, I85, 186, 237

Mesenteries, 124

Metacarpus, 60

Metatarsus, 7 I

Monotremata, 237

Morphology, I

Motor decussation, 201 tract, 203

Mouth, I07

Mucous membrane, I25

Muscles, 77 abdomen, 88

chest, 8I

dissection of, 79 
Muscles, forelimb, $84,90,98$ head and neck, 82 hind limb, 94, IOI, TO2 kinds, 78 structure, I 5 trunk, 92

Myelencephalon, Igo

Nares, 33, 35, I57

Nasal bone, 158

Nerve, afferent, 23I

auditory, 227

cell, I96, I98

efferent, 234

fibers, relation of, 197

tracts, I99

Nerves, arm, 208

cranial, 205

digits, 201

leg, 2 I I

motor, 206

peripheral, 204

plexuses of, 207, 216

sensory, 206

spinal, 194, r95, 207

sympathetic, 2I 4

Neurone, 198

Nomenclature, 3

Nuclei, gracilis and cuneatus, I99

Nucleus caudatus, I89

Occipital bone, 3I

Olfactory organ, 219

Omenta, 124

Optic thalami, I 88

Orbital cavity, 238

Orders, 3

Organs, I3 of the body, 106

Ornithodelphia, 169,238

Ova of manmmals, 169

C.varies, I68

Pacinian corpuscle, 219

Pain, sense organs of, 2J9

Palatine bone, 37

Pancreas, I20, I23

Paralysis, 20I

Parietal bone, 3I

Patella, 67

Peduncles of cerebellum, I9I cerebrum, 238

Penis, I72

Perissodactyla, 238
Peritoneum, II7, I24

Phalanges, 6I, 72, 238

Pharynx, II2

Phylogeny, 2 horse, 238

Physiology, I

Pineal body, I 88

Pituitary body, I78

Plantigrade, 62

Pleura, I6I

Portal system, I20, I44

Premaxillary bone, 36

Preservation of material, 4

Primates, 239

Projection fibers, 203

Protochordata, 2

Prototheria, 3, 239

Quadriceps extensor muscle, 96

Quadrigemina, corpora, I86

Radius, 55

Reflex action, I99

Reproductive system, I67

Respiratory system, 157

Retina, 223

Ribs, 50

Ruminant, 239 stomach of, I 26

Sacral plexus, 213

Sacrum, 46

Salivary glands, I 2I

Scapula, 52

Sciatic nerve, 213

Sebaceous glands, 19

Sense organs, 218

Sensory decussation, 203

Sensory tract, 203

Serous membrane, I25

Sesamoid bones, 21

Shoulder girdle, 53

Skeleton, 2I

Skin, I8, I9 sense organs, 219

Sku1l, 26

Smell, organ of, 219

Solar plexus, 216

Species, 3

Spermatozoa, I72

Sphenoid bone, 33

Spinal cord, I93

Spleen, I20, I54

Sternum, 48 
Stomach, II5

Stprarenal bodies, I55

Sweat glands, 19

Sympathetic nervous system, 2I4

Synovial membrane, 75

Systems, I3

Tarsus, 70

Taste, organ of, 220

Taxonomy, 2

Teeth, Io8 mammalian, III

Telencephalon, 177,240

Temporal bone, 29

Testes, I7o

Thoracic duct, I52, I53

Thymus gland, I55

Thyroid gland, I54

Tibia, 68

Tissues, I3

Tongue, I07

Tonsil, 107, 108

Tooth, structure, I 79

Trachea, I 59, I60

Tympanum, 240

UIna, 55

Ungulata, 240 evolution of, 62

Ureter, I66

Urethra, I66

Urogenital system, I64 mammalian, $I 73$
Uterus, I67, 24I

Vagina, 168

Valves, heart, I29, I32 veins, I43

Vascular system, I29

Veins, 142 injection of, 5-8 lungs, I47 trunk, I45

Vena cava, I45

Vermiform appendix, II7, I26

Vertebræ, 4I caudal, 47 cervical, 45 lumbar, 46 number in mammals, 48 plan of, 44 thoracic, 46

Villi, II9

Viscera, II 3

Vocal cords, I 60

Vomer, 37

Wharton's duct, I2I

Willis, circle of, 136

Xiphoid process, 49

Zygoma, 29

Zygomatic process, 28 






\section{B $\mathbf{N}$ A}

BARKER. Anatomical Nomenclature. With Special Reference to the Basle Anatomical Nomenclature $(B N A)$. By Lewellys F. Barker, M. D., Professor of Medicine, Johns Hopkins University; formerly Profes. sor of Anatomy in Rush Medical College, Chicago. Vocabularies in English and Latin. Two Colored and several other Illustrations. Octavo. Cloth, $\$ 1.00$.

The (BNA) is now widely used in English and foreign tongues by teachers of and writers on Anatomy, Histology Embryology and Biology. In no other work in English are the purposes of the (BNA) described, its scheme explained and its vocabulary given.

P. BLAKISTON'S SON \& CO. PUBLISHERS, - PHILADELPHIA 
